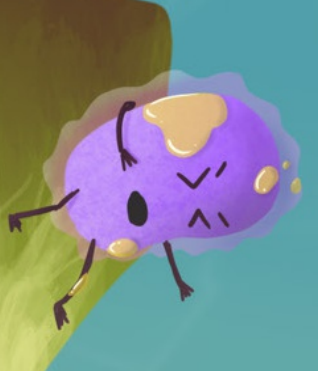

Battling microbes: disinfecting water during fresh-cut lettuce processing

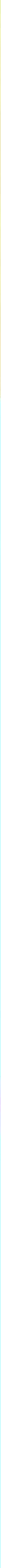





\section{Propositions}

1. Defining one best disinfection technology to prevent crosscontamination during vegetable processing is multifaceted. (this thesis)

2. Applying disinfectants to the water used during fresh-cut produce washing is a critical control point.

(this thesis)

3. The circular economy concept catalyzes risks in agriculture.

4. Open access to data has important disadvantages.

5. In the Netherlands, exhibiting excellence in one's work contradicts cultural norms.

6. One's personal health care should not have to be crowdfunded.

Propositions belonging to the thesis, entitled

Battling microbes: disinfecting water during fresh-cut lettuce processing

Jennifer L. Banach

Wageningen, 9 April 2021 



\title{
Battling microbes: disinfecting water during fresh-cut lettuce processing
}

\author{
Jennifer L. Banach
}




\section{Thesis committee}

\section{Promoters}

Prof. Dr M.H. Zwietering

Professor of Food Microbiology

Wageningen University \& Research

Prof. Dr H.J. van der Fels-Klerx

Special Professor, Food Safety Economics

Wageningen University \& Research

\section{Other members}

Prof. Dr E.J. Woltering, Wageningen University \& Research

Prof. Dr L. Jacxsens, Ghent University, Ghent, Belgium

Dr E. Franz, National Institute for Public Health and the Environment (RIVM), Bilthoven

Dr A.E.I. de Jong, Netherlands Food and Consumer Product Safety Authority (NVWA), Utrecht

This research was conducted under the auspices of the Graduate School VLAG (Advanced studies in Food Technology, Agrobiotechnology, Nutrition and Health Sciences). 


\title{
Battling microbes: disinfecting water during fresh-cut lettuce processing
}

\author{
Jennifer L. Banach
}

\author{
Thesis \\ submitted in fulfilment of the requirements for the degree of doctor \\ at Wageningen University \\ by the authority of the Rector Magnificus, \\ Prof. Dr A.P.J. Mol, \\ in the presence of the \\ Thesis Committee appointed by the Academic Board \\ to be defended in public \\ on Friday 9 April 2021 \\ at 11 a.m. in the Aula.
}


Jennifer L. Banach

Battling microbes: disinfecting water during fresh-cut lettuce processing, 204 pages.

PhD thesis, Wageningen University, Wageningen, the Netherlands (2021) With references, with summary in English

ISBN 978-94-6395-696-3

DOI https://doi.org/10.18174/540675 


\section{Abstract}

Fresh leafy greens like lettuce are often consumed raw and can be contaminated by foodborne pathogens. Washing fresh-cut lettuce can help alleviate foodborne outbreaks and diffuse cases, but the washing process must be controlled to avoid pathogenic cross-contamination. The thesis aimed to evaluate the effectiveness of chemical disinfection of the water during fresh-cut lettuce washing to reduce pathogenic crosscontamination. First, the effectiveness of chlorine, chlorine dioxide $\left(\mathrm{ClO}_{2}\right)$, ozone, and peracetic acid (PAA) during produce processing was studied along with legislation and disinfection by-product production. Next, the effectiveness of sodium hypochlorite, $\mathrm{ClO}_{2}$, and a silver-copper solution to reduce Salmonella enterica serovar Typhimurium and pathogenic Escherichia coli were assessed on the laboratory scale. Results showed that the water's organic load, wash water temperature, and pathogenic characteristics influenced the effectiveness. Then, the effectiveness of $\mathrm{ClO}_{2}(5 \mathrm{mg} / \mathrm{L}$ and $3 \mathrm{mg} / \mathrm{L})$ on reducing supplemented nonpathogenic $E$. coli during fresh-cut lettuce washing at the industrial scale was studied. Also, the effectiveness of a PAA solution (75 mg/L) on reducing supplemented nonpathogenic $E$. coli during fresh-cut lettuce washing at the laboratory and industrial scales was studied. The results showed that laboratory experiments disinfecting water with $\mathrm{ClO}_{2}$ and a PAA solution had similar findings, which were also confirmed at the industrial scale. Finally, a multi-criteria decision analysis was applied to a case study to determine the best control strategy during fresh-cut lettuce processing when disinfection was applied directly in the wash tank. Results showed that PAA was the overall preferred control strategy. This proposed disinfection strategy appears to be the right balance between safety and effective fresh-cut produce disinfection. 



\section{Table of Contents}

Chapter 1 General introduction 9

Chapter 2 Effect of disinfectants on preventing the cross- 25

contamination of pathogens in fresh produce washing

Chapter 3 The efficacy of chemical sanitizers on the reduction of 49

Salmonella Typhimurium and Escherichia coli affected by bacterial cell history and water quality

Chapter 4 Efficacy of chlorine dioxide on Escherichia coli

inactivation during pilot-scale fresh-cut lettuce processing

Chapter 5 Effectiveness of a peracetic acid solution on Escherichia coli reduction during fresh-cut lettuce processing at the laboratory and industrial scales

Chapter 6 Multi-criteria decision analysis to evaluate control strategies for preventing cross-contamination during fresh-cut lettuce washing

Chapter 7 General discussion

Summary

Annexes Acknowledgments, About the author, List of publications, and Overview of completed training activities 

Chapter 1

General introduction 


\subsection{Vegetable production and consumption}

Vegetables are an important part of a healthy diet as they provide nutrients like vitamins, minerals, dietary fiber, and phytochemicals. Its consumption has been shown to decrease the risk of noncommunicable diseases (NCDs) like cardiovascular diseases, hypertension, diabetes, and some cancers (Cena and Calder, 2020; Dias, 2019; World Health Organization (WHO), 2019). In 2017, worldwide, an estimated 3.9 million deaths were attributed to inadequate fruit and vegetable consumption (WHO, 2019). The World Health Organization (WHO) advocates consuming more than $400 \mathrm{~g}$ of fruits and vegetables per day to improve health and reduce certain NCDs (WHO, 2003, 2019). Besides its benefits, shifting towards a plant-based diet can make the planet more sustainable.

Worldwide vegetable production was estimated at 1,089 million metric tons in 2018 (Food and Agriculture Organization of the United Nations (FA0), 2020). Global vegetable production in 2018, per crop, is shown in Figure 1.1. Fresh vegetable crops (not elsewhere specified), followed by tomatoes and onions (dry), made up, respectively, $27.3 \%, 16.7 \%$, and $8.9 \%$ of the total world production, while lettuce and chicory made up $2.5 \%$ of the total world production. In 2018, the 28 European Union member states (EU-28) made up $5.7 \%$ of the total world vegetable production. Overall, EU-28 vegetable production makes up a minor part of global vegetable production.

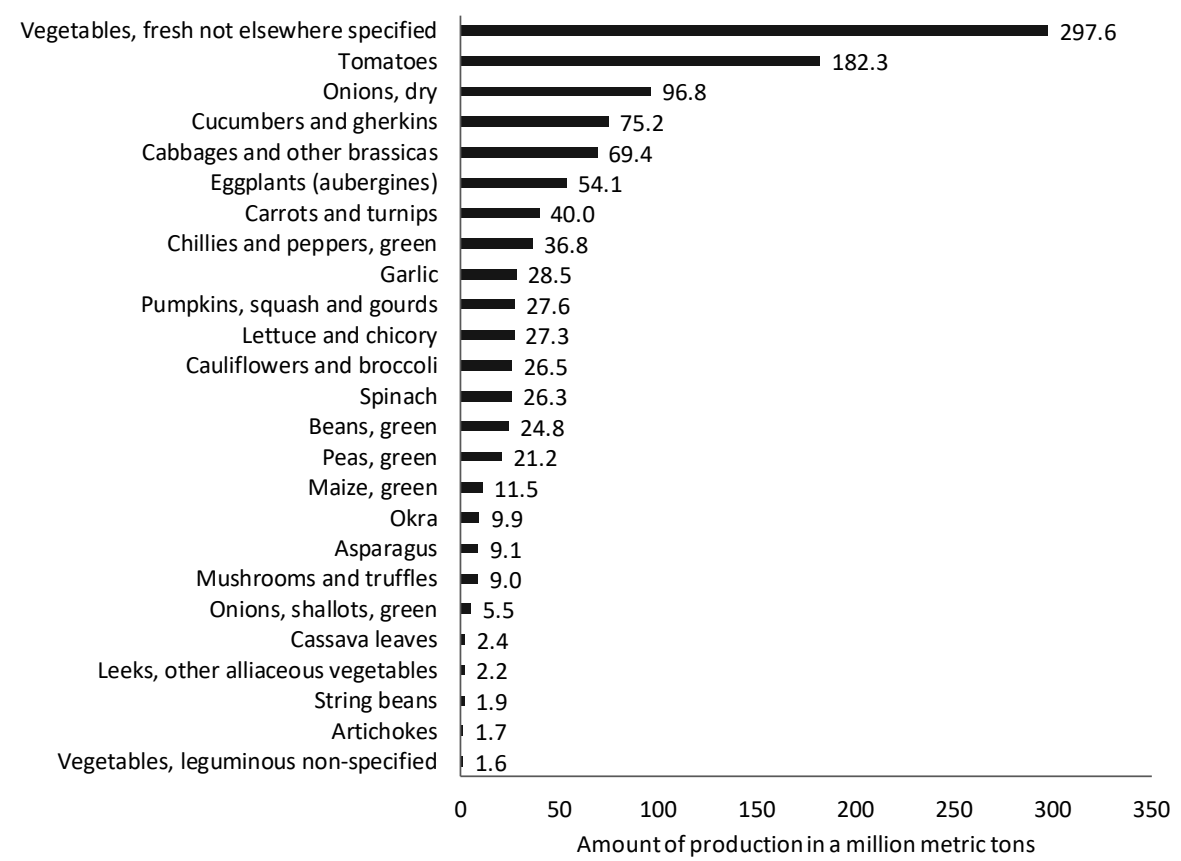

Figure 1.1. Global vegetable production in 2018, reported in a million metric tons. Data are aggregated and may include (semi-)official, estimated, or calculated data. Source: FAOSTAT Database (FAO, 2020). 
In the Netherlands, vegetable production in 2018, per type of crop, is shown in Figure 1.2. Fresh vegetables (not elsewhere specified) were produced at 0.31 million metric tons, followed by lettuce and chicory, at 0.10 million metric tons. Although the Netherlands made up only $0.4 \%$ of the total world vegetable production in 2018 (FAO, 2020 ), it is the only country in northern Europe to have a positive trade balance of fresh fruits and vegetables, and it is an important trade hub with more than $20 \%$ of Europe's imports of fruits and vegetables (Center for the Promotion of Imports (CBI), 2018).

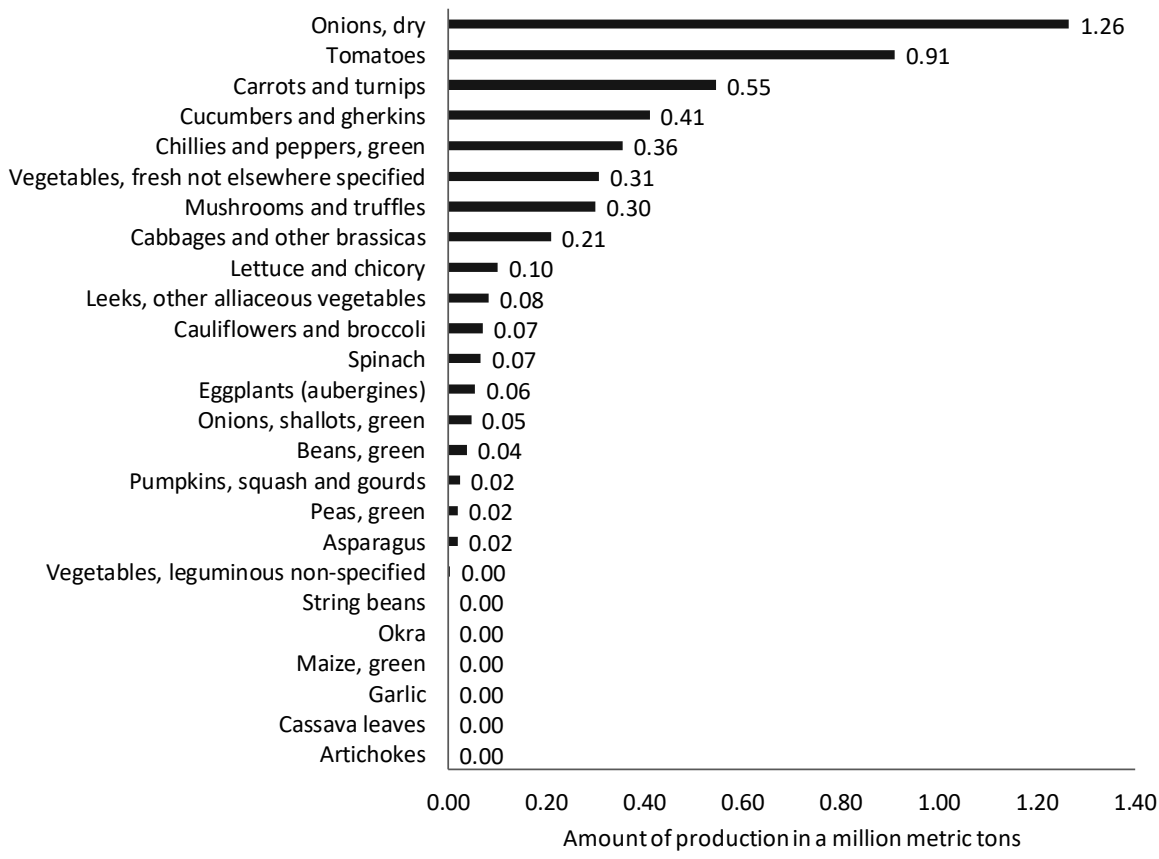

Figure 1.2. Vegetable production per crop in 2018 for the Netherlands, reported in a million metric tons. Data are aggregated and may include (semi-)official, estimated, or calculated data. Source: FAOSTAT Database (FAO, 2020).

The average consumption of vegetables worldwide varies immensely. In 2017, global vegetable consumption per capita averaged $91 \mathrm{~kg}$ per year (249 g per capita per day), with values ranging from about $6 \mathrm{~kg}$ per capita in Chad to over $377 \mathrm{~kg}$ per capita in China (figures not reflecting food loss). In the EU in 2017, the Netherlands had the lowest average for vegetable consumption per capita from all member states of $61.6 \mathrm{~kg}$ (169 g per capita per day). This consumption is below WHO guidelines for vegetables of about 200-250 g per person per day (73-91.3 kg per person per year) (FAO, 2020; Ritchie and Roser, 2020).

Average vegetable consumption in kilograms per capita from 1961 to 2017 for the Netherlands and its surrounding member states is shown in Figure 1.3. Since 1961, annual vegetable consumption in the Netherlands has wavered considerably. The highest average consumption was $105.7 \mathrm{~kg}$ per capita in 2007 , while the lowest average 


\section{Chapter 1}

consumption was $61.6 \mathrm{~kg}$ per capita in 2017. In comparison, vegetable consumption in Germany has steadily increased over time. In Germany, the lowest average consumption was $48.6 \mathrm{~kg}$ in 1965, and the highest average consumption was $96.9 \mathrm{~kg}$ in 2012. In general, vegetable consumption in Belgium(-Luxembourg) is higher than that of the Netherlands and Germany (Fig. 1.3) (FAO, 2020; Ritchie and Roser, 2020).

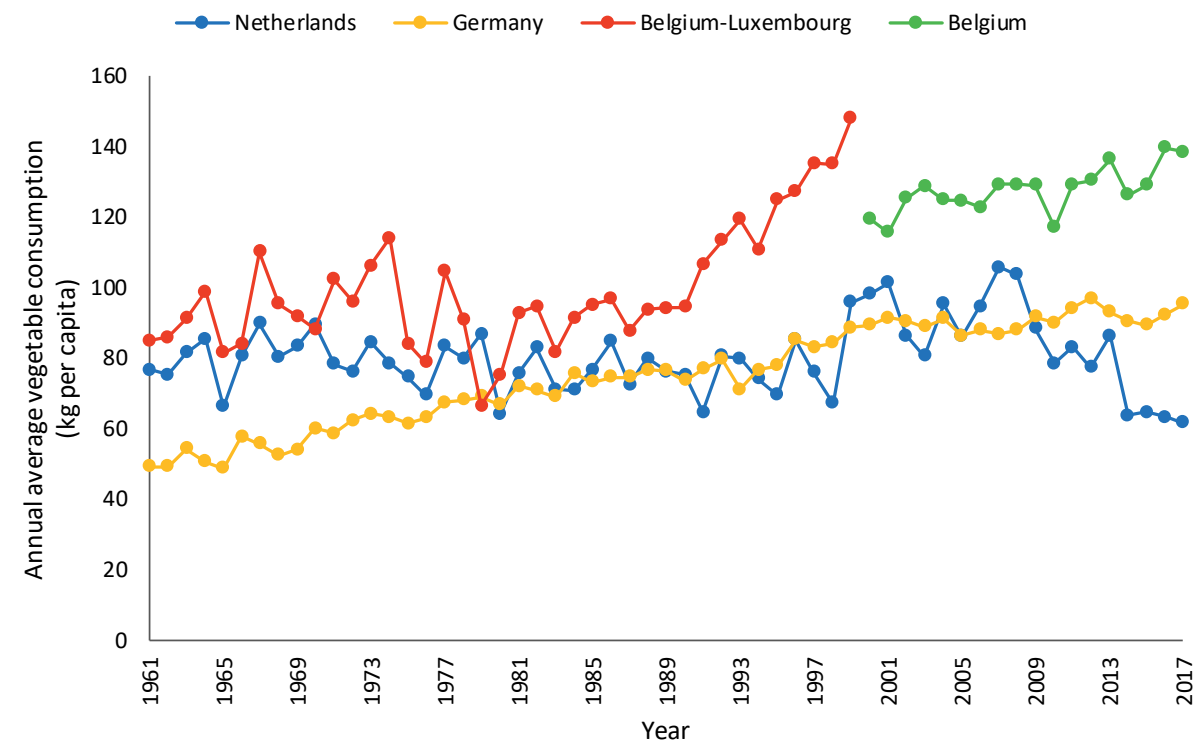

Figure 1.3. Annual average vegetable consumption per capita from 1961 to 2017 for the Netherlands, Germany, and Belgium(-Luxembourg), in kilograms per person per year. Data is based on food consumption at the consumer level and does not reflect food waste. Data from 1961 to 2013 are stored under an "old methodology" variable set, while data from 2014 to 2017 are stored under a "new methodology" for food balance sheets. Sources: FAOSTAT Database (FAO, 2020); Ritchie and Roser (2020).

In the Netherlands, vegetable consumption decreased between 2013 with $86.3 \mathrm{~kg}$ per capita (236 g per capita per day) and 2017 with $61.6 \mathrm{~kg}$ per capita (169 g per capita per day) (Fig. 1.3). FAO data for food balance sheets from 1961 to 2013 were stored under an "old methodology," and data from 2014 to 2017 were stored under a "new methodology." The sharp decrease since 2013 in the Netherlands may partly be attributed to changes in how the data were stored (Fig. 1.3). Overall, average consumption in the Netherlands from 1961 to 2013 of $81.2 \mathrm{~kg}$ per capita $(223 \mathrm{~g}$ per capita per day) is higher than the average consumption from 2014 to 2017 of only 63.2 kg per capita (173 g per capita per day).

For the EU-28, data from 2014 to 2017 showed that vegetable consumption per capita generally increased, with the highest consumption reported in 2016 at $116 \mathrm{~kg}$ per capita (317 g per capita per day) (FAO, 2020). 


\subsection{Foodborne disease and fresh produce}

Foodborne diseases are illnesses caused by the consumption of contaminated foods or beverages. Annually, worldwide an estimated 600 million people become ill, and 420,000 people die after consuming contaminated food (WHO, 2015). The consumption of produce is an important part of a healthy diet and can help decrease the risk of NCDs. However, increased fruit and vegetable consumption alongside the repeated occurrence of foodborne illness from such products represents a public health concern (Callejón, Rodriguez-Naranjo, Ubeda, Hornedo-Ortega, Garcia-Parrilla and Troncoso, 2015). Foodborne diseases can be classified into foodborne infections or foodborne intoxications. Foodborne infections are caused by ingesting foodstuffs that have been contaminated with pathogens, such as pathogenic Escherichia coli or Salmonella. The pathogen can grow and establish itself in the host (e.g., humans). Foodborne intoxications are caused by ingesting foodstuffs containing toxins. Toxins, like those produced by Bacillus, Clostridium, or Staphylococcus, can form when pathogens grow in the food and release the toxin into the food. Toxins are often chemically stable. During food processing, the toxin can become diluted or concentrated. Even if the pathogen is inactivated, toxins present in the food can still result in illness. Acute symptoms of foodborne diseases can be mild and self-limiting, such as nausea, vomiting, abdominal pain, and diarrhea. More severe symptoms can be life-threatening, such as kidney or liver failure, brain and neural disorders, paralysis, and cancer (WHO, 2015).

Globally, the contamination of fresh produce remains high, thereby contributing to the burden of foodborne outbreaks and negatively affecting public health (Callejón et al., 2015; Lynch, Tauxe and Hedberg, 2009). In the Netherlands, the estimated attributed average number of incidences in 2018 for produce was about $6 \%$ of the total attributed incidences for food (i.e., 39,000 incidences for produce per 652,000 total incidences in food) (Pijnacker, Friesema, Mughini Gras, Lagerweij, van Pelt and Franz, 2019). The attributed number of fatalities in 2018 to produce was about $8 \%$ of the total attributed incidences for food (i.e., 6 fatalities for produce per 76 total estimated incidences in food) (Pijnacker et al., 2019). For the Netherlands, the disease burden estimated in 2018 in disability-adjusted life years (DALYs) for produce was 290 DALYs per year (undiscounted), and the mean cost-of-illness (COI) from produce in 2018 was estimated to be 12 million euros per year (undiscounted) (Pijnacker et al., 2019). These estimations are based on a country where fruit and vegetable consumption are below average. Therefore, given the lower than recommended consumption of produce in the Netherlands, estimated at $113 \mathrm{~g}$ of fruits and $131 \mathrm{~g}$ of vegetables per day (National Institute for Public Health and the Environment (RIVM), 2020; RIVM, 2019), the number of food-related incidences and fatalities attributed to produce might be higher if consumption was to meet the WHO dietary recommendations of $400 \mathrm{~g}$ per day (WHO, $2003,2019)$. Overall, with increased exposure to contaminated produce comes an increased probability of getting ill.

Fresh vegetables can become contaminated directly or indirectly via several routes along the supply chain (Fig. 1.4). The use of contaminated water has been pinpointed as an important source of (cross-)contamination of fresh produce (Holvoet, Sampers, 


\section{Chapter 1}

Seynnaeve, Jacxsens and Uyttendaele, 2015; U.S. Food and Drug Administration (FDA), 2015). Water can become contaminated via the feces of humans, animals, or insects, sewage (e.g., from improperly treated wastewater), or contaminated soil or vegetables. Routes by which microbial contamination of vegetables can occur, in addition to water, including via feces/manure, sewage, soil, animal food products, equipment (e.g., via cross-contamination), and humans. If humans consume contaminated vegetables, they run the risk of contracting a foodborne illness. Consequently, to reduce the probability of foodborne disease, it is important to prevent contamination along the supply chain, including possible contamination from water sources.

According to EU data from 2018, 31 outbreaks and 626 cases related to vegetables (and juices) were reported (European Food Safety Authority (EFSA) and European Centre for Disease Prevention and Control (ECDC), 2019). Incidents with bacterial pathogens in the fresh produce chain, like the Shiga toxin-producing Escherichia coli (STEC) strain outbreak in 2011, led to high economic losses and loss of consumer confidence in the EU horticulture sector, including that within the Netherlands (Bleker, 2011; Frugi Venta - Groenten en Fruit Handelsplatform Nederland, 2011; Klis, 2011). Besides this outbreak, other pathogen-product relationships have been mapped out. The European Food Safety Authority (EFSA) evaluated the risks posed by foods of non-animal origin and prioritized potential food-pathogen combinations based on seven criteria "strength of associations between food and pathogen based on the foodborne outbreak data from EU Zoonoses Monitoring (2007-11), incidence of illness, burden of disease, doseresponse relationship, consumption, prevalence of contamination and pathogen growth potential during shelf life" (EFSA Panel on Biological Hazards (BIOHAZ) Panel, 2013). Salmonella spp. in leafy greens eaten raw as salads were ranked highest, partly due to the associations with previous foodborne outbreaks (EFSA Panel on Biological Hazards (BIOHAZ) Panel, 2013). In conclusion, the incidence of foodborne outbreaks and cases in the EU related to vegetables like leafy greens is still prevalent, and pathogens like Salmonella and STEC have contributed to the disease burden. 


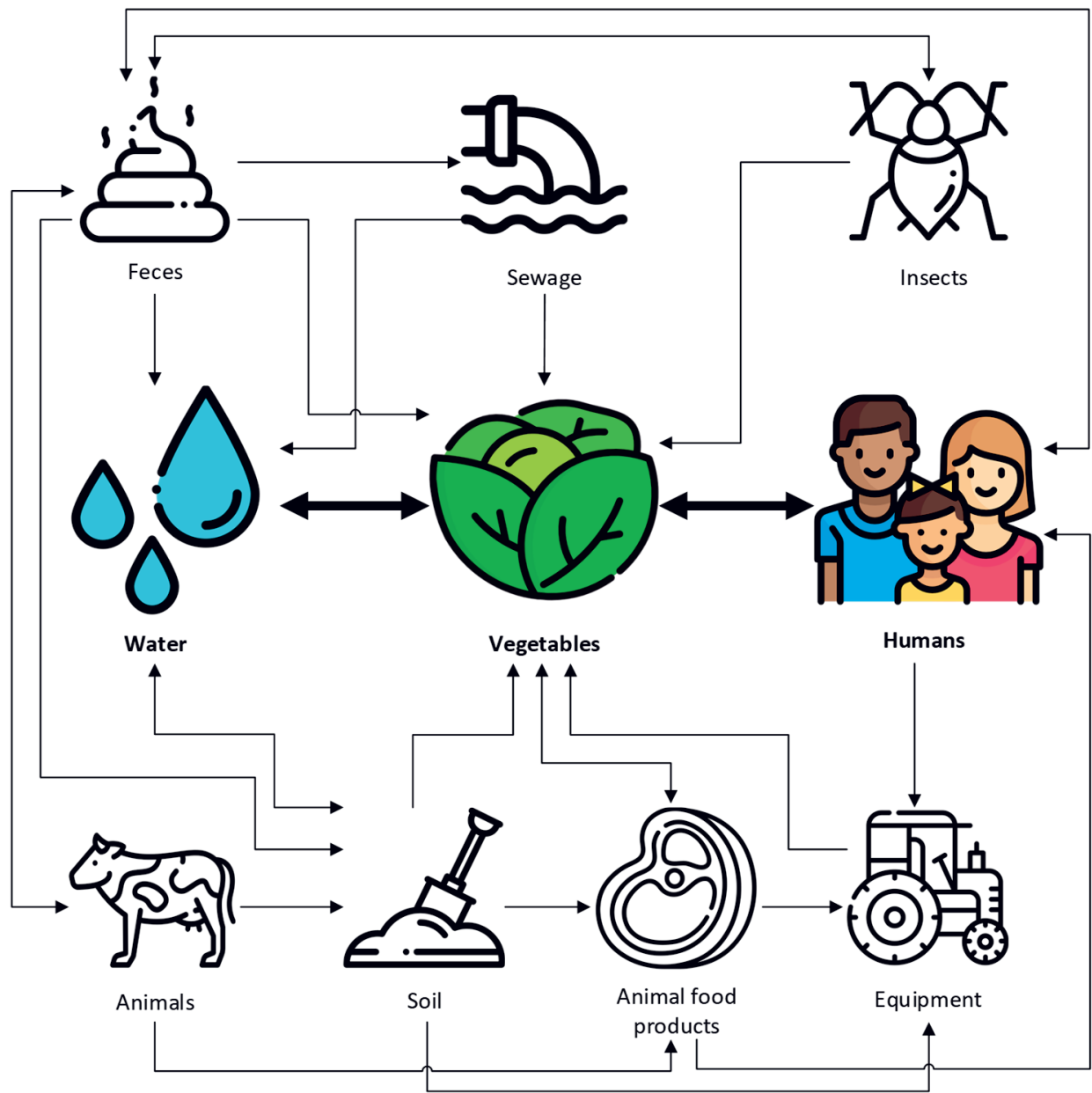

Figure 1.4. Direct and indirect routes of fresh vegetable contamination with pathogenic microorganisms. Icons made by Freepik from www.flaticon.com.

\subsection{Washing fresh-cut produce}

Minimally processed produce, also commonly referred to as fresh-cut produce, are raw or fresh fruits and vegetables that are physically altered from their original form. For instance, they can be peeled; trimmed; sliced, chopped, or shredded; and washed before being bagged or prepackaged and provided to consumers (Erickson, 2012; Francis, Thomas and O'Beirne, 1999). During commercial fresh-cut produce processing, large quantities of produce are washed together. Washing helps remove soil, dirt, and debris from the produce, helping preserve quality and safety (Gil, Selma, López-Gálvez and Allende, 2009). It is also one of the last steps that one can take during processing to reduce the prevalence or concentration of pathogenic bacteria, which may have unintentionally contaminated produce earlier in the supply chain. Therefore, water 
quality is relevant to prevent produce from becoming contaminated during washing (Gil et al., 2009; Parish, Beuchat, Suslow, Harris, Garrett, Farber and Busta, 2003; Van Haute, Sampers, Jacxsens and Uyttendaele, 2015). To ensure the water quality during processing, wash water disinfectants are often used to disinfectant the water.

During processing, fresh produce is sometimes cut, and doing so can increase the opportunity for (cross-)contamination. Plant cells become damaged during cutting, and nutrients are leached, providing a favorable condition for microbial growth. If a plants' surface is contaminated, internalization through cut edges and stomata can occur (Erickson, 2012; Murray, Wu, Shi, Jun Xue and Warriner, 2017). Research has shown that produce that is recently damaged or has exposed cut surfaces had increased internalized cells (Erickson, 2012; Takeuchi and Frank, 2000). The motivation for using clean, pathogenic-free water becomes even more evident when fresh-cut produce is then washed. Since produce is, in a way, already vulnerable from being processed (e.g., cut), they may be further susceptible to pathogenic contamination, the degree to which can depend on the type of produce. Overall, if pathogens are present on produce or in the water used to wash the produce, the probability for cross-contamination is evident.

\subsection{Disinfecting water during processing}

Previous research has shown that water disinfectants are important in maintaining the wash water quality during fresh-cut produce processing. Water disinfection should aim to prevent cross-contamination between clean and contaminated produce, rather than as an initiative to increase shelf-life or to guarantee produce safety through produce decontamination (Al-Nabulsi, Osaili, Obaidat, Shaker, Awaisheh and Holley, 2014; Davidson, Buchholz and Ryser, 2013; Gil et al., 2009; López-Gálvez, Allende, Selma and Gil, 2009). Therefore, effective produce washing remains a pivotal step towards removing and limiting cross-contamination of microorganisms, including pathogens. To achieve this objective, one can apply chemical water disinfection technologies and monitor the process wash water (PWW) to prevent cross-contamination via the washing water.

Water disinfection during fresh-cut lettuce processing can occur directly in the washing tank (in-line), or the water can be reconditioned separately (e.g., in a by-pass) before being re-circulated back into the processing system or elsewhere in a processing facility. A simplified diagram of these two water disinfection possibilities is shown in Figure 1.5.

The use of chemicals for PWW disinfection has advantages and disadvantages, and several criteria can be considered to evaluate chemicals used for PWW disinfection. One aspect to consider is the effect that the disinfectant dose and contact time have on the effectiveness of the microbial log reductions. Some chemical water disinfection technologies may be more suitable for an in-line application, e.g., given their effectiveness with the short contact time. In contrast, others may be better suited for a by-pass application, allowing for longer contact times. Besides the effectiveness (expressed in microbial log reduction), the possible side-effects on human health and 
the role of legislation are important criteria to consider when evaluating which chemical to use to disinfect the PWW. The potential formation of disinfection byproducts (DBPs), which is further elaborated in this thesis (Chapter 2), can result in unknown or adverse effects on human health. Also, workers' safety from the (incorrect) use of a disinfectant is critical to consider in terms of adverse acute or long-term occupational health effects. International and local legislation, as these can differ, could be considered when applying a PWW disinfection strategy. Overall, the effectiveness of a PWW disinfectant (expressed in microbial log reduction) and the side effects on human health are important aspects to consider alongside other criteria like legislation.

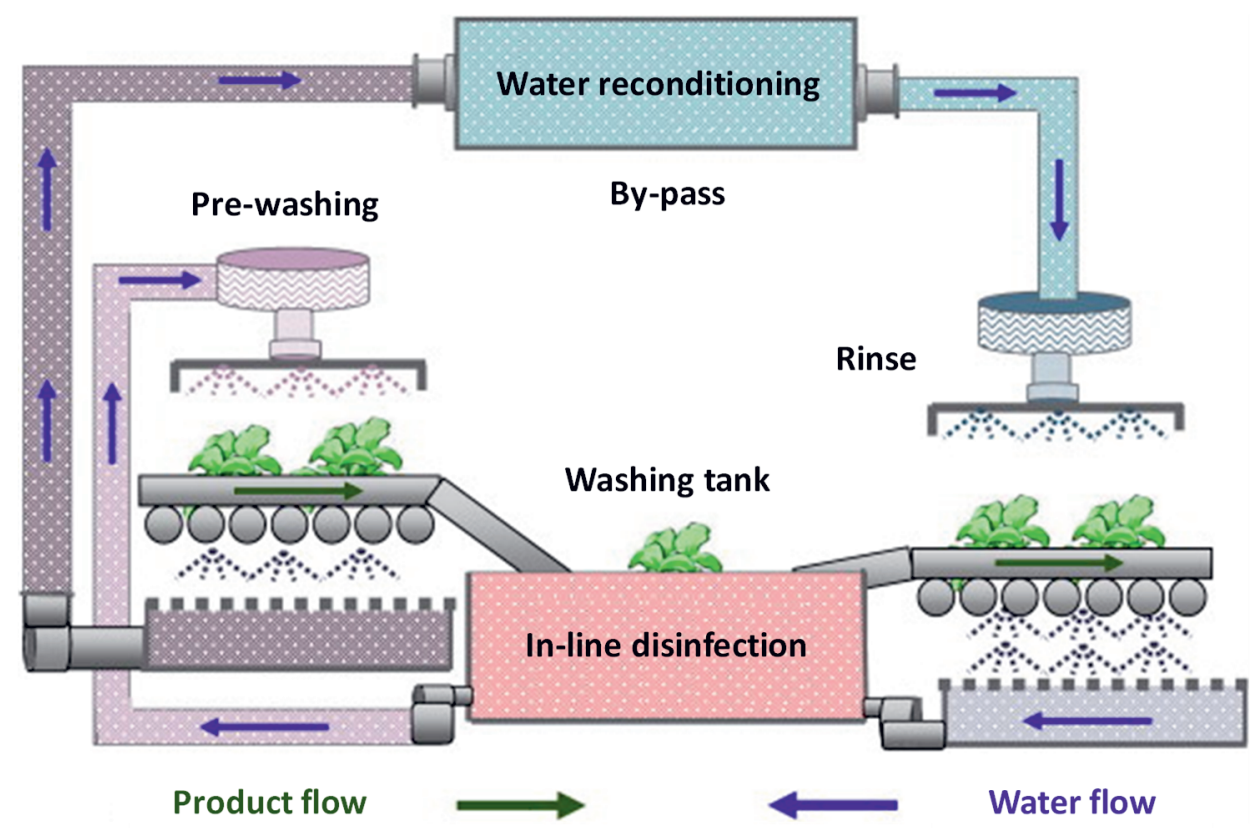

Figure 1.5. Diagram of fresh-cut produce water disinfection in a washing tank (in-line) and of water reconditioning (in a by-pass). Adapted from Gil et al. (2009).

Furthermore, other criteria like the type of technology and its easiness to apply, consumer acceptance, or costs from using the PWW disinfectant technology may be considered when selecting a PWW disinfection technology. In general, a PWW disinfectant that is easy to use and apply, that remains robust during processing, and can be fitted to both small and large scales is desirable. Consumer acceptance may be another criterion of relevance. Consumer perception of using a PWW disinfectant and the probability of any adverse or undesirable organoleptic effects on the produce can influence how consumers view the final product. Economic aspects like potential direct or indirect costs and the costs associated with reducing water required are relevant. In conclusion, other criteria like the type of technology, its easiness to apply, consumer acceptance, or costs can be considered when selecting a PWW disinfectant. 
Some of the criteria mentioned above are subjective. Using decision-making tools can help evaluate the choices. A multi-criteria decision analysis (MCDA) is a method to use to examine potential control strategies and how stakeholders may view these. With an MCDA, stakeholders can rank the relative importance of multiple diverse, complex, or even conflicting criteria associated with a case study. This method can help facilitate policy and decision-makers in selecting alternatives and making decisions by comparing potential choices and can bring structure to the decision-making process.

There is currently limited data on the microbial effectiveness of PWW disinfectants during fresh-cut lettuce processing at the industrial-scale. Also, data on the possible formation of DBPs during processing is scarce. Stakeholders can differ in their view on which control strategies should be used. Also, given current legislation, chemical disinfection technologies are not commonly applied during fresh-cut processing in countries like the Netherlands, meaning there is a barrier to scale-up and apply chemical disinfectants for PWW disinfection.

\subsection{Objectives of the thesis}

The main aim of this thesis was to evaluate the effectiveness of chemical disinfection of the water during fresh-cut lettuce washing to reduce pathogenic cross-contamination. In order to answer the main aim, the following five sub-objectives (SOs) were derived:

1) To obtain state-of-the-art knowledge on the effectiveness of chemical disinfectants suitable for PWW disinfection and their use to prevent pathogenic cross-contamination (Chapter 2).

2) To evaluate the effectiveness of chemicals used during PWW disinfection on reducing pathogenic bacteria at the laboratory-scale (Chapter 3 ).

3) To evaluate the effectiveness of chlorine dioxide $\left(\mathrm{ClO}_{2}\right)$ during industrial-scale processing of fresh-cut lettuce on the reduction of $E$. coli in the PWW and on the processed fresh-cut lettuce itself, and to evaluate the possible formation of DBPs (Chapter 4).

4) To evaluate the effectiveness of peracetic acid (PAA), in solution with hydrogen peroxide $\left(\mathrm{H}_{2} \mathrm{O}_{2}\right)$, during laboratory and industrial-scale processing on the reduction of $E$. coli in the PWW and on processed fresh-cut lettuce (Chapter 5).

5) To determine the best control strategy for stakeholders by evaluating strategies to treat the PWW used during washing fresh-cut lettuce, considering effectiveness, easiness of use/robustness of the technology, consumer acceptance, costs, and side effects on human health (Chapter 6).

This research focused on water used directly in the wash tank during commercial processing, i.e., cutting and washing, of lettuce. 


\subsection{Outline of the thesis}

This thesis consists of seven chapters, of which Chapters $2,3,4,5$, and 6 focus on the five sub-objectives mentioned above. Chapter 7 presents a synthesis of the findings of this thesis, as well as overall conclusions. Figure 1.6 summarizes the outline of the thesis and the links between the chapters.

Chapter 2 addresses the first sub-objective and presents a literature review describing the effectiveness of chlorine, $\mathrm{ClO}_{2}$, ozone, and PAA during produce processing to reduce the potential cross-contamination of pathogens in the PWW. These chemicals were assessed for their potential use as PWW disinfectants. PWW disinfection requires short contact times, so pathogens need to be rapidly inactivated. Current research often focuses on produce decontamination and less on preventing cross-contamination in the washing tank. The review highlights the effectiveness in terms of microbial reductions while also assessing legislation and possible DBP production.

Chapter 3 addresses the second sub-objective and evaluates three chemicals, i.e., chlorine, $\mathrm{ClO}_{2}$, and a silver-copper solution at a laboratory setting for their potential to reduce Salmonella enterica serovar Typhimurium and extended-spectrum betalactamase (ESBL) Escherichia coli in water. Three scenarios evaluated the effect of strain history, such as between starved and non-starved cultures, and of water quality, e.g., in different water matrices, on the effectiveness.

Chapter 4 addresses the third sub-objective and evaluates the effectiveness of $\mathrm{ClO}_{2}$ in terms of the reduction of cross-contamination in the PWW during fresh-cut lettuce washing, piloted at an industrial-scale washing tank. The chapter evaluates the disinfection effectiveness of $\mathrm{ClO}_{2}$ on the reduction of nonpathogenic $E$. coli supplemented to the PWW. The impact that a fixed residual concentration of $\mathrm{ClO}_{2}$ at 5 $\mathrm{mg} / \mathrm{L}$ and $3 \mathrm{mg} / \mathrm{L}$ had during washing (in situ) on the microbiological and chemical safety of the water was assessed. Also, quantitative values for DBPs like chlorate and chlorite, as well as of perchlorate, were determined.

Chapter $\mathbf{5}$ addresses the fourth sub-objective of the thesis focusing on the use of PAA to disinfect the water used during fresh-cut lettuce washing at the laboratory and industrial scales. The chapter compares the results of the treated water, namely the effect of a PAA solution on the reduction of nonpathogenic E. coli in the water. The physicochemical and microbial quality of the water and the microbial quality of the fresh-cut lettuce were evaluated. This research aimed to show the effectiveness of PAA to disinfect the PWW and the importance of monitoring water quality and dosing PAA during processing.

Chapter 6 addresses the fifth sub-objective of the thesis, with a case study on processing fresh-cut lettuce. The chapter uses an MCDA method to select the most suitable control strategy to treat the wash water used during fresh-cut lettuce processing to control pathogenic cross-contamination. 


\section{Chapter 1}

Finally, Chapter 7 discusses this thesis's main findings, reflects on the applied research approach, discusses the implications of the research for decision-makers, elaborates on future research opportunities, and ends with the main conclusions.

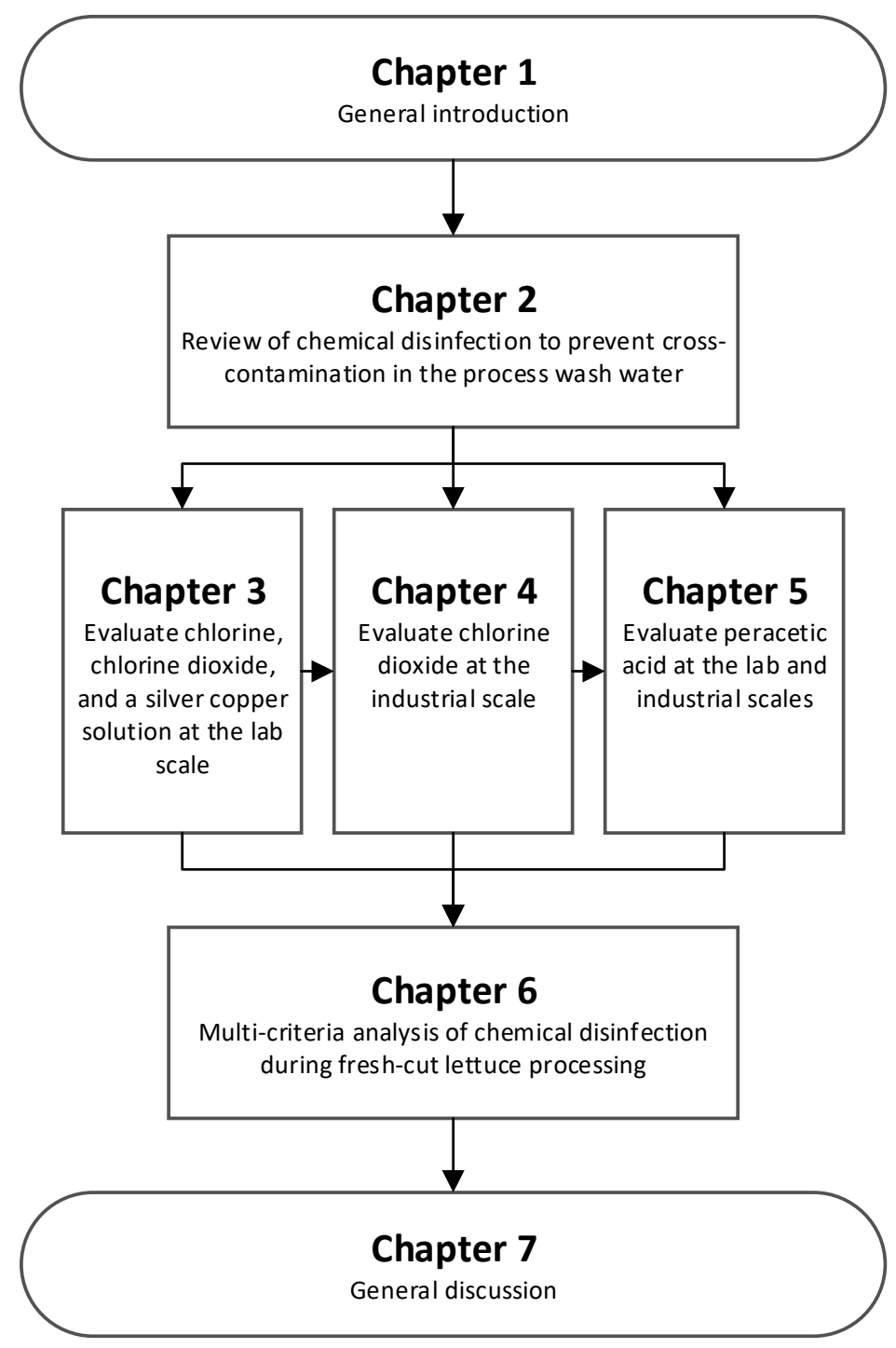

Figure 1.6. Outline and links between the chapters of the thesis. 


\section{References}

Al-Nabulsi, A.A., Osaili, T.M., Obaidat, H.M., Shaker, R.R., Awaisheh, S.S., Holley, R.A., 2014. Inactivation of stressed Escherichia coli 0157:H7 cells on the surfaces of rocket salad leaves by chlorine and peroxyacetic acid. J. Food Prot. 77, 32-39. doi: 10.4315/0362-028x.Jfp-13-019.

Bleker, H., 2011. Antwoorden kamervragen koopmans (CDA) over schadebedragen voor de Nederlandse teelt en handel, in: De Voorzitter van de Tweede Kamer (Ed.). De Tweede Kamer der Staten-Generaal, Den Haag, Nederland.

Callejón, R.M., Rodriguez-Naranjo, M.I., Ubeda, C., Hornedo-Ortega, R., Garcia-Parrilla, M.C., Troncoso, A.M., 2015. Reported foodborne outbreaks due to fresh produce in the United States and European Union: trends and causes. Foodborne Pathog. Dis. 12, 32-38. doi: 10.1089/fpd.2014.1821.

Cena, H., Calder, P.C., 2020. Defining a healthy diet: evidence for the role of contemporary dietary patterns in health and disease. Nutrients 12, 334. doi: 10.3390/nu12020334.

Center for the Promotion of Imports (CBI), 2018. Exporting fresh fruit and vegetables to the Netherlands.

Davidson, G.R., Buchholz, A.L., Ryser, E.T., 2013. Efficacy of commercial produce sanitizers against nontoxigenic Escherichia coli 0157:H7 during processing of iceberg lettuce in a pilot-scale leafy green processing line. J. Food Prot. 76, 1838-1845. doi: 10.4315/0362-028x.Jfp-13-111.

Dias, J.S., 2019. Nutritional quality and effect on disease prevention of vegetables. Food Nutr. Sci. 10, 369. doi: 10.4236/fns.2019.104029.

EFSA Panel on Biological Hazards (BIOHAZ) Panel, 2013. Scientific opinion on the risk posed by pathogens in food of non-animal origin. Part 1 (outbreak data analysis and risk ranking of food/pathogen combinations). EFSA J. 11, 138. doi:10.2903/j.efsa.2013.3025.

Erickson, M.C., 2012. Internalization of fresh produce by foodborne pathogens. Annu. Rev. Food Sci. Technol. 3, 283-310. doi: 10.1146/annurev-food-022811-101211.

European Food Safety Authority (EFSA), European Centre for Disease Prevention and Control (ECDC), 2019. The European Union one health 2018 zoonoses report, EFSA J. European Food Safety Authority (EFSA), p. 276.

Food and Agriculture Organization of the United Nations (FAO), 2020. FAOSTAT Database, March 4, 2020 ed. Food and Agriculture Organization of the United Nations (FAO), Rome, IT.

Francis, G.A., Thomas, C., O'Beirne, D., 1999. The microbiological safety of minimally processed vegetables. Int. J. Food Sci. Technol. 34, 1-22. doi: 10.1046/j.1365-2621.1999.00253.x.

Frugi Venta - Groenten en Fruit Handelsplatform Nederland, 2011. Frugi Venta jaarverslag 2011, Den Haag, p. 75.

Gil, M.I., Selma, M.V., López-Gálvez, F., Allende, A., 2009. Fresh-cut product sanitation and wash water disinfection: problems and solutions. Int. J. Food Microbiol. 134, 37-45. doi: 10.1016/j.ijfoodmicro.2009.05.021.

Holvoet, K., Sampers, I., Seynnaeve, M., Jacxsens, L., Uyttendaele, M., 2015. Agricultural and management practices and bacterial contamination in greenhouse versus open field lettuce production. Int. J. Environ. Res. Pu. 12, 32. doi: 10.3390/ijerph120100032.

Klis, H., 2011. EHEC-schade kan oplopen tot 350 miljoen, NRC Handelsblad. NRC, nrc.nl.

López-Gálvez, F., Allende, A., Selma, M.V., Gil, M.I., 2009. Prevention of Escherichia coli cross-contamination by different commercial sanitizers during washing of fresh-cut lettuce. Int. J. Food Microbiol. 133, 167171. doi: 10.1016/j.ijfoodmicro.2009.05.017.

Lynch, M.F., Tauxe, R.V., Hedberg, C.W., 2009. The growing burden of foodborne outbreaks due to contaminated fresh produce: risks and opportunities. Epidemiol. Infect. 137, 307-315. doi: $10.1017 / \mathrm{s} 0950268808001969$.

Murray, K., Wu, F., Shi, J., Jun Xue, S., Warriner, K., 2017. Challenges in the microbiological food safety of fresh produce: limitations of post-harvest washing and the need for alternative interventions. Food Qual. Saf. 1, 289-301. doi: 10.1093/fqsafe/fyx027.

National Institute for Public Health and the Environment (RIVM), 2020. Groenten. National Institute for Public Health and the Environment (RIVM).

National Institute for Public Health and the Environment (RIVM), 2019. Consumptie van fruit, noten en olijven. National Institute for Public Health and Environment (RIVM).

Parish, M.E., Beuchat, L.R., Suslow, T.V., Harris, L.J., Garrett, E.H., Farber, J.N., Busta, F.F., 2003. Methods to reduce/eliminate pathogens from fresh and fresh-cut produce. Compr. Rev. Food Sci. 2, 161-173. doi: 10.1111/j.1541-4337.2003.tb00033.x. 


\section{Chapter 1}

Pijnacker, R., Friesema, I.H.M., Mughini Gras, L., Lagerweij, G.R., van Pelt, W., Franz, E., 2019. Disease burden of food-related pathogens in the Netherlands, 2018. National Institute for Public Health and the Environment (RIVM).

Ritchie, H., Roser, M., 2020. Diet compositions. OurWorldInData.org.

Takeuchi, K., Frank, J.F., 2000. Penetration of Escherichia coli 0157:H7 into lettuce tissues as affected by inoculum size and temperature and the effect of chlorine treatment on cell viability. J. Food Prot. 63, 434-440.

U.S. Food and Drug Administration (FDA), 2015. Analysis and evaluation of preventive control measures for the control and reduction/elimination of microbial hazards on fresh and fresh-cut produce: Chapter IV. Outbreaks associated with fresh and fresh-cut produce. Incidence, growth, and survival of pathogens in fresh and fresh-cut produce. U.S. Food and Drug Administration (FDA).

Van Haute, S., Sampers, I., Jacxsens, L., Uyttendaele, M., 2015. Selection criteria for water disinfection techniques in agricultural practices. Crit. Rev. Food Sci. Nutr. 55, 1529-1551. doi: 10.1080/10408398.2012.705360.

World Health Organization (WHO), 2003. Diet, nutrition, and the prevention of chronic diseases: report of a joint WHO/FAO expert consultation. World Health Organization (WHO).

World Health Organization (WHO), 2015. WHO estimates of the global burden of foodborne diseases: foodborne disease burden epidemiology reference group 2007-2015. World Health Organization (WHO).

World Health Organization (WHO), 2019. Increasing fruit and vegetable consumption to reduce the risk of noncommunicable diseases. World Health Organization (WHO), e-Library of Evidence for Nutrition Actions (eLENA) 




\section{Chapter 2}

\section{Effect of disinfectants on preventing the cross- contamination of pathogens in fresh produce washing}

J.L. Banach

I. Sampers

S. Van Haute

H.J. van der Fels-Klerx

Published in: International Journal of Environmental Research and Public Health (2015), 12, 8658-8677.

doi: 10.3390/ijerph120808658 


\section{Chapter 2}

\section{Abstract}

The potential cross-contamination of pathogens between clean and contaminated produce in the washing tank is highly dependent on the water quality. Process wash water disinfectants are applied to maintain the water quality during processing. The review examines the efficacy of process wash water disinfectants during produce processing with the aim to prevent cross-contamination of pathogens. Process wash water disinfection requires short contact times, so microorganisms are rapidly inactivated. Free chlorine, chlorine dioxide, ozone, and peracetic acid were considered suitable disinfectants. A disinfectant's reactivity with the organic matter will determine the disinfectant residual, which is of paramount importance for microbial inactivation and should be monitored in situ. Furthermore, the chemical and worker safety and the legislative framework will determine the suitability of a disinfection technique. Current research often focuses on produce decontamination and, to a lesser extent, on preventing cross-contamination. Further research on a sanitizer's efficacy in the washing water is recommended at the laboratory scale, in particular with experimental designs reflecting industrial conditions. Validation on the industrial scale is warranted to better understand the overall effects of a sanitizer.

\section{Keywords}

Water disinfection; Fresh produce; Cross-contamination; Chlorine; Chlorine dioxide; Peracetic acid; Ozone; Disinfection by-products; Water quality 


\subsection{Introduction}

Microbial food safety and quality issues with leafy vegetables, including the presence of pathogens on leafy greens, have been reported. During the production of fresh-cut vegetables, the washing step has been identified as a potential pathway for dispersion of microorganisms, and more specifically Escherichia coli, to the end product (Holvoet, Jacxsens, Sampers and Uyttendaele, 2012). Although washing with potable water helps to remove microorganisms to a certain extent, sanitizers have also been applied to enhance the disinfection of the produce (i.e., decontamination) (Van Haute, Sampers, Holvoet and Uyttendaele, 2013a; World Health Organization. Food Safety Team and Food and Agriculture Organization of the United Nations, 1998). Nevertheless, the ability to remove naturally present microorganisms from fresh-cut produce is limited (0.5-2.0-log reduction), i.e., some microbial reductions occur, but total reduction is unachievable (Goodburn and Wallace, 2013; Olaimat and Holley, 2012; Tirpanalan, Zunabovic, Domig and Kneifel, 2011; Van Haute, Uyttendaele and Sampers, 2013b). These limitations are attributed to microbial attachment to surfaces, including those at crevices or cut edges, or as a result of irregular surface structures. In addition, microorganisms may form biofilms, or become internalized within plant tissues, through stomata, cut surfaces, or other tissue wounds, or during the pre-harvest stage via the root system, although the significance of the latter has yet to be confirmed (Holvoet et al., 2012; Holvoet, Sampers, Callens, Dewulf and Uyttendaele, 2013; Keskinen, Burke and Annous, 2009; López-Gálvez, Gil, Truchado, Selma and Allende, 2010b; Sapers, 2001). In short, the disinfectant dose used to avoid cross-contamination is lower compared to the dose needed for microbial inactivation in the fresh produce, thus reducing the formation of disinfection by-products (DBPs). Therefore, sanitizing strategies should focus primarily on preventing cross-contamination in the washing tank rather than on ensuring produce safety as a result of product decontamination. The potential cross-contamination during washing between clean and contaminated produce may be minimized by maintaining the water quality throughout processing (Gil, Selma, López-Gálvez and Allende, 2009; Parish, Beuchat, Suslow, Harris, Garrett, Farber and Busta, 2003; Van Haute, Sampers, Jacxsens and Uyttendaele, 2015b), since once the produce becomes contaminated, decontamination of the final product is unlikely to remove attached microorganisms (Van Haute, López-Gálvez, Gómez-López, Eriksson, Devlieghere, Allende and Sampers, 2015a; Van Haute et al., 2015b). In particular, Gil et al. (2009) have reviewed fresh-cut produce sanitation and wash water disinfection outlining the problems and potential solutions to current applications. These authors highlight that sanitizers are key for hygiene in the fresh-cut produce industry, yet stress that water disinfection should be aimed at preventing crosscontamination between clean and contaminated products. In other words, sanitizers are used to maintain the quality of the washing water despite limited, direct microbial benefits on the produce (Gil et al., 2009). Davidson, Buchholz and Ryser (2013) have also stressed this argument, stating that the aim of sanitizer application is mainly to lessen the effects of cross-contamination during washing and have concluded that sanitizers are not to be used to guarantee product safety. Such conclusions have also been highlighted by other authors (Al-Nabulsi, Osaili, Obaidat, Shaker, Awaisheh and Holley, 2014; Davidson et al., 2013; López-Gálvez, Allende, Selma and Gil, 2009). 
In the fresh-cut produce industry, water disinfection occurs in washing tanks, or immersion washers, in which the produce is washed (Pao, Long, Kim and Kelsey, 2012); however, water disinfection can also be used to recycle process water (i.e., water reconditioning) (Gómez-López, Gil, Allende, Vanhee and Selma, 2015). Process wash water and water reconditioning can be distinguished based on where and when the disinfection takes place: (i) process wash water disinfection occurs in the washing tank where a disinfectant residual is maintained during washing, i.e., all the water is treated, and (ii) water reconditioning occurs outside the washing tank where only part of the water is treated at a specific time (Van Haute et al., 2015a; Van Haute et al., 2015b). A distinction between these disinfection methods is important when considering the potential for reducing microbial cross-contamination. For example, during water reconditioning, microbial inactivation occurs at another location than the contamination event (i.e., the washing tank), which increases the probability of crosscontamination, such as pathogen point-contaminations (Van Haute et al., 2015b).

The effect of disinfectants on reducing cross-contamination can be estimated using disinfection kinetics. Disinfection kinetics are based on the disinfectant dose (chemical, irradiation, or ultrasound (US) power consumption) and contact time (concentration $\times$ time). Water disinfection treatments demonstrate vastly different kinetic behaviors towards microorganism inactivation, which are dependent on the inherent disinfection efficiency as well as the influence of the physicochemical quality of the water matrix on the disinfectant concentration. The exposure (i.e., contact time) is a major limiting factor for process wash water disinfection due to required short contact times (30 seconds up to a few minutes); thus, microorganisms in the wash water must be instantaneously inactivated (Gómez-López et al., 2015; Van Haute et al., 2015b).

Due to the increasing presence of organic matter in the wash water during a production cycle, the disinfectant dose reduces over time. This reduction demonstrates the premise for a disinfectant residual during washing. Principally, wash water disinfection of process washing water with sanitizers can only function adequately for preventing cross-contamination when the required disinfectant residual is controlled in the washing bath through automated monitoring and dosing of the disinfectant.

Water quality of the process wash water can only be maintained when disinfection kinetics favor quick, efficient disinfectants. To date, the following chemical disinfectants appear to be appropriate for process wash water disinfection: free chlorine, chlorine dioxide $\left(\mathrm{ClO}_{2}\right)$, ozone $\left(\mathrm{O}_{3}\right)$, and peracetic acid (PAA). This review explores the influences on the disinfection efficacy of these disinfectants in the wash water during produce processing with the aim to prevent cross-contamination of pathogens on the fresh produce via the process wash water. 


\subsection{Selection of wash water disinfectants}

Besides free chlorine, $\mathrm{ClO}_{2}, \mathrm{O}_{3}$, and PAA, other disinfectants are currently available; however, these options appear less suitable for preventing cross-contamination during fresh produce washing, i.e., during process washing (Van Haute et al., 2015b). In other words, processing limitations influence the appropriate sanitizer choice for disinfection techniques. The limitations for wash water disinfection are: (i) how the sanitizer can be used in the wash water system, and (ii) the necessary disinfectant residual (which can be based on physicochemical parameters like the organic matter) in order to achieve sufficient disinfection. Specifically, current applications for hydrogen peroxide $\left(\mathrm{H}_{2} \mathrm{O}_{2}\right)$, organic acids, US, and ultraviolet (UV) irradiation should not be recommended as process wash water disinfectants for fresh produce.

$\mathrm{H}_{2} \mathrm{O}_{2}$ requires a high residual alongside a high disinfectant demand due to its strong influence with organics in the wash water, and thus rapid consumption and slow disinfection kinetics (Van Haute, Tryland, Veys and Sampers, 2015c). Organic acids require high concentrations to be applied, yet despite these concentrations, minimum effective doses for strong organic acids, like acetic or lactic acid, exceed levels that would prevent adverse effects on the sensory quality of produce (Koutsoumanis and Skandamis, 2013; López-Gálvez et al., 2009; Ölmez and Kretzschmar, 2009; Van Haute et al., 2013b). Current ultrasonic generating devices are not effective at delivering rapid inactivation of microorganisms. The necessary energy demand is too high for application during process wash water disinfection (Drakopoulou, Terzakis, Fountoulakis, Mantzavinos and Manios, 2009; Gogate, 2007; Joyce, Phull, Lorimer and Mason, 2003). With respect to fresh-cut produce wash water, Gómez-López, Lannoo, Gil and Allende (2014b) demonstrated that increasing the chemical oxygen demand (COD) in the wash water did not influence the inactivation of E. coli 0157:H7. However, current ultrasonication methods require high sonication intensities and long contact times, making these methods impractical when preventing microbial crosscontamination in the process wash water (Gómez-López, Gil, Allende, Blancke, Schouteten and Selma, 2014a; Gómez-López et al., 2015). UV water disinfection involves circulating a thin layer of water along suspended UV lamps. This type of setup is required since UV transmittance in the water is highly influenced by the presence of organic matter or suspended particles, which can absorb or shield UV rays (Environmental Protection Agency (EPA), 2006; Van Haute et al., 2015b). Evidently, UV application in the fresh produce process wash water would have considerable UV absorbance. Furthermore, traditional washing tank designs prevent the close proximity of all water in the washing tank to the lamps at all times, which would be a prerequisite in order to prevent cross-contamination utilizing this method. Therefore, UV irradiation is de facto a reconditioning technique and is not optimal when preventing microbial cross-contamination (Van Haute et al., 2015b).

These aforementioned wash water disinfectants or current water treatment technologies are simply not appropriate for preventing cross-contamination in fresh produce washing operations owing to the need for very high disinfectant residuals (or electrical energy consumption), which is due to the slow microbial inactivation kinetics and/or great interference from organic matter. 


\subsection{Sanitizer efficacy}

Sanitizer efficacy depends on many parameters such as the disinfectant type, dosage, residual concentration, contact time, temperature, $\mathrm{pH}$, produce to water ratio in the process wash water where the sanitizer is applied, and the extent of organic matter in the washing tank as well as other physicochemical properties of the process wash water (Davidson et al., 2013; Gil et al., 2009; Van Haute et al., 2015a).

Gil et al. (2009) note the difficulties in comparing the efficacy of disinfection technologies as several factors in the experimental set-up influence the efficacy. These include the water quality, sanitizers, target microorganisms, inoculation procedure (e.g., spray, submersion, etc.), methods of detection, produce, and time interval (Gil et al., 2009). In order to evaluate potential disinfection treatments, Van Haute et al. (2015b) have evaluated several water disinfection technologies, aimed at inactivating pathogenic microorganisms, in order to characterize criteria that influence the suitability of a technology and provide a selection tool for fresh-cut produce methods during pre-and post-harvest practices.

Overall, the process wash water quality is of utmost concern since during processing the composition is perpetually changing and is a cause of concern for potential microbiological contaminations (Allende, Selma, Lopez-Galvez, Villaescusa and Gil, 2008; López-Gálvez et al., 2009). Furthermore, the process wash water quality is influenced by the disinfectant choice (Van Haute et al., 2015a), while the efficacy of a sanitizer is a function of the disinfectant residual. The efficiency of wash water disinfection is not restricted to issues that affect produce decontamination, but the effectiveness of chemical oxidants is rather hindered by the presence of organic matter in the wash water (Gómez-López et al., 2015; López-Gálvez et al., 2009; Van Haute et al., 2015b; Van Haute et al., 2015c). In particular, the influence of physicochemical parameters (e.g., organic matter) on the stability of the processing wash water disinfectants can be summarized as a function of decreasing reactivity: $\mathrm{O}_{3}>\mathrm{HOCl}$ (hypochlorous acid) $>\mathrm{ClO}_{2}>$ PAA (Baert, Vandekinderen, Devlieghere, Van, Debevere and Uyttendaele, 2009; López-Gálvez et al., 2009; Van Haute et al., 2015a; Van Haute et al., 2015b; Zhang, Ma, Phelan and Doyle, 2009). Thus, when there is a decreasing reactivity with the organic matter, there is a decreasing dose that is necessary to maintain the residual. The general disinfection efficacy of process wash water disinfectants is as follows: $\mathrm{O}_{3}>\mathrm{HOCl} \approx \mathrm{ClO}_{2}>$ PAA. Since a fast inactivation in the washing tank is of paramount importance, the disinfectant residual is the parameter that can be adjusted. Accordingly, the amount of necessary disinfectant residual is as follows: $\mathrm{PAA}>\mathrm{HOCl} \approx \mathrm{ClO}_{2}>\mathrm{O}_{3}$. In brief, the organic matter in the process wash water has shown to influence the disinfectant demand and dosage in order to maintain a disinfectant residual, of which is important to maintain continuously throughout processing (Gómez-López et al., 2014b; Van Haute et al., 2015a; Van Haute et al., 2015b).

Furthermore, the target microorganism in question is an important consideration when selecting an appropriate process wash water disinfectant. Whether it be vegetative bacteria, bacterial spores, Gram-positive pathogens (e.g., Listeria monocytogenes, Gramnegative pathogens (e.g., E. coli 0157:H7 or Salmonella spp.), viruses (Norovirus or 
bacteriophages), or protozoa (Giardia or Cryptosporidium), or even several of these, this choice influences the achievable microbial reduction and disinfection strategy to be applied. Van Haute et al. (2015b) have evaluated the influence of the microorganism type on process wash water disinfectants. The surrogate type investigated (e.g., murine norovirus (MNV) for Norovirus), as well as the inoculum composition, mixed or cocktail strains, also play a role in the efficacy of the applied technology during experiments. In general, the necessary disinfection residuals to inactivate vegetative bacteria in the wash water versus on the produce, e.g., for free chlorine, differ as such: residuals of 1-5 $\mathrm{mg} / \mathrm{L}$ inactivate microorganisms in the wash water (wash water disinfection), whereas residuals of $20-200 \mathrm{mg} / \mathrm{L}$ or more are usually applied for inactivation of microorganisms on fresh produce (i.e., decontamination) (Parish et al., 2003; Van Haute et al., 2013a; Van Haute et al., 2013b). The differences in the doses required to avoid cross-contamination and those required to reduce the microbial load of fresh produce have a main impact on DBP formation.

In current literature, sanitizer efficacy is mainly expressed in terms of microbiological reductions, with much attention to produce decontamination and, to a lesser extent, on cross-contamination prevention. Nevertheless, one should also consider microbiological and chemical safety for the consumer as well as quality aspects such as the sensory and nutritional value of the produce when evaluating overall sanitizer efficacy. Many of these parameters can help to validate and weigh the usefulness of a sanitizer. Furthermore, a cost analysis of the implemented sanitizer could help to validate the economic cost efficacy of a fresh-cut produce treatment or investment for a certain disinfection technology. In addition, Gil et al. (2009) reference another pivotal influence, the variations between laboratory, pilot, and factory scale experiments with respect to sanitizer efficacy (Beuchat, Adler and Lang, 2004; Sapers, 2001). These differences may create another challenge when trying to evaluate sanitizer efficacy based on scientific literature or on a laboratory scale.

\subsection{Legislation and disinfection by-products}

In the European Union (EU), Regulation (EU) No 528/2012, applicable as of 1 September 2013, aims to improve the functioning of the internal market of biocidal products while ensuring a high level of environmental and human health protection (European Commission (EC), Regulation (EU) No 528/2012). With respect to this regulation, the European Chemicals Agency (ECHA) provides a summary of the status of applications in which substances including active chlorine (manufactured), $\mathrm{ClO}_{2}$, and PAA are currently under review; these substances are also recognized for review in Annex II Part 1 of the Commission Delegated Regulation (EU) No 1062/2014 of 4 August 2014 (EC, Regulation (EU) No 528/2012; EC, Regulation (EU) No 1062/2014; ECHA, 2015).

In the United States of America (USA), both the United States Environmental Protection Agency (EPA) and the United States Food and Drug Administration (FDA) exhibit judicial power regarding raw agricultural commodities that are washed in, for example, a fresh-cut facility. Sanitizers that are used for fresh produce are regulated as secondary direct food additives by the FDA, meaning they exhibit a technical effect during 
processing yet not in the finished product, although in some cases, they are considered generally recognized as safe (GRAS). Disinfectants are registered as pesticides with the EPA (Gil et al., 2009).

The reaction of chemical disinfectants with water matrix constitutes leads to the production of DBPs. In particular, the challenges surrounding the presence of high amounts of organic matter and the resulting DBPs have raised scientific, industrial, and political concerns (Artés, Gómez, Aguayo, Escalona and Artés-Hernández, 2009; Chaidez, Castro-del Campo, Heredia, Contreras-Angulo, González-Aguilar and AyalaZavala, 2012; Gil et al., 2009; Gómez-López et al., 2014b; Parish et al., 2003).

\subsubsection{Chlorine}

Several concerns arise as a result of the potential health and environmental concerns due to the formation of carcinogenic, halogenated DBPs such as trihalomethanes (THMs) and haloacetic acids (HAAs) during chlorine application (Artés et al., 2009; Gil et al., 2009; López-Gálvez, Allende, Truchado, Martínez-Sánchez, Tudela, Selma and Gil, 2010a; Ölmez and Kretzschmar, 2009; Parish et al., 2003; Van Haute et al., 2015b). Furthermore, the high or excessive use of chlorine, i.e., hyperchlorination, in order to combat the increasing organic load in the wash water may produce unacceptable levels of DBPs (López-Gálvez et al., 2010a; Ölmez and Kretzschmar, 2009). The potential formation of these toxic DBPs in addition to potential future regulatory restrictions has motivated scientists and processors to investigate alternative disinfection methods, such as $\mathrm{ClO}_{2}, \mathrm{O}_{3}$, and PAA during produce washing. Currently, there is lacking evidence on chlorine DBP residues in fresh produce (e.g., in prepared salads) and subsequent human exposure (Committee on Toxicity of Chemicals in Food Consumer Products and the Environment (COT), 2006; Gómez-López, Marín, Medina-Martínez, Gil and Allende, 2013).

Some EU member states have explicitly stated certain boundary conditions for chlorine use in fresh produce washing processes, e.g., the United Kingdom poses limits concerning free and total chlorine in the wash water, the $\mathrm{pH}$, the produce residence time in the washing tank, and the produce to water ratio (Chilled Food Association (CFA), 2010), whereas France mentions free chlorine residual limits in the wash water and limits the halogenated organic compounds on the produce (Direction générale de la concurrence de la consommation et de la répression des fraudes (DGCCRF), 2006). During storage, the degradation of chlorine solutions leads to the formation of chlorate/perchlorate. These degradation products are introduced into the wash water during chlorination, and it is undesirable to have these degradation products absorbed into the fresh produce. To avoid this, chlorine solutions should be stored in the dark, at cool temperatures, and in a diluted solution if possible. Also, it is preferable to use sodium hypochlorite $(\mathrm{NaClO})$ solutions within a few weeks after production. At $5{ }^{\circ} \mathrm{C}$, the degradation is very limited in the absence of heavy metal contamination, and with an increase in temperature of $10^{\circ} \mathrm{C}$, the degradation rate increases 3-4 fold (Black \& Veatch Corporation, 2010). 


\subsubsection{Chlorine dioxide}

The high oxidizing capacity of $\mathrm{ClO}_{2}$ can be attributed to its reactivity via oxidation rather than electrophilic or oxidation substitution, as seen with chlorine (Gómez-López, 2012). Due to such selective mechanisms, $\mathrm{ClO}_{2}$ forms the major by-products chlorite and chlorate upon decomposition, yet no direct organochlorine compounds form (Artés et al., 2009; Gómez-López, 2012; Hebert, Forestier, Lenes, Benanou, Jacob, Arfi, Lambolez and Levi, 2010; Van Haute et al., 2015b). When iodide is present in the water, more iodinated DBPs, especially iodoform, are formed with $\mathrm{ClO}_{2}$ than with chlorine, and iodinated DBPs may be more toxic than chlorinated DBPs (Hua and Reckhow, 2007). Furthermore, since $\mathrm{ClO}_{2}$ is more selective and possesses a lower oxidation strength than chlorine, its reactivity is less sensitive to organic matter (Gómez-López, 2012; Parish et al., 2003).

Within the EU, there are no regulations concerning $\mathrm{ClO}_{2}$ application in fresh-cut produce washing (López-Gálvez et al., 2010a). According to Regulation (EC) No $396 / 2005$, the default maximum residue limit (MRL) for chlorate was $0.01 \mathrm{mg} / \mathrm{kg}$ (EC, Regulation (EC) No 396/2005). However, the European Commission (EC) Standing Committee on the Food Chain and Animal Health (SCoFCAH) have recognized that such as default level does not cover the presence of chlorate due to legal uses of, e.g., disinfectants, and there are no indications of illegal use of chlorate as a pesticide (European Commission (EC), 2014a, b). Therefore, as a provisional solution, it was agreed that the individual member states would be given the ability to establish enforcement levels at the national level until risk management can take place based on European Food Safety Authority (EFSA) scientific opinion and monitoring data (EC, 2014b).

In the USA, the FDA permits $\mathrm{ClO}_{2}$ as an antimicrobial agent in the wash water of not raw agricultural commodities, provided that the residual $\mathrm{ClO}_{2}$ is below $3 \mathrm{ppm}$ and the treatment is followed by a potable rinse or another specified preservative method (FDA, 2013).

\subsubsection{Ozone}

The main DBP of concern is bromate, which results from the oxidation of bromide to hypobromous acid. Hypobromous acid is further oxidized to bromite and bromate (Rakness, 2005; von Gunten, 2003a). Bromide concentrations in natural waters are highly variable. However, in many water sources, low concentrations of bromide $(<20$ $\mu \mathrm{g} / \mathrm{L})$ are present yet are not considered problematic. Higher concentrations of bromide (50-100 $\mu \mathrm{g} / \mathrm{L})$ result in excessive bromate formation, and bromate becomes a serious problem when bromide levels exceed $100 \mu \mathrm{g} / \mathrm{L}$ (Camel and Bermond, 1998; von Gunten, 2003b). Bromate induces deoxyribonucleic acid (DNA) damage and is a possible human carcinogen (Camel and Bermond, 1998; Kim, 2007; von Gunten, 2003b; Wert, Neemann, Rexing and Zegers, 2008). Bromate is particularly problematic because it is not biodegradable (Wert et al., 2008).

Bromo-organic DBPs have been identified and can form by the reaction of hypobromous acid with organic matter (Huang, Fang and Wang, 2005). However, the 
concentrations of these bromo-organic compounds are usually far below current drinking water standards (von Gunten, 2003b). Non-brominated organic compounds result from the oxidative breakdown of organic matter. Alkenes, activated aromatic systems, amines, and sulfur-containing organic compounds can lead to the fast formation of low molecular weight organic compounds (e.g., organic acids, aldehydes, ketones, alcohols, and esters) (Hammes, Salhi, Köster, Kaiser, Egli and von Gunten, 2006; Huang et al., 2005; National Research Council (US) Safe Drinking Water Committee, 1980). The largest fraction of low molecular weight organic compounds constitutes organic acids, whereas aldehydes and ketones are only formed in small amounts (Huang et al., 2005). Iodate is the main by-product formed by direct oxidations with molecular $\mathrm{O}_{3}$ in iodide containing waters. Iodate is considered non-problematic because it is transformed back to iodide in the human body (National Research Council (US) Safe Drinking Water Committee, 1980; von Gunten, 2003b). Amines are highly reactive towards $\mathrm{O}_{3}$, which leads to the formation of odorous agents (e.g., isovaleraldehydes, phenylacetaldehydes, isobutyraldehydes, and 2methylbutyraldehyde).

Within the EU and the USA, bromate presence is regulated in the drinking water with a maximum level of $10 \mu \mathrm{g}$ bromate/L (EPA, 2009; European Communities, 2007). In the USA, $\mathrm{O}_{3}$ has been granted GRAS approval for direct contact with food products; it can be used as a sanitizer for foods when used at levels and by methods of application consistent with good manufacturing practices (GMP) (Ölmez, 2012). $\mathrm{O}_{3}$ is classified by the FDA as a secondary direct food additive (processing aid) for foods, i.a. on raw agricultural products (FDA, 2014).

\subsubsection{Peracetic acid}

In comparison to the other process wash water disinfectants, PAA has the least potential of producing DBPs (Van Haute et al., 2015b). Unlike chlorine-based sanitizers, PAA degradation by-products can easily dissolve in water and are non-toxic; thus, making PAA an effective biocide (Vandekinderen, Devlieghere, De Meulenaer, Ragaert and Van Camp, 2009; Warburton, 2014). Van Haute et al. (2015b) have indicated that negligible or low levels of aldehydes may form.

\section{$2.5 \quad$ Process wash water disinfectants}

\subsubsection{Chlorine}

Chlorine application, for example, as $\mathrm{NaClO}$, calcium hypochlorite $\mathrm{Ca}(\mathrm{ClO})_{2}$ or chlorine gas $\left(\mathrm{Cl}_{2}\right)$, is widely utilized due to its bactericidal properties and cost efficiency (Artés et al., 2009; Chaidez et al., 2012; Goodburn and Wallace, 2013; Joshi, Mahendran, Alagusundaram, Norton and Tiwari, 2013; Luo, Nou, Millner, Zhou, Shen, Yang, Wu, Wang, Feng and Shelton, 2012; Parish et al., 2003; Sapers, 2014; Tapia and WeltiChanes, 2012; Van Haute et al., 2015b; World Health Organization. Food Safety Team and Food and Agriculture Organization of the United Nations, 1998). During produce washing, chlorine dissolves in the water causing $\mathrm{HOCl}$, an efficient oxidizer for pathogen inactivation. However, $\mathrm{HOCl}$ can readily dissociate into hypochlorite ions (OCl-) at high 
pH or into $\mathrm{Cl}_{2}$ at low pH (Artés et al., 2009; Chaidez et al., 2012; Luo et al., 2012). Typical industrial application of free chlorine concentrations range from 50 to $200 \mathrm{mg} / \mathrm{L}$, with a short contact time (i.e., 1-2 $\mathrm{min}$ ), and $\mathrm{pH}$ values between 6.0 and 7.5 in order to stabilize the $\mathrm{HOCl}$ form alongside minimizing corrosion of processing equipment (Artés et al., 2009; Chaidez et al., 2012; Parish et al., 2003; Sapers, 2014; Tapia and WeltiChanes, 2012; World Health Organization. Food Safety Team and Food and Agriculture Organization of the United Nations, 1998).

Maintaining a stable $\mathrm{HOCl}$ form during washing remains a challenge since soil, debris, and exudates can accumulate and contribute to an increasing organic load (Artés et al., 2009; Chaidez et al., 2012; Gómez-López et al., 2014b; Luo et al., 2012; Parish et al., 2003). Luo, Ingram and Khurana (2014) have examined cross-contamination prevention during produce washing and specify that the free chlorine concentration (e.g., disinfectant residual) in the washing water is a main critical control factor for cross-contamination prevention (Hurst, 2002; Luo et al., 2014). During produce washing, an increasing organic load is evident from the increased COD and turbidity in the washing water and declining disinfectant residual, which can be indirectly estimated by the oxidation-reduction potential (ORP) (Chaidez et al., 2012; Luo et al., 2012). In brief, the disinfectant residual and, if relevant, the $\mathrm{pH}$ of the process wash water are important to monitor in situ.

Researchers have investigated the formation of DBPs during chlorine sanitization treatments for fresh-cut produce. For example, López-Gálvez et al. (2010a) found THM formation $(217 \pm 38 \mu \mathrm{g} / \mathrm{L})$ in fresh-cut lettuce processing water following a 30 -minute $\mathrm{NaClO}$ treatment $(100 \mathrm{mg} / \mathrm{L})$ in washing water with a COD of $700 \mathrm{mg} / \mathrm{L}$ in a reconditioning setup. THM formation on the fresh-cut lettuce was only detected under more extreme processing conditions with $60 \mathrm{~min} \mathrm{NaClO}$ treatment $(700 \mathrm{mg} / \mathrm{L})$ in washing water with a COD of 1800 mg/L (López-Gálvez et al., 2010a). Hence, optimizing chlorine application and avoiding hyperchlorination during fresh-cut produce washing can help to avoid the excessive formation of THMs, while maintaining efficient microbial inactivation.

In order to evaluate the effectiveness of chlorine application as a wash water disinfectant during fresh-cut lettuce processing, Van Haute et al. (2013a) examined the effects of the wash water quality during processing and chlorine treatment. These authors determined that maintaining a residual concentration of $1 \mathrm{mg} / \mathrm{L}$ free chlorine in the washing water during the processing of lettuce leaves initially contaminated with E. coli 0157 (c.a. 4.0 log CFU/g) resulted in contaminations below 2.7 and $2.5 \mathrm{log}$ CFU/100 mL, respectively for tap water and artificially processed water (CODs of 500 and $1000 \mathrm{mg} \mathrm{O}_{2}$ /L were evaluated) (Van Haute et al., 2013a). Furthermore, the authors evaluated the total THM accumulation during wash water disinfection. THM levels reached $124.5 \pm 13.4 \mu \mathrm{g} / \mathrm{L}$ following a $1 \mathrm{~h}$ washing processing with a COD of $1000 \mathrm{mg}$ $\mathrm{O}_{2} / \mathrm{L}$ and a chlorine dose of $609.0 \mathrm{mg} / \mathrm{L}$; however, THMs were not detected on the freshcut lettuce post rinse (Van Haute et al., 2013a). Overall, the authors stress dosage and the residual concentrations are key parameters to consider when evaluating the effectiveness of chorine as a wash water disinfectant (Van Haute et al., 2013a). In addition, these results provide evidence to apply lower chlorine concentrations; in order to avoid cross-contamination, online monitoring of chlorine levels during washing would be essential (Van Haute et al., 2013a). 
Optimizing the concentration of free chlorine during produce washing to ensure water quality and prevent cross-contamination in the processing water alongside the evaluation of DBPs that can form during this process presents a challenge for scientists and industry alike. Gómez-López et al. (2014b) sought to evaluate these issues by simulating the fresh-cut processing of spinach inoculated with an Escherichia coli 0157:H7 cocktail (5 log CFU/mL) treated with several concentrations of free chlorine. The authors concluded that maintaining a free chlorine residual at $7 \mathrm{mg} / \mathrm{L}$ during processing, attainable with continuous monitoring of the dose and adjusting the concentration applied as a result of increasing COD, is able to completely eliminate $E$. coli 0157:H7 cells in the process wash water (Gómez-López et al., 2014b). By simulating a pilot plant approach, these authors were able to provide evidence for minimizing chlorination levels that can be applied within the industry; nevertheless, THMs ( $>1000$ $\mu \mathrm{g} / \mathrm{L}$ ) were still generated and, consequently, these results support the overwhelming concern of DBP generation at higher chlorine doses that are commonly applied at industry (Gómez-López et al., 2014b).

Although chlorine is commonly applied as a disinfectant in processing wash water to prevent cross-contamination, recent studies are investigating alternatives disinfectants, hurdle technologies as well as chemical combinations in order to achieve a higher safety for fresh produce (Joshi et al., 2013). For example, in order to enhance chlorine efficacy on a pilot plant scale, the addition of the process aid T128-a chemical mixture that helps to stabilize $\mathrm{HOCl}$ in wash water with high organic matter-was examined (Luo et al., 2012). T128 was determined to significantly reduce the occurrence and survival of $E$. coli 0157:H7 in the wash water and cross-contamination to un-inoculated shredded iceberg lettuce. Hence, T128 application in chlorine fresh produce sanitization systems has the potential to increase safety margins during fresh-cut processing (Luo et al., 2012).

\subsubsection{Chlorine dioxide}

$\mathrm{ClO}_{2}$ may be utilized as a gas or dissolved in water during produce processing (GómezLópez, 2012; Joshi et al., 2013). Although gaseous $\mathrm{ClO}_{2}$ can reach and penetrate microorganisms better than aqueous sanitizers, industrial applications remain limited due to factors like worker's safety and complications with on-site generation (instability) (Gómez-López, 2012; Parish et al., 2003). For example, when applying gaseous chemicals, like $\mathrm{ClO}_{2}$, or even $\mathrm{Cl}_{2}$ or $\mathrm{O}_{3}$, ambient concentration levels in the workplace should in principle be monitored to protect worker safety (Black \& Veatch Corporation, 2010; EPA, 1999; Pascual, Llorca and Canut, 2007; Tarrass, Benjelloun and Benjelloun, 2010). $\mathrm{ClO}_{2}$ has shown to effectively inactivate a broad range of microorganisms by disrupting membrane permeability hindering certain metabolic activities such as protein synthesis (Artés et al., 2009; Gómez-López, 2012; Joshi et al., 2013). In particular, as a bactericide and virucide at lower concentrations ( $0.1 \mathrm{ppm}), \mathrm{ClO}_{2}$ is reported to be effective against several microorganisms, including: bacterial spores, amoebal cysts, Giardia cysts, Cryptosporidium, Mycobacterium tuberculosis, Legionella, E. coli, Salmonella, and Listeria. In addition, $\mathrm{ClO}_{2}$ has been shown to affect the formation of biofilms by hindering re-growth (Artés et al., 2009; Joshi et al., 2013). 
$\mathrm{ClO}_{2}$ efficacy may be due to its high oxidation and penetration capacity that can function at a wide $\mathrm{pH}$ range. For example, with an increasing $\mathrm{pH}$, the degree of inactivation is also reported to increase (Artés et al., 2009; Gómez-López, 2012; Joshi et al., 2013; Parish et al., 2003). Such broad capacities make this disinfectant a promising choice within the fresh-cut produce industry. In particular, gaseous $\mathrm{ClO}_{2}$ has been reported to reach and penetrate microorganisms better than aqueous sanitizers (Gómez-López, 2012; Parish et al., 2003). In terms of more quality-related attributes, aqueous $\mathrm{ClO}_{2}$ has demonstrated variable results for spoilage microflora in produce. Nevertheless, gaseous $\mathrm{ClO}_{2}$ does display acceptable findings. Gaseous $\mathrm{ClO}_{2}$ is promising in terms of prolonging shelf life storage; however, Gómez-López (2012) notes that some authors have reported a bleaching effect due to gaseous treatments. On the other hand, sensory changes due to $\mathrm{ClO}_{2}$ gas treatments can vary depending on the product as well as applied concentrations and times. From these parameters, information on the effects of applying higher concentrations of gaseous $\mathrm{ClO}_{2}$ on the natural microflora, which can protect produce from attachment from other microorganisms, is currently limited to date.

Rodgers, Cash, Siddiq and Ryser (2004) have preliminarily investigated the efficacy of aqueous $\mathrm{ClO}_{2}$ (3 ppm and 5 ppm), as well as chlorine (100 and $\left.200 \mathrm{ppm}\right), \mathrm{O}_{3}$ (3 ppm), and PAA (80 ppm), to determine reductions of E. coli 0157:H7 and L. monocytogenes in an aqueous model system. Both pathogens decreased $>5 \log$ following a 2 to 5 min exposure, with ozone being most effective (15 s) followed by $\mathrm{ClO}_{2}$ (19 to $21 \mathrm{~s}$ ), chlorinated trisodium phosphate ( 25 to $27 \mathrm{~s}$ ), and PAA ( 70 to $75 \mathrm{~s}$ ). In comparison, log reduction times (i.e., the time required to reduce populations $1 \log$ at 21 to $23{ }^{\circ} \mathrm{C}$ ) in the aqueous model system were significantly lower than those seen on the produce; this was partly due to the presence of organic matter on the produce surface (Rodgers et al., 2004). More recently, López-Gálvez et al. (2010a) showed that aqueous $\mathrm{ClO}_{2}$ application (3 ppm) is effective in reducing pathogen cross-contamination in fresh-cut iceberg lettuce washing water, while also preventing THM formation (Gómez-López, 2012; López-Gálvez et al., 2010a). In general, industrial-scale experiments for aqueous $\mathrm{ClO}_{2}$ efficacy in fresh-cut produce washing with an emphasis on preventing recontamination within the washing tank remain limited.

\subsubsection{Ozone}

$\mathrm{O}_{3}$ is a powerful oxidant $(\mathrm{ORP}=2.07 \mathrm{~V}$ ) in water treatment, second only to the hydroxyl radical (ORP $=2.80 \mathrm{~V}$ ) (Audenaert, 2012). It is produced commercially from pure oxygen or dry air by corona discharge of electricity (the most cost-effective method) or through photochemical reactions when low amounts are required (e.g., in laboratories). Due to the short half-life as well as the reactive and toxic nature, $\mathrm{O}_{3}$ has to be produced on-site (Black \& Veatch Corporation, 2010; EPA, 1999; National Research Council (US) Safe Drinking Water Committee, 1980; Rakness, Gordon, Langlais, Masschelein, Matsumoto, Richard, Robson and Somiya, 1996). Concentrations $\geq 30 \%$ in gas are unstable and can be explosive. Once produced, gaseous $\mathrm{O}_{3}$ is transferred into the water; however, $\mathrm{O}_{3}$ is not readily soluble in water (Cheremisinoff, 2002; EPA, 1999; National Research Council (US) Safe Drinking Water Committee, 1980; Rakness, 2005). Aqueous $\mathrm{O}_{3}$ reacts with (in) organic compounds via direct oxidation with molecular $\mathrm{O}_{3}$ or indirect oxidation with hydroxyl radicals, formed from $\mathrm{O}_{3}$ decomposition (LeChevallier and $\mathrm{Au}$, 
2004; von Gunten, 2003b). Formation of the hydroxyl radical from $\mathrm{O}_{3}$ is promoted by increasing the $\mathrm{pH}$ (Reaction (1) and (2)), with the addition of $\mathrm{H}_{2} \mathrm{O}_{2}$, or by photolysis (Choi, Cho, Lee, Choi and Yoon, 2007; Kim, 2007).

$$
\begin{gathered}
\mathrm{O}_{3}+\mathrm{OH}^{-} \rightarrow \mathrm{O}_{2}+\mathrm{HO}_{2}^{-} \\
\mathrm{O}_{3}+\mathrm{HO}_{2}^{-} \rightarrow \mathrm{HO} \bullet+\mathrm{O}_{2} \bullet^{-}+\mathrm{O}_{2}
\end{gathered}
$$

$\mathrm{O}_{3}$ reacts primarily with activated aromatic structures, carbon-carbon double bonds, and non-protonated amines. Carbohydrates and fatty acids react slowly with $\mathrm{O}_{3}$, while amines, amino acids, nucleic acids, proteins, and protein functional groups react more rapidly. The reaction of $\mathrm{O}_{3}$ with inorganic compounds occurs mainly through the transfer of an oxygen atom to the inorganic compound in a two electron oxidation of said compound. The high reactivity of the hydroxyl radical leads to near diffusion controlled reaction rates with water matrix constituents (von Gunten, 2003a). Since $\mathrm{O}_{3}$ has a high reactivity towards (in) organic matter in the wash water, more $\mathrm{O}_{3}$ has to be dosed to maintain the residual compared to other process wash water disinfectants.

Disinfection is generally more efficient at a slightly acidic $\mathrm{pH}$ (Harakeh and Butler, 1984; Lim, Kim, Lee and Ko, 2010; Zuma, Lin and Jonnalagadda, 2009) or relatively independent of $\mathrm{pH}$ in the range of $\mathrm{pH} 6$ to 9, as has been observed for viruses, bacteria, and protozoa (Domingue, Tyndall, Mayberry and Pancorbo, 1988; EPA, 1999; Gyürék, Li, Belosevic and Finch, 1999; Li, Gyürék, Finch, Smith and Belosevic, 2001; Rennecker, Kim, Corona-Vasquez and Mariñas, 2001). In addition, as hydroxyl ions initiate ozone decomposition, the ozone decay in water is higher at alkaline $\mathrm{pH}$. Therefore, it is advised to perform washing at about pH 6 (Van Haute et al., 2015b; von Gunten, 2003a). Besides the efficacy of $\mathrm{O}_{3}$ as a water disinfectant, the damage to fruit and vegetable tissues caused by contact with $\mathrm{O}_{3}$ should be critically considered. For various produce, including lettuce, apples, strawberries, blueberries, cantaloupes, and celery, no adverse effects on sensory quality were reported when washed in ozonated water in the range 2-10 mg/L for up to 5 min (Beltrán, Selma, Marín and Gil, 2005; Bialka and Demirci, 2007; Ölmez, 2012; Ölmez and Akbas, 2009; Rodgers et al., 2004; Wei, Zhou, Zhou and Gong, 2007; Zhang, Lu, Yu and Gao, 2005).

$\mathrm{O}_{3}$, as is $\mathrm{ClO}_{2}$, is easily removed from dilute aqueous solutions by turbulent aeration. Therefore, washing baths with turbulence created by water jets appear to be a better choice than baths where turbulence is generated by air nozzles. Due to its volatile nature, $\mathrm{O}_{3}$ is well-suited for use in plug flow reactors such as pipes (e.g., pipes used in fresh produce washing to assure a certain contact time with the disinfectant) (EPA, 1999). In order to avoid $\mathrm{O}_{3}$ and $\mathrm{ClO}_{2}$ evaporation from washing tanks, especially at high residuals, covered tanks with limited headspace could be advantageous. 


\subsubsection{Peracetic acid}

PAA $\left(\mathrm{CH}_{3} \mathrm{CO}_{3} \mathrm{H}\right)$ is the peroxide of acetic acid (González-Aguilar, Ayala-Zavala, ChaidezQuiroz, Heredia and Castro-del Campo, 2012; Kitis, 2004). It is commercially available as a quaternary equilibrium mixture of acetic acid $\left(\mathrm{CH}_{3} \mathrm{CO}_{2} \mathrm{H}\right), \mathrm{H}_{2} \mathrm{O}_{2}, \mathrm{CH}_{3} \mathrm{CO}_{3} \mathrm{H}$, and $\mathrm{H}_{2} \mathrm{O}$, as shown by Reaction (3) (Kitis, 2004; Vandekinderen et al., 2009). It is a colorless liquid with a piercing vinegar-like odor with a pH of less than 2 (González-Aguilar et al., 2012; Kitis, 2004).

$$
\mathrm{CH}_{3} \mathrm{CO}_{2} \mathrm{H}+\mathrm{H}_{2} \mathrm{O}_{2} \leftrightarrow \mathrm{CH}_{3} \mathrm{CO}_{3} \mathrm{H}+\mathrm{H}_{2} \mathrm{O}
$$

Vandekinderen et al. (2009) elaborate on the antimicrobial properties of PAA as being related to the production of reactive oxygen species, which damage DNA and lipids, as well as cell membrane disruptions, blockage of enzymatic and transport systems, denaturation of proteins and enzymes, and increased cell membrane permeability via oxidation of sulfhydryl and disulfide bonds. These authors also note that commercially available PAA often contains considerable amounts of $\mathrm{H}_{2} \mathrm{O}_{2}$, which also possesses antimicrobial properties, although such properties are predominated by PAA disinfection power (Vandekinderen et al., 2009). In short, some limitations to the use of such a sanitizer include its instability at higher concentrations (15\%); in particular, commercially available PAA solutions (10-15\%) are more stable than other concentrations (Kitis, 2004). Other limitations include the higher costs (e.g., operational) in comparison to more traditional chlorine-based methods (Van Haute et al., 2015b; Vandekinderen et al., 2009). However, its reported limited susceptibility to organic matter, broad temperature range usage, broad $\mathrm{pH}$ spectrum (3.0-7.5), and reported non-toxic decomposition products (being acetic acid and oxygen) make it a relevant alternative for application in the process wash water (Kunigk and Almeida, 2001; Vandekinderen et al., 2009). More recently, though, Van Haute et al. (2015a) have found that the disinfection efficacy of PAA plus lactic acid showed increased efficiency with decreasing $\mathrm{pH}$. PAA reacts more slowly with organic matter in the wash water than free chlorine, and as such, a lower dose is necessary to maintain the desired residual (Van Haute et al., 2015a; Vandekinderen et al., 2009). However, the disinfection rate of PAA is also much slower, and as such, a higher disinfectant residual is necessary to achieve equally rapid microbial inactivation (Mezzanotte, Antonelli, Citterio and Nurizzo, 2007; Van Haute et al., 2015a).

Van Haute et al. (2015b) also evaluated PAA based on managerial criteria such as costs and complexity of the operation. In brief, PAA is reported to be more cost-effective on lower scale applications. In addition, inactivation of coliforms had required longer concentration and contact times for $\mathrm{O}_{3}$ in contrast to PAA or $\mathrm{ClO}_{2}$ (Van Haute et al., 2015b). Furthermore, Van Haute et al. (2015b) stressed that PAA maintenance and operation, as also seen with hypochlorite solutions, are relatively simple to execute in comparison to other chemical disinfection methods.

Furthermore, the final quality-related effects on the end product (e.g., post storage) should be considered. For example, Rodgers et al. (2004) noted that sensory panelists were able to detect the use of 80 ppm of PAA on chopped lettuce. Unfortunately, such objectives are often not the main aim of studies; nevertheless, authors sometimes note 
sanitizer application in the process wash water as a final recommendation. For example, Baert et al. (2009) highlight $\mathrm{NaClO}$ and PAA as useful sanitizers for crosscontamination prevention in the washing water as well as sanitizers that are necessary to maintain the viral and bacterial microbiological quality of recycled wash water, yet these sanitizers were seen as less relevant for decontaminating microbial populations on the lettuce.

In order to improve PAA efficacy, acquiring knowledge on the inactivation kinetics of microorganisms, including approaches that target multiple hurdle strategies such as combined physical and chemical or multiple chemical treatments, should be investigated. Sánchez, Elizaquível, Aznar and Selma (2015) evaluated the applicability of PAA based sanitizer (Tsunami ${ }^{\circledR} 100$ ) in combination with high power ultrasound (HPU) to inactive the MNV-1 strain in the process wash water; however, these authors determined that these methods were insufficient during process washing since a rapid inactivation of MNV was necessary. MNV-1 was determined to be more resistant to hurdle technologies than pathogenic bacteria E. coli 0157:H7 and Salmonella. In short, PAA efficacy was not enhanced when combined with HPU during MNV inactivation. Other HPU conditions like higher frequencies and combinations of HPU with physical treatments were recommended for further investigation. Nevertheless, these authors concluded that given the recommended concentrations of PAA, it is shown to be an alternative choice to chlorine-based sanitizers when preventing MNV crosscontamination during produce washing in the process wash water. Other PAA based sanitizers, such as a combination of lactic acid and peroxyacetic acid (LA-PAA), have been more recently investigated in terms of microbial efficacy and have been suggested as a possible alternative to chlorine-based disinfectants in fresh produce washing water (Grace Ho, Luzuriaga, Rodde, Tang and Phan, 2011).

\subsection{Conclusions}

Various parameters can affect the efficacy of disinfection treatments on fresh-cut produce. Sanitizers should be used to maintain the quality of washing water in order to prevent cross-contamination rather than as a last resort for produce decontamination. The influence of organic matter on the disinfectant, and consequently the necessary residual concentration during process wash water disinfection, is critical to monitor, e.g., by online monitoring and dosing. In addition to the microbiological and the chemical safety of a disinfectant, the effect on product quality is essential to consider in parallel with legal aspects when selecting disinfectants and methods. Thus, optimizing the amount of sanitizer required for disinfection is key in order to reduce undesirable impacts, especially those that may negatively impact public health. Additional investigation into the influencing factors for the appropriate selection of disinfectants is critical. Further research on a sanitizer's efficacy in the washing water is recommended at the laboratory scale, in particular with experimental designs reflecting industrial conditions. Validation on the industrial scale is warranted to better understand the overall effects of a sanitizer. 


\section{Acknowledgments}

This research has been financed by the Dutch Ministry of Economic Affairs (EZ), under the Topsector project Microbiology in Horticulture (PPS 296, B0-33.05-001-001). The authors acknowledge the contributions from the Dutch fruit and vegetable industry. The authors also acknowledge the European Community's Seventh Framework Program (FP7) under grant agreement no. 244994 (project VEG-i-TRADE) for the support. 


\section{References}

Al-Nabulsi, A.A., Osaili, T.M., Obaidat, H.M., Shaker, R.R., Awaisheh, S.S., Holley, R.A., 2014. Inactivation of stressed Escherichia coli 0157:H7 cells on the surfaces of rocket salad leaves by chlorine and peroxyacetic acid. J. Food Prot. 77, 32-39. doi: 10.4315/0362-028x.Jfp-13-019.

Allende, A., Selma, M.V., Lopez-Galvez, F., Villaescusa, R., Gil, M.I., 2008. Impact of wash water quality on sensory and microbial quality, including Escherichia coli cross-contamination, of fresh-cut escarole. J. Food Prot. 71, 2514-2518. doi: 10.4315/0362-028x-71.12.2514.

Artés, F., Gómez, P., Aguayo, E., Escalona, V., Artés-Hernández, F., 2009. Sustainable sanitation techniques for keeping quality and safety of fresh-cut plant commodities. Postharvest Biol. Technol. 51, 287-296. doi: 10.1016/j.postharvbio.2008.10.003.

Audenaert, W.T.M., 2012. Ozonation and UV/hydrogen peroxide treatment of natural water and secondary wastewater effluent: experimental study and mathematical modeling. Ghent University, Ghent, BE.

Baert, L., Vandekinderen, I., Devlieghere, F., Van, E.C., Debevere, J., Uyttendaele, M., 2009. Efficacy of sodium hypochlorite and peroxyacetic acid to reduce murine norovirus 1, B40-8, Listeria monocytogenes, and Escherichia coli 0157:H7 on shredded iceberg lettuce and in residual wash water. J. Food Prot. 72, 1047-1054. doi: 10.4315/0362-028x-72.5.1047.

Beltrán, D., Selma, M.V., Marín, A., Gil, M.I., 2005. Ozonated water extends the shelf life of fresh-cut lettuce. J. Agric. Food Chem. 53, 5654-5663. doi: 10.1021/Jf050359c.

Beuchat, L.R., Adler, B.B., Lang, M.M., 2004. Efficacy of chlorine and a peroxyacetic acid sanitizer in killing Listeria monocytogenes on iceberg and Romaine lettuce using simulated commercial processing conditions. J. Food Prot. 67, 1238-1242. doi: 10.4315/0362-028x-67.6.1238.

Bialka, K.L., Demirci, A., 2007. Decontamination of Escherichia coli 0157:H7 and Salmonella enterica on blueberries using ozone and pulsed UV-Light. J. Food Sci. 72, M391-M396. doi: 10.1111/j.17503841.2007.00517.x.

Black \& Veatch Corporation, 2010. White's handbook of chlorination and alternative disinfectants, 5th ed. John Wiley \& Sons, Inc., Hoboken, NJ, US.

Camel, V., Bermond, A., 1998. The use of ozone and associated oxidation processes in drinking water treatment. Water Res. 32, 3208-3222. doi: 10.1016/S0043-1354(98)00130-4.

Chaidez, C., Castro-del Campo, N., Heredia, J.B., Contreras-Angulo, L., González-Aguilar, G., Ayala-Zavala, J.F., 2012. Chlorine, in: Gómez-López, V.M. (Ed.), Decontamination of fresh and minimally processed produce, 1st ed. Wiley-Blackwell, Oxford, UK, pp. 121-133.

Cheremisinoff, N.P., 2002. Handbook of water and wastewater treatment technologies. ButterworthHeinemann, Boston [etc.], MA, US.

Chilled Food Association (CFA), 2010. Protocol for produce washing.

Choi, Y., Cho, M., Lee, Y., Choi, J., Yoon, J., 2007. Inactivation of Bacillus subtilis spores during ozonation in water treatment plant: influence of pre-treatment and consequences for positioning of the ozonation step. Chemosphere 69, 675-681. doi: 10.1016/j.chemosphere.2007.05.045.

Committee on Toxicity of Chemicals in Food Consumer Products and the Environment (COT), 2006. COT statement on a commercial survey investigating the occurrence of disinfectants and disinfection by-products in prepared salads.

Davidson, G.R., Buchholz, A.L., Ryser, E.T., 2013. Efficacy of commercial produce sanitizers against nontoxigenic Escherichia coli 0157:H7 during processing of iceberg lettuce in a pilot-scale leafy green processing line. J. Food Prot. 76, 1838-1845. doi: 10.4315/0362-028x.Jfp-13-111.

Direction générale de la concurrence de la consommation et de la répression des fraudes (DGCCRF), 2006. Arrêté du 19 octobre 2006 relatif à l'emploi d'auxiliaires technologiques dans la fabrication de certaines denrées alimentaires.

Domingue, E.L., Tyndall, R.L., Mayberry, W.R., Pancorbo, O.C., 1988. Effects of three oxidizing biocides on Legionella pneumophila serogroup 1. Appl. Environ. Microbiol. 54, 741-747. doi: 10.1128/AEM.54.3.741-747.1988.

Drakopoulou, S., Terzakis, S., Fountoulakis, M.S., Mantzavinos, D., Manios, T., 2009. Ultrasound-induced inactivation of Gram-negative and Gram-positive bacteria in secondary treated municipal wastewater. Ultrason. Sonochem. 16, 629-634. doi: 10.1016/j.ultsonch.2008.11.011.

Environmental Protection Agency (EPA), 1999. Alternative disinfectants and oxidants guidance manual, in: Office of Water (Ed.), Washington, D.C., US.

Environmental Protection Agency (EPA), 2006. Ultraviolet disinfection guidance manual for the final long term 2 enhanced surface water treatment rule, in: Office of Water (Ed.), Washington, D.C.,US. 
Environmental Protection Agency (EPA), 2009. National primary drinking water standards.

European Chemicals Agency (ECHA), 2015. Biocidal active substances - summary of status of applications for approval of active substance/product-type combinations under the BPD or the BPR.

European Commission (EC), Commission delegated Regulation (EU) No 1062/2014 of 4 August 2014 on the work programme for the systematic examination of all existing active substances contained in biocidal products referred to in Regulation (EU) No 528/2012 of the European Parliament and of the Council Text, in: Official Journal of the European Communities (Ed.), (OJ/L 294/10.10.2014, p.1-34).

European Commission (EC), Regulation (EC) No 396/2005 of the European Parliament and of the Council of 23 February 2005 on maximum residue levels of pesticides in or on food and feed of plant and animal origin and amending Council Directive 91/414/EEC, in: Official Journal of the European Communities (Ed.), (OJ/L 070/16.3.2005, p.1-16).

European Commission (EC), Regulation (EU) No 528/2012 of the European Parliament and of the Council of 22 May 2012 concerning the making available on the market and use of biocidal products, in: Official Journal of the European Communities (Ed.), (OJ/L 167/27.6.2012, p.1-123).

European Commission (EC), 2014a. Statement as regards the presence of chlorate in food and feed SANCO2014-11180-Rev0 agreed by the Standing Committee of the Food Chain and Animal Health on 1213 June 2014, in: Health and Consumers Directorate-General (Ed.).

European Commission (EC), 2014b. Summary report of the Standing Committee on Plants, Animals, Food and Feed held in Brussels on 22 September 2014 - 23 September 2014 (Section phytopharmaceuticals - pesticides pesidues), in: Health and Consumers Directorate-General (Ed.).

European Communities, 2007. European Communities (drinking water) (No. 2) Regulations 2007.

Gil, M.I., Selma, M.V., López-Gálvez, F., Allende, A., 2009. Fresh-cut product sanitation and wash water disinfection: problems and solutions. Int. J. Food Microbiol. 134, 37-45. doi: 10.1016/j.ijfoodmicro.2009.05.021.

Gogate, P.R., 2007. Application of cavitational reactors for water disinfection: current status and path forward. J. Environ. Manage. 85, 801-815. doi: 10.1016/j.jenvman.2007.07.001.

Gómez-López, V.M., 2012. Chlorine dioxide, in: Gómez-López, V.M. (Ed.), Decontamination of fresh and minimally processed produce, 1st ed. Wiley-Blackwell, Oxford, UK, pp. 165-175.

Gómez-López, V.M., Gil, M.I., Allende, A., Blancke, J., Schouteten, L., Selma, M.V., 2014a. Disinfection capacity of high-power ultrasound against E. coli 0157:H7 in process water of the fresh-cut industry. Food Bioprocess Technol. 7, 3390-3397. doi: 10.1007/s11947-014-1346-2.

Gómez-López, V.M., Gil, M.I., Allende, A., Vanhee, B., Selma, M.V., 2015. Water reconditioning by high power ultrasound combined with residual chemical sanitizers to inactivate foodborne pathogens associated with fresh-cut products. Food Control 53, 29-34. doi: 10.1016/j.foodcont.2014.12.032.

Gómez-López, V.M., Lannoo, A.S., Gil, M.I., Allende, A., 2014b. Minimum free chlorine residual level required for the inactivation of Escherichia coli 0157:H7 and trihalomethane generation during dynamic washing of fresh-cut spinach. Food Control 42, 132-138. doi: 10.1016/j.foodcont.2014.01.034.

Gómez-López, V.M., Marín, A., Medina-Martínez, M.S., Gil, M.I., Allende, A., 2013. Generation of trihalomethanes with chlorine-based sanitizers and impact on microbial, nutritional and sensory quality of baby spinach. Postharvest Biol. Technol. 85, 210-217. doi: 10.1016/j.postharvbio.2013.05.012.

González-Aguilar, G., Ayala-Zavala, J.F., Chaidez-Quiroz, C., Heredia, J.B., Castro-del Campo, N., 2012. Peroxyacetic acid, in: Gómez-López, V.M. (Ed.), Decontamination of fresh and minimally processed produce, 1st ed. Wiley-Blackwell, Oxford, UK, pp. 215-223.

Goodburn, C., Wallace, C.A., 2013. The microbiological efficacy of decontamination methodologies for fresh produce: a review. Food Control 32, 418-427. doi: 10.1016/j.foodcont.2012.12.012.

Grace Ho, K.L., Luzuriaga, D.A., Rodde, K.M., Tang, S., Phan, C., 2011. Efficacy of a novel sanitizer composed of lactic acid and peroxyacetic acid against single strains of nonpathogenic Escherichia coli K-12, Listeria innocua, and Lactobacillus plantarum in aqueous solution and on surfaces of romaine lettuce and spinach. J. Food Prot. 74, 1468-1474. doi: 10.4315/0362-028x.Jfp-11-110.

Gyürék, L.L., Li, H., Belosevic, M., Finch, G.R., 1999. Ozone inactivation kinetics of Cryptosporidium in phosphate buffer. J. Environ. Eng. 125, 913-924. doi: 10.1061/(ASCE)07339372(1999)125:10(913).

Hammes, F., Salhi, E., Köster, O., Kaiser, H.P., Egli, T., von Gunten, U., 2006. Mechanistic and kinetic evaluation of organic disinfection by-product and assimilable organic carbon (AOC) formation during the ozonation of drinking water. Water Res. 40, 2275-2286. doi: 10.1016/j.watres.2006.04.029. 
Harakeh, M.S., Butler, M., 1984. Factors increasing the ozone inactivation of enteric viruses in effluent. Ozone Sci. Eng. 6, 235-243. doi: 10.1080/01919518408551029.

Hebert, A., Forestier, D., Lenes, D., Benanou, D., Jacob, S., Arfi, C., Lambolez, L., Levi, Y., 2010. Innovative method for prioritizing emerging disinfection by-products (DBPs) in drinking water on the basis of their potential impact on public health. Water Res. 44, 3147-3165. doi: 10.1016/j.watres.2010.02.004.

Holvoet, K., Jacxsens, L., Sampers, I., Uyttendaele, M., 2012. Insight into the prevalence and distribution of microbial contamination to evaluate water management in the fresh produce processing industry. J. Food Prot. 75, 671-681. doi: 10.4315/0362-028x.Jfp-11-175.

Holvoet, K., Sampers, I., Callens, B., Dewulf, J., Uyttendaele, M., 2013. Moderate prevalence of antimicrobial resistance in Escherichia coli isolates from lettuce, irrigation water, and soil. Appl. Environ. Microbiol. 79, 6677-6683. doi: 10.1128/AEM.01995-13.

Hua, G., Reckhow, D.A., 2007. Comparison of disinfection byproduct formation from chlorine and alternative disinfectants. Water Res. 41, 1667-1678. doi: 10.1016/j.watres.2007.01.032.

Huang, W.J., Fang, G.C., Wang, C.C., 2005. The determination and fate of disinfection by-products from ozonation of polluted raw water. Sci. Total Environ. 345, 261-272. doi: 10.1016/j.scitotenv.2004.10.019.

Hurst, W.C., 2002. Safety aspects of fresh-cut fruits and vegetables, in: Lamikanra, O. (Ed.), Fresh-cut fruits and vegetables: science, technology, and market. CRC Press, Boca Raton, FL, US [etc.].

Joshi, K., Mahendran, R., Alagusundaram, K., Norton, T., Tiwari, B.K., 2013. Novel disinfectants for fresh produce. Trends Food Sci. Technol. 34, 54-61. doi: 10.1016/j.tifs.2013.08.008.

Joyce, E., Phull, S.S., Lorimer, J.P., Mason, T.J., 2003. The development and evaluation of ultrasound for the treatment of bacterial suspensions. A study of frequency, power and sonication time on cultured Bacillus species. Ultrason. Sonochem. 10, 315-318. doi: 10.1016/S1350-4177(03)00101-9.

Keskinen, L.A., Burke, A., Annous, B.A., 2009. Efficacy of chlorine, acidic electrolyzed water and aqueous chlorine dioxide solutions to decontaminate Escherichia coli 0157:H7 from lettuce leaves. Int. J. Food Microbiol. 132, 134-140. doi: 10.1016/j.ijfoodmicro.2009.04.006.

Kim, D.I., 2007. Development and application of integrated ozone contactor design and optimization tools. Georgia Institute of Technology, Atlanta, GA, US.

Kitis, M., 2004. Disinfection of wastewater with peracetic acid: a review. Environ. Int. 30, 47-55. doi: 10.1016/S0160-4120(03)00147-8.

Koutsoumanis, K., Skandamis, P., 2013. New research on organic acids and pathogen behaviour, in: Sofos, J. (Ed.), Advances in microbial food safety, 1st ed. Woodhead Publishing, Cambridge [etc.], UK, pp. 355-384.

Kunigk, L., Almeida, M.C.B., 2001. Action of peracetic acid on Escherichia coli and Staphylococcus aureus in suspension and on stainless steel surfaces. Braz. J. Microbiol. 32, 38-41. doi: 10.1590/S151783822001000100009.

LeChevallier, M.W., Au, K.K., 2004. Water treatment and pathogen control: process efficiency in achieving safe drinking water. IWA Publishing, London, UK.

Li, H., Gyürék, L.L., Finch, G.R., Smith, D.W., Belosevic, M., 2001. Effect of temperature on ozone inactivation of Cryptosporidium parvum in oxidant demand-free phosphate buffer. J. Environ. Eng. 127, 456-467. doi: 10.1061/(Asce)0733-9372(2001)127:5(456).

Lim, M.Y., Kim, J.M., Lee, J.E., Ko, G., 2010. Characterization of ozone disinfection of murine norovirus. Appl. Environ. Microbiol. 76, 1120-1124. doi: 10.1128/Aem.01955-09.

López-Gálvez, F., Allende, A., Selma, M.V., Gil, M.I., 2009. Prevention of Escherichia coli cross-contamination by different commercial sanitizers during washing of fresh-cut lettuce. Int. J. Food Microbiol. 133, 167171. doi: 10.1016/j.ijfoodmicro.2009.05.017.

López-Gálvez, F., Allende, A., Truchado, P., Martínez-Sánchez, A., Tudela, J.A., Selma, M.V., Gil, M.I., $2010 a$. Suitability of aqueous chlorine dioxide versus sodium hypochlorite as an effective sanitizer for preserving quality of fresh-cut lettuce while avoiding by-product formation. Postharvest Biol. Technol. 55, 53-60. doi: 10.1016/j.postharvbio.2009.08.001.

López-Gálvez, F., Gil, M.I., Truchado, P., Selma, M.V., Allende, A., 2010b. Cross-contamination of fresh-cut lettuce after a short-term exposure during pre-washing cannot be controlled after subsequent washing with chlorine dioxide or sodium hypochlorite. Food Microbiol. 27, 199-204. doi: 10.1016/J.Fm.2009.09.009.

Luo, Y., Ingram, D.T., Khurana, K., 2014. Preventing cross-contamination during produce wash operations, in: Hoorfar, J. (Ed.), Global safety of fresh produce: a handbook of best-practice examples, innovative commercial solutions and case studies. Woodhead Publishing, Oxford, UK, pp. 103-111. 
Luo, Y., Nou, X., Millner, P., Zhou, B., Shen, C., Yang, Y., Wu, Y., Wang, Q., Feng, H., Shelton, D., 2012. A pilot plant scale evaluation of a new process aid for enhancing chlorine efficacy against pathogen survival and cross-contamination during produce wash. Int. J. Food Microbiol. 158, 133-139. doi: 10.1016/j.ijfoodmicro.2012.07.008.

Mezzanotte, V., Antonelli, M., Citterio, S., Nurizzo, C., 2007. Wastewater disinfection alternatives: chlorine, ozone, peracetic acid, and UV light. Water Environ. Res. 79, 2373-2379. doi: $10.2175 / 106143007 \times 183763$.

National Research Council (US) Safe Drinking Water Committee, 1980. Drinking water and health: volume 2. National Academies Press, Washington, D.C., US.

Olaimat, A.N., Holley, R.A., 2012. Factors influencing the microbial safety of fresh produce: a review. Food Microbiol. 32, 1-19. doi: 10.1016/j.fm.2012.04.016.

Ölmez, H., 2012. Ozone, in: Gómez-López, V.M. (Ed.), Decontamination of fresh and minimally processed produce, 1st ed. Wiley-Blackwell, Oxford, UK, pp. 177-195.

Ölmez, H., Akbas, M.Y., 2009. Optimization of ozone treatment of fresh-cut green leaf lettuce. J. Food Eng. 90, 487-494. doi: 10.1016/j.jfoodeng.2008.07.026.

Ölmez, H., Kretzschmar, U., 2009. Potential alternative disinfection methods for organic fresh-cut industry for minimizing water consumption and environmental impact. LWT Food Sci. Technol. 42, 686-693. doi: 10.1016/j.lwt.2008.08.001.

Pao, S., Long, W., Kim, C., Kelsey, D.F., 2012. Produce washers, in: Gómez-López, V.M. (Ed.), Decontamination of fresh and minimally processed produce, 1st ed. Wiley-Blackwell, Oxford, UK, pp. 87-103.

Parish, M.E., Beuchat, L.R., Suslow, T.V., Harris, L.J., Garrett, E.H., Farber, J.N., Busta, F.F., 2003. Methods to reduce/eliminate pathogens from fresh and fresh-cut produce. Compr. Rev. Food Sci. Food Saf. 2, 161-173. doi: 10.1111/j.1541-4337.2003.tb00033.x.

Pascual, A., Llorca, I., Canut, A., 2007. Use of ozone in food industries for reducing the environmental impact of cleaning and disinfection activities. Trends Food Sci. Technol. 18, S29-S35. doi: 10.1016/j.tifs.2006.10.006.

Rakness, K., Gordon, G., Langlais, B., Masschelein, W., Matsumoto, N., Richard, Y., Robson, C.M., Somiya, I., 1996. Guideline for measurement of ozone concentration in the process gas from an ozone generator. Ozone Sci. Eng. 18, 209-229. doi: 10.1080/01919519608547327.

Rakness, K.L., 2005. Ozone in drinking water treatment: process design, operation, and optimization, 1st ed. American Water Works Association, Denver, CO, US.

Rennecker, J.L., Kim, J.H., Corona-Vasquez, B., Mariñas, B.J., 2001. Role of disinfectant concentration and pH in the inactivation kinetics of Cryptosporidium parvum oocysts with ozone and monochloramine. Environ. Sci. Technol. 35, 2752-2757. doi: 10.1021/Es010526z.

Rodgers, S.L., Cash, J.N., Siddiq, M., Ryser, E.T., 2004. A comparison of different chemical sanitizers for inactivating Escherichia coli 0157:H7 and Listeria monocytogenes in solution and on apples, lettuce, strawberries, and cantaloupe. J. Food Prot. 67, 721-731. doi: 10.4315/0362-028x-67.4.721.

Sánchez, G., Elizaquível, P., Aznar, R., Selma, M.V., 2015. Virucidal effect of high power ultrasound combined with a chemical sanitizer containing peroxyacetic acid for water reconditioning in the fresh-cut industry. Food Control 52, 126-131. doi: 10.1016/j.foodcont.2014.12.021.

Sapers, G.M., 2001. Efficacy of washing and sanitizing methods for disinfection of fresh fruit and vegetable products. Food Technol. Biotechnol. 39, 305-311.

Sapers, G.M., 2014. Disinfection of contaminated produce with conventional washing and sanitizing technology, in: Matthews, K.R., Sapers, G.M., Gerba, C.P. (Eds.), The produce contamination problem: causes and solutions, 2nd ed. Academic Press, San Diego, CA, US, pp. 389-431.

Tapia, M.S., Welti-Chanes, J., 2012. Hurdle technology principles applied in decontamination of whole and fresh-cut produce, in: Gómez-López, V.M. (Ed.), Decontamination of fresh and minimally processed produce, 1st ed. Wiley-Blackwell, Oxford, UK, pp. 417-449.

Tarrass, F., Benjelloun, M., Benjelloun, 0., 2010. Current understanding of ozone use for disinfecting hemodialysis water treatment systems. Blood Purif. 30, 64-70. doi: 10.1159/000317123.

Tirpanalan, Ö., Zunabovic, M., Domig, K., Kneifel, W., 2011. Mini review: antimicrobial strategies in the production of fresh-cut lettuce products, in: Méndez-Vilas, A. (Ed.), Science against microbial pathogens: communicating current research and technological advances. Formatex Research Center, Badajoz, ES, pp. 176-188.

U.S. Food and Drug Administration (FDA), 2013. Code of Federal Regulations. Sec. 173.300 chlorine dioxide.

U.S. Food and Drug Administration (FDA), 2014. Code of Federal Regulations. Sec. 173.368 ozone. 


\section{Chapter 2}

Van Haute, S., López-Gálvez, F., Gómez-López, V.M., Eriksson, M., Devlieghere, F., Allende, A., Sampers, I., 2015a. Methodology for modeling the disinfection efficiency of fresh-cut leafy vegetables wash water applied on peracetic acid combined with lactic acid. Int. J. Food Microbiol. 208, 102-113. doi: 10.1016/j.ijfoodmicro.2015.05.020.

Van Haute, S., Sampers, I., Holvoet, K., Uyttendaele, M., 2013a. Physicochemical quality and chemical safety of chlorine as a reconditioning agent and wash water disinfectant for fresh-cut lettuce washing. Appl. Environ. Microbiol. 79, 2850-2861. doi: 10.1128/AEM.03283-12.

Van Haute, S., Sampers, I., Jacxsens, L., Uyttendaele, M., 2015b. Selection criteria for water disinfection techniques in agricultural practices. Crit. Rev. Food Sci. Nutr. 55, 1529-1551. doi: 10.1080/10408398.2012.705360.

Van Haute, S., Tryland, I., Veys, A., Sampers, I., 2015c. Wash water disinfection of a full-scale leafy vegetables washing process with hydrogen peroxide and the use of a commercial metal ion mixture to improve disinfection efficiency. Food Control 50, 173-183. doi: 10.1016/j.foodcont.2014.08.028.

Van Haute, S., Uyttendaele, M., Sampers, I., 2013b. Organic acid based sanitizers and free chlorine to improve the microbial quality and shelf-life of sugar snaps. Int. J. Food Microbiol. 167, 161-169. doi: 10.1016/j.ijfoodmicro.2013.09.007.

Vandekinderen, I., Devlieghere, F., De Meulenaer, B., Ragaert, P., Van Camp, J., 2009. Optimization and evaluation of a decontamination step with peroxyacetic acid for fresh-cut produce. Food Microbiol. 26, 882-888. doi: 10.1016/j.fm.2009.06.004.

von Gunten, U., 2003a. Ozonation of drinking water: part I. Oxidation kinetics and product formation. Water Res. 37, 1443-1467. doi: 10.1016/S0043-1354(02)00457-8.

von Gunten, U., 2003b. Ozonation of drinking water: part II. Disinfection and by-product formation in presence of bromide, iodide or chlorine. Water Res. 37, 1469-1487. doi: 10.1016/S00431354(02)00458-X.

Warburton, R., 2014. Peracetic acid in the fresh food industry, Food Safety Magazine. Food Safety Magazine.

Wei, K., Zhou, H., Zhou, T., Gong, J., 2007. Comparison of aqueous ozone and chlorine as sanitizers in the food processing industry: impact on fresh agricultural produce quality. Ozone Sci. Eng. 29, 113-120. doi: $10.1080 / 01919510601186592$.

Wert, E.C., Neemann, J.J., Rexing, D.J., Zegers, R.E., 2008. Biofiltration for removal of BOM and residual ammonia following control of bromate formation. Water Res. 42, 372-378. doi: 10.1016/j.watres.2007.07.028.

World Health Organization. Food Safety Team, Food and Agriculture Organization of the United Nations, 1998. Surface decontamination of fruits and vegetables eaten raw: a review / prepared by Larry R. Beuchat. World Health Organization (WHO), Geneva, $\mathrm{CH}$.

Zhang, G., Ma, L., Phelan, V.H., Doyle, M.P., 2009. Efficacy of antimicrobial agents in lettuce leaf processing water for control of Escherichia coli 0157:H7. J. Food Prot. 72, 1392-1397. doi: 10.4315/0362028x-72.7.1392.

Zhang, L., Lu, Z., Yu, Z., Gao, X., 2005. Preservation of fresh-cut celery by treatment of ozonated water. Food Control 16, 279-283. doi: 10.1016/j.foodcont.2004.03.007.

Zuma, F., Lin, J., Jonnalagadda, S.B., 2009. Ozone-initiated disinfection kinetics of Escherichia coli in water. J. Environ. Sci. Health A 44, 48-56. doi: 10.1080/10934520802515335. 




\title{
Chapter 3
}

\section{The efficacy of chemical sanitizers on the reduction of Salmonella Typhimurium and Escherichia coli affected by bacterial cell history and water quality}

\author{
J.L. Banach \\ H. van Bokhorst-van de Veen
}

L.S. van Overbeek

P.S. van der Zouwen

H.J. van der Fels-Klerx

M.N. Nierop Groot

Published in: Food Control (2017), 81, 134-146.

doi: 10.1016/j.foodcont.2017.05.044 


\begin{abstract}
Washing fresh produce with potable water helps to remove microorganisms, providing about a 1- to 2-log reduction, but this process can also pose an opportunity for crosscontamination of bacteria in the washing tank. The objective of this study was to evaluate the efficacy of three chemical sanitizers, sodium hypochlorite, chlorine dioxide, and a silver-copper solution on the reduction of $S$. Typhimurium and extendedspectrum beta-lactamase (ESBL) E. coli as well as to evaluate the impact bacterial cell history and water quality had on sanitizer efficacy. This was investigated with three scenarios representing different contamination routes and history of cells: (i) on starved and non-starved cells in potable water, (ii) on starved and non-starved cells in the lettuce wash water and on lettuce leaf punches, and (iii) on non-starved cells in organically loaded process wash water (PWW). Sodium hypochlorite ( $\mathrm{NaClO})$ and chlorine dioxide $\left(\mathrm{ClO}_{2}\right)$ were more effective in preventing cross-contamination in the potable water than the silver-copper solution. Starved and non-starved bacterial cells displayed minor differences in their susceptibility to sanitizing agents in the (i) potable water and (ii) lettuce wash water demonstrating that other conditions greater influenced sanitizer efficacy. Particularly, the organic load of the water, wash water temperature, and pathogen attachment and release from the produce were shown to affect a sanitizer's efficacy during washing. Furthermore, results emphasize that chemical sanitizer use should focus more on wash water disinfection, rather than produce decontamination, to prevent pathogenic cross-contamination during processing. Future research should investigate the feasibility of $\mathrm{ClO}_{2}$ application during pilot-scale processing.
\end{abstract}

\title{
Keywords
}

Water disinfection; Leafy greens; Cross-contamination; Bacterial attachment; Pathogen inactivation; Starvation 


\subsection{Introduction}

Different studies have reported the increased consumption of fresh produce in the last decades (Olaimat and Holley, 2012; Warriner, Huber, Namvar, Fan and Dunfield, 2009). Consumers are increasingly interested in consuming healthy, convenient foods, including fresh-cut or ready-to-eat produce (Jacxsens, Luning, van der Vorst, Devlieghere, Leemans and Uyttendaele, 2010) as these may help them to conveniently reach dietary recommendations and may reduce the risk of certain cancers (Bradbury, Appleby and Key, 2014). When microbiological food safety does not improve, consumers have a higher probability of consuming contaminated fresh produce. Fresh produce is reported to be vulnerable to pathogenic contamination such as from Salmonella spp. and pathogenic Escherichia coli (Callejón, Rodríguez-Naranjo, Ubeda, Hornedo-Ortega, Garcia-Parrilla and Troncoso, 2015; EFSA Panel on Biological Hazards (BIOHAZ) Panel, 2013; Food and Agriculture Organization of the United Nations (FAO) and World Health Organization (WHO), 2008; Tirpanalan, Zunabovic, Domig and Kneifel, 2011; Van Haute, Sampers, Holvoet and Uyttendaele, 2013). In order to maintain the safety and quality of fresh and fresh-cut produce, prevention and control measures should be implemented along the supply chain (Gil, Selma, Suslow, Jacxsens, Uyttendaele and Allende, 2015).

At the fresh(-cut) produce processor, washing aims to remove dirt and reduce microbial contaminants from the surface of the product. However, during washing, pathogens that may be incidentally present on the produce can be released into the washing water and thus, cross-contamination between clean and contaminated produce may occur. Since washing can be a potential cause of cross-contamination during processing, techniques that can improve processing, including those that can limit pathogenic cross-contamination, are proposed (Holvoet, Jacxsens, Sampers and Uyttendaele, 2012; Luo, Ingram and Khurana, 2014). Some processing practices include washing with or without sanitizing agents like chlorine (e.g., as sodium hypochlorite, calcium hypochlorite, or chlorine gas) to prevent dispersal and transmission of pathogens. Current insights show that the main expected effect of sanitizing treatments during produce washing is to reduce and control the microbial load of the water rather than produce decontamination (Van Haute, López-Gálvez, Gómez-López, Eriksson, Devlieghere, Allende and Sampers, 2015a; Van Haute, Tryland, Veys and Sampers, 2015c). Consequently, by maintaining the water quality throughout produce processing, the potential for cross-contamination during washing can be diminished (Gil, Selma, López-Gálvez and Allende, 2009; Parish, Beuchat, Suslow, Harris, Garrett, Farber and Busta, 2003; Van Haute, Sampers, Jacxsens and Uyttendaele, 2015b).

Overall, there is a need to reduce cross-contamination events; this need is particularly apparent when sanitizers are not applied during washing, which is the current situation for some European Union countries (Holvoet et al., 2012). Certain process wash water (PWW) disinfectants have shown potential in pilot-scale studies (Davidson, Buchholz and Ryser, 2013; Gil, Marín, Andujar and Allende, 2016; Luo, Nou, Millner, Zhou, Shen, Yang, Wu, Wang, Feng and Shelton, 2012) to maintain the water quality during processing and prevent cross-contamination of pathogens, such as Salmonella spp. and E. coli. The objective of this study was to evaluate the efficacy of three chemical 
sanitizers, sodium hypochlorite, chlorine dioxide, and a silver-copper solution on the reduction of Salmonella Typhimurium and extended-spectrum beta-lactamase (ESBL) E. coli. This evaluation was investigated with three scenarios related to bacterial cell history: (i) on non-starved and "short-term" starved cells in potable water, (ii) on nonstarved and "long-term" starved cells in the lettuce wash water and on lettuce leaf punches, and (iii) on non-starved cells in organically loaded PWW. These three scenarios provided a novel (i.e., not published) perspective for evaluating the effect of strain history on efficacy, for example, between starved and non-starved cultures, as well as in different water mediums. Furthermore, the extent to which bacterial cell release and (re-) attachment to fresh-cut produce occurs provides insight on recontamination dynamics of $S$. Typhimurium and $E$. coli as well as the impact of chemical sanitizers during fresh(-cut) washing.

\subsection{Materials and methods}

\subsubsection{Bacterial strain and inoculum preparations}

A Salmonella enterica subspecies enterica serovar Typhimurium ( $S$. Typhimurium) lettuce isolate 1638 and an E. coli ESBL-positive human isolate, reported as 0247_1 (van Hoek, Schouls, van Santen, Florijn, de Greeff and van Duijkeren, 2015), were maintained at $-80^{\circ} \mathrm{C}$ in Luria Broth (LB; BD Difco ${ }^{\mathrm{TM}}$ Luria Broth Base, Miller) containing $25 \%(\mathrm{v} / \mathrm{v}$ ) glycerol. Cultures were prepared by inoculation of a single colony isolate in one-fifth filled Erlenmeyer flasks with LB at $37^{\circ} \mathrm{C}$ in a $200 \mathrm{rpm}$ shaking air incubator and were grown for $18( \pm 1)$ h to obtain stationary phase cells. The cultures (c.a. $10^{9} \mathrm{CFU} / \mathrm{mL}$ ) were transferred into sterile Greiner tubes and centrifuged $(1800 \times \mathrm{g})$ at $20^{\circ} \mathrm{C}$ for 10 min. The supernatant was decanted, and the resulting pellet was resuspended in $20 \mathrm{~mL}$ of potable water and re-centrifuged at the conditions above. This washing step was repeated twice more. The pellet was then resuspended in potable water, and the overnight culture solution was separated into two equal parts. One part of the culture was diluted a hundredfold with potable water to obtain a final concentration of c.a. $10^{7}$ $\mathrm{CFU} / \mathrm{mL}$. From this solution, $200 \mu \mathrm{L}$ was added to $20 \mathrm{~mL}$ of potable water, resulting in a concentration of c.a. $10^{5} \mathrm{CFU} / \mathrm{mL}$. The other part of the culture was used to make "short-term" and "long-term" starved cultures. For short-term starvation experiments, cultures were incubated for $24 \mathrm{~h}$ at $5{ }^{\circ} \mathrm{C}$ before further dilution with potable water, as previously described, and then used in the inactivation experiments in potable water. For long-term starvation experiments, $S$. Typhimurium and $E$. coli were examined for $430 \mathrm{~h}$ at $5{ }^{\circ} \mathrm{C}$ in ultra-pure water. Cultures of both strains survived after $430 \mathrm{~h}$ with the difference between initial and final concentrations of $\leq 1 \log \mathrm{CFU} / \mathrm{mL}$ (data not shown). Further analyses were not investigated. This long-term starved culture was used for subsequent experiments in the lettuce wash water and on leaf punches. Fig. S3.1 provides an overview of the experiments with non-starved and starved cultures. For both cultures examined during these experiments, the cell history (i.e., non-starved and starved) was investigated. 


\subsubsection{Preparation of treatment solutions}

All solutions were freshly prepared before each experiment. Sodium hypochlorite (NaClO; Sigma-Aldrich, Schnelldorf, Germany) stock solutions were prepared by diluting the solution obtained from the supplier (4.00-4.99\%) with potable water to achieve a final concentration of $10 \mathrm{mg} / \mathrm{L}$ active chlorine. Aqueous chlorine dioxide $\left(\mathrm{ClO}_{2}\right.$; Lifarma B.V., Baexem, the Netherlands) stock solutions were prepared according to the manufacturer's instructions. In brief, one $\mathrm{ClO}_{2}$ tablet was dissolved in $1 \mathrm{~L}$ potable water within a sealed container to obtain a $0.2 \%(\mathrm{w} / \mathrm{v})$ solution (i.e., $2000 \mathrm{mg} / \mathrm{L}$ ). Subsequently, $50 \mu \mathrm{L}$ of the $\mathrm{ClO}_{2}$ stock solution was diluted with potable water to obtain $20 \mathrm{~mL}$ final volume with a final concentration of $5 \mathrm{mg} / \mathrm{L}$. For $\mathrm{NaClO}$ and $\mathrm{ClO}_{2}$, concentrations were verified with a DULCOTEST ${ }^{\circledR}$ DT4B photometer (ProMinent Verder B.V., Vleuten, the Netherlands); values were within a 1-5\% deviation from the set value. An antimicrobial solution consisting of an undiluted mixture of silver and copper was commercially supplied and prepared according to the manufacturer's instructions (Modern Water, Cambridge, United Kingdom). The concentration of the silver-copper (Ag-Cu) solution was determined using inductively coupled plasma atomic emission spectroscopy/optical emission spectrometry (ICP-AES/OES; Vista MPX, Varian) to be $9.1-9.9 \mathrm{mg} / \mathrm{L} \mathrm{Ag}$ and $1.2 \mathrm{mg} / \mathrm{L} \mathrm{Cu}$.

\subsubsection{Lettuce cultivation conditions and pre-treatment of lettuce leaf punches}

Iceberg lettuce (Lactuca sativa 'Dublin') was grown in a greenhouse at a day/night regime of $16 \mathrm{~h}$ at $20^{\circ} \mathrm{C} / 8 \mathrm{~h}$ at $16^{\circ} \mathrm{C}$ in potting soil (Lentse Potgrond B.V., Katwijk, the Netherlands) without applied insecticides or fungicides. The outer leaves of three to five-week-old lettuce were sliced off and placed into plastic bags or boxes to prevent dehydration, and then, transported at room temperature before being processed for analysis within $2 \mathrm{~h}$ upon arrival.

Circular punches of the adaxial side of the lettuce leaves were made with a sterilized apple borer (22 $\mathrm{mm}$ diameter) in the middle of the leaf, excluding major veins. One punch per leaf, with a maximum of two punches (technical replicates) from the lettuce leaves, was taken. Leaf punches were placed onto Petri dishes and inoculated by pipetting $10 \mu \mathrm{L}$ non-starved or long-term starved culture suspensions of $S$. Typhimurium and E. coli at densities of $10^{4}, 10^{6}$, or $10^{8} \mathrm{CFU} / \mathrm{mL}$, reaching total inoculum cell numbers per leaf punch of $10^{2}, 10^{4}$, or $10^{6} \mathrm{CFU}$, respectively. Liquid drops were placed in the middle of the leaf punch to avoid contact of the bacterial inocula with leaf wounds. Sterilized potable water was used as a control. Leaf punches with bacterial inoculum or water were then incubated for $15 \mathrm{~s}, 1,2,5,10,30$, or $60 \mathrm{~min}$ at room temperature. Afterward, the lettuce leaf punches were removed using sterile forceps, and liquid drops were carefully removed with a sterile pipet, thereby avoiding contact of the pipet tip with the leaf punch. Any remaining liquid on the leaf punch surface was carefully removed by blotting with sterile filter paper. 


\subsubsection{Process washing water}

PWW was obtained from an endive wash line of a commercial Dutch fresh-cut vegetable processor. This industrially-supplied PWW was transported under refrigerated conditions to the lab for further analysis. The pH (Beckman \$34), total ammonia, nitrate, phosphate (SFA-CaCl 2 , Skalar, SAN++), and total organic carbon (TOC; Shimadzu 5050A) of potable water and industrially-supplied PWW were determined (Table 3.1). Briefly, the relationship between chemical oxygen demand (COD) or TOC can be characterized and varies according to water composition (The Dow Chemical Company, 2015); for example, Dubber and Gray (2010) observed that TOC could be used for generic replacement of COD in final effluents (i.e., treated wastewater). Previous research modeling water quality has indicated TOC as a predictive parameter for disinfection by-products (DBPs) in (drinking) water (Sadiq and Rodriguez, 2004).

Table 3.1. Potable and industrially-supplied process wash water (PWW) characteristics $(n=2)$.

\begin{tabular}{lll}
\hline Parameter & Mean value \pm SD \\
\cline { 2 - 3 } & Potable water & Industrially-supplied PWW \\
\hline $\mathrm{pH}$ at $20 \pm 1^{\circ} \mathrm{C}$ & $8.23 \pm 0.06$ & $8.28 \pm 0.24$ \\
$\mathrm{NH}_{4}-\mathrm{N}[\mathrm{mg} / \mathrm{L}]$ & $0.00 \pm 0.00$ & $0.19 \pm 0.04$ \\
$\mathrm{NO}_{3}-\mathrm{N}\left(+\mathrm{NO}{ }_{2}-\mathrm{N}\right)[\mathrm{mg} / \mathrm{L}]$ & $0.04 \pm 0.01$ & $10.39 \pm 0.58$ \\
$\mathrm{PO}_{4}-\mathrm{N}[\mathrm{mg} / \mathrm{L}]$ & $0.01 \pm 0.002$ & $3.37 \pm 0.05$ \\
$\mathrm{TOC}[\mathrm{mg} / \mathrm{L}]$ & $2.30 \pm 1.41$ & $354 \pm 15$ \\
\hline
\end{tabular}

The industrially-supplied PWW was also analyzed for aerobic mesophilic plate counts and aerobic psychrotrophic plate counts on Tryptone Soy Agar (TSA; Oxoid Ltd., Basingstoke, United Kingdom) and incubated at $25{ }^{\circ} \mathrm{C}$ for $3 \mathrm{~d}$ and $7{ }^{\circ} \mathrm{C}$ for $7 \mathrm{~d}$, respectively. This wash water was aliquoted and stored at $-20{ }^{\circ} \mathrm{C}$ until further use. For each additional experiment, a new tube was taken from the freezer. Experiments were performed within 2 months of storage. TOC of the wash water was re-measured after 9 months and had declined by only $5 \%$. For experiments with $\mathrm{NaClO}$ on E. coli nonstarved cultures, wash water was laboratory-made. The $\mathrm{pH}$, total ammonia, nitrate, and phosphate were measured as described above; these were 7.06, $0.45 \mathrm{mg} / \mathrm{L}, 10.9 \mathrm{mg} / \mathrm{L}$, and $9.83 \mathrm{mg} / \mathrm{L}$, respectively. Laboratory-made wash water was prepared by hand cutting endive from a local supermarket and washing it in $1 \mathrm{~L}$ cold potable water. Cutting and washing were repeated twice, each time using the same water to achieve the highest organic carbon load concentration. The wash water was then diluted with cold potable water to obtain a TOC measurement equal to the industrially-supplied PWW.

\subsubsection{Pathogen releasing efficacy and (re-) attachment to lettuce leaf punches}

\section{during washing}

The methods used to evaluate the releasing efficiency of the pathogens from the lettuce leaf punches into the washing water and bacterial reattachment from contaminated wash water to uninoculated lettuce leaf punches was investigated (Fig. S3.2). First, to 
determine the releasing capacity of $S$. Typhimurium or $E$. coli cells to the water, leaf punches were inoculated with $S$. Typhimurium (6.8 log CFU/punch) or E. coli (6.0 log $\mathrm{CFU} /$ punch) and remained on the punch for $1 \mathrm{~h}$ at $20^{\circ} \mathrm{C}$. Directly afterward, the inocula were removed, and the punch was washed three times, in which each time the inoculated leaf punch was transferred to a fresh tube with $10 \mathrm{~mL}$ potable water (Fig. S3.2A). Also, to determine if $S$. Typhimurium and $E$. coli cells that had released from contaminated leaf punches would re-adhere to uncontaminated leaf punches, fresh leaf punches were added to the wash water from the first wash rinse ( $S$. Typhimurium 6.3 $\log \mathrm{CFU} / \mathrm{mL}$; E. coli $5.5 \log \mathrm{CFU} / \mathrm{mL}$ ) and were incubated for $2 \mathrm{~min}$ at room temperature (Fig. S3.2B). After the final wash, punches were transferred to BioReba (10 mL volume) bags (BioReba AG, Reinach, Switzerland) containing $1 \mathrm{~mL}$ of sterile Ringer's solution (BR0052; Oxoid, part of Thermo Fisher Scientific, Breda, the Netherlands), and were gently homogenized. Subsequently, tenfold serial dilutions in Ringer's solution were made from the leaf punch homogenates. Then, $100 \mu \mathrm{L}$ of lettuce punch wash water and diluted leaf punch homogenates were pipetted onto Petri dishes of Xylose-LysineDesoxycholate agar (XLD; Oxoid Ltd., Basingstoke, United Kingdom) and Brilliance $E$. coli/coliform selective agar (BECSA; Oxoid Ltd., Basingstoke, United Kingdom) \pm 1 $\mathrm{mg} / \mathrm{mL}$ Cefotaxime sodium salt (Ct; Sigma-Aldrich, Zwijndrecht, the Netherlands), respectively for $S$. Typhimurium and $E$. coli recoveries. Afterward, liquid drops were spread over the agar surfaces to allow enumeration of individual CFUs of $S$. Typhimurium or E. coli following incubation for $18 \mathrm{~h}$ at $37^{\circ} \mathrm{C}$.

\subsubsection{Inactivation experiments in potable water}

The inactivation efficacy of sanitizer treatment solutions $\mathrm{NaClO}(10 \mathrm{mg} / \mathrm{L}), \mathrm{ClO}_{2}(5$ $\mathrm{mg} / \mathrm{L})$, and $\mathrm{Ag}-\mathrm{Cu}$ (9.1-9.9 mg/L Ag, $1.2 \mathrm{mg} / \mathrm{L} \mathrm{Cu}$ ) on non-starved and short-term starved cultures of $S$. Typhimurium and $E$. coli in potable water were investigated (Fig. S3.1A). During sanitizer treatments, the respective cultures were periodically swirled and continuously kept in ice water to maintain the temperature at $5{ }^{\circ} \mathrm{C}$ to simulate conditions at the industrial setting. At regular time intervals, $1 \mathrm{~mL}$ samples were taken and serially diluted into a peptone physiological salt solution (PPS; Tritium Microbiologie B.V., Eindhoven, the Netherlands). Following exposure to the sanitizer treatments, $100 \mu \mathrm{L}$ of the appropriate dilutions were plated onto LB agar (LBA) plates containing $1.2 \%$ agar and incubated at $37{ }^{\circ} \mathrm{C}$ for $5 \mathrm{~d}$ with daily inspection of colonies. Colonies were inspected for up to $5 \mathrm{~d}$ to check if potentially damaged cells could eventually grow out. The number of culturable cells was determined between 0 and 20 minutes to compare the efficacy of all chemicals sanitizers overtime for both cell types.

\subsubsection{Sanitizing experiments in lettuce washing water and on lettuce leaf punches}

The releasing efficiency of bacteria from inoculated lettuce leaf punches to the lettuce wash water and the effects of the pathogens on the lettuce leaf punches were investigated (Fig. S3.1B). The lettuce leaf punches, cut as described in section 3.2.3, were inoculated with either non-starved cells (c.a. $10^{5} \mathrm{CFU} /$ punch) or long-term starved cells (c.a. $10^{6} \mathrm{CFU} /$ punch) of $S$. Typhimurium or E. coli. Then, the punches were placed for $1 \mathrm{~h}$ at $20^{\circ} \mathrm{C}$ in $50 \mathrm{~mL}$ sterilized Greiner tubes, after which the punches were 
taken out of the Greiner tubes, and the inoculum was removed from the surfaces as described in section 3.2.3. Directly afterward, the punches were treated for 2 min with $10 \mathrm{~mL}$ of potable water or $10 \mathrm{~mL}$ solutions of $\mathrm{NaClO}(10 \mathrm{mg} / \mathrm{L}), \mathrm{ClO}_{2}(5 \mathrm{mg} / \mathrm{L})$, or $\mathrm{Ag}-\mathrm{Cu}$ (9.1-9.9 mg/L Ag, $1.2 \mathrm{mg} / \mathrm{L} \mathrm{Cu}$ ) at 5 or $20^{\circ} \mathrm{C}$; these punches were gently shaken to simulate processing conditions. Then, punches were washed in $50 \mathrm{~mL}$ potable water in order to remove residues of disinfecting agents before further analysis; neutralizing agents were not applied. After treatments, CFUs from the lettuce wash water and lettuce leaf punches were enumerated on XLD and BECSA $+\mathrm{Ct}$, respectively, for recovery of $S$. Typhimurium and E. coli.

\subsubsection{Inactivation experiments in process wash water}

The inactivation efficacy of sanitizer treatment solutions $\mathrm{NaClO}(10 \mathrm{mg} / \mathrm{L})$ and $\mathrm{ClO}_{2}(5$ $\mathrm{mg} / \mathrm{L})$ was performed as described in section 3.2.6 yet with non-starved $S$. Typhimurium cultures in industrially-supplied PWW with TOCs of 354 and $177 \mathrm{mg} / \mathrm{L}$, of which the latter was diluted with potable water. Similarly, the inactivation efficacy of $\mathrm{ClO}_{2}$ on E. coli was determined. The inactivation efficacy of $\mathrm{NaClO}$ was also determined, yet with laboratory-made PWW with TOCs of 354 and $177 \mathrm{mg} / \mathrm{L}$ (Fig. S3.1C). Cells were recovered on LBA media, as outlined in section 3.2.6. The number of culturable cells was determined between 0 and 20 minutes, representing the inactivation efficiency of sanitizers in PWW.

Furthermore, the inactivation efficacy of $\mathrm{NaClO}$ and $\mathrm{ClO}_{2}$ on non-starved E. coli cultures in PWW with a TOC of $354 \mathrm{mg} / \mathrm{L}$, being laboratory-made and industrially-supplied, respectively, were recovered on the selective media BECSA + Ct to allow for the potential qualification of Ct resistant $E$. coli. After exposure to the sanitizing treatment, $100 \mu \mathrm{L}$ of PPS diluted samples were plated on BECSA + Ct media and were incubated at $37^{\circ} \mathrm{C}$ for up to $5 \mathrm{~d}$ with daily inspection of the colonies after $48 \mathrm{~h}$.

\subsubsection{Statistical analysis}

For the sanitizing experiments in lettuce washing water and on lettuce leaf punches (Fig. S3.1B), fractions of $S$. Typhimurium or E. coli CFUs, expressed as percentages of the inoculum densities, were calculated and used for statistical comparisons of average values with sanitizing agent type and incubation temperature as treatments and replicate experiments as separate blocks using analysis of variance (ANOVA; GenStat release 12.1, Hemel Hempstead, United Kingdom). These independent experiments were carried out in duplicate $(n=2)$, each time by using four leaf punches from two separate plants. 


\subsection{Results}

\subsubsection{Pathogen releasing efficacy and (re-) attachment to lettuce leaf punches during washing}

The attachment capacity of non-starved cultures of $S$. Typhimurium and E. coli to lettuce leaf punches, their release and medium recovery efficacy in the wash water, and reattachment to uninoculated lettuce punches were previously investigated. Results showed that the percentage of cells that adhered to the lettuce leaf punches, expressed as a fraction of inoculum, increased from $<1 \%$ after 15 s to $6 \%$ after $60 \mathrm{~min}$ for $S$. Typhimurium, while for $E$. coli, this was $<1 \%$ after $15 \mathrm{~s}$ to $2 \%$ after 60 min (data not shown). For both strains, maximum attachment occurred after 30 to $60 \mathrm{~min}$. In this study, the inoculation time for both strains was standardized to $60 \mathrm{~min}$.

Previous experiments also indicated that the recovery of $S$. Typhimurium cells that adhered to lettuce leaf punches was observed at the lowest tested inoculum level of $10^{2}$ cells, of which $15 \%$ of the inoculum cells were recovered. For E. coli, the recovery percentage was substantially lower, $<1 \%$ of the inoculum cells, meaning fewer cells attached to the lettuce leaf punch at this inoculum level compared to $S$. Typhimurium cells (data not shown). The difference in inoculum density for both strains did not severely affect the percentage of bacterial cells that adhered to and were recovered from the lettuce leaves. Therefore, in this study, the inoculum cell number was standardized to $10^{6}$ bacterial cells for subsequent experiments.

Within the lettuce leaf punch wash water (Fig. S3.2A), transfer results demonstrated that $S$. Typhimurium cells from the non-starved culture were detected at $40 \%, 1 \%$, and $<1 \%$ of the original inoculum after the first, second, and third (final) wash, respectively. Cells that adhered to the lettuce leaf punches after the third rinsing step were detected at $<1 \%$ of the original inoculum. Similarly, for the E. coli non-starved culture, cell counts in the lettuce washing water were $32 \%, 3 \%$, and $1 \%$ of the original inoculum after the first, second, and third (final) wash, respectively. Cells that adhered to the lettuce leaf punches after the third rinsing step were detected at $2 \%$ of the original inoculum.

Furthermore, the ability of bacterial cells to reattach to uninoculated lettuce leaf punches were investigated (Fig. S3.2B). Results indicated that $S$. Typhimurium cells that initially adhered to the lettuce leaves but then were released during the first washing into the wash water, were still able to reattach to new, uninoculated lettuce punches ( $9 \%$ of the wash water inoculum), which was also observed by the decreased cell count in the washing water ( $30 \%$ of the wash water inoculum). Similarly, for E. coli cells, these values were $4 \%$ and $11 \%$, respectively.

\subsubsection{Inactivation efficiency of sanitizers in potable water}

The inactivation efficiency of $\mathrm{NaClO}(10 \mathrm{mg} / \mathrm{L}), \mathrm{ClO}_{2}(5 \mathrm{mg} / \mathrm{L})$, and Ag-Cu (9.1-9.9 mg/L $\mathrm{Ag}, 1.2 \mathrm{mg} / \mathrm{L} \mathrm{Cu}$ ) solutions, dissolved in potable water, against $S$. Typhimurium and $E$. coli were investigated (Fig. S3.1A). Results for $S$. Typhimurium and E. coli exhibited a 4 log reduction after short contact times with $\mathrm{NaClO}$ (seconds) and $\mathrm{ClO}_{2}(1 \mathrm{~min})$ in potable water (Fig. 3.1). This result was observed for cells from the non-starved culture, which 


\section{Chapter 3}

were grown in a rich medium (LB) at $37^{\circ} \mathrm{C}$, and short-term starved cultures, which were grown in potable water at $5^{\circ} \mathrm{C}$ for $24 \mathrm{~h}$. Although results may be influenced by the non-use of neutralizers for the sanitizing agents, serial dilutions in PPS were made before plating. In a previous experiment, $\mathrm{NaClO}(1.5 \mathrm{mg} / \mathrm{L})$ and $\mathrm{ClO}_{2}(10 \mathrm{mg} / \mathrm{L})$ were measured in potable water and industrially-supplied PWW (TOC $=354 \mathrm{mg} / \mathrm{L})$ without pathogens. Results demonstrated a 20 -fold and 10-fold reduction within 20 seconds between potable and industrially-supplied $\mathrm{PWW}$, respectively, for $\mathrm{NaClO}$ and $\mathrm{ClO}_{2}$ (data not shown). Furthermore, in our study, the Ag-Cu solution resulted in a 4 log reduction in potable water within $10 \mathrm{~min}$ for non-starved and short-term starved cultures of $S$. Typhimurium, while for both E. coli culture types, a 4 log reduction occurred within 20 min. Overall, the cell history, being non-starved vs. starved, did not affect the inactivation rate of the sanitizers.

(A)

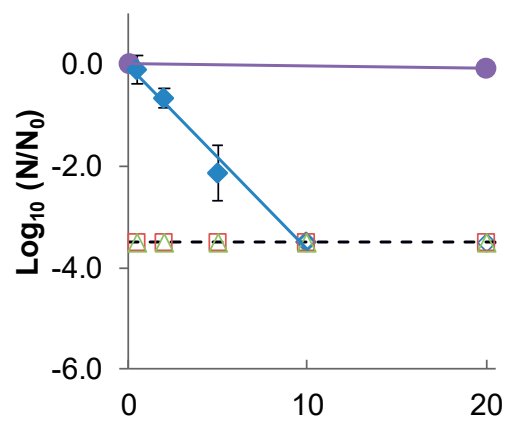

(C)

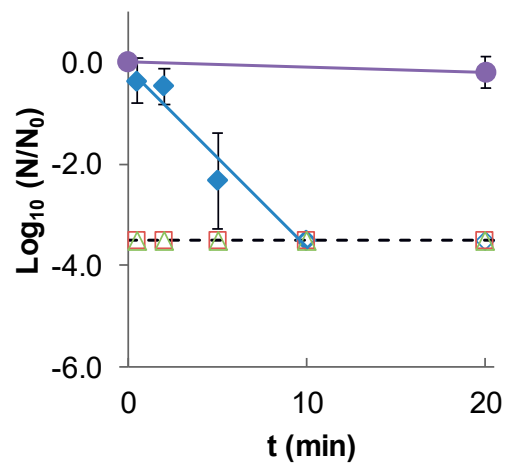

(B)

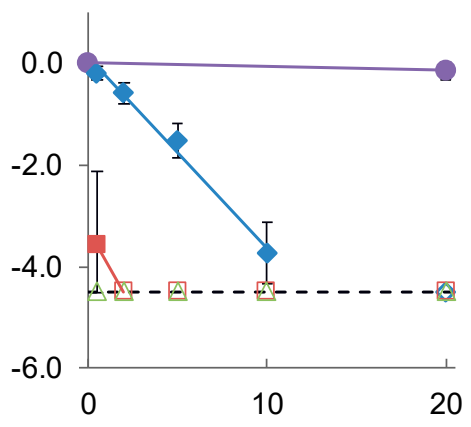

(D)

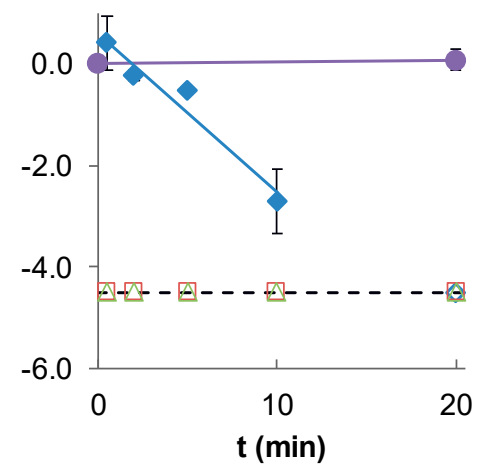

Figure 3.1. Inactivation of Salmonella enterica Typhimurium 1638 (A, C) and Escherichia coli isolate 0247_1 (B, D) with $10 \mathrm{mg} / \mathrm{L} \mathrm{NaClO} \mathrm{( \triangle ),} 5 \mathrm{mg} / \mathrm{L} \mathrm{ClO2}(\bullet)$, Ag-Cu with 9.1-9.9 mg/L Ag and $1.2 \mathrm{mg} / \mathrm{L} \mathrm{Cu}(\diamond)$, and no sanitizer $(\bullet)$ in $5{ }^{\circ} \mathrm{C}$ potable water: $(\mathrm{A}, \mathrm{B})$ cells from the non-starved culture at $37^{\circ} \mathrm{C},(\mathrm{C}, \mathrm{D})$ cells adjusted to 5 ${ }^{\circ} \mathrm{C}$ for $24 \mathrm{~h}$ representing "short-term" starved cultures. Data represent the average of triplicate experiments, and error bars represent standard deviation. --- limit of detection. 


\subsubsection{Sanitizer efficacy in lettuce washing water and on lettuce leaf punches}

The efficacy of $\mathrm{NaClO}(10 \mathrm{mg} / \mathrm{L}), \mathrm{ClO}_{2}$ (5 mg/L), and Ag-Cu (9.1-9.9 mg/L Ag, $1.2 \mathrm{mg} / \mathrm{L}$ $\mathrm{Cu}$ ) solutions in iceberg lettuce wash water on $S$. Typhimurium and $E$. coli non-starved and long-term starved cultures that had been released from contaminated lettuce leaf punches into the water was investigated at two temperatures: 5 and $20^{\circ} \mathrm{C}$ (Fig. S3.1B). Although results may be influenced by the non-use of neutralizers for the sanitizing agents, punches had been washed to remove agents before analysis.

\subsubsection{Treatments in lettuce wash water}

Results for the control treatments (i.e., with no sanitizer) indicated that $S$. Typhimurium non-starved cells that had released from the lettuce leaf punches into the washing water were detectable, irrespective of the applied incubation temperature. $S$. Typhimurium cells were 3.7 and $4.3 \log \mathrm{CFU} /$ punch, respectively, during washing with no sanitizers at 5 and $20{ }^{\circ} \mathrm{C}$ (Fig. 3.2A). This result contrasts the results for the sanitizing treatments with $\mathrm{NaClO}, \mathrm{ClO}_{2}$, and $\mathrm{Ag}-\mathrm{Cu}$, which demonstrated that $S$. Typhimurium non-starved cells were not recovered (Fig. 3.2A). Therefore, the application of all three sanitizing agents resulted in the complete eradication of culturable cells in the lettuce wash water. In brief, $S$. Typhimurium cell survival in the wash water was not statistically significant at 5 and $20^{\circ} \mathrm{C}(\mathrm{p}>0.05, \mathrm{n}=2)$.

E. coli cells that released into the lettuce washing water during control treatments were 2.6 and $1.3 \log \mathrm{CFU} /$ punch, respectively, during washing at 5 and $20{ }^{\circ} \mathrm{C}$ (Fig. 3.2B). In contrast to $S$. Typhimurium cells, fewer non-starved $E$. coli cells were present in the water at $5{ }^{\circ} \mathrm{C}$ compared to $20{ }^{\circ} \mathrm{C}$ (Fig. 3.2B). For non-starved E. coli, there was statistically a highly significant difference in averaged values of the control-treated wash water between incubation temperatures $(\mathrm{p}<0.001, \mathrm{n}=2)$, meaning that temperature had an effect on colony recoverability in the wash water and/or cell release from the leaf surface (Fig. 3.2B); this phenomenon was not observed with $S$. Typhimurium (Fig. 3.2A). Similar to S. Typhimurium, for E. coli, treatment of all sanitizing agents resulted in complete eradication of culturable cells in the lettuce wash water.

\subsubsection{Treatments on lettuce leaf punches}

Results on the lettuce leaf punches showed that non-starved $S$. Typhimurium and E. coli cells remained attached during control treatments irrespective of the applied incubation temperature. The control treatments represent the maximum number of attached CFUs. $S$. Typhimurium on the lettuce leaf punches during control treatments was 2.4 and $2.3 \log$ CFU/punch, respectively, for 5 and $20^{\circ} \mathrm{C}$ (Fig. 3.2C), while for E. coli, this was $2.6 \log$ and $2.8 \log \mathrm{CFU} /$ punch, respectively (Fig. 3.2D). $S$. Typhimurium cells from the lettuce leaf punches were also recovered following treatments with all sanitizing agents at both 5 and $20{ }^{\circ} \mathrm{C}$. However, the washing temperature during treatments affected survival; fewer cell numbers were reduced when wash water was maintained at $20^{\circ} \mathrm{C}$ than at $5{ }^{\circ} \mathrm{C}$ for all treatments $(\mathrm{p}=0.001, \mathrm{n}=2)$. Similarly, E. coli cells were recovered from the leaf punches following all treatments, i.e., after the control treatment without sanitizer as well as for the sanitizing agents at both incubation 


\section{Chapter 3}

temperatures (Fig. 3.2D). On average, the E. coli cells from the lettuce leaf punches (Fig. 3.2D) had a higher reduction than $S$. Typhimurium cells from lettuce leaf punches (Fig. 3.2C), demonstrating that the non-starved E. coli cells survive to a lesser extent on the lettuce leaf punch surface than the non-starved $S$. Typhimurium cells.

(A)

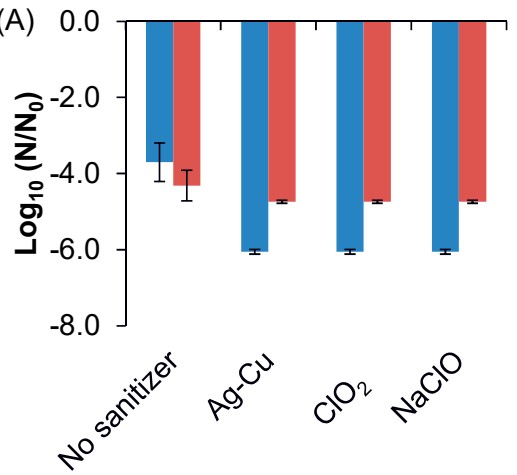

(C)

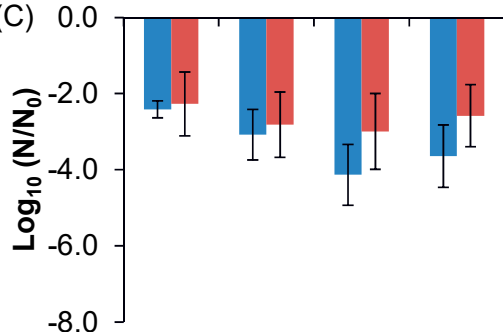

Treatment

(B)

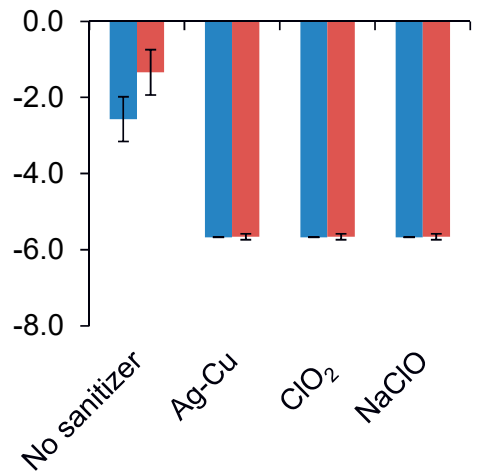

(D)

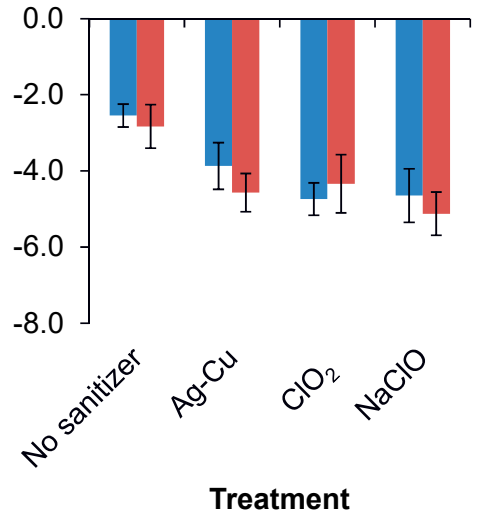

Figure 3.2. Salmonella enterica Typhimurium 1638 (A, C) and Escherichia coli isolate 0247_1 (B, D) cell release after a two minute treatment at $5^{\circ} \mathrm{C}$ and at $20{ }^{\circ} \mathrm{C}$ with no sanitizer, $\mathrm{Ag}-\mathrm{Cu}$ at 9.1-9.9 mg/L Ag and 1.2 $\mathrm{mg} / \mathrm{L} \mathrm{Cu}, 5 \mathrm{mg} / \mathrm{L} \mathrm{ClO}_{2}$, and $10 \mathrm{mg} / \mathrm{L} \mathrm{NaClO}$ : non-starved culture at $37^{\circ} \mathrm{C}$ in $(\mathrm{A}, \mathrm{B})$ iceberg lettuce punch wash water, and on (C, D) iceberg lettuce leaf punches. The $\log _{10}\left(\mathrm{~N} / \mathrm{N}_{\mathrm{o}}\right)$ of 0 indicates the number of attached bacterial cells to the leaf punches. Data represent the average of four experiments, and error bars represent standard deviation. 


\subsubsection{Survival of "long-term" starved cells}

In order to compare the potential effect that the cell history may have on the efficacy and survival from these treatments, long-term starved cells were examined in the iceberg lettuce wash water and on lettuce leaf punches. S. Typhimurium and E. coli longterm starved cells were recovered following the control treatment without sanitizer at both 5 and $20^{\circ} \mathrm{C}$ wash water, yet were undetectable in the lettuce wash water after treatment with the sanitizing agents (data not shown). When comparing the $S$. Typhimurium non-starved culture from the lettuce leaf punches washed in $20^{\circ} \mathrm{C}$ water (Fig. 3.2C) with the long-term starved cells, the starved cells displayed no significant differences $(p>0.05, n=2)$ during all treatments indicating that starvation did not lead to any detectable changes in survival against the sanitizing agents. Similarly, there was no significant difference ( $p>0.05, n=2)$ visualized during cell treatment on non-starved versus long-termed starved cultures for $E$. coli indicating that starvation did not result in a detectable, changed resistance towards sanitizing agents.

\subsubsection{Inactivation efficiency of sanitizers in process wash water}

$\mathrm{NaClO}(10 \mathrm{mg} / \mathrm{L})$ and $\mathrm{ClO}_{2}(5 \mathrm{mg} / \mathrm{L})$ were tested in organically loaded water with nonstarved cultures of $S$. Typhimurium and E. coli. Results for $S$. Typhimurium in the industrially-supplied PWW (Fig. 3.3A, C) demonstrated incomplete inactivation for both sanitizers when the PWW had a TOC of $354 \mathrm{mg} / \mathrm{L}$ (Fig. 3.3A). When the PWW had a TOC of $177 \mathrm{mg} / \mathrm{L}$ (Fig. 3.3C), $\mathrm{ClO}_{2}$ inactivated $S$. Typhimurium more than NaClO. Results for $E$. coli in industrially-supplied PWW (for $5 \mathrm{mg} / \mathrm{L} \mathrm{ClO}_{2}$ ) and laboratory-made PWW (for $10 \mathrm{mg} / \mathrm{L} \mathrm{NaClO}$ ) were observed (Fig. 3.3B, D). For ClO2, there was <1 log reduction at a TOC of $354 \mathrm{mg} / \mathrm{L}$ (Fig. 3.3B), while at a TOC of $177 \mathrm{mg} / \mathrm{L}$, there was a 4.5 log reduction (Fig. 3.3D). NaClO had little to no inactivation in laboratory-made PWWs with TOCs of 354 and $177 \mathrm{mg} / \mathrm{L}$. Similar experiments with E. coli at a TOC of $354 \mathrm{mg} / \mathrm{L}$ were cultured on BECSA + Ct and showed at least a 3 log reduction with $\mathrm{ClO}_{2}(5 \mathrm{mg} / \mathrm{L})$ in industrially-supplied PWW (data not shown). Although results may be influenced by the non-use of neutralizers for sanitizing agents, serial dilutions in PPS were made before plating. Overall, water quality, including the organic load measured as TOC, and the media used to culture E. coli were relevant variables. 
(A)

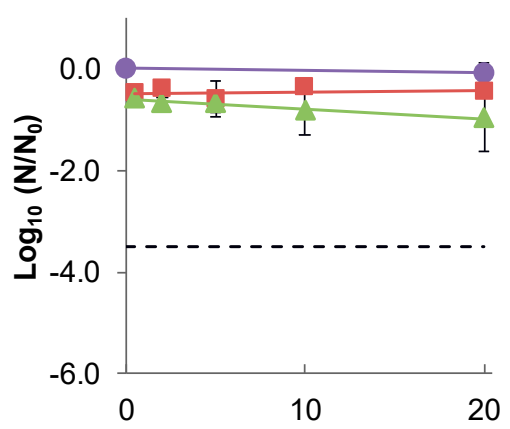

(C)

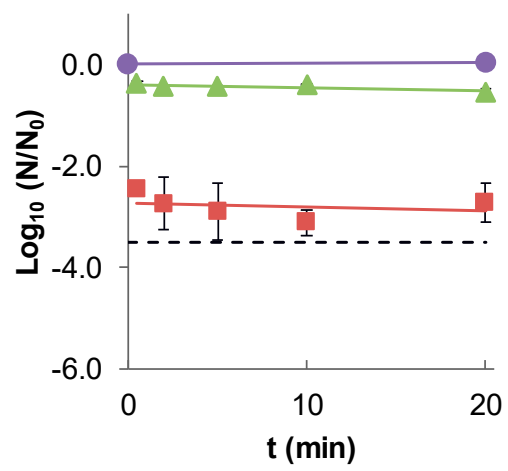

(B)

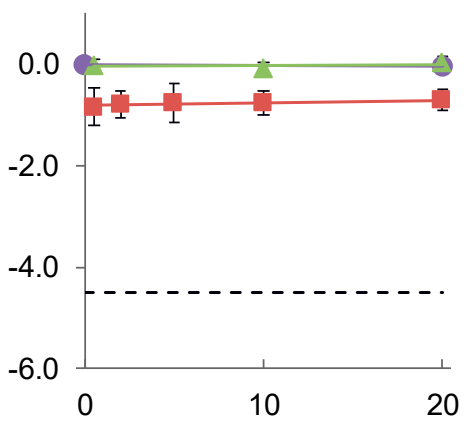

(D)

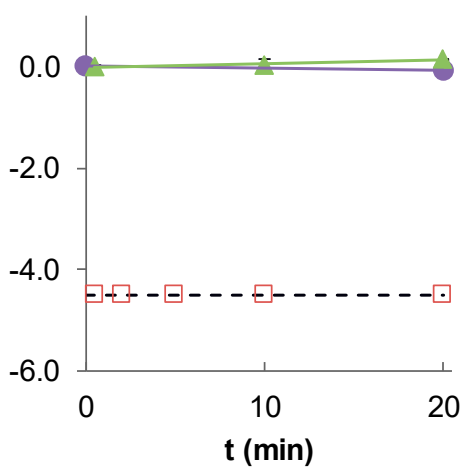

Figure 3.3. Inactivation of Salmonella enterica Typhimurium 1638 (A, C) and Escherichia coli isolate 0247_1 $(B, D)$ cells from the non-starved culture at $37^{\circ} \mathrm{C}$ on LBA media with $10 \mathrm{mg} / \mathrm{L} \mathrm{NaClO} \mathrm{( \triangle ),} 5 \mathrm{mg} / \mathrm{L} \mathrm{ClO} 2$ ( $\square$ ), and no sanitizer $(\bullet)$ in process washing water: $(\mathrm{A}, \mathrm{B}) \mathrm{TOC}=354 \mathrm{mg} / \mathrm{L},(\mathrm{C}, \mathrm{D}) \mathrm{TOC}=177 \mathrm{mg} / \mathrm{L}$. Data represent the average of duplicate experiments, and error bars represent standard deviation. --- limit of detection.

\subsection{Discussion}

\subsubsection{Pathogen releasing efficacy and (re-) attachment to lettuce leaf punches during washing}

Our results indicated that bacterial cell attachment to the iceberg lettuce leaf punches occurred within $15 \mathrm{~s}$, while maximum attachment occurred after 30 to $60 \mathrm{~min}$. These results are consistent with data obtained by Patel and Sharma (2010), which reported that Salmonella enterica serovars quickly attached to both intact and cut produce surfaces with attachment increasing over time. Furthermore, Takeuchi, Matute, Hassan and Frank (2000) reported that E. coli 0157:H7 preferentially attached to iceberg lettuce cut-edges rather than the surface, possibly a result of its non-hydrophobic surface, while $S$. Typhimurium attached equally at cut edges and surfaces. This non- 
preferential attachment mechanism for $S$. Typhimurium may be a reason for the difference in cell attachment numbers over time, as well as the lower attachment of $E$. coli cells on the lettuce leaf punch surface at the $10^{2} \mathrm{CFU}$ inoculum level compared to $S$. Typhimurium cells at the $10^{2} \mathrm{CFU}$ inoculum level. Overall, $S$. Typhimurium and E. coli attachment capabilities are shown to differ, with higher attachment rates after $60 \mathrm{~min}$ for $S$. Typhimurium than for $E$. coli, yet with minimal differences in the adherence and recovery based on higher inoculum densities $\left(10^{6} \mathrm{CFU}\right)$.

Bacterial cell (re-)attachment to and release from produce can affect the degree of contamination during produce washing. In our study, although bacteria were added to the middle of the leaf punch, avoiding contact with the cut-edges, during re-attachment, the bacteria may have diffused to the edges. Cell attachment can be characterized by a two-stage process: (i) initial cell attachment, which can occur within seconds, is based on a weak, unspecific, and reversible binding; and (ii) irreversible or "firm" attachment, which is multi-mechanistic as it can be influenced by several factors including bacterial strain features, produce, and type of processing. Due to the presence of stronger forces (e.g., covalent and hydrogen bonds, strong hydrophobic interactions), bacterial cells cannot easily be removed; to overcome this, even stronger forces such as from physical methods or chemical sanitizers would need to be employed to remove or inactivate the pathogens (Goulter, Gentle and Dykes, 2009; Van der Linden, Cottyn, Uyttendaele, Vlaemynck, Maes and Heyndrickx, 2014; Yaron and Romling, 2014). The results of our study indicated that bacterial adherence for $S$. Typhimurium and $E$. coli to the lettuce was firm even after multiple washings. According to these data, we can infer that after bacterial cell attachment to the leaves, bacteria were more difficult to inactivate with sanitizers. These results may be related to produce surface properties such as the hydrophobic cuticle, abrasions in tissues, or preferred binding sites; such sites make pathogen inactivation, through the use of sanitizers, difficult as sanitizers cannot access the 'protected' sites where pathogens may be harboring (Beuchat, 2004). Overall, the number of bacterial cells that attached to the lettuce leaf punches may be related to the preferred binding sites as well as a microorganism's ability to attach weakly or firmly. These findings can help us to understand further the importance of preventing pathogenic cross-contamination and, consequently, the principal aim to maintain the PWW quality during produce washing.

\subsubsection{Survival of non-starved and starved cells}

\subsubsection{Inactivation efficiency of sanitizers in potable water}

Drinking water disinfection with chlorine-based disinfectants has long been employed to control waterborne diseases, namely to eliminate harmful pathogens in the drinking water and to provide safe and potable water. Our results with $\mathrm{NaClO}$ and $\mathrm{ClO}_{2}$ for both non-starved and short-term starved cultures demonstrated a $>4$ log reduction in potable water given short contact times. Nevertheless, health-related concerns from the use of chlorine, due to the formation of chlorine DBPs such as trihalomethanes, haloacetic acids, and aldehydes, has prompted the need for alternatives. $\mathrm{ClO}_{2}$ is one potential alternative for chlorine-based disinfection since it does not form organohalogen DBPs (Gopal, Tripathy, Bersillon and Dubey, 2007) and is less affected 
by the presence of organic matter than chlorine (Van Haute et al., 2015c). However, the formation of chlorate residues could be problematic, yet studies on chloroxyanion accumulation in the PWW and presence on fresh-cut produce when $\mathrm{ClO}_{2}$ is used as a sanitizer during processing are limited (López-Gálvez, Allende, Truchado, MartínezSánchez, Tudela, Selma and Gil, 2010; Van Haute, Tryland, Escudero, Vanneste and Sampers, 2017) and are not the main objectives of this study.

Furthermore, our study investigated a silver-copper sanitizer. Metals such as silver and copper have been employed in their ionic form, both unaided and in combination with other sanitizers, to control pathogenic microorganisms present in water for human consumption as well as for recreational purposes, in cooling towers and large water distribution systems such as those employed by hospitals, and for municipal wastewater management (Huang, Shih, Lee, Yang, Lay and Lin, 2008; Luna-Pabello, Rios, Jimenez and de Velasquez, 2009; Silvestry-Rodriguez, Sicairos-Ruelas, Gerba and Bright, 2007). In our study, Ag-Cu demonstrated a $4 \log$ reduction of $S$. Typhimurium and $E$. coli in potable water after longer contact times in comparison to $\mathrm{NaClO}$ and $\mathrm{ClO}_{2}$. Also, after $10 \mathrm{~min}$ of $E$. coli exposure to $\mathrm{Ag}-\mathrm{Cu}$, there was about a 1 log difference between non-starved and short-term starved cultures. Accordingly, the short-term starved E. coli culture may survive better towards the $\mathrm{Ag}-\mathrm{Cu}$ solution meaning $S$. Typhimurium cultures are more susceptible compared to E. coli cultures.

Overall in our study, no substantial differences were observed in the potable water between non-starved and short-term starved cultures for all tested sanitizers. Given the longer inactivation kinetics required for the $\mathrm{Ag}-\mathrm{Cu}$ solution, it is not suitable for application to the PWW since PWW disinfection requires fast inactivation kinetics (Banach, Sampers, Haute and van der Fels-Klerx, 2015).

\subsubsection{Sanitizer efficacy in lettuce washing water and on lettuce leaf punches}

Our results indicated that $S$. Typhimurium and $E$. coli cells that had released from the lettuce leaf punches during the control washing could be detected, and cells remain attached to the produce during control treatments, both irrespective of the applied incubation temperature. Furthermore, sanitizing treatments eradicated cultural cells in the lettuce wash water. Regarding lettuce leaf punches, the washing temperature during treatments affected survival; fewer cells were reduced when wash water was maintained at $20^{\circ} \mathrm{C}$ than at $5{ }^{\circ} \mathrm{C}$ for all treatments $(\mathrm{p}=0.001, \mathrm{n}=2)$. Nevertheless, overall cells were able to survive treatments when adhered to the lettuce leaf surface. These results concur with previous research, which has indicated that bacterial adhesion to produce during washing was less extensive at lower temperatures and with short exposure times (Patel and Sharma, 2010; Reina, Fleming and Breidt, 2002). For example, for chopped and unchopped parsley, the efficacy of washing disinfectants against $S$. Typhimurium during different temperature-time conditions $\left(5{ }^{\circ} \mathrm{C} / 4 \mathrm{~h} ; 5{ }^{\circ} \mathrm{C} / 24 \mathrm{~h} ; 30^{\circ} \mathrm{C} / 4 \mathrm{~h}\right)$ indicated the highest log reduction for unchopped parsley in a chlorine wash at low temperatures $\left(5^{\circ} \mathrm{C}\right)$ and with a shorter exposure $(4 \mathrm{~h})$ (Faour-Klingbeil, Kuri and Todd, 2016). An important implication of our results is that pathogen reduction in the wash water can be influenced by processing parameters such as the use of chemical sanitizers in the wash water. Furthermore, produce decontamination may be less effective due to irreversible bacterial attachment 
mechanisms and/or protective mechanisms of the plant, and focus should, therefore, be aimed at preventing bacterial attachment at all steps along the chain.

Previous research has described the difficulties in culturing bacteria, like E. coli 0157:H7, in water as when bacteria are exposed to sub-lethal stresses such as temperature, $\mathrm{pH}$, nutrient changes, sanitizer exposure, etc., they may enter a viable but non-culturable (VNBC) state making isolation problematic (Li, Mendis, Trigui, Oliver and Faucher, 2014; Liu, Gilchrist, Zhang and Li, 2008; Oliver, 2005; Oliver, Dagher and Linden, 2005; Sata, Osawa, Asai and Yamai, 1999; Wang and Doyle, 1998). Thus, treatments with sanitizers may lead to non-culturability, while cells may still be alive. In our study, the long-term starved cells of both strains were recovered from the leaf punches after treatments with control and sanitizing agents at both 5 and $20^{\circ} \mathrm{C}$ washing water temperatures. These results are consistent with Van der Linden et al. (2014), which reported that E. coli 0157:H7 stressed cells, from temperature and fewer nutrients, attached similarly to the lettuce leaves as did unstressed, freshly grown cells. Similarly, Al-Nabulsi, Osaili, Obaidat, Shaker, Awaisheh and Holley (2014) described no apparent differences between stressed and unstressed $E$. coli 0157:H7 cell attachment and survival on lettuce leaves after disinfection. Overall, the long-term starved cells of both strains from our study demonstrated minor detectable differences in cell survival after treatment with sanitizers in both the iceberg lettuce wash water and on lettuce leaf punches.

\subsubsection{Inactivation efficiency of sanitizers in process wash water}

Our results indicated that the efficacy of $\mathrm{NaClO}$ and $\mathrm{ClO}_{2}$ is dependent on water quality, measured as the TOC of the PWW. Similarly, Van Haute et al. (2013) observed that in high organically loaded water, chlorine was quickly inactivated. Moreover, during pilotscale experiments, Davidson et al. (2013) observed that chlorine-based sanitizers might help prevent cross-contamination in water with lower organic loads. In our study, $\mathrm{ClO}_{2}$ was observed to prevent potential cross-contamination when the TOC of the PWW was $177 \mathrm{mg} / \mathrm{L}$, yet not at $354 \mathrm{mg} / \mathrm{L}$. However, our results were observed on a non-selective media, yet when $E$. coli was cultured on selective media, at least a 3 log reduction was seen with the industrially-supplied PWW (TOC $=354 \mathrm{mg} / \mathrm{L})$. These variations may occur because $\mathrm{ClO}_{2}$ treatment caused damage, but not inactivation. Overall, given the fluctuating environment of the PWW, the sanitizer dose needs to be properly controlled throughout processing to prevent cross-contamination.

Moreover, in our study, we observed inactivation differences between non-starved $S$. Typhimurium and E. coli with $\mathrm{ClO}_{2}(5 \mathrm{mg} / \mathrm{L})$ in PWW with a TOC of $177 \mathrm{mg} / \mathrm{L}$. Consequently, sanitizer efficacy is also shown to be influenced by the pathogen type. This result concurs with Lopez-Velasco, Tomas-Callejas, Sbodio, Artes-Hernandez and Suslow (2012), who observed $S$. enterica serovar variability to $\mathrm{ClO}_{2}$ dose and tolerance thereof in water. Therefore, along with the organic load of the PWW, pathogen and subtype variability are parameters that should not be overlooked as they can be relevant factors for sanitizer selection and application (in situ). 


\subsection{Conclusions}

Sodium hypochlorite $(10 \mathrm{mg} / \mathrm{L})$ and chlorine dioxide $(5 \mathrm{mg} / \mathrm{L})$ were similarly effective in inactivating $S$. Typhimurium and ESBL E. coli in (i) potable water and (ii) lettuce wash water. The silver-copper solution was comparatively less effective in inactivating $S$. Typhimurium and ESBL E. coli in (i) potable water, yet sanitizer differences, for the tested chemical sanitizers, in (ii) lettuce wash water were less apparent. The difference between non-starved and starved cell survival in (i) potable water and (ii) lettuce wash water and on lettuce leaf punches was minimal and did not affect the inactivation rate of sanitizers. Sanitizer application in (iii) process wash water was shown to be dependent on the water quality (i.e., organic load of the water) and the pathogen type. In brief, pathogen inactivation was shown to be dependent on the organic load of the water, water temperature, and pathogen attachment and release from the produce. Furthermore, experiments with multiple washings demonstrated the firm attachment of pathogenic cells, once attached to the produce, and thus, stress the relevance of preventing microbial attachment along the fresh(-cut) produce chain. Future research should investigate the feasibility of chlorine dioxide application, given minimum effective concentrations, as a process wash water disinfectant during pilot-scale processing.

\section{Acknowledgments}

This research has been financed by the Dutch Ministry of Economic Affairs (EZ) under the project Microbiology in Horticulture (PPS 296, BO-33.05-001-001) from the Topsector Horticulture and Starting Materials. The authors acknowledge the contributions from the Dutch fruit and vegetable industry. Marcel H. Zwietering is kindly thanked for his suggestions to the paper. 


\section{References}

Al-Nabulsi, A.A., Osaili, T.M., Obaidat, H.M., Shaker, R.R., Awaisheh, S.S., Holley, R.A., 2014. Inactivation of stressed Escherichia coli 0157:H7 cells on the surfaces of rocket salad leaves by chlorine and peroxyacetic acid. J. Food Prot. 77, 32-39. doi: 10.4315/0362-028x.Jfp-13-019.

Banach, J.L., Sampers, I., Haute, S.V., van der Fels-Klerx, H.J., 2015. Effect of disinfectants on preventing the cross-contamination of pathogens in fresh produce washing water. Int. J. Environ. Res. Public Health 12, 8658-8677. doi: 10.3390/ijerph120808658.

Beuchat, L.R., 2004. Difficulties in eliminating human pathogenic microorganisms on raw fruits and vegetables, Acta Horticulturae, 642 ed. International Society for Horticultural Science (ISHS), Leuven, BE, pp. 151-160.

Bradbury, K.E., Appleby, P.N., Key, T.J., 2014. Fruit, vegetable, and fiber intake in relation to cancer risk: findings from the European Prospective Investigation into Cancer and Nutrition (EPIC). Am. J. Clin. Nutr. 100 Suppl 1, 394S-398S. doi: 10.3945/ajcn.113.071357.

Callejón, R.M., Rodríguez-Naranjo, M.I., Ubeda, C., Hornedo-Ortega, R., Garcia-Parrilla, M.C., Troncoso, A.M., 2015. Reported foodborne outbreaks due to fresh produce in the United States and European Union: trends and causes. Foodborne Pathog. Dis. 12, 32-38. doi: 10.1089/fpd.2014.1821.

Davidson, G.R., Buchholz, A.L., Ryser, E.T., 2013. Efficacy of commercial produce sanitizers against nontoxigenic Escherichia coli 0157:H7 during processing of iceberg lettuce in a pilot-scale leafy green processing line. J. Food Prot. 76, 1838-1845. doi: 10.4315/0362-028x.Jfp-13-111.

Dubber, D., Gray, N.F., 2010. Replacement of chemical oxygen demand (COD) with total organic carbon (TOC) for monitoring wastewater treatment performance to minimize disposal of toxic analytical waste. J. Environ. Sci. Health A 45, 1595-1600. doi: 10.1080/10934529.2010.506116.

EFSA Panel on Biological Hazards (BIOHAZ) Panel, 2013. Scientific opinion on the risk posed by pathogens in food of non-animal origin. Part 1 (outbreak data analysis and risk ranking of food/pathogen combinations). EFSA J. 11, 138. doi: 10.2903/j.efsa.2013.3025.

Faour-Klingbeil, D., Kuri, V., Todd, E.C.D., 2016. The influence of pre-wash chopping and storage conditions of parsley on the efficacy of disinfection against $S$. Typhimurium. Food Control 65, 121-131. doi: 10.1016/j.foodcont.2016.01.019.

Food and Agriculture Organization of the United Nations (FAO), World Health Organization (WHO), 2008. Microbiological hazards in fresh leafy vegetables and herbs: meeting report. World Health Organization [etc.], Geneva [etc.].

Gil, M.I., Marín, A., Andujar, S., Allende, A., 2016. Should chlorate residues be of concern in fresh-cut salads? Food Control 60, 416-421. doi: 10.1016/j.foodcont.2015.08.023.

Gil, M.I., Selma, M.V., López-Gálvez, F., Allende, A., 2009. Fresh-cut product sanitation and wash water disinfection: problems and solutions. Int. J. Food Microbiol. 134, 37-45. doi: 10.1016/j.ijfoodmicro.2009.05.021.

Gil, M.I., Selma, M.V., Suslow, T., Jacxsens, L., Uyttendaele, M., Allende, A., 2015. Pre- and postharvest preventive measures and intervention strategies to control microbial food safety hazards of fresh leafy vegetables. Crit. Rev. Food Sci. Nutr. 55, 453-468. doi: 10.1080/10408398.2012.657808.

Gopal, K., Tripathy, S.S., Bersillon, J.L., Dubey, S.P., 2007. Chlorination byproducts, their toxicodynamics and removal from drinking water. J. Hazard. Mater. 140, 1-6. doi: 10.1016/j.jhazmat.2006.10.063.

Goulter, R.M., Gentle, I.R., Dykes, G.A., 2009. Issues in determining factors influencing bacterial attachment: a review using the attachment of Escherichia coli to abiotic surfaces as an example. Lett. Appl. Microbiol. 49, 1-7. doi: 10.1111/j.1472-765X.2009.02591.x.

Holvoet, K., Jacxsens, L., Sampers, I., Uyttendaele, M., 2012. Insight into the prevalence and distribution of microbial contamination to evaluate water management in the fresh produce processing industry. J. Food Prot. 75, 671-681. doi: 10.4315/0362-028x.Jfp-11-175.

Huang, H.I., Shih, H.Y., Lee, C.M., Yang, T.C., Lay, J.J., Lin, Y.E., 2008. In vitro efficacy of copper and silver ions in eradicating Pseudomonas aeruginosa, Stenotrophomonas maltophilia and Acinetobacter baumannii: implications for on-site disinfection for hospital infection control. Water Res. 42, 73-80. doi: 10.1016/j.watres.2007.07.003.

Jacxsens, L., Luning, P.A., van der Vorst, J.G.A.J., Devlieghere, F., Leemans, R., Uyttendaele, M., 2010. Simulation modelling and risk assessment as tools to identify the impact of climate change on microbiological food safety - the case study of fresh produce supply chain. Food Res. Int. 43, 1925-1935. doi: 10.1016/j.foodres.2009.07.009. 


\section{Chapter 3}

Li, L., Mendis, N., Trigui, H., Oliver, J.D., Faucher, S.P., 2014. The importance of the viable but non-culturable state in human bacterial pathogens. Front. Microbiol. 5. doi: 10.3389/Fmicb.2014.00258.

Liu, Y., Gilchrist, A., Zhang, J., Li, X.F., 2008. Detection of viable but nonculturable Escherichia coli 0157:H7 bacteria in drinking water and river water. Appl. Environ. Microbiol. 74, 1502-1507. doi: 10.1128/AEM.02125-07.

López-Gálvez, F., Allende, A., Truchado, P., Martínez-Sánchez, A., Tudela, J.A., Selma, M.V., Gil, M.I., 2010. Suitability of aqueous chlorine dioxide versus sodium hypochlorite as an effective sanitizer for preserving quality of fresh-cut lettuce while avoiding by-product formation. Postharvest Biol. Technol. 55, 53-60. doi: 10.1016/j.postharvbio.2009.08.001.

Lopez-Velasco, G., Tomas-Callejas, A., Sbodio, A., Artes-Hernandez, F., Suslow, T.V., 2012. Chlorine dioxide dose, water quality and temperature affect the oxidative status of tomato processing water and its ability to inactivate Salmonella. Food Control 26, 28-35. doi: 10.1016/j.foodcont.2011.12.016.

Luna-Pabello, V.M., Rios, M.M., Jimenez, B., de Velasquez, M.T.O., 2009. Effectiveness of the use of Ag, Cu and PAA to disinfect municipal wastewater. Environ. Technol. 30, 129-139. doi: 10.1080/09593330802422506.

Luo, Y., Ingram, D.T., Khurana, K., 2014. Preventing cross-contamination during produce wash operations, in: Hoorfar, J. (Ed.), Global safety of fresh produce: a handbook of best-practice examples, innovative commercial solutions and case studies. Woodhead Publishing, Oxford, UK, pp. 103-111.

Luo, Y., Nou, X., Millner, P., Zhou, B., Shen, C., Yang, Y., Wu, Y., Wang, Q., Feng, H., Shelton, D., 2012. A pilot plant scale evaluation of a new process aid for enhancing chlorine efficacy against pathogen survival and cross-contamination during produce wash. Int. J. Food Microbiol. 158, 133-139. doi: 10.1016/j.ijfoodmicro.2012.07.008.

Olaimat, A.N., Holley, R.A., 2012. Factors influencing the microbial safety of fresh produce: a review. Food Microbiol. 32, 1-19. doi: 10.1016/j.fm.2012.04.016.

Oliver, J.D., 2005. The viable but nonculturable state in bacteria. J. Microbiol. 43 Spec No, 93-100.

Oliver, J.D., Dagher, M., Linden, K., 2005. Induction of Escherichia coli and Salmonella Typhimurium into the viable but nonculturable state following chlorination of wastewater. J. Water Health 3, 249-257. doi: 10.2166/wh.2005.040.

Parish, M.E., Beuchat, L.R., Suslow, T.V., Harris, L.J., Garrett, E.H., Farber, J.N., Busta, F.F., 2003. Methods to reduce/eliminate pathogens from fresh and fresh-cut produce. Compr. Rev. Food Sci. Food Saf. 2, 161-173. doi: 10.1111/j.1541-4337.2003.tb00033.x.

Patel, J., Sharma, M., 2010. Differences in attachment of Salmonella enterica serovars to cabbage and lettuce leaves. Int. J. Food Microbiol. 139, 41-47. doi: 10.1016/j.ijfoodmicro.2010.02.005.

Reina, L.D., Fleming, H.P., Breidt, F., Jr., 2002. Bacterial contamination of cucumber fruit through adhesion. J. Food Prot. 65, 1881-1887. doi: 10.4315/0362-028x-65.12.1881.

Sadiq, R., Rodriguez, M.J., 2004. Disinfection by-products (DBPs) in drinking water and predictive models for their occurrence: a review. Sci. Total Environ. 321, 21-46. doi: 10.1016/j.scitotenv.2003.05.001.

Sata, S., Osawa, R., Asai, Y., Yamai, S., 1999. Growth of starved Escherichia coli 0157 cells in selective and nonselective media. Microbiol. Immunol. 43, 217-227. doi: 10.1111/j.1348-0421.1999.tb02396.x.

Silvestry-Rodriguez, N., Sicairos-Ruelas, E.E., Gerba, C.P., Bright, K.R., 2007. Silver as a disinfectant, in: Ware, G.W. (Ed.), Reviews of environmental contamination and toxicology. Springer, pp. 23-45.

Takeuchi, K., Matute, C.M., Hassan, A.N., Frank, J.F., 2000. Comparison of the attachment of Escherichia coli 0157:H7, Listeria monocytogenes, Salmonella Typhimurium, and Pseudomonas fluorescens to lettuce leaves. J. Food Prot. 63, 1433-1437. doi: 10.4315/0362-028x-63.10.1433.

The Dow Chemical Company, 2015. Dow water and process solutions - correlation between KMn04, COD, BOD, DOC and TOC.

Tirpanalan, Ö., Zunabovic, M., Domig, K.J., Kneifel, W., 2011. Mini review: antimicrobial strategies in the production of fresh-cut lettuce products, in: Méndez-Vilas, A. (Ed.), Science against microbial pathogens: communicating current research and technological advances. Formatex Research Center, Badajoz, ES, pp. 176-188.

Van der Linden, I., Cottyn, B., Uyttendaele, M., Vlaemynck, G., Maes, M., Heyndrickx, M., 2014. Evaluation of an attachment assay on lettuce leaves with temperature- and starvation-stressed Escherichia coli 0157:H7 MB3885. J. Food Prot. 77, 549-557. doi: 10.4315/0362-028X.JFP-13-332.

Van Haute, S., López-Gálvez, F., Gómez-López, V.M., Eriksson, M., Devlieghere, F., Allende, A., Sampers, I., 2015a. Methodology for modeling the disinfection efficiency of fresh-cut leafy vegetables wash water applied on peracetic acid combined with lactic acid. Int. J. Food Microbiol. 208, 102-113. doi: 10.1016/j.ijfoodmicro.2015.05.020. 
Van Haute, S., Sampers, I., Holvoet, K., Uyttendaele, M., 2013. Physicochemical quality and chemical safety of chlorine as a reconditioning agent and wash water disinfectant for fresh-cut lettuce washing. Appl. Environ. Microbiol. 79, 2850-2861. doi: 10.1128/AEM.03283-12.

Van Haute, S., Sampers, I., Jacxsens, L., Uyttendaele, M., 2015b. Selection criteria for water disinfection techniques in agricultural practices. Crit. Rev. Food Sci. Nutr. 55, 1529-1551. doi: 10.1080/10408398.2012.705360.

Van Haute, S., Tryland, I., Escudero, C., Vanneste, M., Sampers, I., 2017. Chlorine dioxide as water disinfectant during fresh-cut iceberg lettuce washing: disinfectant demand, disinfection efficiency, and chlorite formation. LWT Food Sci. Technol. 75, 301-304. doi: 10.1016/j.lwt.2016.09.002.

Van Haute, S., Tryland, I., Veys, A., Sampers, I., 2015c. Wash water disinfection of a full-scale leafy vegetables washing process with hydrogen peroxide and the use of a commercial metal ion mixture to improve disinfection efficiency. Food Control 50, 173-183. doi: 10.1016/j.foodcont.2014.08.028.

van Hoek, A.H., Schouls, L., van Santen, M.G., Florijn, A., de Greeff, S.C., van Duijkeren, E., 2015. Molecular characteristics of extended-spectrum cephalosporin-resistant Enterobacteriaceae from humans in the community. PLoS One 10, e0129085. doi: 10.1371/journal.pone.0129085.

Wang, G., Doyle, M.P., 1998. Survival of enterohemorrhagic Escherichia coli 0157:H7 in water. J. Food Prot. 61, 662-667. doi: 10.4315/0362-028x-61.6.662.

Warriner, K., Huber, A., Namvar, A., Fan, W., Dunfield, K., 2009. Recent advances in the microbial safety of fresh fruits and vegetables, in: Taylor, S.L. (Ed.), Adv. Food Nutr. Res. Elsevier Inc., pp. 155-208.

Yaron, S., Romling, U., 2014. Biofilm formation by enteric pathogens and its role in plant colonization and persistence. Microb. Biotechnol. 7, 496-516. doi: 10.1111/1751-7915.12186. 


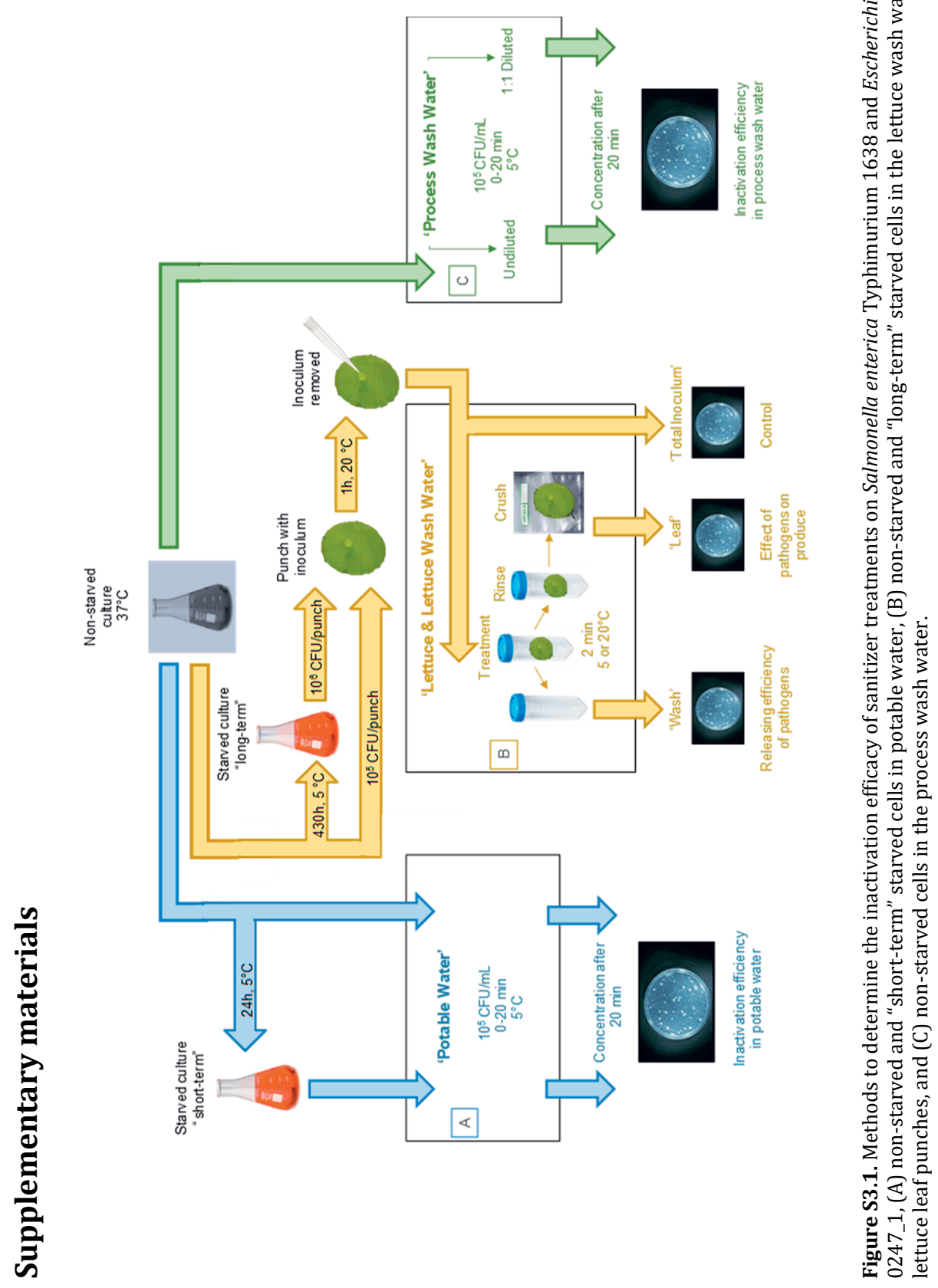




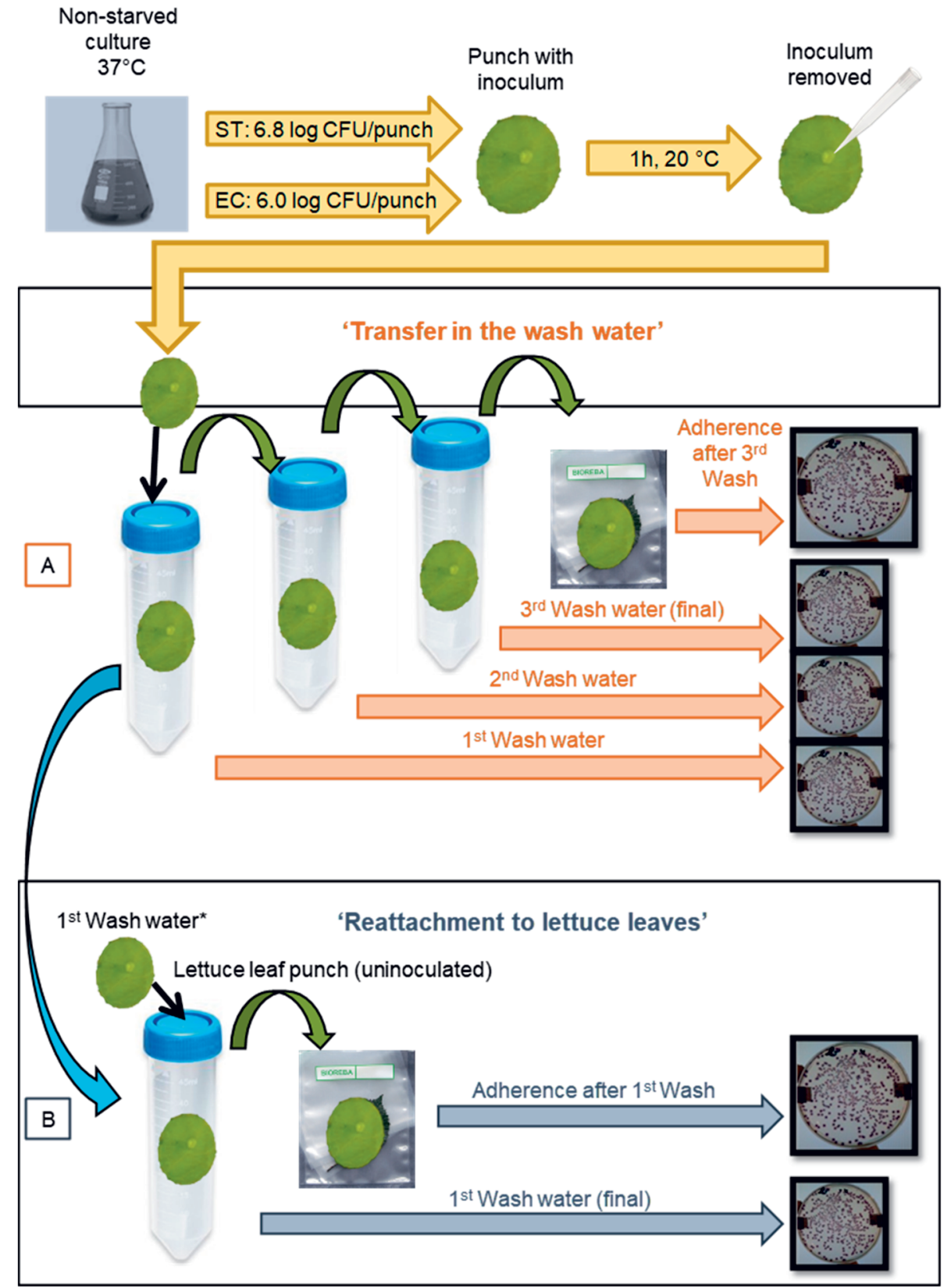

Figure S3.2. Methods to evaluate (A) the releasing efficiency of pathogens on the lettuce into the washing water and (B) reattachment from contaminated process wash water to uninoculated lettuce leaves. ST: Salmonella enterica Typhimurium isolate 1638; EC: and Escherichia coli isolate 0247_1. *The wash water concentrations of $S$. Typhimurium was $6.3 \log \mathrm{CFU} / \mathrm{mL}$ and of E. coli was $5.5 \log \mathrm{CFU} / \mathrm{mL}$. 



\title{
Chapter 4
}

\section{Efficacy of chlorine dioxide on Escherichia coli inactivation during pilot-scale fresh-cut lettuce processing}

\author{
J.L. Banach \\ L.S. van Overbeek \\ M.N. Nierop Groot \\ P.S. van der Zouwen \\ H.J. van der Fels-Klerx
}

Published in: International Journal of Food Microbiology (2018), 269, 128-136.

doi: 10.1016/j.ijfoodmicro.2018.01.013 


\begin{abstract}
Controlling water quality is critical in preventing cross-contamination during fresh produce washing. Process wash water (PWW) quality can be controlled by implementing chemical disinfection strategies. The aim of this study was to evaluate the pilot-scale efficacy of chlorine dioxide $\left(\mathrm{ClO}_{2}\right)$ during processing on the reduction of Escherichia coli in the PWW and on processed fresh-cut 'Lollo Rossa' lettuce. The objective was to have a residual target concentration of either 5 or $3 \mathrm{mg} / \mathrm{L} \mathrm{ClO}_{2}$ in the washing tank $\left(3.5 \mathrm{~m}^{3}\right)$ before and during $800 \mathrm{~kg}$ of lettuce processing (90 min). After 90 min., a nonpathogenic, non-Extended Spectrum Beta-Lactamase (ESBL) E. coli inoculum from an overnight culture broth $\left(37^{\circ} \mathrm{C}\right)$ was added to the tank resulting in an approximate final level of $10^{6} \mathrm{CFU} / \mathrm{mL}$. PWW and lettuce samples for microbiological and chemical analyses were taken before and after the input and supply halted. $\mathrm{ClO}_{2}$ concentrations quickly decreased after $\mathrm{ClO}_{2}$ input halted, yet a residual concentration of $\geq 2.5 \mathrm{mg} / \mathrm{L}$ and $\geq 2.1 \mathrm{mg} / \mathrm{L} \mathrm{ClO}_{2}$, respectively for 5 and $3 \mathrm{mg} / \mathrm{L}$ pilots, was present 12 min after the supply halted. No detectable levels of $E$. coli (limit of detection 5 log) were determined in the water within 1 min after $E$. coli was added to the $\mathrm{ClO}_{2}$ containing wash water. Results demonstrated that $\mathrm{ClO}_{2}$ use at the semi-commercial pilot scale was able to reduce the E. coli peak contamination in the PWW. After storage ( 5 days, $4{ }^{\circ} \mathrm{C}$ ), background microbial communities (i.e., fluorescent pseudomonads and total heterotrophic bacteria) grew out on lettuce. Overall, $\mathrm{ClO}_{2}$ decreased the potential for cross-contamination between batches compared to when no sanitizer was used. Chlorate levels of the lettuce sampled before entering the wash water ranged from 7.3$11.6 \mu \mathrm{g} / \mathrm{kg}$. The chlorate levels of the lettuce sampled after being washed in the $\mathrm{ClO}_{2}$ containing wash water, as well as after rinsing and centrifugation, ranged from 22.8$60.4 \mu \mathrm{g} / \mathrm{kg}$; chlorite levels ranged from $1.3-1.6 \mathrm{mg} / \mathrm{kg}$, while perchlorate levels were below the limit of quantification ( $\mathrm{LOQ},<5 \mathrm{ng} / \mathrm{g})$. In this study, we report the semicommercial pilot-scale evaluation of $\mathrm{ClO}_{2}$ for its ability to maintain the PWW quality and to prevent cross-contamination in the washing tank during fresh-cut lettuce processing. Furthermore, we provide quantitative values of $\mathrm{ClO}_{2}$ disinfection byproducts chlorate and chlorite as well as of perchlorate from PWW and/or lettuce samples.
\end{abstract}

\title{
Keywords
}

Water disinfection; Microbial cross-contamination; Disinfection by-products; Fresh-cut produce wash; Pilot 


\subsection{Introduction}

The ability to guarantee fresh(-cut) produce safety has become arduous despite control measures at all stages of the chain. Callejón, Rodríguez-Naranjo, Ubeda, HornedoOrtega, Garcia-Parrilla and Troncoso (2015) have provided evidence that pathogenic contamination of fresh produce significantly contributes to the overall burden of foodborne disease. One of the main obstacles in supplying safe and high quality fresh(cut) produce, which thereby prevents foodborne disease, originates from the overwhelming responsibility required by all actors along the fresh produce chain (i.e., from farm to fork) to ensure safety despite the limited control measures available for such minimally processed products. Despite their ongoing efforts, there are several sources or pathways by which pathogens can be introduced. Although current practices for actors, such as Good Agricultural Practices (GAP) for primary producers and Food Safety Management Systems (FSMS) for processors, aim to prevent the potential for (cross-) contamination, the burden is still present (Kirezieva, Nanyunja, Jacxsens, van der Vorst, Uyttendaele and Luning, 2013). Particularly, the post-harvest processor is substantially responsible for the safety and quality, albeit fresh (-cut) produce may only be minimally processed.

During post-harvest processing, produce washing can help to remove soil and debris. However, washing can also serve as a potential pathway for pathogenic (cross-) contamination in the wash tank. This can occur when bacterial cells release from contaminated produce into the PWW and then attach to uncontaminated produce; thus, leading to batch contaminations (Banach, van Bokhorst-van de Veen, van Overbeek, van der Zouwen, van der Fels-Klerx and Nierop Groot, 2017; Danyluk and Schaffner, 2011; Gil, Selma, López-Gálvez and Allende, 2009; Jensen, Friedrich, Harris, Danyluk and Schaffner, 2015; López-Gálvez, Allende, Truchado, Martínez-Sánchez, Tudela, Selma and Gil, 2010; Luo, Ingram and Khurana, 2014; Van Haute, Sampers, Holvoet and Uyttendaele, 2013). Despite this washing conundrum, the processor can influence the potential for pathogenic (cross-) contamination by implementing technical and managerial controls on the water used during processing. These controls may include wash water disinfection strategies such as the use of chemical sanitizers in the PWW. Therefore, fresh(-cut) produce washing, that is, with the use of chemical sanitizers, may be a potential solution to combat cross-contamination via the PWW.

Several research groups have argued that the aim of PWW disinfection - with sanitizers - during produce processing is to reduce the likelihood of cross-contamination (Allende, Selma, Lopez-Galvez, Villaescusa and Gil, 2008; Baert, Vandekinderen, Devlieghere, Van, Debevere and Uyttendaele, 2009; Banach, Sampers, Haute and van der Fels-Klerx, 2015; Chardon, Swart, Evers and Franz, 2016; Danyluk and Schaffner, 2011; Davidson, Buchholz and Ryser, 2013; Gil et al., 2009; Gil, Selma, Suslow, Jacxsens, Uyttendaele and Allende, 2015; Holvoet, Jacxsens, Sampers and Uyttendaele, 2012; López-Gálvez, Allende, Selma and Gil, 2009; López-Gálvez, Gil, Truchado, Selma and Allende, 2010; Luo et al., 2014; U.S. Food and Drug Administration (FDA), 2009; Van Haute, Tryland, Veys and Sampers, 2015b; Zhao, Zhao and Doyle, 2009). Although the application of chlorine during fresh (-cut) produce washing has been a prominent choice for industry, potential health, and environmental concerns as raised by, e.g., European countries, like the 
formation of carcinogenic compounds (e.g., trihalomethanes (THMs)), have prompted research for alternatives (Artés, Gómez, Aguayo, Escalona and Artés-Hernández, 2009; Gil et al., 2009; Gómez-López, 2012; Joshi, Mahendran, Alagusundaram, Norton and Tiwari, 2013).

This study aims to evaluate the pilot-scale efficacy of chlorine dioxide $\left(\mathrm{ClO}_{2}\right)$ during processing on the reduction of Escherichia coli in the PWW and on processed fresh-cut 'Lollo Rossa' lettuce. Foremost, we assess the impact that a residual concentration of $\mathrm{ClO}_{2}$ had during washing (in situ) on the microbiological and chemical safety of the PWW. Secondarily, we examine the efficacy of $\mathrm{ClO}_{2}$ on processed fresh-cut lettuce to demonstrate if $\mathrm{ClO}_{2}$ can prevent cross-contamination in the washing tank. Our study presents an innovative method of investigating the pilot-scale application of $\mathrm{ClO}_{2}$ as a PWW sanitizer during fresh-cut lettuce processing while considering the potential presence of disinfection by-products (DBPs) like chlorate and chlorite as well as of perchlorate.

\subsection{Materials and methods}

\subsubsection{Experimental design}

Preliminary pilot experiments evaluated the chemical parameters of the $\mathrm{PWW}(\mathrm{pH}$, ammonium-N $\left(\mathrm{NH}_{4}-\mathrm{N}\right)$, nitrate-N $\left(\left(\mathrm{NO}_{3}+\mathrm{NO}_{2}\right)-\mathrm{N}\right)$, phosphate-P $\left(\mathrm{PO}_{4}-\mathrm{P}\right)$, and total organic carbon (TOC)) during $180 \mathrm{~min}$ of processing (data not shown). Since the TOC after $90 \mathrm{~min}$ (43 $\mathrm{mg} / \mathrm{L})$ was similar to that after $180 \mathrm{~min}(45 \mathrm{mg} / \mathrm{L}), 800 \mathrm{~kg}$ of 'Lollo Rossa' lettuce processed in 90 min was investigated during the $\mathrm{ClO}_{2}$ pilots to allow an accumulation of organic compounds in the PWW.

Based on the potential practical application of a minimum $\mathrm{ClO}_{2}$ concentration and the results of previous lab experiments, $\mathrm{ClO}_{2}$ concentrations of 5 and $3 \mathrm{mg} / \mathrm{L}$ were assessed (data not shown); each concentration was tested in duplicate during the pilots. The application of $\mathrm{ClO}_{2}(5 \mathrm{mg} / \mathrm{L})$, also given minimum effective concentrations, warranted further research as a potential process wash water disinfectant during pilot-scale processing (Banach et al., 2017). $\mathrm{ClO}_{2}$ concentrations were evaluated against $E$. coli by processing an $800 \mathrm{~kg}$ batch of 'Lollo Rossa' lettuce in $90 \mathrm{~min}$ through a $3.5 \mathrm{~m}^{3}$ commercial washer (Flotation washer, Remie, build year mid-1997), after which PWW was inoculated with $E$. coli to achieve a final level of $10^{6} \mathrm{CFU} / \mathrm{mL} E$. coli. Pilot trials with sanitizer-free water and non-supplemented E. coli served as controls. During lettuce processing, water and lettuce samples were collected and quantitatively examined for the presence of $E$. coli as well as chlorate, chlorite, and/or perchlorate. Water samples were also analyzed for $\mathrm{pH}, \mathrm{NH}_{4}-\mathrm{N}, \mathrm{NO}_{3}+\mathrm{NO}_{2}-\mathrm{N}, \mathrm{PO}_{4}-\mathrm{P}, \mathrm{TOC}$, and chemical oxygen demand (COD). Pre-processing and post-processing swabs of the processing line after routine cleaning were quantified for E. coli. 


\subsection{2 'Lollo Rossa' lettuce}

Crated shipments of a loose leaf-type lettuce (Lactuca sativa var. crispa 'Lollo Rossa') grown in Spain were obtained from a supplier of the processor; one supply per experimental run was used. Lettuce was stored in a $4{ }^{\circ} \mathrm{C}$ walk-in cooler and used within 2-3 days of delivery. Directly before the lettuce entered the processing line, it was cored with a knife, and any damaged outermost leaves were removed (pre-trimmed). In short, lettuce was processed by pre-trimming (by hand), shredding, conveying, vibrating, washing, rinsing, centrifuging, and, when applicable, were packaged.

\subsubsection{Bacterial strain preparation}

A nonpathogenic, non-Extended Spectrum Beta-Lactamase (ESBL) E. coli strain (12123.2) was obtained from the National Institute for Public Health and the Environment (RIVM), Bilthoven, the Netherlands. The strain had been isolated from surface water. The strain was maintained at $-80{ }^{\circ} \mathrm{C}$ in Luria Broth (LB; L1704 LB Broth High Salt, Duchefa Biochemie B.V., Haarlem, the Netherlands) supplemented with $25 \%(\mathrm{v} / \mathrm{v})$ glycerol. Bacteria were streaked on Brilliance $E$. coli coliform selective agar (BECSA; CM1046, Oxoid Ltd., Basingstoke, United Kingdom).

Cultures were prepared by inoculation of a single colony from BECSA by growing them overnight (16-18h) in $25 \mathrm{~mL} \mathrm{LB}$ at $37^{\circ} \mathrm{C}$ in a $200 \mathrm{rpm}$ shaking air incubator. Afterward, $0.5 \mathrm{~mL}$ of the culture was added to $2 \mathrm{~L}$ Erlenmeyer flasks filled with $500 \mathrm{~mL}$ of LB. After growth for $18( \pm 1) \mathrm{h}$, to obtain stationary phase cells, the liquid cultures (c.a. $10^{9}$ $\mathrm{CFU} / \mathrm{mL}$ ) were collected in a $5 \mathrm{~L}$ plastic container. All liquid (c.a. $4.5 \mathrm{~L}$ ) was added directly to the wash tank.

\subsubsection{Processing line}

A semi-commercial lettuce processing line, housed at $10^{\circ} \mathrm{C}$, and capable of processing $400 \mathrm{~kg} / \mathrm{h}$, or approximately $800 \mathrm{~kg} / 90 \mathrm{~min}$, was used. It consisted of a lettuce shredder, step conveyer, infeed vibrator, washer, and hand centrifuge. Tap water $\left(7^{\circ} \mathrm{C}\right.$, optimally $\left.4{ }^{\circ} \mathrm{C}, \mathrm{pH} \sim 7.2-7.6\right)$ was pumped into a $3.5 \mathrm{~m}^{3}$ stainless steel washer, which had a refreshment rate of 1000-1500 liters/h. The washer was modified with a stainless steel cover with a sliding inlet for $E$. coli supply. $\mathrm{ClO}_{2}$ was produced in situ under controlled conditions (in a specially developed generator - P3-Oxy-Gen Plus 170, Ecolab B.V., Nieuwegein, the Netherlands) by mixing and dilution of two precursors: P3-Oxonet, a sodium chlorite $\left(\mathrm{NaClO}_{2}\right)$ solution, and $\mathrm{P} 3-0 x o d e s$ a hydrochloric acid $(\mathrm{HCl})$ solution; hence, it is referred to as the acid-chlorite reaction. This is shown by Reaction (1).

$$
5 \mathrm{NaClO}_{2}+4 \mathrm{HCl} \rightarrow 4 \mathrm{ClO}_{2}+5 \mathrm{NaCl}+2 \mathrm{H}_{2} \mathrm{O}
$$

$\mathrm{ClO}_{2}$ and fresh water were supplied via air inlets to the washer furthest from the product inflow and E. coli supply. Water flow was in a circular motion (front to back to front) in the washing tank, and product inflow was facilitated with the use of product transport paddles. Product outflow was collected and centrifuged before packaging onsite. 


\subsubsection{Semi-commercial pilots}

Pilot control and treatment trials $(n=6)$ were performed in duplicate. For treatment trials, we aimed to have a $\mathrm{ClO}_{2}$ residual concentration of either 5 or $3 \mathrm{mg} / \mathrm{L}$ in the washing tank before and during $800 \mathrm{~kg}$ of 'Lolla Rossa' lettuce processing. Half of the trials were evaluated with inoculated E. coli (Table 4.1). The concentration of $\mathrm{ClO}_{2}$ was monitored and manually adjusted to obtain the desired concentration; measurements were performed every 15-20 minutes and repeated for verification as required. After $800 \mathrm{~kg}$ of lettuce had been fed into the shredder, the produce inflow and the $\mathrm{ClO}_{2}$ supply halted to be able to distinguish the effect of $\mathrm{ClO}_{2}$ had versus that from a dilution effect. During the pilots with $E$. coli addition, the strain $(\sim 4.5 \mathrm{~L})$ was simultaneously added to the tank at the time the $\mathrm{ClO}_{2}$ input and lettuce input halted; this resulted in a final level of approximately $10^{6} \mathrm{CFU} / \mathrm{mL}$. During this time, the processing line continued operating, resulting in the remaining outflow of lettuce.

Pilot trials occurred over six different days. There were two pilot trials per day, of which the first one was without the supplemented E. coli and the second one with the supplemented E. coli. There were four days with $\mathrm{ClO}_{2}$ pilot trials, two with $5 \mathrm{mg} / \mathrm{L}$ and two with $3 \mathrm{mg} / \mathrm{L}$ as the targeted disinfectant concentration (Table 4.1). The equipment was cleaned between each run and was thoroughly sanitized at the end of the day. Equipment was swabbed with swab rinse kits (SRK; 922C, CR, SRK $10 \mathrm{~mL}$ TRIPLE PACKED, Copan Italia SpA, Brescia, Italy) pre-and post-processing for inoculated E. coli at the (i) infeed vibrator, (ii) front wall of the washer, (iii) rear wall of the washer, and (iv) output band of the washer to verify hygiene. Subsequently, $100 \mu \mathrm{L}$ of the undiluted swab fluid was plated on BECSA and incubated at $37^{\circ} \mathrm{C}$ for $24 \mathrm{~h}$. Furthermore, during the $3 \mathrm{mg} / \mathrm{L}$ pilots, swab samples were quantified on King's B Agar (KB; K5165 KB Medium, Duchefa Biochemie B.V., Haarlem, the Netherlands) and R2A Agar (218262 Difco $^{\text {TM }}$ R2A Agar, BD Diagnostics, Breda, the Netherlands) to determine background microbial communities, respectively, fluorescent pseudomonads and total heterotrophic plate counts. Plates were incubated at $35 \pm 2{ }^{\circ} \mathrm{C}$ for $42-48 \mathrm{~h}$. 
Table 4.1. Pilot control and treatment trials $(n=6)$, in duplicate, including the day of the trial, measured chlorine dioxide $\left(\mathrm{ClO}_{2}\right)$ concentrations $(\mathrm{mg} / \mathrm{L})$ at $80 \mathrm{~min}$ in the process wash water (PWW) and final level of E. coli $(\log \mathrm{CFU} / \mathrm{mL})$ at $90 \mathrm{~min}$ in the washer.

\begin{tabular}{|c|c|c|c|}
\hline Pilot Trial $^{\mathrm{a}}$ & Day of trial & $\begin{array}{l}\mathrm{ClO}_{2}(\mathrm{mg} / \mathrm{L}) \text { at } 80 \\
\min \end{array}$ & $\begin{array}{l}\text { E. coli }(\log \mathrm{CFU} / \mathrm{mL}) \text { added at } \\
90 \mathrm{~min}\end{array}$ \\
\hline Control A.1 & 2 & - & - \\
\hline Control A.2 & 4 & - & - \\
\hline Control B.1 & 1 & - & 6.5 \\
\hline Control B.2 & 3 & - & 5.8 \\
\hline Treatment A.1 & 1 & 5.2 & - \\
\hline Treatment A.2 & 3 & 3.4 & - \\
\hline Treatment B.1 & 2 & 6.7 & 6.2 \\
\hline Treatment B.2 & 4 & 4.5 & 6.1 \\
\hline Treatment C.1 & 5 & 3.1 & - \\
\hline Treatment C.2 & 6 & 2.8 & - \\
\hline Treatment D.1 & 5 & 3.6 & 6.3 \\
\hline Treatment D.2 & 6 & 2.8 & 6.2 \\
\hline
\end{tabular}

${ }^{a}$ Each control or treatment trial was performed in duplicate as indicated by 1 and 2 . Control trials were performed without addition of $\mathrm{ClO}_{2}$ and either without (Control A) or with (Control B) E. coli. Treatment trials were performed with $\mathrm{ClO}_{2}$, of which either $5 \mathrm{mg} / \mathrm{L}$ (Treatments A and B) or $3 \mathrm{mg} / \mathrm{L}$ (Treatments $\mathrm{C}$ and D) were tested. Of the treatment trials, E. coli was added during Treatments B and D.

\subsubsection{Sample collection}

PWW samples for microbiological analyses were collected $(2 \mathrm{~L})$ from the wash tank at $80 \mathrm{~min}$ (i.e., before the lettuce input and $\mathrm{ClO}_{2}$ supply halted at $90 \mathrm{~min}$ ) as well as at 91 , 93, 96, and 102 or $110 \mathrm{~min}$ (Table 4.2). Samples to determine the $\mathrm{ClO}_{2}$ concentration of the PWW were collected $(50 \mathrm{~mL})$ in duplicate periodically throughout processing. These samples were processed on-site. PWW samples for chemical analyses $\left(\mathrm{pH}, \mathrm{NH}_{4}\right.$ $\mathrm{N}, \mathrm{NO}_{3}+\mathrm{NO}_{2}-\mathrm{N}, \mathrm{PO}_{4}-\mathrm{P}, \mathrm{TOC}, \mathrm{COD}$, chlorate, chlorite, and perchlorate) were collected at the same time points as for the microbiological analyses. Additionally, water from the centrifuged lettuce samples that were processed on-site was collected during the pilots with $3 \mathrm{mg} / \mathrm{L}$ (i.e., Treatments C and D in Table 4.1) and analyzed for the potential presence of chlorate and perchlorate. All water samples were collected in sealed containers and transported under refrigerated conditions to the laboratory.

Lettuce samples for microbiological analyses were sampled before lettuce entered the wash tank (i.e., after the lettuce was pre-trimmed and shredded), after lettuce exited the wash tank at 80 min (i.e., before the lettuce input and $\mathrm{ClO}_{2}$ supply halted at $90 \mathrm{~min}$ ) as well as at 91, 93, and 95 min (Table 4.2). These samples were processed on-site as described in section 4.2.7. Additionally, lettuce samples were collected for storage and further analyses before the lettuce entered the wash tank and between 2 and 3 min after the lettuce input and $\mathrm{ClO}_{2}$ supply halted (i.e., between 92 and $93 \mathrm{~min}$ ). These samples were subsequently rinsed and centrifuged before packaging, to dilute out $\mathrm{ClO}_{2}$ and to remove unattached E. coli cells. All samples were packaged on-site and transported under refrigerated conditions to the laboratory for microbiological and chemical analyses. Packaged lettuce samples were stored for 5 days at $4{ }^{\circ} \mathrm{C}$ before microbiological analyses. During the pilots with $3 \mathrm{mg} / \mathrm{L}$, chlorate and perchlorate levels of the lettuce were analyzed to assess the potential transfer. These lettuce samples were 
stored at $4{ }^{\circ} \mathrm{C}$ and extracts from 3 to 5 samples of the packaged lettuce of about $68 \mathrm{~g}$ (SD $\pm 15 \mathrm{~g}$ ) each, were prepared within 5 days. Extracts were stored at $-20^{\circ} \mathrm{C}$ until analyses.

\subsubsection{Microbiological analyses}

Preliminary pilot experiments were performed before pilot trials; they evaluated the microbiological parameters of the PWW on Luria Broth agar (LBA) plates containing 1.2\% agar Luria Broth (LBA; No. 241420 Difco $^{\mathrm{TM}}$ Luria Broth Base, BD Diagnostics, Breda, the Netherlands) and BECSA. Plates were incubated at $37^{\circ} \mathrm{C}$ for $24 \mathrm{~h}$ with daily inspection of colonies for up to 5 days to check if potentially damaged cells could eventually grow out. Total viable counts demonstrated a negligible increase over time and averaged $4 \mathrm{log} \mathrm{CFU} / \mathrm{mL}$ during processing (data not shown). There was no observed difference between CFUs quantified on LB and BECSA (data not shown). Hence during the pilot trials, PWW was determined on BECSA. Samples were collected as described in section 4.2.6.

During the pilot trials, directly after collection of the PWW samples, $100 \mu \mathrm{L}$ was directly plated, and $1 \mathrm{~mL}$ was serially diluted into a peptone physiological salt solution (PPS; Tritium Microbiologie B.V., Eindhoven, the Netherlands). Then, $100 \mu \mathrm{L}$ of the appropriate dilutions were plated. Plates were incubated at $37^{\circ} \mathrm{C}$ for $24 \mathrm{~h}$ with daily inspection of colonies for up to 5 days to check if potentially damaged cells could eventually grow out.

Furthermore, during the pilot trials, lettuce samples for on-site analyses were collected from the outflow of the processing line and were directly hand-centrifuged (Zyliss Smart Touch Salad Spinner, Farnborough, United Kingdom). Approximately $10 \mathrm{~g}$ of lettuce was washed twice with potable water to simulate commercial processing conditions. Packaged lettuce samples were collected and processed as described in section 4.2.6. Lettuce samples were transferred to BioReba (10 mL volume) bags (Bioreba AG, Reinach, Switzerland) in which $10 \mathrm{~mL}$ of sterile Ringer's solution (BR0052; 177 Oxoid, part of Thermo Fisher Scientific, Breda, the Netherlands) was added and gently homogenized. Tenfold serial dilutions of Ringer's solution were made from the lettuce homogenates. Then, $100 \mu \mathrm{L}$ of undiluted and diluted lettuce homogenates were pipetted onto BECSA. Afterward, liquid drops were spread over the agar surfaces to allow enumeration of individual CFUs of $E$. coli following incubation at $37{ }^{\circ} \mathrm{C}$ for $24 \mathrm{~h}$. Additionally, during the $3 \mathrm{mg} / \mathrm{L}$ pilot trials, lettuce samples were quantified on $\mathrm{KB}$ and $\mathrm{R} 2 \mathrm{~A}$, to determine fluorescent pseudomonads and total heterotrophic plate counts, respectively, and incubated at $35 \pm 2{ }^{\circ} \mathrm{C}$ for $42-48 \mathrm{~h}$. For lettuce samples, the effect of $\mathrm{ClO}_{2}$ before and after the addition of $E$. coli to the PWW on fluorescent pseudomonads (KB) and total heterotrophic bacteria (R2A) was calculated and used for statistical comparison using Student's t-test (GenStat release 12.1, Hemel Hempstead, United Kingdom). 

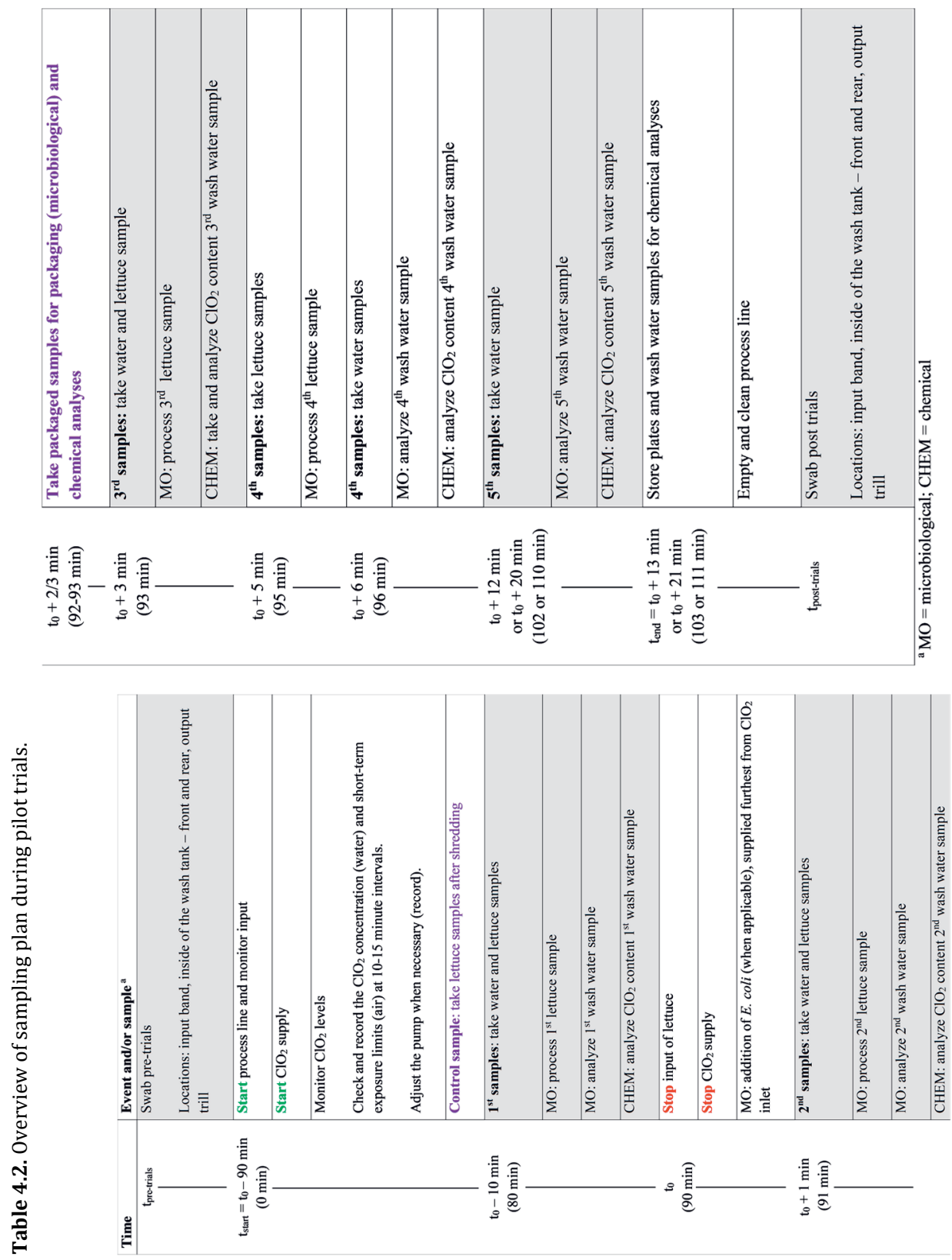


\subsubsection{Chemical analyses}

$\mathrm{ClO}_{2}$ was analyzed with the DULCOTEST ${ }^{\circledR}$ DT4B and DT1B photometer (ProMinent Verder B.V., Vleuten, the Netherlands) and the Hach Lange DR $2800^{\mathrm{Tm}}$ spectrophotometer (Hach, Tiel, the Netherlands). The $\mathrm{pH}$ was determined with a Beckman $\Phi 34$ pH meter; $\mathrm{NH}_{4}-\mathrm{N}, \mathrm{NO}_{3}+\mathrm{NO}_{2}-\mathrm{N}$, and $\mathrm{PO}_{4}-\mathrm{P}$ were analyzed, all in $0.01 \mathrm{M}$ $\mathrm{CaCl}_{2}$, with a Skalar segmented flow analyzer (SFA; model SAN++); and TOC was analyzed with a Skalar SFA, model SAN++ in accordance with NEN-EN 1484 (Chemical Biological Soil Laboratory, Wageningen, the Netherlands). COD was determined according to the sealed tube method in accordance with NEN-ISO 15705 (Waterlab Noord, Glimmen, the Netherlands). Chlorite concentrations were determined by ion chromatography in accordance with NEN-EN-ISO 10304-4 (Vitens N.V., Leeuwarden, the Netherlands). Chlorate and perchlorate concentrations were determined by liquid chromatography-tandem mass spectrometry (LC-MS/MS) according to the Quick Polar Pesticides (QuPPE) Method, as described by Anastassiades, Kolberg, Mack, Wildgrube, Sigalov and Dörk (2013), at RIKILT Wageningen University \& Research, Wageningen, the Netherlands.

\subsection{Results}

\subsubsection{Pilot process washing water assessment}

An overview of the pilot control and treatment trials, including the day of the trial, the concentration of $\mathrm{ClO}_{2}$ measured at $80 \mathrm{~min}$ in the $\mathrm{PWW}$, and the final level of E. coli in the wash tank, which was added at $90 \mathrm{~min}$, is shown in Table 4.1. For Control A, Treatment A, and Treatment C pilot trials, E. coli had not been supplemented to the washing water, nor was it detected in the water samples measured thereafter. For Control B pilot trials, E. coli was added at 90 min to the non- $\mathrm{ClO}_{2}$ containing $\mathrm{PWW}$; results showed no reduction of $E$. coli in the water samples measured thereafter (Table 4.1). Results of pilot trials with $5 \mathrm{mg} \mathrm{ClO}_{2} / \mathrm{L}$ (Treatment B) and $3 \mathrm{mg} \mathrm{ClO}_{2} / \mathrm{L}$ (Treatment D), during which E. coli had been added to the PWW at $90 \mathrm{~min}$, showed that $E$. coli were not detected in the PWW when analyzed on BECSA 1 min after E. coli was added to the PWW (i.e., at $91 \mathrm{~min}$ ) (data not shown). Furthermore, PWW samples measured thereafter (i.e., at 93, 96, 102, or $110 \mathrm{~min}$ ) showed that $E$. coli were not detected, and thus, at least a 5 log reduction occurred (data not shown).

The concentration of $\mathrm{ClO}_{2}$, as well as byproducts chlorate and chlorite in the PWW, are shown in Fig. 4.1 and Fig. 4.2 for pilot treatments with a targeted $\mathrm{ClO}_{2}$ concentration of 5 and $3 \mathrm{mg} / \mathrm{L}$, respectively, including trials without E. coli (A-B) and with E. coli (C-D). For these pilot trials, before 'Lollo Rossa' lettuce processing began, the washing tank had a starting concentration of $\mathrm{ClO}_{2} \geq 5$ or $3 \mathrm{mg} / \mathrm{L}$, respectively. The concentration of $\mathrm{ClO}_{2}$ in the PWW ranged from 3.4-6.7 mg/L and 2.8-3.6 mg/L after $80 \mathrm{~min}$ of processing, respectively, for 5 and $3 \mathrm{mg} / \mathrm{L}$ pilots (Fig. 4.1 and Fig. 4.2). A downward trend in $\mathrm{ClO}_{2}$ in the PWW after 90 min was visualized for pilots tested without and with $E$. coli, yet a residual concentration of $\mathrm{ClO}_{2}$ being $\geq 2.5 \mathrm{mg} / \mathrm{L}$ and $\geq 2.1 \mathrm{mg} / \mathrm{L}$, respectively for 5 and 3 $\mathrm{mg} / \mathrm{L}$ pilots, was observed at $102 \mathrm{~min}$ (i.e., $12 \mathrm{~min}$ after the input of lettuce and $\mathrm{ClO}_{2}$ supply halted) (Fig. 4.1 and Fig. 4.2). Chlorate and chlorite in the PWW ranged from 8- 
$11 \mathrm{mg} / \mathrm{L}$ and 13-19 mg/L, respectively, after $80 \mathrm{~min}$ of processing for the $5 \mathrm{mg} / \mathrm{L}$ pilots (Fig. 4.1). Similarly, for the $3 \mathrm{mg} / \mathrm{L}$ pilots, chlorate and chlorite ranged from $9-22 \mathrm{mg} / \mathrm{L}$ and 31-34 mg/L, respectively (Fig. 4.2). Additionally, during $3 \mathrm{mg} / \mathrm{L}$ pilots, the concentration of perchlorate was $<20 \mathrm{mg} / \mathrm{L}$ (limit of detection, LOD) for all sampled time points in the PWW.

In addition, several quality parameters of the $\mathrm{PWW}\left(\mathrm{NH}_{4}-\mathrm{N}, \mathrm{NO}_{3}+\mathrm{NO}_{2}-\mathrm{N}, \mathrm{PO}_{4}-\mathrm{P}, \mathrm{pH}\right.$, $\mathrm{COD}$, and TOC) are shown for pilot control trials without $\mathrm{ClO}_{2}$, i.e., Control A without $E$. $\operatorname{coli}$ (A, B) and Control B with E. coli (C, D) (Fig. S4.1), as well as for 5 and $3 \mathrm{mg} / \mathrm{L} \mathrm{ClO}_{2}$ pilot treatment trials, respectively (Fig. S4.2 and Fig. S4.3). In general, PWW from the pilot trials had a pH range of 7.1-8.0 after 80 min of processing. The $\mathrm{pH}$ during processing without $\mathrm{ClO}_{2}$ (Fig. S4.1) were similar to the PWW previously measured during preliminary pilot experiments (data not shown), while the $\mathrm{pH}$ during processing with $\mathrm{ClO}_{2}$ (Fig. S4.2 and Fig. S4.3) was lower, yet demonstrated an increase after $90 \mathrm{~min}$ (i.e., after the $\mathrm{ClO}_{2}$ supply halted). Pilot results for $\mathrm{NH}_{4}-\mathrm{N}, \mathrm{NO}_{3}+\mathrm{NO}_{2}-\mathrm{N}, \mathrm{PO}_{4}-\mathrm{P}$ after 80 min of processing ranged from $0.1-0.6 \mathrm{mg} / \mathrm{L}, 3.8-6.1 \mathrm{mg} / \mathrm{L}$, and $0.6-1.2 \mathrm{mg} / \mathrm{L}$, respectively. COD and TOC ranged from $84-800 \mathrm{mg} / \mathrm{L}$ and $79-150 \mathrm{mg} / \mathrm{L}$, respectively, after $80 \mathrm{~min}$ of processing. The TOC after $80 \mathrm{~min}$ of processing without $\mathrm{ClO}_{2}$ (Fig. S4.1) was higher (86-132 mg/L) than that of the PWW previously measured during preliminary pilot experiments (data not shown). An upward trend in COD and TOC between 91 and 93 min was observed for pilot trials tested with E. coli because of the addition of $E$. coli to the PWW at $90 \mathrm{~min}$.

\subsubsection{Pilot 'Lollo Rossa' lettuce assessment}

During pilot trials, the lettuce leaf surface was not inoculated beforehand; rather, the $E$. coli was added as a suspension to the wash tank. After addition, E. coli cells adhered to leaf surfaces, and the difference in adherence was observed between treatment trials with $\mathrm{ClO}_{2}$ and control trials.

During the $5 \mathrm{mg} / \mathrm{L} \mathrm{ClO}_{2}$ pilot trials (Treatment B), a 2.3 log reduction of E. coli was observed on lettuce leaf samples at 93 min compared to Control B pilot trials (without supplemented $\mathrm{ClO}_{2}$, yet with added $E$. coli at $90 \mathrm{~min}$ ); i.e., $2.8 \mathrm{log} \mathrm{CFU} / \mathrm{g}$ leaf $-0.5 \mathrm{log}$ $\mathrm{CFU} / \mathrm{g}$ leaf $=2.3 \mathrm{log} \mathrm{CFU} / \mathrm{g}$ leaf (Table 4.3). Also, the centrifuged rinse water of the lettuce samples analyzed on-site that were measured after the second centrifugation had a $1.2 \log$ reduction of E. coli at 93 min compared to Control B pilot trials at $93 \mathrm{~min}$. Stored lettuce samples, collected during 92-93 min of processing, had on average a 2.5 log reduction of E. coli compared to Control B pilot trials (Table 4.3).

During the $3 \mathrm{mg} / \mathrm{L} \mathrm{ClO}_{2}$ pilot trials (Treatment D), a similar reduction, about $2.0 \mathrm{log}$ reduction of $E$. coli, was observed on lettuce leaf samples at 93 min compared to Control B pilot trials (without supplemented $\mathrm{ClO}_{2}$, yet with added E. coli at $90 \mathrm{~min}$ ); i.e., $2.8 \mathrm{log}$ CFU/g leaf - $0.8 \log$ CFU/g leaf $=2.0 \log$ CFU/g leaf (Table 4.3, Table 4.4). During these pilots, a clear effect of $\mathrm{ClO}_{2}$ on background microbial communities, non- $E$. coli cells on $\mathrm{KB}$ and R2A, after E. coli administration was not observed (Table 4.4). It is clear that the background microbial communities, i.e., fluorescent pseudomonads and total heterotrophic bacteria, remain on the lettuce after $\mathrm{ClO}_{2}$ treatments as observed during the $3 \mathrm{mg} / \mathrm{L}$ pilots (Table 4.4) and after storage (Table 4.5). According to Student's $t$-test, 
the effect of $\mathrm{ClO}_{2}$ before and after the addition of $E$. coli to the PWW is not significant at $\mathrm{p}<0.05$, meaning there is no measurable effect of $\mathrm{ClO}_{2}$ on these microbial communities. Moreover, $\mathrm{ClO}_{2}$ influenced $E$. coli counts on lettuce (Table 4.3, Table 4.4) and in the second centrifuged wash water (Table 4.3). Wash water disinfection during pilot trials with supplemented $E$. coli did not prevent eventual outgrowth of $E$. coli in packaged lettuce (Table 4.3, Table 4.5); however, background microbial communities were able to grow out at these temperatures due to their psychrophilic nature (Table 4.5). The impact of outgrowth of these microbial communities on $E$. coli was not further investigated as it was out of the scope of this research.

Furthermore, during the $3 \mathrm{mg} / \mathrm{L}$ pilot trials, chlorate levels of the lettuce sampled before entry into the wash tank were on average $7.3 \mu \mathrm{g} / \mathrm{kg}(\mathrm{SD} \pm 2.1 \mu \mathrm{g} / \mathrm{kg}$ ) for Treatment C. 2 and $11.6 \mu \mathrm{g} / \mathrm{kg}(\mathrm{SD} \pm 2.9 \mu \mathrm{g} / \mathrm{kg}$ ) for Treatment D.2. Levels on the lettuce after washing, rinsing, and centrifugation was on average $23.9 \mu \mathrm{g} / \mathrm{kg}$ (SD $\pm 6.7 \mu \mathrm{g} / \mathrm{kg}$ ) and $60.4 \mu \mathrm{g} / \mathrm{kg}(\mathrm{SD} \pm 17.7 \mu \mathrm{g} / \mathrm{kg}$ ) for Treatment C.1 and C.2, respectively, and on average $22.8 \mu \mathrm{g} / \mathrm{kg}(\mathrm{SD} \pm 0.9 \mu \mathrm{g} / \mathrm{kg}$ ) and $58.8 \mu \mathrm{g} / \mathrm{kg}(\mathrm{SD} \pm 31.7 \mu \mathrm{g} / \mathrm{kg}$ ) for Treatment D.1 and D.2, respectively (data not shown). Chlorite was analyzed for lettuce samples taken post-disinfection during Treatment C.2 and D.2; values were 1.6 and $1.3 \mathrm{mg} / \mathrm{kg}$, respectively. Perchlorate analyses for Treatments $C$ and $D$ demonstrated levels $<5 \mathrm{ng} / \mathrm{g}$ (limit of quantification, LOQ). For first centrifuged lettuce rinse water samples at 80, 91, 93, and $95 \mathrm{~min}$, chlorate values ranged from 3.0 to $14.1 \mathrm{mg} / \mathrm{L}$ (Treatment C.1 and D.1). For second centrifuged lettuce rinse water samples at 80, 91, 93, and $95 \mathrm{~min}$, chlorate values ranged from 0.0340 to $0.073 \mathrm{mg} / \mathrm{L}$ (Treatment C.2 and D.2). Perchlorate samples for centrifuged samples from Treatments $C$ and D, regardless of the time point, were $<20 \mathrm{mg} / \mathrm{L}$. 


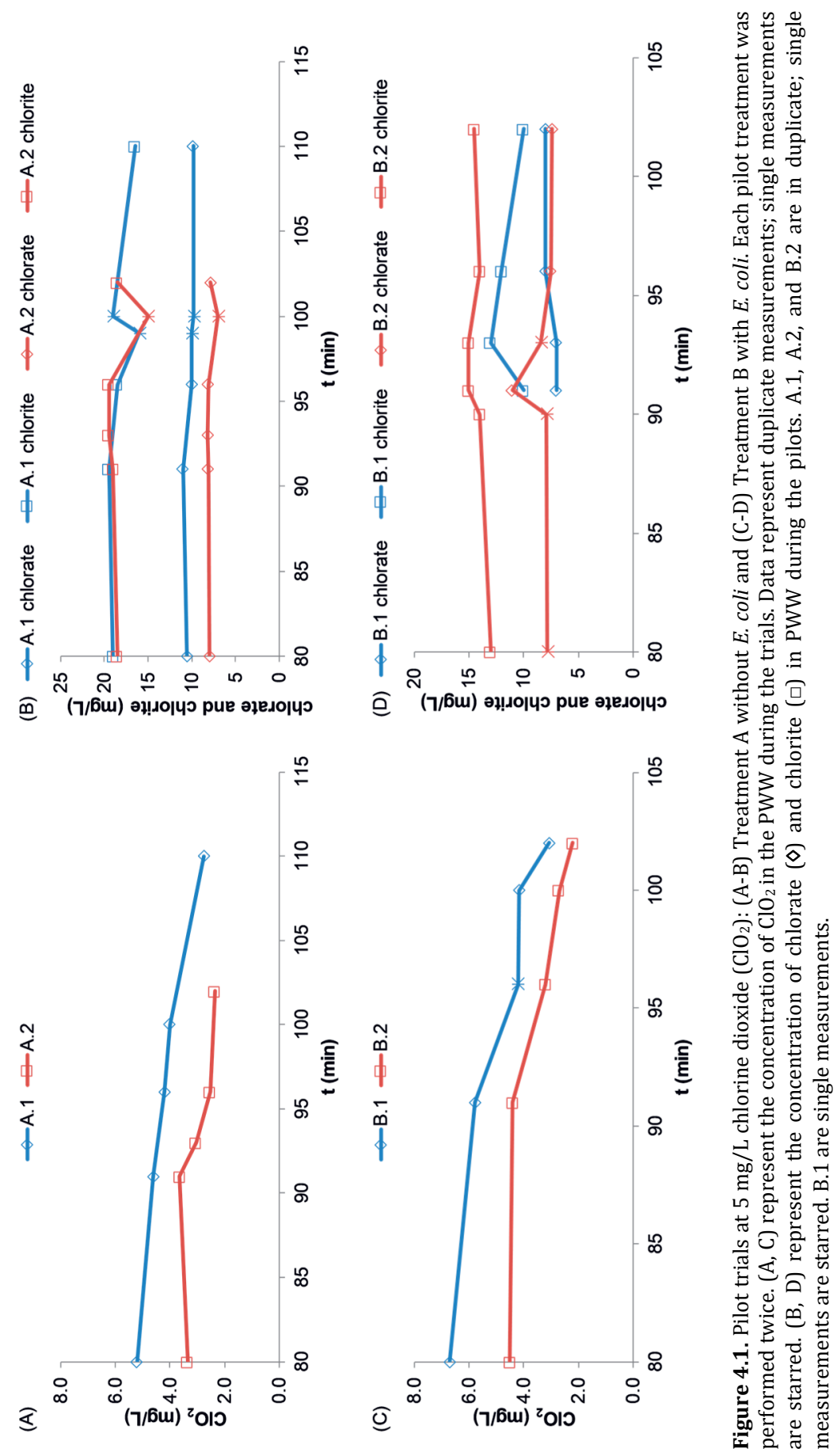




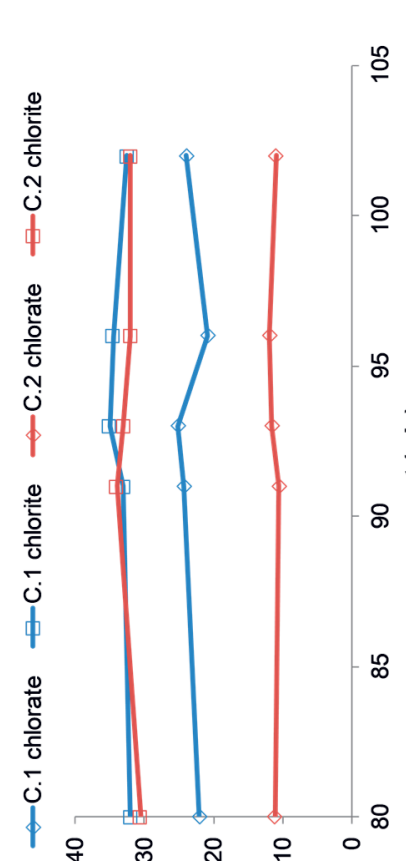

응

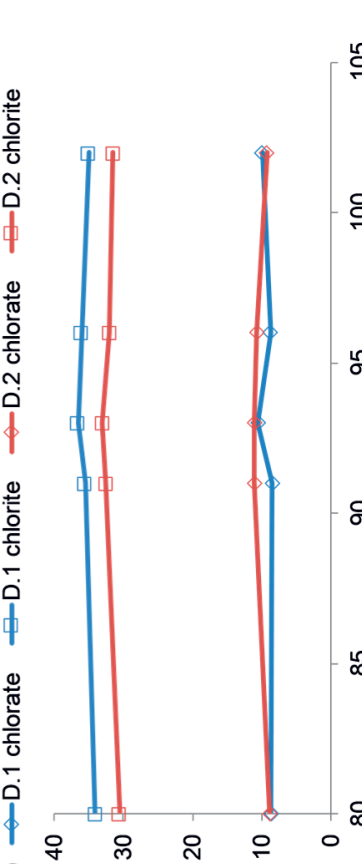

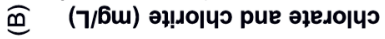

อ (7/6m) 리잉 pue әㄹㅇㅣํ

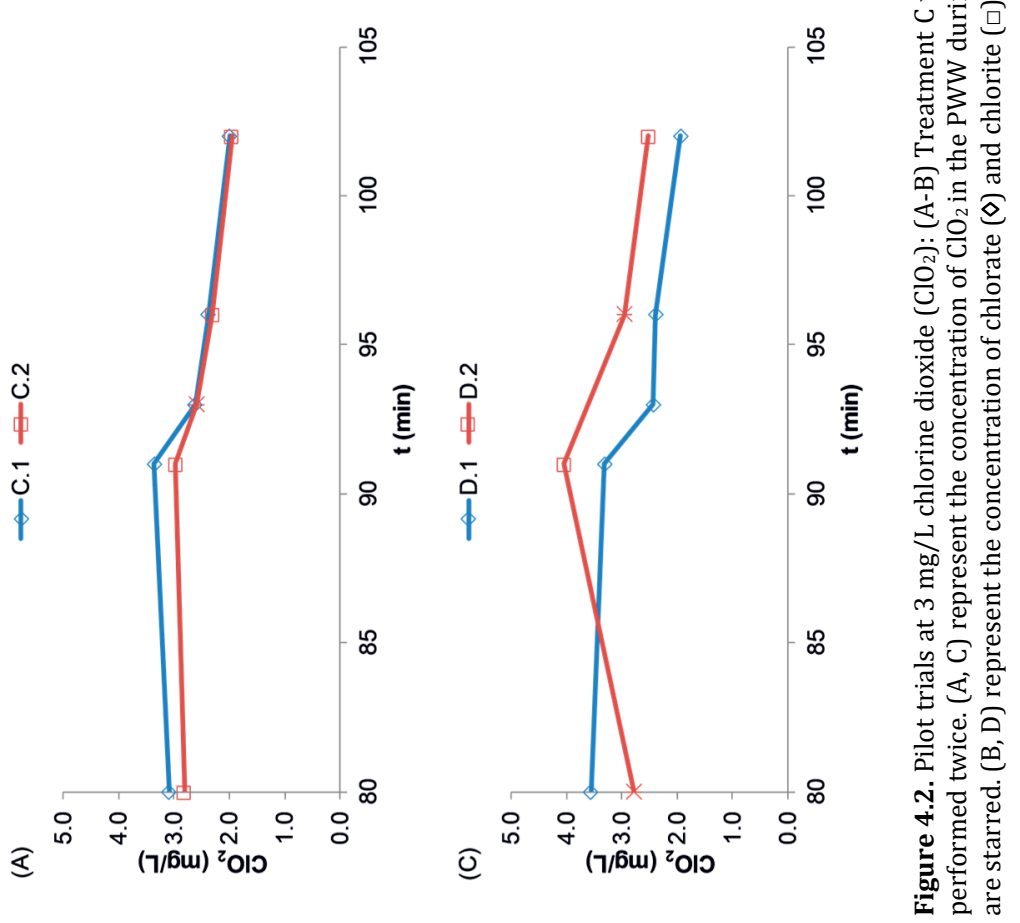


Efficacy of chlorine dioxide

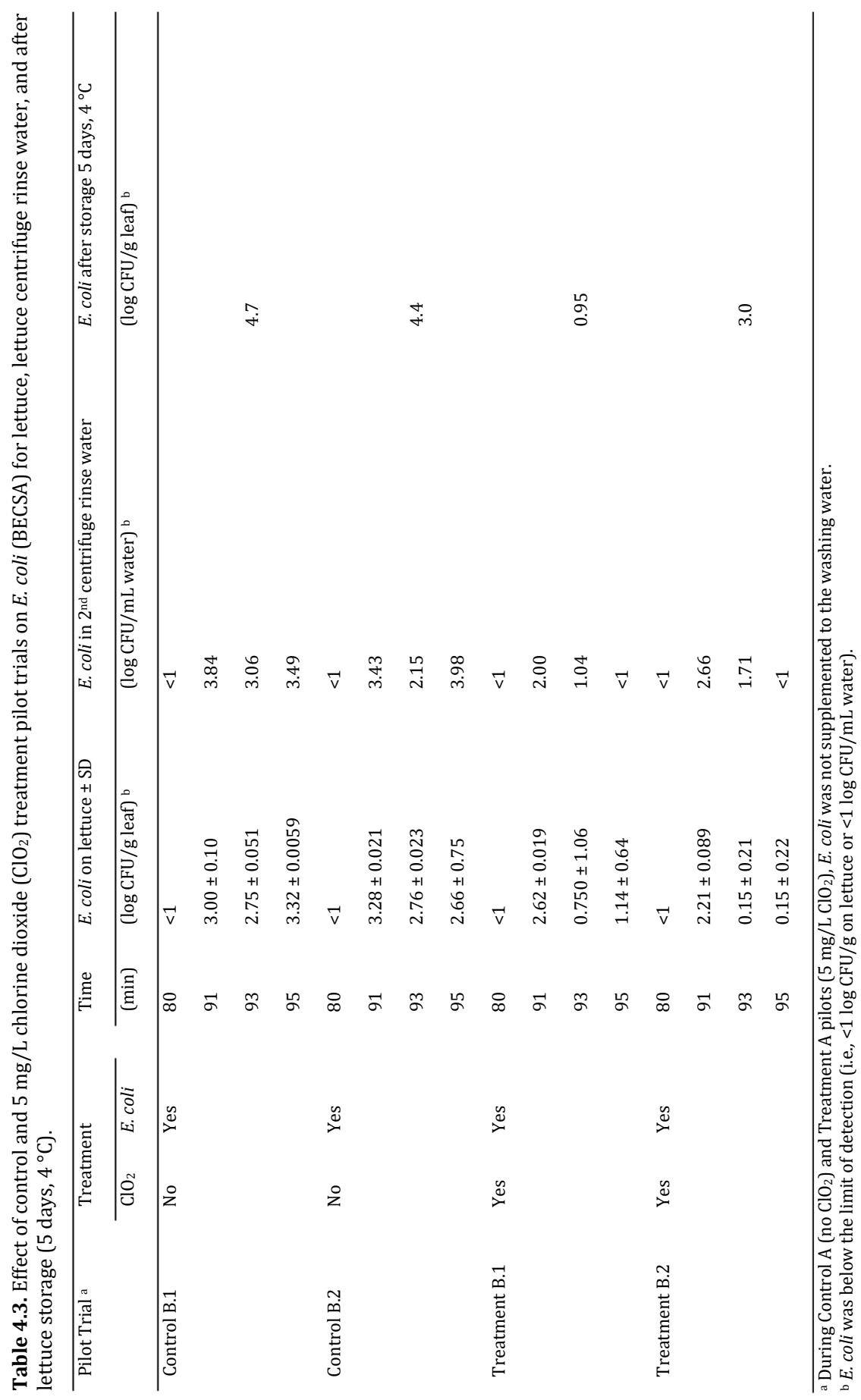




\section{Chapter 4}

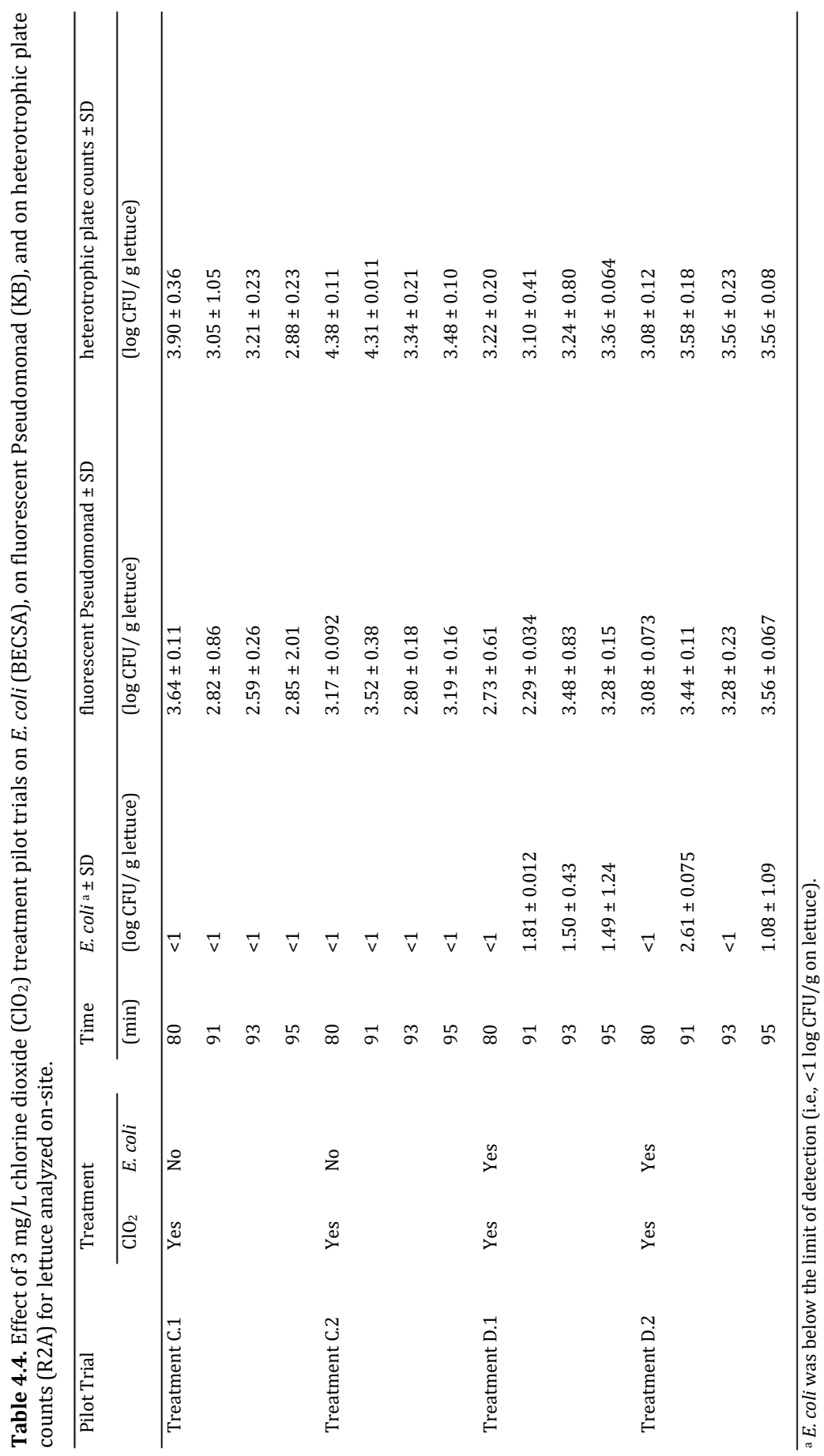




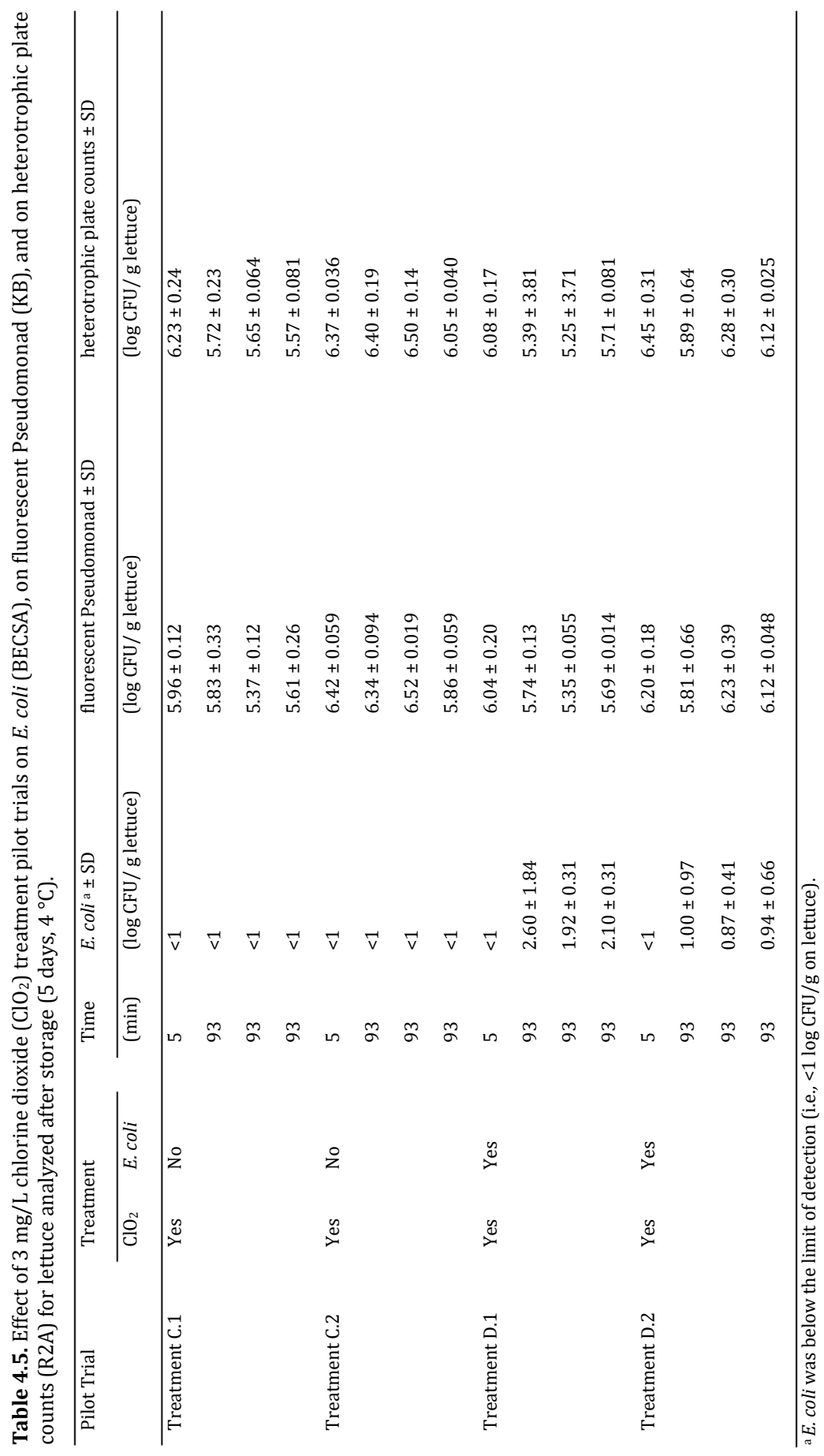




\subsection{Discussion}

This study demonstrates that $\mathrm{ClO}_{2}$ use at the semi-commercial pilot-scale reduced the E. coli peak contamination that entered the PWW, and thus, supports the ability for $\mathrm{ClO}_{2}$ to prevent cross-contamination in the washing tank during fresh-cut 'Lollo Rossa' lettuce processing. Our results concur with a recent publication that investigated the efficiency of $\mathrm{ClO}_{2}$ in standardized process water (i.e., laboratory prepared water). Van Haute, Tryland, Escudero, Vanneste and Sampers (2017) reports that with $5 \mathrm{mg} / \mathrm{L}$ of $\mathrm{ClO}_{2}$, E. coli was reduced more than 5 orders of magnitude after $3 \mathrm{~min}$ (COD $1130 \mathrm{mg}$ $\mathrm{O}_{2} / \mathrm{L}$ ) and with $4 \mathrm{mg} / \mathrm{L}$ of $\mathrm{ClO}_{2}$, E. coli was reduced $>5 \log$ units after 1 min (COD 625 and $734 \mathrm{mg} \mathrm{O}_{2} / \mathrm{L}$ ). The COD of the PWW determined during our pilots was lower than that reported by Van Haute et al. (2017), most presumably due to the residual concentration of $\mathrm{ClO}_{2}$ available throughout processing and water refreshment of the system. Besides this, the general differences in experimental design and equipment used in our study compared to Van Haute et al. (2017) can exhibit other factors that may influence the difference in COD reported. During the pilot treatment trials, interactions between the organic components and $\mathrm{ClO}_{2}$ presumably occurred before the addition of $E$. coli. The residual concentration of $\mathrm{ClO}_{2}$ available during the pilot treatment trials was therefore available to interact with incoming microorganisms and other organic matter in contrast to what was observed during the Control B pilot trials without $\mathrm{ClO}_{2}$.

Our results demonstrate that $\mathrm{ClO}_{2}$ treatments did not prevent $E$. coli attachment to the lettuce; however, the use of $\mathrm{ClO}_{2}$ decreased the probability for cross-contamination between lettuce batches during a point contamination ( $6 \log \mathrm{CFU} / \mathrm{mL}$ ) compared to when no sanitizer was applied. Moreover, the background microbial communities investigated remained on the lettuce, as observed during the $3 \mathrm{mg} / \mathrm{L}$ pilots and after storage ( 5 days, $4{ }^{\circ} \mathrm{C}$ ). Our results concur with Allende et al. (2008), who observed that the extent of $E$. coli cross-contamination was influenced by wash water quality, particularly when fresh-cut escarole was highly contaminated (5.1 log CFU/g). Our results further demonstrated that the application and residual concentration of $\mathrm{ClO}_{2}$ in the wash water could be maintained during fresh(-cut) processing. In brief, the quality of the PWW during processing can be questionable regarding microbiological safety when controls regarding the water quality, such as water disinfection strategies, are not implemented.

Furthermore, our study shows the concentrations of chlorate and chlorite in situ given real-time processing conditions and procedures. According to the World Health Organization (WHO), provisional guidelines for chlorate and chlorite in drinking water are $0.7 \mathrm{mg} / \mathrm{L}$ for each DBP, yet authorities indicate that the use of $\mathrm{ClO}_{2}$ as a disinfectant may result in the value being exceeded, and thus, stress that difficulties in meeting such a guideline value should not constitute compromising adequate disinfection (WHO, 2005). More recently, the European Food Safety Authority (EFSA) has evaluated the presence of chlorate in food; given a hypothetical maximum residue limit (MRL) of 0.7 $\mathrm{mg} / \mathrm{kg}$ for foodstuffs and $0.7 \mathrm{mg} / \mathrm{L}$ for drinking water, both chronic and acute exposures, based on the available occurrence data, would only minimally reduce exposure and associated risks (EFSA, 2015). Until the European Commission (EC) has 
re-evaluated the maximum residue limit (MRL) for chlorate in foods, member states have the authority to dictate national levels. The results from our study can serve to minimize the data gaps concerning the impact of food processing on chlorate and chlorite residues in food. For example, our study demonstrates that the $0.7 \mathrm{mg} / \mathrm{L}$ guideline for both chlorate and chlorite is exceeded in the PWW, but not in the lettuce, when $\mathrm{ClO}_{2}$ was used at 5 and $3 \mathrm{mg} / \mathrm{L}$. Nevertheless, regarding the potential burden on public health, given both a microbiological and toxicological standpoint, $\mathrm{ClO}_{2}$ application in the PWW may be favorable given additional processing parameters like a final rinse step with potable water. For example, the FDA designates that $\mathrm{ClO}_{2}$ treatment of fruits and vegetables shall be followed by either a potable rinse or another preservative method (FDA, 2013). Future research that quantifies the effect that a final rinse step has on public health, e.g., as observed during pilots, is warranted. In our pilot treatment trials with $3 \mathrm{mg} / \mathrm{L} \mathrm{ClO}_{2}$, we quantified the levels of chlorate on the lettuce pre-and post- washing, rinsing, and centrifugation demonstrating that results were below the previous default MRL of $0.01 \mathrm{mg} / \mathrm{kg}$ set by Regulation (EC) 396/2005 (EC, 2005). These results coincide with a previous study that evaluated the commercialscale application of sodium hypochlorite as a PWW sanitizer, demonstrating that chlorate residues on the washed fresh (-cut) lettuce after a 1 min tap water rinse were below LOQ $(0.0024 \mathrm{mg} / \mathrm{L})$ even when chlorate levels in the PWW were as high as 13 mg/L (Gil, Marín, Andujar and Allende, 2016). Future research can investigate the use of multiple wash tanks, including analysis of the DBPs in the PWW of the subsequent washers.

As with any chemical, worker safety and health alongside processing precautions should be considered (Parish, Beuchat, Suslow, Harris, Garrett, Farber and Busta, 2003) as well as the environmental impact, associated costs (Van Haute, Sampers, Jacxsens and Uyttendaele, 2015a), and sustainability of the method. Some restrictions for the use of $\mathrm{ClO}_{2}$ as a PWW sanitizer include the operational costs and maintenance requirements, the operating skills and training needed to apply the technology, and the safety management of the technology at the processing site (on-site formation of hazardous compounds, monitoring ambient concentration levels, etc.) (Van Haute et al., 2015a). Despite these restrictions, other suitable technologies to treat the PWW (e.g., ozone, peracetic acid) exhibit comparable limitations on either technical, managerial, and /or sustainability aspects (Uyttendaele, Jaykus, Amoah, Chiodini, Cunliffe, Jacxsens, Holvoet, Korsten, Lau and McClure, 2015; Van Haute et al., 2015a). Further research and modeling on the efficacy of sanitizers at both the laboratory and pilot scales are warranted to optimize the residual concentrations, among other parameters, in practice. Additionally, research into the use of other sustainable chemical and/or physical methods that meet food safety and quality objectives are warranted. Overall, cross-contamination prevention via the washing water remains a critical step during produce processing, and the application of $\mathrm{ClO}_{2}$ at the industrial scale is attainable with continuous application and monitoring. 


\section{Chapter 4}

\section{Acknowledgments}

This research has been financed by the Dutch Ministry of Economic Affairs (EZ) under the project Microbiology in Horticulture (PPS 296, B0-33.05-001-001) from the Topsector Horticulture and Starting Materials. We gratefully acknowledge C. van Kekem, L.B.J.M. Berendsen, C.H. Lombaers-van der Plas, C. van Tongeren, M.T.J. Helmond (Wageningen University \& Research), and R. Dolmans, G. van Wezel, M. Scheffer, A. van Empel (Ecolab B.V.) for their technical assistance. H.M. Vollebregt (Wageningen University \& Research) is kindly thanked for her contribution to this project, including setting up the pilot trials. M. H. Zwietering (Wageningen University \& Research) is kindly thanked for his suggestions on an earlier version of the paper. The authors acknowledge the contributions from the Dutch fruit and vegetable industry, the Fresh Produce Centre (GFH), and in particular, Hessing B.V. for the pilot plant facilities. 


\section{References}

Allende, A., Selma, M.V., Lopez-Galvez, F., Villaescusa, R., Gil, M.I., 2008. Impact of wash water quality on sensory and microbial quality, including Escherichia coli cross-contamination, of fresh-cut escarole. J. Food Prot. 71, 2514-2518. doi: 10.4315/0362-028x-71.12.2514.

Anastassiades, M., Kolberg, D.I., Mack, D., Wildgrube, C., Sigalov, I., Dörk, D., 2013. Quick method for the analysis of residues of numerous highly polar pesticides in foods of plant origin involving simultaneous extraction with methanol and LC-MS/MS determination (QuPPe-Method) version 7.1. Stuttgart: EU Reference Laboratory for pesticides requiring Single Residue Methods (EURLSRM).

Artés, F., Gómez, P., Aguayo, E., Escalona, V., Artés-Hernández, F., 2009. Sustainable sanitation techniques for keeping quality and safety of fresh-cut plant commodities. Postharvest Biol. Technol. 51, 287-296. doi: 10.1016/j.postharvbio.2008.10.003.

Baert, L., Vandekinderen, I., Devlieghere, F., Van, E.C., Debevere, J., Uyttendaele, M., 2009. Efficacy of sodium hypochlorite and peroxyacetic acid to reduce murine norovirus 1, B40-8, Listeria monocytogenes, and Escherichia coli 0157:H7 on shredded iceberg lettuce and in residual wash water. J. Food Prot. 72, 1047-1054. doi: 10.4315/0362-028x-72.5.1047.

Banach, J.L., Sampers, I., Haute, S.V., van der Fels-Klerx, H.J., 2015. Effect of disinfectants on preventing the cross-contamination of pathogens in fresh produce washing water. Int. J. Environ. Res. Public Health 12, 8658-8677. doi: 10.3390/ijerph120808658.

Banach, J.L., van Bokhorst-van de Veen, H., van Overbeek, L.S., van der Zouwen, P.S., van der Fels-Klerx, H.J., Nierop Groot, M.N., 2017. The efficacy of chemical sanitizers on the reduction of Salmonella Typhimurium and Escherichia coli affected by bacterial cell history and water quality. Food Control 81, 137-146. doi: 10.1016/j.foodcont.2017.05.044.

Callejón, R.M., Rodríguez-Naranjo, M.I., Ubeda, C., Hornedo-Ortega, R., Garcia-Parrilla, M.C., Troncoso, A.M., 2015. Reported foodborne outbreaks due to fresh produce in the United States and European Union: trends and causes. Foodborne Pathog. Dis. 12, 32-38. doi: 10.1089/fpd.2014.1821.

Chardon, J., Swart, A., Evers, E., Franz, E., 2016. Public health relevance of cross-contamination in the freshcut vegetable industry. J. Food Prot. 79, 30-36. doi: 10.4315/0362-028X.JFP-15-272.

Danyluk, M.D., Schaffner, D.W., 2011. Quantitative assessment of the microbial risk of leafy greens from farm to consumption: preliminary framework, data, and risk estimates. J. Food Prot. 74, 700-708. doi: 10.4315/0362-028X.JFP-10-373.

Davidson, G.R., Buchholz, A.L., Ryser, E.T., 2013. Efficacy of commercial produce sanitizers against nontoxigenic Escherichia coli 0157:H7 during processing of iceberg lettuce in a pilot-scale leafy green processing line. J. Food Prot. 76, 1838-1845. doi: 10.4315/0362-028x.Jfp-13-111.

European Commission (EC), 2005. Regulation (EC) No 396/2005 of the European Parliament and of the Council of 23 February 2005 on maximum residue levels of pesticides in or on food and feed of plant and animal origin and amending Council Directive 91/414/EEC in: Official Journal of the European Communities (Ed.), (OJ/ L 70/1).

European Food Safety Authority (EFSA), 2015. Risks for public health related to the presence of chlorate in food. EFSA J. 13, 103. doi: 10.2903/j.efsa.2015.4135.

Gil, M.I., Marín, A., Andujar, S., Allende, A., 2016. Should chlorate residues be of concern in fresh-cut salads? Food Control 60, 416-421. doi: 10.1016/j.foodcont.2015.08.023.

Gil, M.I., Selma, M.V., López-Gálvez, F., Allende, A., 2009. Fresh-cut product sanitation and wash water disinfection: problems and solutions. Int. J. Food Microbiol. 134, 37-45. doi: 10.1016/j.ijfoodmicro.2009.05.021.

Gil, M.I., Selma, M.V., Suslow, T., Jacxsens, L., Uyttendaele, M., Allende, A., 2015. Pre- and postharvest preventive measures and intervention strategies to control microbial food safety hazards of fresh leafy vegetables. Crit. Rev. Food Sci. Nutr. 55, 453-468. doi: 10.1080/10408398.2012.657808.

Gómez-López, V.M., 2012. Chlorine dioxide, in: Gómez-López, V.M. (Ed.), Decontamination of fresh and minimally processed produce, 1st ed. Wiley-Blackwell, Oxford, UK, pp. 165-175.

Holvoet, K., Jacxsens, L., Sampers, I., Uyttendaele, M., 2012. Insight into the prevalence and distribution of microbial contamination to evaluate water management in the fresh produce processing industry. J. Food Prot. 75, 671-681. doi: 10.4315/0362-028x.Jfp-11-175.

Jensen, D.A., Friedrich, L.M., Harris, L.J., Danyluk, M.D., Schaffner, D.W., 2015. Cross contamination of Escherichia coli 0157:H7 between lettuce and wash water during home-scale washing. Food Microbiol. 46, 428-433. doi: 10.1016/j.fm.2014.08.025. 


\section{Chapter 4}

Joshi, K., Mahendran, R., Alagusundaram, K., Norton, T., Tiwari, B.K., 2013. Novel disinfectants for fresh produce. Trends Food Sci. Technol. 34, 54-61. doi: 10.1016/j.tifs.2013.08.008.

Kirezieva, K., Nanyunja, J., Jacxsens, L., van der Vorst, J.G.A.J., Uyttendaele, M., Luning, P.A., 2013. Context factors affecting design and operation of food safety management systems in the fresh produce chain. Trends Food Sci. Technol. 32, 108-127. doi: 10.1016/j.tifs.2013.06.001.

López-Gálvez, F., Allende, A., Selma, M.V., Gil, M.I., 2009. Prevention of Escherichia coli cross-contamination by different commercial sanitizers during washing of fresh-cut lettuce. Int. J. Food Microbiol. 133, 167171. doi: 10.1016/j.ijfoodmicro.2009.05.017.

López-Gálvez, F., Allende, A., Truchado, P., Martínez-Sánchez, A., Tudela, J.A., Selma, M.V., Gil, M.I., 2010. Suitability of aqueous chlorine dioxide versus sodium hypochlorite as an effective sanitizer for preserving quality of fresh-cut lettuce while avoiding by-product formation. Postharvest Biol. Technol. 55, 53-60. doi: 10.1016/j.postharvbio.2009.08.001.

López-Gálvez, F., Gil, M.I., Truchado, P., Selma, M.V., Allende, A., 2010. Cross-contamination of fresh-cut lettuce after a short-term exposure during pre-washing cannot be controlled after subsequent washing with chlorine dioxide or sodium hypochlorite. Food Microbiol. 27, 199-204. doi: 10.1016/J.Fm.2009.09.009.

Luo, Y., Ingram, D.T., Khurana, K., 2014. Preventing cross-contamination during produce wash operations, in: Hoorfar, J. (Ed.), Global safety of fresh produce: a handbook of best-practice examples, innovative commercial solutions and case studies. Woodhead Publishing, Oxford, UK, pp. 103-111.

Parish, M.E., Beuchat, L.R., Suslow, T.V., Harris, L.J., Garrett, E.H., Farber, J.N., Busta, F.F., 2003. Methods to reduce/eliminate pathogens from fresh and fresh-cut produce. Compr. Rev. Food Sci. Food Saf. 2, 161-173. doi: 10.1111/j.1541-4337.2003.tb00033.x.

U.S. Food and Drug Administration (FDA), 2009. Draft guidance for industry: guide to minimize microbial food safety hazards of leafy greens, in: U.S. Department of Health and Human Services, Food and Drug Administration, Center for Food Safety and Applied Nutrition (Eds.). U.S. Food and Drug Administration.

U.S. Food and Drug Administration (FDA), 2013. Code of Federal Regulations. Sec. 173.300 chlorine dioxide. Uyttendaele, M., Jaykus, L.A., Amoah, P., Chiodini, A., Cunliffe, D., Jacxsens, L., Holvoet, K., Korsten, L., Lau, M., McClure, P., 2015. Microbial hazards in irrigation water: standards, norms, and testing to manage use of water in fresh produce primary production. Compr. Rev. Food Sci. Food Saf. 14, 336-356. doi: 10.1111/1541-4337.12133.

Van Haute, S., Sampers, I., Holvoet, K., Uyttendaele, M., 2013. Physicochemical quality and chemical safety of chlorine as a reconditioning agent and wash water disinfectant for fresh-cut lettuce washing. Appl. Environ. Microbiol. 79, 2850-2861. doi: 10.1128/AEM.03283-12.

Van Haute, S., Sampers, I., Jacxsens, L., Uyttendaele, M., 2015a. Selection criteria for water disinfection techniques in agricultural practices. Crit. Rev. Food Sci. Nutr. 55, 1529-1551. doi: 10.1080/10408398.2012.705360.

Van Haute, S., Tryland, I., Escudero, C., Vanneste, M., Sampers, I., 2017. Chlorine dioxide as water disinfectant during fresh-cut iceberg lettuce washing: disinfectant demand, disinfection efficiency, and chlorite formation. LWT Food Sci. Technol. 75, 301-304. doi: 10.1016/j.lwt.2016.09.002.

Van Haute, S., Tryland, I., Veys, A., Sampers, I., 2015b. Wash water disinfection of a full-scale leafy vegetables washing process with hydrogen peroxide and the use of a commercial metal ion mixture to improve disinfection efficiency. Food Control 50, 173-183. doi: 10.1016/j.foodcont.2014.08.028.

World Health Organization (WHO), 2005. Chlorite and chlorate in drinking-water.

Zhao, T., Zhao, P., Doyle, M.P., 2009. Inactivation of Salmonella and Escherichia coli 0157:H7 on lettuce and poultry skin by combinations of levulinic acid and sodium dodecyl sulfate. J. Food Prot. 72, 928936. doi: 10.4315/0362-028X-72.5.928. 


\section{Supplementary materials}
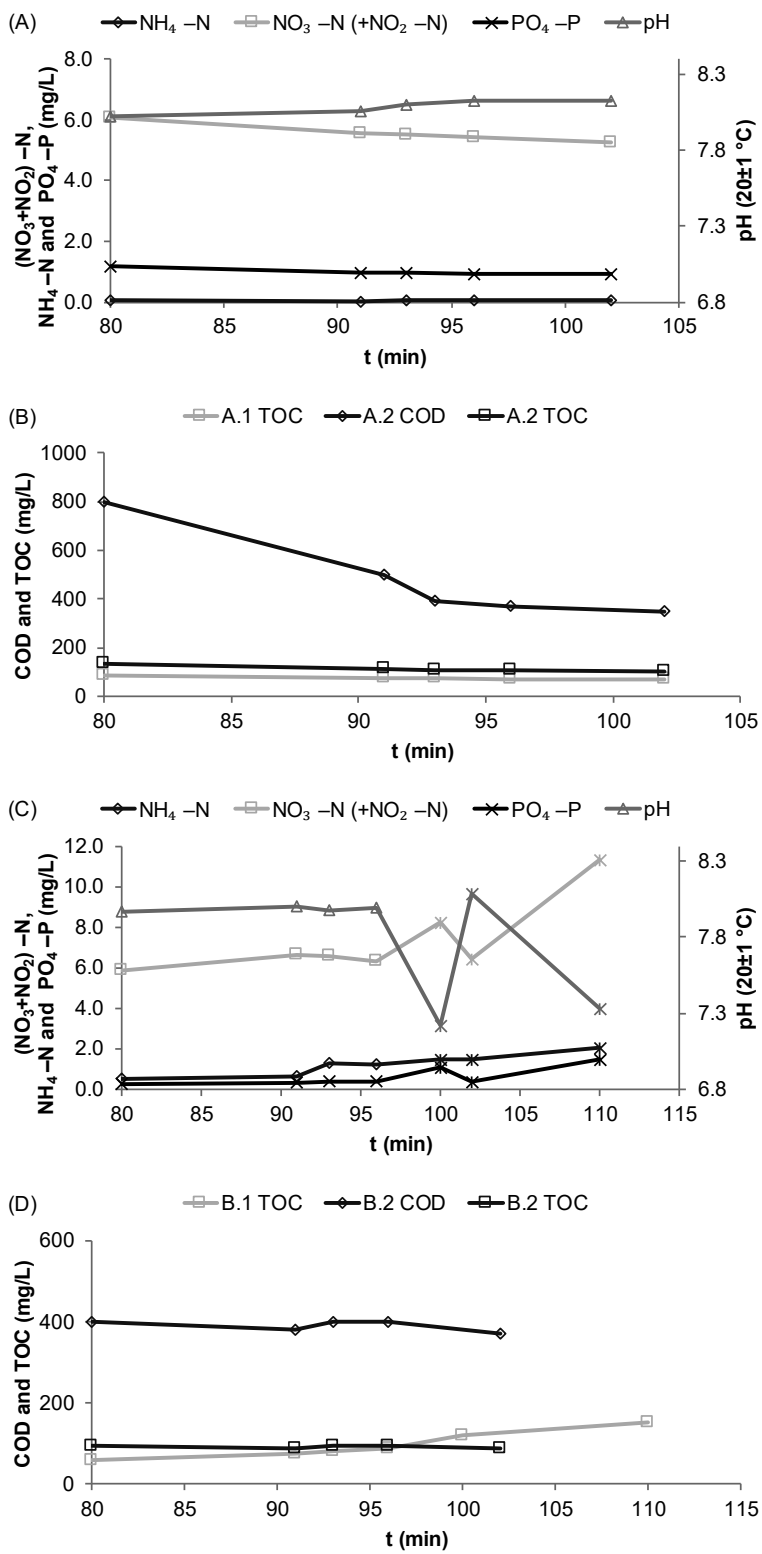

Figure S4.1. Pilot trials without chlorine dioxide $\left(\mathrm{ClO}_{2}\right)$ : (A, B) Control A without E. coli and (C, D) Control B with E. coli. Each pilot control was performed twice. (A, C) represent the averaged values of each control for ammonium-N $\left(\mathrm{NH}_{4}-\mathrm{N}\right)$, nitrate-N $\left(\left(\mathrm{NO}_{3}+\mathrm{NO}_{2}\right)-\mathrm{N}\right)$, phosphate-P $\left(\mathrm{PO}_{4}-\mathrm{P}\right)$, and $\mathrm{pH}$ during the trials; single measurements are starred. (B, D) represent the chemical oxygen demand, COD ( $\diamond)$, and total organic carbon, TOC ( $\square$ ), of the process wash water (PWW) during the trials. The COD of A.1 and B.1 were not available. These data represent single measurements. 

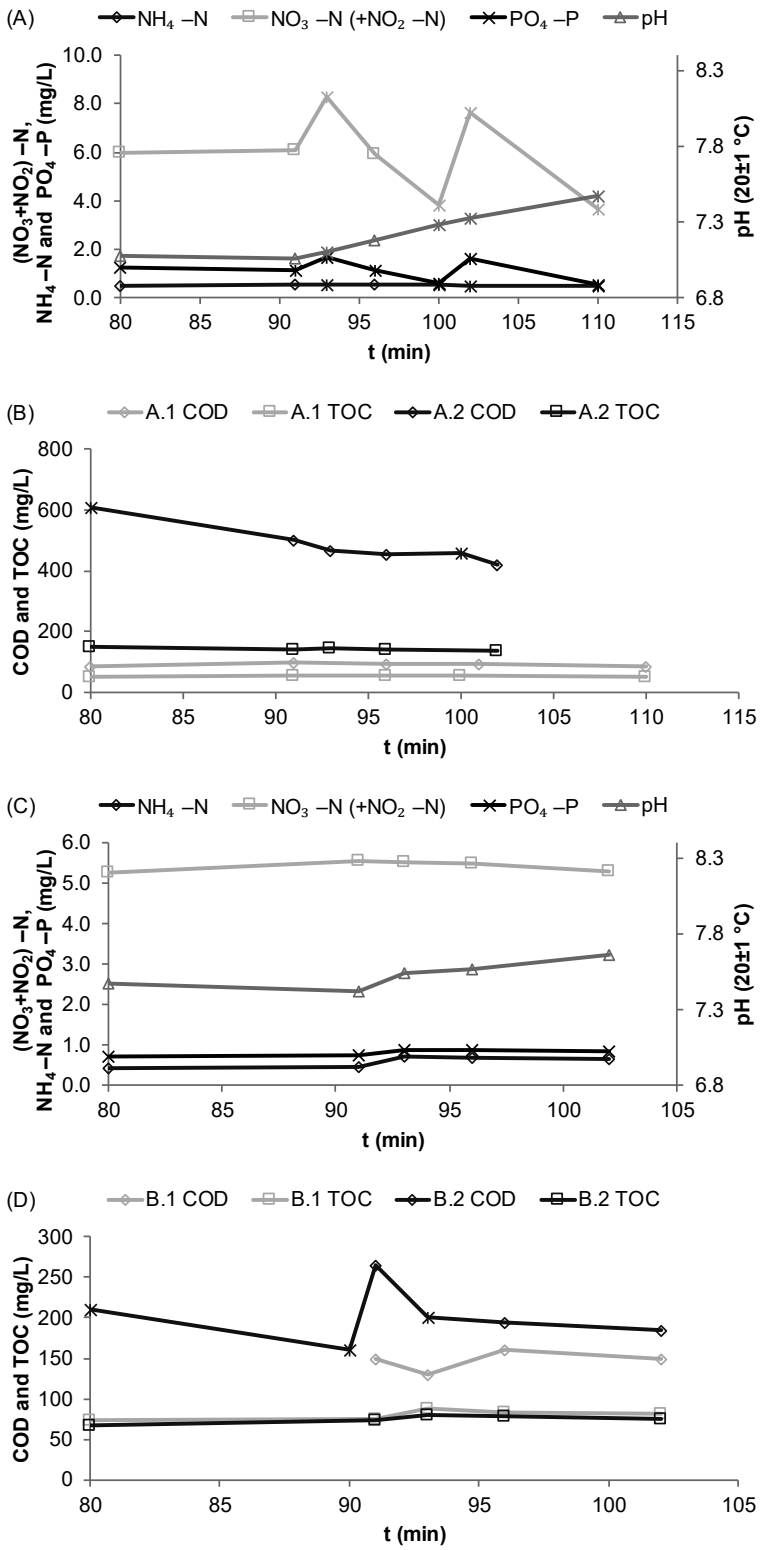

Figure S4.2. Pilot trials at $5 \mathrm{mg} / \mathrm{L}$ chlorine dioxide $\left(\mathrm{ClO}_{2}\right)$ : (A-B) Treatment A without E. coli and (C-D) Treatment B with E. coli. Each pilot treatment was performed twice. (A, C) represent the averaged values of each treatment for ammonium-N $\left(\mathrm{NH}_{4}-\mathrm{N}\right)$, nitrate- $\mathrm{N}\left(\left(\mathrm{NO}_{3}+\mathrm{NO}_{2}\right)-\mathrm{N}\right)$, phosphate-P $\left(\mathrm{PO}_{4}-\mathrm{P}\right)$, and $\mathrm{pH}$ during the trials; single measurements are starred. (B, D) represent the chemical oxygen demand, COD ( $\square$ ), and total organic carbon, TOC (口), of the process wash water (PWW) during the trials. A.1 COD, B.1 COD, and TOC are single measurements. A.2 COD and B.2 COD are in duplicate; single measurements are starred. 

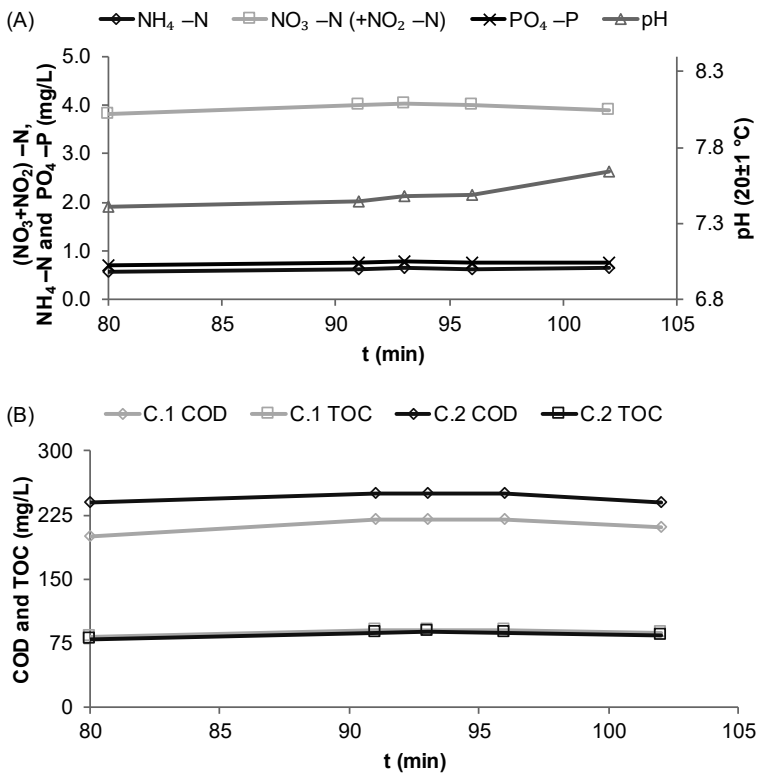

(C) $\longrightarrow \mathrm{NH}_{4}-\mathrm{N} \simeq \mathrm{NO}_{3}-\mathrm{N}\left(+\mathrm{NO}_{2}-\mathrm{N}\right) \multimap \mathrm{PO}_{4}-\mathrm{P} \rightleftharpoons \mathrm{pH}$

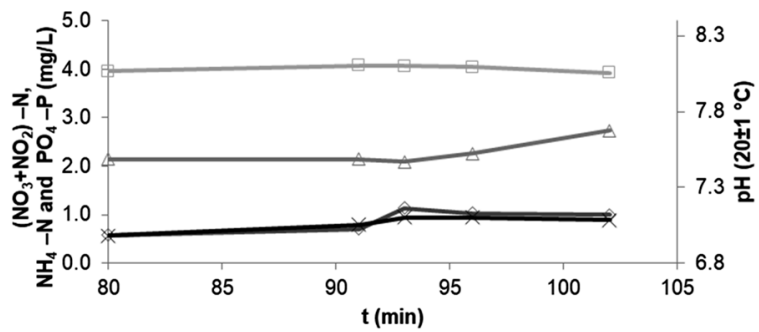

(D) $\multimap \mathrm{D} .1 \mathrm{COD} \neg \mathrm{D} .1 \mathrm{TOC} \rightleftharpoons \mathrm{D} .2 \mathrm{COD} \multimap \mathrm{D} .2 \mathrm{TOC}$

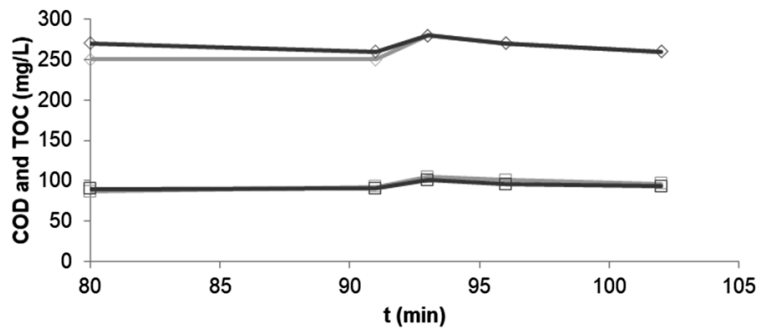

Figure S4.3. Pilot trials at $3 \mathrm{mg} / \mathrm{L}$ chlorine dioxide $\left(\mathrm{ClO}_{2}\right)$ : (A-B) Treatment $\mathrm{C}$ without E. coli and (C-D) Treatment D with $E$. coli. Each pilot treatment was performed twice. (A, C) represent the averaged values of each treatment for ammonium-N $\left(\mathrm{NH}_{4}-\mathrm{N}\right)$, nitrate- $\mathrm{N}\left(\left(\mathrm{NO}_{3}+\mathrm{NO}_{2}\right)-\mathrm{N}\right)$, phosphate-P $\left(\mathrm{PO}_{4}-\mathrm{P}\right)$, and $\mathrm{pH}$ during the trials. (B, D) represent the chemical oxygen demand, COD $(\diamond)$, and total organic carbon, TOC ( $\square$ ), of the process wash water (PWW) during the trials; data represent single measurements. 



\title{
Chapter 5
}

\section{Effectiveness of a peracetic acid solution on Escherichia coli reduction during fresh-cut lettuce processing at the laboratory and industrial scales}

\author{
J.L. Banach \\ H. van Bokhorst-van de Veen
}

L.S. van Overbeek

P.S. van der Zouwen

M.H. Zwietering

H.J. van der Fels-Klerx

Published in: International Journal of Food Microbiology (2020), 321, 108537.

doi: 10.1016/j.ijfoodmicro.2020.108537 


\begin{abstract}
Fresh leafy greens like lettuce can be consumed raw and are susceptible to foodborne pathogens if they become contaminated. Recently, the number of reported pathogenic foodborne outbreaks related to leafy greens has increased. Therefore, it is important to try to alleviate the human health burden associated with these outbreaks. Processing of fresh-cut lettuce, including washing, is a step in the supply chain that needs to be well controlled to avoid cross-contamination. Current measures to control the quality of lettuce during washing includes the use of chemicals like chlorine; however, questions regarding the safety of chlorine have prompted research for alternative solutions with peracetic acid (PAA). This study evaluates the effectiveness of a PAA (c.a. $75 \mathrm{mg} / \mathrm{L}$ ) solution on the reduction of a commensal E. coli strain during the washing of fresh-cut lettuce. Experiments were performed at the laboratory scale and validated at the industrial scale. We observed that the use of PAA was not adversely affected by the organic load in the water. The contact time and dose of the PAA showed to be relevant factors, as observed by the approximately 5-log reduction of $E$. coli in the water. Results showed that once introduced during washing, E. coli remained attached to the lettuce, thus supporting the need to control for pathogenic bacteria earlier in the supply chain (e.g., during primary production) as well as during washing. Moreover, our results showed that the use of PAA during washing did not have an apparent effect on the levels of fluorescent pseudomonads (FP) and total heterotrophic bacteria (THB) in lettuce. Overall, our results at the laboratory and industrial-scales confirmed that during the processing of fresh-cut produce, where the accumulation of soil, debris, and other plant exudates can negatively affect washing, the use of a PAA (c.a. $75 \mathrm{mg} / \mathrm{L}$ ) solution was an effective and safe wash water disinfectant that can potentially be used at the industrialscale.
\end{abstract}

\title{
Keywords
}

Cross-contamination; Water; Disinfection; Food industry; Vegetables 


\subsection{Introduction}

Fresh leafy greens like lettuce can be consumed raw and are susceptible to foodborne pathogens if they become contaminated. Several outbreaks of Escherichia coli 0157:H7 related to leafy greens have been reported recently in the United States (Centers for Disease Control and Prevention (CDC) 2018a, b, c). Therefore, it is important to try to alleviate the human health burden associated with these outbreaks. During fresh-cut vegetable processing, the cutting and washing steps can encourage the opportunity for (pathogenic) cross-contamination. Therefore, these steps are critical to control in order to ensure food safety and quality during processing. Since washing can bring the possibility for pathogen survival and cross-contamination, additional measures to control the water quality, such as disinfecting the wash water, would then be needed.

One commonly applied disinfectant used during fresh(-cut) vegetable processing is chlorine. There is an ongoing discussion surrounding the use of chlorine, given the potentially harmful by-products that may form (e.g., trihalomethanes and haloacetic acids) and its effect on public health. This discussion has prompted research for alternative wash water disinfectants to chlorine (Allende, Selma, López-Gálvez, Villaescusa and Gil, 2008; Banach, Sampers, Van Haute and van der Fels-Klerx, 2015; Fatica and Schneider, 2009; Meireles, Giaouris and Simoes, 2016; Ölmez and Kretzschmar, 2009) such as peracetic acid (PAA) which has a similar effectivity and is less controversial in terms of its effect on public health. In comparison to other chemical disinfectants, PAA is an oxidizing agent that can dissolve in water to hydrogen peroxide and acetic acid, which can further break down into water, oxygen, and carbon dioxide. By-products of PAA are non-toxic, while only negligible or low levels of aldehydes (Banach et al., 2015; Van Haute, Sampers, Jacxsens and Uyttendaele, 2015) and modest levels of carboxylic acids have been reported to form (Dominguez Henao, Turolla and Antonelli, 2018). PAA disinfection has been attributed to the denaturation of proteins and enzymes and increased cell wall permeability due to the disruption of sulfhydryl (SH) and sulfur (S-S) bonds (McDonnell and Russell, 1999; Muñío and Poyatos, 2011). In brief, PAA is an alternative water disinfectant to consider for use during food processing.

PAA disinfection in other domains, like that for wastewater treatment, has been studied and reported in the scientific literature. The attributes of PAA such as its ease of implementation also considering costs, broad-spectrum of activity given organic matter presence, short contact time, limited dependence on $\mathrm{pH}$, and absence of toxic or mutagenic residual by-products, making it advantageous to use for wastewater disinfection (Fatica and Schneider, 2009; Kitis, 2004). Nonetheless, the application of PAA to improve the microbial quality of water effluent needs further research to ascertain its efficacy (Bonetta, Pignata, Lorenzi, De Ceglia, Meucci, Bonetta, Gilli and Carraro, 2017). Similarly, additional research is needed in the food (safety) domain. The use of PAA for treating water has been suggested for agricultural practices (Van Haute et al., 2015). Research has shown the effect of PAA on foodborne pathogens like E. coli 0157:H7 in the residual water after lettuce processing, demonstrating that PAA may help prevent cross-contamination (Baert, Vandekinderen, Devlieghere, Van Coillie, 
Debevere and Uyttendaele, 2009). However, experiments at the laboratory scale and validation of industrial-scale processing of (fresh-cut) produce are needed (Banach et al., 2015).

The objective of this study is to evaluate the effectiveness of PAA to disinfect the water used during the washing of fresh-cut lettuce at the laboratory and industrial scales. We compared the results of the treated water, namely the effect of a PAA solution on the reduction of $E$. coli in the water, by evaluating the physicochemical and microbial quality of the water and the microbial quality of the fresh-cut lettuce.

\subsection{Materials and methods}

This study was conducted at both laboratory and industrial scales. Experiments used the same bacterial strain (section 5.2.1), PAA solution (section 5.2.2), and statistical analyses (section 5.2.5); preparation differences are specified. The experimental design, subsequent materials and processing, and analyses are described for laboratory (section 5.2.3) and industrial-scale experiments (section 5.2.4).

\subsubsection{Bacterial strain and inoculum preparation}

A commensal E. coli strain (meaning without any selectable makers like extendedspectrum beta-lactamase (ESBL)) isolated from surface water, previously reported as 12-123.2 (Banach, van Overbeek, Nierop Groot, van der Zouwen and van der Fels-Klerx, 2018), had been stored at $-80^{\circ} \mathrm{C}$ in Luria Broth (LB; L1704 LB Broth High Salt, Duchefa Biochemie B.V., Haarlem, the Netherlands), supplemented with 25\% (v/v) glycerol, before use. The strain was streaked on Brilliance E. coli coliform selective agar (BECSA; CM1046, Oxoid Ltd., part of Thermo Fisher Scientific, Basingstoke, United Kingdom). Cultures were prepared by transferring a single colony from a BECSA plate to $25 \mathrm{~mL} \mathrm{LB}$ followed by incubation at $37{ }^{\circ} \mathrm{C}$ in a $200 \mathrm{rpm}$ shaking incubator until either the exponential phase (4-8 h) or the stationary phase (16-18 h), respectively, for laboratory and industrial-scale experiments.

For laboratory experiments, the cells were transferred into sterile Eppendorf tubes (1.5 $\mathrm{mL}$ volume) with $1 \mathrm{~mL}$ LB media and centrifuged at 9,391 $\times g$ (Eppendorf Microcentrifuge 5415, VWR International B.V., Amsterdam, the Netherlands) for 1 min at room temperature. After centrifugation and decanting, the cells were resuspended in sterile Ringer's solution (BR0052; Oxoid Ltd., part of Thermo Fisher Scientific, Breda, the Netherlands). Centrifugation, decanting, and resuspension in Ringer's solution proceeded twice more; however, before the final resuspension, cells were measured at an optical density of $600 \mathrm{~nm}\left(\mathrm{OD}_{600}\right.$; Ultrospec 10 Cell Density Meter, Amersham Biosciences) and then were diluted with sterile Ringer's solution to an $\mathrm{OD}_{600}$ of 0.1 (given a start suspension of about $10^{9} \mathrm{CFU} / \mathrm{mL}$ ).

For industrial-scale experiments, cells were not washed as described above for the laboratory experiments; instead, they were further prepared as described by Banach et al. (2018), of which about $4.5 \mathrm{~L}$ of the liquid cultures (c.a. $10^{9} \mathrm{CFU} / \mathrm{mL}$ ) was added to the wash tank $\left(3.5 \mathrm{~m}^{3}\right)$, resulting in a final concentration of about $10^{6} \mathrm{CFU} / \mathrm{mL}$. 


\subsubsection{Peracetic acid solution}

A commercial solution with a concentration of $15.2 \%$ PAA and $17.1 \%$ hydrogen peroxide $\left(\mathrm{H}_{2} \mathrm{O}_{2}\right)$ was used (Tsunami 100, Ecolab B.V., Nieuwegein, the Netherlands). The following procedure was used to obtain the desired concentrations. A two-step iodometric titration procedure, based on Greenspan and MacKellar (1948) and Sully and Williams (1962), was used to determine PAA and $\mathrm{H}_{2} \mathrm{O}_{2}$ concentrations. First, $\mathrm{H}_{2} \mathrm{O}_{2}$ was consumed from the addition of potassium permanganate solutions, and then, PAA was titrated with iodide/thiosulfate. Here, $25 \mathrm{~mL}$ of $25 \%$ sulfuric acid (diluted from $98 \%$ sulfuric acid, $\mathrm{k} 47573680$, Merck) was added to a $50 \mathrm{~mL}$ sample mixed with $50 \mathrm{~mL}$ tap water at $20-25^{\circ} \mathrm{C}$. The solution was then mixed and titrated with $0.1 \mathrm{~N}$ potassium permanganate (Fixanal, 38136-1EA, Fluka) until a stable, faint pink color appeared. The amount $(\mathrm{mL})$ of consumed potassium permanganate was multiplied by 17 to calculate the concentration of $\mathrm{H}_{2} \mathrm{O}_{2}(\mathrm{ppm})$ of the solution. Then, 1-2 $\mathrm{g}$ of potassium iodide (6227.1000, J.T. Baker A.C.S.) was added and mixed, followed by $20 \mathrm{~mL}$ of $25 \%$ sulfuric acid (diluted from 98\% sulfuric acid, k47573680, Merck). The solution was then titrated with a $0.1 \mathrm{~N}$ sodium thiosulfate solution (Titrisol, 1.09961.0001, Merck) using a starch indicator ( 3 drops of a 1\% solution, Zulkowsky, 1.01257.0250, Merck) to show the end of the titration. The amount $(\mathrm{mL})$ of consumed potassium permanganate was multiplied by 34 to calculate the available PAA concentration (ppm) of the solution. For laboratory experiments, concentrations of 0, 20, 40, 60, and $80 \mathrm{mg} / \mathrm{L}$ PAA were used.

For industrial-scale experiments, the target concentration was about $75 \mathrm{mg} / \mathrm{L}$ of PAA and was continuously supplied to the washing tank throughout processing up until the input of the lettuce stopped (i.e., after 90 min of processing). The PAA and $\mathrm{H}_{2} \mathrm{O}_{2}$ concentrations were determined, as indicated above, and manually adjusted during the first 90 min of processing to obtain the target concentration (ELADOS® EMP II, E10 or 60 Diaphragm Metering Pump, Ecolab B.V., Nieuwegein, the Netherlands). PAA and $\mathrm{H}_{2} \mathrm{O}_{2}$ measurements during processing were performed about every $20 \mathrm{~min}$ and repeated for verification as required.

\subsubsection{Laboratory experiments}

Laboratory experiments evaluated the effectiveness of the PAA solution in laboratorymade washing water and on 'Batavia' lettuce washed with laboratory-made washing water. PAA was tested with and without the addition of E. coli. Experiments with tap water and non-supplemented E. coli served as controls. Water and lettuce were quantitatively examined for the presence of E. coli.

\subsubsection{Laboratory-made wash water}

Laboratory wash water was made from whole endive, which was purchased from a local supermarket (Wageningen, the Netherlands) and transported within 15 min to the laboratory. The endive was used to make the wash water as previous analyses of endive washing waters had shown the highest concentrations of total organic carbon (TOC) (data not shown). The outer leaves of the endive were manually removed and discarded, while the internal leaves were cut by hand and washed with $2 \mathrm{~L}$ of potable (tap) water. Cutting and washing were repeated twice with the same endive, each time 
using the same wash water. The endive was cut into $1 \mathrm{~cm}$ pieces and then into about 0.5 $\mathrm{cm}$ pieces. After aliquoting, the wash water was stored at $-20^{\circ} \mathrm{C}$ until further use during experiments.

\subsubsection{Experiments with laboratory-made wash water}

The laboratory-made wash water was defrosted and then diluted with cold tap water to obtain TOC concentrations of about $500 \mathrm{mg} / \mathrm{L}$ and $750 \mathrm{mg} / \mathrm{L}$, reflecting high and very high organically loaded waters, respectively. The TOC was determined before experiments with PAA at 0,20 , and $40 \mathrm{mg} / \mathrm{L}$ (Shimadzu 5050A). These PAA concentrations were chosen to evaluate the effect of lowered PAA concentrations on $E$. coli.

The efficacy of the PAA solution at 0,20 , and $40 \mathrm{mg} / \mathrm{L}$ on E. coli (initially about $5^{*} 10^{6}$ $\mathrm{CFU} / \mathrm{mL}$ ) in tap water, and laboratory-made wash water with TOCs of 500 and 750 $\mathrm{mg} / \mathrm{L}$ were used. During these experiments, the $E$. coli culture was periodically swirled and maintained at a temperature of about $4-5^{\circ} \mathrm{C}$ to reflect industrial conditions. The $\mathrm{pH}$ was measured before and after the experiments. The PAA and $\mathrm{H}_{2} \mathrm{O}_{2}$ concentrations of the stocks were measured using iodometric titration, as previously described. The PAA solution was freshly prepared before each experiment. At regular time intervals, $1 \mathrm{~mL}$ samples were taken and serially diluted into a peptone physiological salt solution (PPS; Tritium Microbiologie B.V., Eindhoven, the Netherlands); neutralizing agents were not applied. After 1, 3, and $5 \mathrm{~min}$ of treatment with the PAA solution, $100 \mu \mathrm{L}$ of the appropriate dilutions were plated on BECSA and incubated at $37^{\circ} \mathrm{C}$ for $2 \mathrm{~d}$ (i.e., until no additional colonies appeared). The number of culturable cells was determined at 0,1 , 3 , and 5 min to compare the efficacy over time. Also, a control with no disinfectant was included and determined at 0 and $12 \mathrm{~min}$.

\subsubsection{Lettuce}

Batavia lettuce (Lactuca sativa L. var. capitata) was purchased from a local farm (De Hoge Born, Wageningen, the Netherlands). All lettuce was stored at $4{ }^{\circ} \mathrm{C}$ and used within $14 \mathrm{~d}$ of delivery. Circular punches of the lettuce were made (c.a. $1.5 \mathrm{~g}$ ) and pre-treated as described by Banach, van Bokhorst-van de Veen, van Overbeek, van der Zouwen, van der Fels-Klerx and Nierop Groot (2017) with slight variations as follows. Lettuce leaf punches $(\mathrm{n}=2)$ were placed into each Petri dish and inoculated by pipetting $10 \mu \mathrm{L}$ of a $100 x$ diluted $E$. coli starting suspension (which was c.a. $10^{5.9} \mathrm{CFU} / \mathrm{mL}$ ). After $1 \mathrm{~h}$ incubation at room temperature, $E$. coli liquid drops were removed with sterile filter paper.

\subsubsection{Experiments with lettuce}

The lettuce leaf punches were cut and exposed to E. coli as previously described. The laboratory-made wash water was defrosted and then diluted with cold tap water to obtain TOC concentrations of about $500 \mathrm{mg} / \mathrm{L}$ and $750 \mathrm{mg} / \mathrm{L}$. TOCs were verified directly before experiments with PAA at 0, 60, and $80 \mathrm{mg} / \mathrm{L}$ (Skalar SFA, model SAN++ in accordance with NEN-EN 1484). These PAA concentrations were chosen to correlate with the industrial-scale experiments. 
Lettuce leaf punches were quickly prewashed with 40-50 mL of tap water. Then, lettuce leaf punches were gently shaken and treated for $2 \mathrm{~min}$ at room temperature with 20 $\mathrm{mL}$ of water at $4-5{ }^{\circ} \mathrm{C}$ (i.e., with either tap water or laboratory-made washing waters with TOCs of $500 \mathrm{mg} / \mathrm{L}$ or $750 \mathrm{mg} / \mathrm{L}$ ). Treatments were with and without 60 and 80 $\mathrm{mg} / \mathrm{L}$ PAA, after which lettuce punches were rinsed with $50 \mathrm{~mL}$ tap water to remove possible residues before further analysis; neutralizing agents were not applied. Afterward, the lettuce punches were transferred to BioReba bags (BioReba AG, Reinach, Switzerland) containing $1 \mathrm{~mL}$ sterile Ringer's solution (BR0052; Oxoid, part of Thermo Fisher Scientific, Breda, the Netherlands) and gently homogenized. Tenfold serial dilutions in Ringer's solution of the homogenized lettuce leaf punches were plated on BECSA and incubated for $18-24 \mathrm{~h}$ at $37^{\circ} \mathrm{C}$ for the recovery of E. coli CFUs. Independent experiments on lettuce were carried out in duplicate $(n=2)$ each time by using four leaf punches from two separate plants.

\subsubsection{Industrial-scale experiments}

Industrial-scale experiments assessed the efficacy of a PAA solution during 'Lollo Rossa' lettuce processing $(800 \mathrm{~kg})$, with and without the addition of E. coli. A target concentration of about $75 \mathrm{mg} / \mathrm{L}$ of PAA was assessed in the wash tank $\left(3.5 \mathrm{~m}^{3}\right.$ flotation washer, Remie, build year 1997). Experiments with disinfectant-free (tap) water and non-supplemented $E$. coli served as controls. Two independent runs of the washing operations were conducted for both experiments with and without E. coli additions. Lettuce processing took about $90 \mathrm{~min}$, after which the PAA supply stopped and, when applicable, E. coli was added directly to the water of the wash tank.

Before each experiment, the processing line was swabbed to verify hygiene (i.e., to check for the absence of background $E$. coli) with swab rinse kits (SRK; 922C, CR, SRK 10 mL TRIPLE PACKED, Copan Italia SpA, Brescia, Italy) as described by Banach et al. (2018). Water and lettuce samples collected during the experimental runs were quantitatively examined for $E$. coli. Furthermore, water samples were analyzed for several physicochemical parameters: $\mathrm{pH}, \mathrm{T}$, ammonium-N $\left(\mathrm{NH}_{4}-\mathrm{N}\right)$, nitrate-N $\left(\left(\mathrm{NO}_{3}+\mathrm{NO}_{2}\right)-\mathrm{N}\right)$, phosphate-P $\left(\mathrm{PO}_{4}-\mathrm{P}\right)$, TOC, and chemical oxygen demand (COD). Stored lettuce samples were quantitatively examined for $E$. coli as well as microbial communities: fluorescent pseudomonads (FP) and total heterotrophic bacteria (THB).

\subsubsection{Lettuce and processing line}

Lolla Rossa lettuce (Lactuca sativa var. crispa 'Lollo Rossa') cultivated in Spain was delivered $\left(<7^{\circ} \mathrm{C}\right)$ to a Dutch processor who stored it at $4{ }^{\circ} \mathrm{C}$ and used it for experiments within $3 \mathrm{~d}$ of delivery. Lettuce was cored and pre-trimmed onsite by hand before further processing. A small-scale commercial lettuce processing line consisting of a lettuce shredder, step conveyor, infeed vibrator, washer - with output trill band and produce chute, and centrifuge was used for processing as described by Banach et al. (2018). PAA and potable (tap) water were supplied via inlets on the washer furthest from the product inflow and E. coli supply. PAA and lettuce were supplied for $90 \mathrm{~min}$ after which the inflow of each stopped and, when included in the treatment, the $E$. coli were added to the wash tank. The processing line continued running for an additional $12 \mathrm{~min}$ (i.e., 102 min after the initial start). 


\section{Chapter 5}

\subsubsection{Sample collection and analyses}

Sample collection of the process wash water (PWW) and lettuce was performed as described by Banach et al. (2018). A diagram of the commercial lettuce processing line with PWW, lettuce, and swab sampling points is depicted in Fig. 5.1.

The PWW samples ( $\sim 2$ L) were collected from the wash tank after 80, 91, 93, 96, and 102 min of processing, corresponding to first, second, third, fourth, and fifth-time points for water samples. These times were chosen as once the inflow of lettuce stops (at 90 $\mathrm{min}$ ), the outflow of lettuce is minimal after $96 \mathrm{~min}$. For microbiological analyses, 100 $\mu \mathrm{L}$ was directly plated on BECSA, and $1 \mathrm{~mL}$ was serially diluted into PPS, of which 100 $\mu \mathrm{L}$ of the appropriate dilutions were subsequently plated; all plating took place on-site. Plates were transported the same day to the laboratory. Plates were then incubated at $37{ }^{\circ} \mathrm{C}$ with daily inspection of colonies for up to one week. In addition to $E$. coli quantification, the concentration of the PAA and $\mathrm{H}_{2} \mathrm{O}_{2}$, as well as the temperature and $\mathrm{pH}$ of the PWW, were periodically determined during processing by collecting $50 \mathrm{~mL}$ of PWW (in duplicate) and analyzed with iodometric titration as described earlier (section 5.2.2). For chemical analyses, PWW samples were stored in sealed containers and transported under refrigerated conditions to the laboratory before analyses for $\mathrm{pH}$, ammonium-N $\left(\mathrm{NH}_{4}-\mathrm{N}\right)$, nitrate- $\mathrm{N}\left(\left(\mathrm{NO}_{3}+\mathrm{NO}_{2}\right)-\mathrm{N}\right)$, phosphate-P $\left(\mathrm{PO}_{4}-\mathrm{P}\right), \mathrm{TOC}$, and COD.

Lettuce samples were collected after $80,91,93$, and 95 min of processing (i.e., $10 \mathrm{~min}$ before and 1, 3, and 5 min after the PAA and lettuce inflow stopped). Samples were collected from the outflow of the line before being centrifuged (Zyliss Smart Touch Salad Spinner, Farnborough, United Kingdom) and processed on-site. A sample of the lettuce from the crate was also taken. Lettuce (10 g) was rinsed with potable water, twice, transferred to BioReba bags (Bioreba AG, Reinach, Switzerland), to which about $10 \mathrm{~mL}$ sterile Ringer's solution was added before being gently homogenized. Subsequently, tenfold serial dilutions of the lettuce homogenates were made in Ringer's solution, of which $100 \mu \mathrm{L}$ of undiluted and diluted homogenates were spread plated onto BECSA, King's B Agar (KB; K5165 KB Medium, Duchefa Biochemie B.V., Haarlem, the Netherlands) and R2A Agar (218262 Difco $^{\mathrm{TM}}$ R2A Agar, BD Diagnostics, Breda, the Netherlands), to determine E. coli, FP, and THB, respectively. Plates were then transferred the same day to the laboratory. BECSA plates were then incubated at $37{ }^{\circ} \mathrm{C}$ for $24 \mathrm{~h}$ with daily inspection of colonies for up to one week, while KB and R2A plates were incubated at $27^{\circ} \mathrm{C}$ for $24-48 \mathrm{~h}$.

Furthermore, lettuce samples were collected from the step conveyor at 2-3 min and from the product chute at 92-93 min to elucidate the effects of storage on E. coli, FP, and THB. Samples were immediately rinsed with potable water and centrifuged before packaging on-site and then were transported under refrigerated conditions to the laboratory for further analyses. Packaged lettuce samples were stored for $5 \mathrm{~d}$ at $4{ }^{\circ} \mathrm{C}$ before microbiological analyses, as previously described for E. coli, FP, and THB. No chemical analyses were performed on stored lettuce samples.

Swab samples of the equipment (c.a. $9 \mathrm{~cm}^{2}$ ) were taken at (i) the infeed vibrator, (ii) the front wall of the washer, (iii) the rear wall of the washer, and (iv) the output trill band of the washer and analyzed for E. coli as described by Banach et al. (2018). 


\subsubsection{Statistical analyses}

The effect that PAA had on E. coli, FP, and/or THB CFUs in lettuce washing water (laboratory), lettuce leaf punches (laboratory), and lettuce samples (industrial scale) were averaged for each independent experiment before being log-transformed to achieve a normal distribution. To visualize the data as $\log _{10}\left(\mathrm{~N} / \mathrm{N}_{0}\right)$, the log reduction of each experiment was determined by subtracting the log CFUs before treatment from the log CFUs after treatment, i.e., $\log$ reduction $=\log _{10}$ (CFUs after treatment) $-\log _{10}$ (CFUs before treatment). Data were used for statistical comparison using a two-way analysis of variance (ANOVA) with a Bonferroni post hoc test in GraphPad Prism (version 5.02). 


\section{Chapter 5}

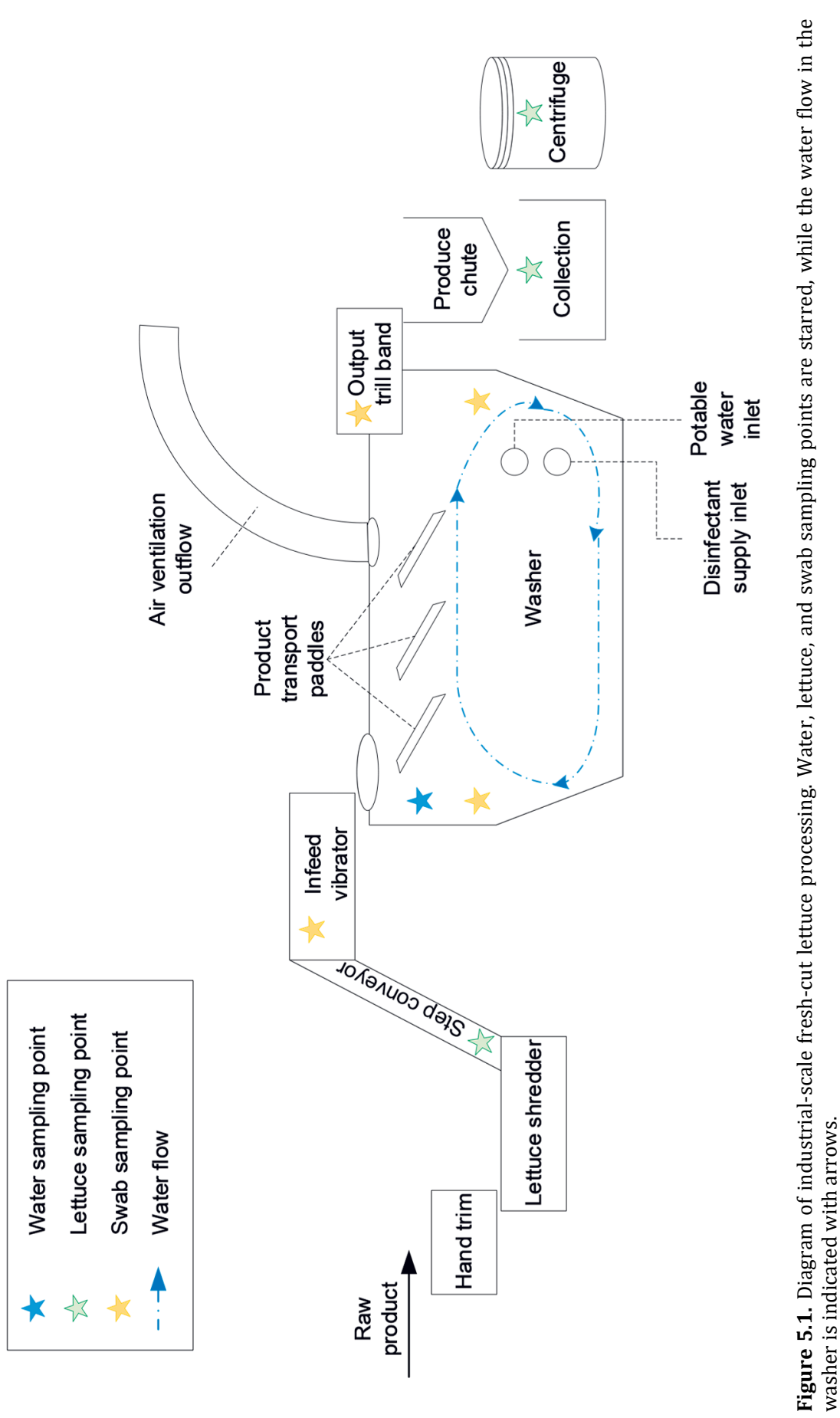




\subsection{Results}

\subsubsection{Physiochemical properties of the wash water}

During laboratory experiments with 20 and $40 \mathrm{mg} / \mathrm{L}$ of PAA, the $\mathrm{pH}$ decreased during washing. The $\mathrm{pH}$ before and after treatment was, respectively, 7.0 and 6.1 during 20 mg/L PAA experiments with $500 \mathrm{mg} / \mathrm{L}$ of TOC; 7.2 and 5.9 during $20 \mathrm{mg} / \mathrm{L}$ PAA experiments with $750 \mathrm{mg} / \mathrm{L}$ of TOC; and 7.2 and 5.3 during $40 \mathrm{mg} / \mathrm{L}$ PAA experiments with $750 \mathrm{mg} / \mathrm{L}$ of TOC. During laboratory experiments with 0, 60, and $80 \mathrm{mg} / \mathrm{L}$ of PAA, the concentrations of PAA and $\mathrm{H}_{2} \mathrm{O}_{2}$ were determined after treatments with and without the addition of $E$. coli (Table S1). Measurements to estimate $\mathrm{H}_{2} \mathrm{O}_{2}$ in laboratorymade wash water were more challenging to determine given the change in color during titration and the greenish hue of the water. Results showed that post-treatment, $\mathrm{H}_{2} \mathrm{O}_{2}$ and PAA were present in the water that had been used to wash lettuce leaf punches. A lower concentration of $\mathrm{H}_{2} \mathrm{O}_{2}$ and PAA is expected since the solution was not dosed into the water throughout the experiments.

During industrial-scale experiments, the PAA, $\mathrm{H}_{2} \mathrm{O}_{2}, \mathrm{COD}$, and TOC concentrations of the PWW were measured for Treatment 1 (E. coli excluded from the PWW) and Treatment 2 (E. coli included in the PWW). During Treatment 1, the PAA, $\mathrm{H}_{2} \mathrm{O}_{2}, \mathrm{COD}$, and TOC concentrations appeared stable (Fig. S5.1A, Fig. S5.1B). The water temperature was controlled, ranging from $2.9-3.4{ }^{\circ} \mathrm{C}$ (data not shown). During Treatment 2 , the PAA, $\mathrm{H}_{2} \mathrm{O}_{2}$, COD, and TOC concentrations also appeared stable (Fig. S5.1C, Fig. S5.1D). The water temperature was controlled, ranging from 3.0-3.9 ${ }^{\circ} \mathrm{C}$ (data not shown). Similar to Treatment 1, the $\mathrm{pH}$ of the water increased after $90 \mathrm{~min}$ due to the stopped supply of the PAA solution at $90 \mathrm{~min}$. Ammonium-N and phosphate-P appeared stable, with a slight increase during Treatment 2, due to the addition of E. coli at $90 \mathrm{~min}$ (Fig. S5.2).

\subsubsection{Microbial reduction in the wash water}

In a preliminary study, laboratory experiments evaluated the efficacy of PAA at 20 and $40 \mathrm{mg} / \mathrm{L}$ on $E$. coli added to potable water and laboratory-made wash water with TOCs of 500 and $750 \mathrm{mg} / \mathrm{L}$. Results exhibited at least a 5-log reduction after $1 \mathrm{~min}$. The control treatment (with no disinfectant) indicated no log reduction after 0 and 12 min (data not shown).

Results of the laboratory experiments varied for the reduction of $E$. coli in the wash water of the inoculated lettuce leaf punches (Fig. 5.2A). For treatments with no disinfectant, E. coli cells were recovered in all the wash water types, with a decreasing trend in cell recovery observed for wash waters with increasing TOCs. Average E. coli reduction was $1.1,2.4$, and $2.8 \log \mathrm{CFU} / \mathrm{mL}$, respectively, for treatments with no disinfectant in tap water, in laboratory-made wash water with a TOC of $500 \mathrm{mg} / \mathrm{L}$ and with a TOC of $750 \mathrm{mg} / \mathrm{L}$. These results differ from the treatments with 60 and $80 \mathrm{mg} / \mathrm{L}$ of PAA, which both demonstrated that no E. coli cells were recovered given each of the three water types tested, indicating that almost a 6-log reduction occurred. Although results may be influenced by the non-use of neutralizers on PAA, serial dilutions in PPS were made before plating. Overall, there is a significant difference between the use of 
no disinfectant and the use of PAA for each of the concentrations tested.

Results of industrial-scale experiments where E. coli were excluded (Treatment 1) and included (Treatment 2) in the PWW at 90 min showed that no E. coli were detected in the PWW when analyzed on BECSA 1 min after the PAA solution supply stopped, i.e., after $91 \mathrm{~min}$ of processing (data not shown). Moreover, the samples measured afterward (i.e., at 93, 96, and 102 min of processing) for both treatments showed that no $E$. coli cells were detected. Similar to the lab experiments, neutralizers were not used, but serial dilutions in PPS were made before plating. Overall, Treatment 2 experiments resulted in about a 5-log reduction of $E$. coli (data not shown). Also, swab samples for the four tested locations of the equipment were negative (i.e., 0 CFUs of $E$. coli per $9 \mathrm{~cm}^{2}$ were detected).

\subsubsection{Microbial quality of the lettuce}

Results for the laboratory experiments of the washed lettuce leaf punches showed that E. coli cells remained attached to the lettuce after treatments (Fig. 5.2B). For treatments with no disinfectant, E. coli decline averaged 1.6, 2.5, and $3.0 \mathrm{log}$ CFU/punch, respectively, after washing in tap water, laboratory-made wash water with a TOC of 500 $\mathrm{mg} / \mathrm{L}$ and with a TOC of $750 \mathrm{mg} / \mathrm{L}$. E. coli were also recovered on the lettuce leaf punches following treatments with 60 and $80 \mathrm{mg} / \mathrm{L}$ PAA in all three water types. Treatments with $60 \mathrm{mg} / \mathrm{L}$ PAA indicated that E. coli decline on the lettuce averaged 3.9, 2.8, and $2.2 \log$ CFU/punch, respectively, following washing with no disinfectants in tap water, laboratory-made wash water with a TOC of $500 \mathrm{mg} / \mathrm{L}$, and with a TOC of 750 $\mathrm{mg} / \mathrm{L}$. Treatments with $80 \mathrm{mg} / \mathrm{L}$ PAA indicated that $E$. coli decline on the lettuce averaged 2.8, 3.0, and $2.7 \mathrm{log} \mathrm{CFU} /$ punch, respectively, following washing with no disinfectants in tap water, laboratory-made wash water with a TOC of $500 \mathrm{mg} / \mathrm{L}$, and with a TOC of $750 \mathrm{mg} / \mathrm{L}$. Although results may be influenced by the non-use of neutralizers on PAA, lettuce was washed with water before analysis. Overall, no significant differences were observed (Fig. 5.2B).

Results of industrial-scale experiments where E. coli were excluded (Treatment 1) and added (Treatment 2) to the PWW at 90 min on the recovery of E. coli, FP, and THB were measured from the lettuce during the experiments (Fig. 5.3). E. coli cells were not detected on the lettuce during experiments where $E$. coli had been excluded (Treatment 1) (Fig. 5.3A). Similarly, for Treatment 2, E. coli cells were not detected on the lettuce from the crate (data not shown) or on the lettuce sampled at $80 \mathrm{~min}$ (below the limit of detection). E. coli cells were detected on the lettuce samples taken after that, i.e., at 91, 93, and $95 \mathrm{~min}$ (Fig. 5.3A), with significant differences observed between the treatments from samples at $93 \mathrm{~min}$ and samples at $95 \mathrm{~min}$. Even though PAA appeared to influence $E$. coli counts on lettuce, the disinfection of the water with PAA did not result in the complete elimination of $E$. coli from the washed produce. Similar to the laboratory experiments, neutralizers were not used, but the lettuce was washed with water before analysis. With PAA application, a rinsing step after washing and before packaging reflects industrial practice. Moreover, considering the presence of microbial communities on the lettuce, FP (Fig. 5.3B) and THB (Fig. 5.3C) were detected before (80 min) and after $(91,93$, and $95 \mathrm{~min})$ the lettuce had been processed in the PAA 
disinfected washing water, with no significant differences observed between the treatments.

Also, E. coli, FP, and THB were measured on the lettuce after storage for $5 \mathrm{~d}$ at $4{ }^{\circ} \mathrm{C}$ (Fig. 5.4). E. coli cells were not detected on the lettuce during experiments where $E$. coli had been excluded (Treatment 1) (Fig. 5.4A), which is expected. During experiments where E. coli had been supplemented to the wash water (Treatment 2), E. coli cells were detected on the lettuce samples taken from the product chute. There was a significant difference in $E$. coli cells $(p<0.001)$ between treatments from samples taken from product chute at 92- $93 \mathrm{~min}$ (i.e., after washing with PAA). This result is to be expected as $E$. coli was added to the washing tank at 90 min during Treatment 2. PAA disinfection of the water in these experiments did not prevent the survival of $E$. coli in packaged lettuce samples. FP (Fig. 5.4B) and THB (Fig. 5.4C) were detected on stored lettuce samples before and after the lettuce had been processed in the PAA disinfected washing water, with no significant differences observed between the treatments. 


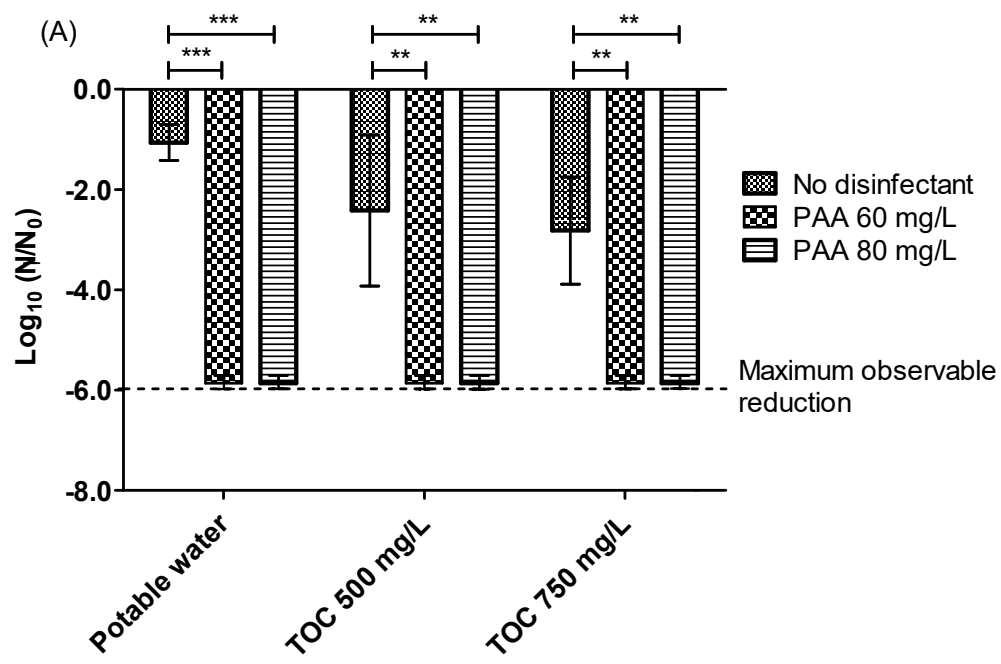

Water type

(B)

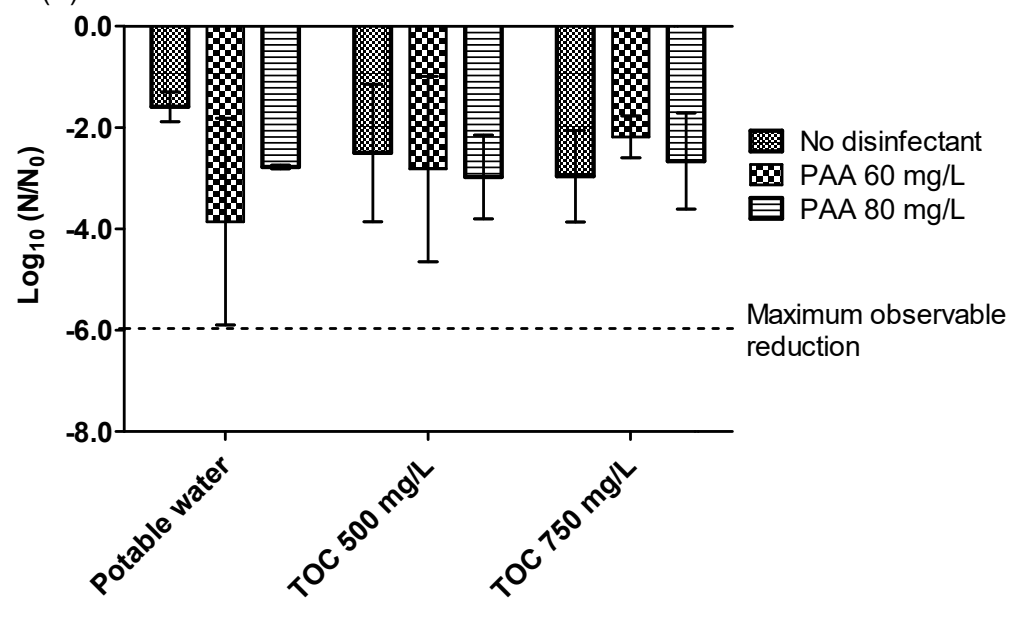

Water type

Figure 5.2. Average $E$. coli reduction after a two-minute treatment at $4-5^{\circ} \mathrm{C}$ with no disinfectant, a peracetic acid (PAA) solution of $60 \mathrm{mg} / \mathrm{L}$, and $80 \mathrm{mg} / \mathrm{L}$. Laboratory experiments were with tap water and laboratorymade wash water with total organic carbon (TOC) concentrations of $500 \mathrm{mg} / \mathrm{L}$ and $750 \mathrm{mg} / \mathrm{L}$. (A) Reduction in the wash water of inoculated lettuce leaf punches. (B) Reduction on the inoculated lettuce leaf punches. The $\log _{10}\left(\mathrm{~N} / \mathrm{N}_{\mathrm{o}}\right)$ of 0 indicates that all bacterial cells remained in the water $(\mathrm{A})$ or attached to the leaf punches (B). Data represent the average of four experiments, and error bars represent standard deviation. Significant differences are denoted by asterisks, for $p<0.01\left(^{* *}\right)$ and $p<0.001\left(^{* * *}\right)$. --- Maximum observable reduction. 


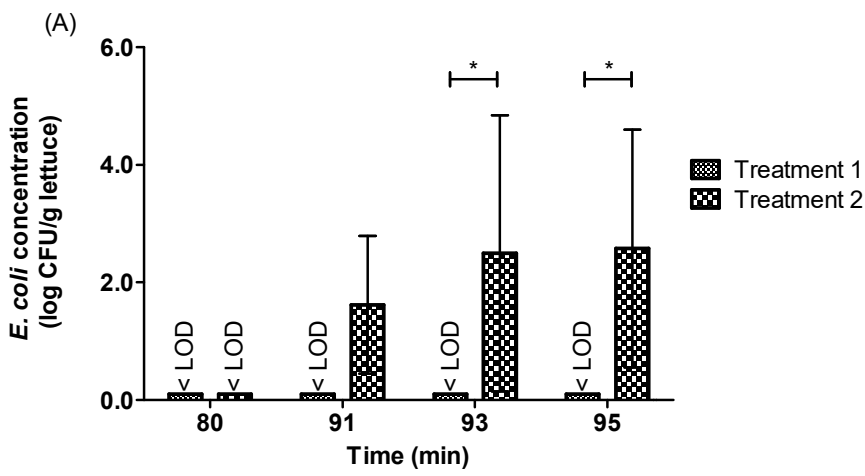

(B)

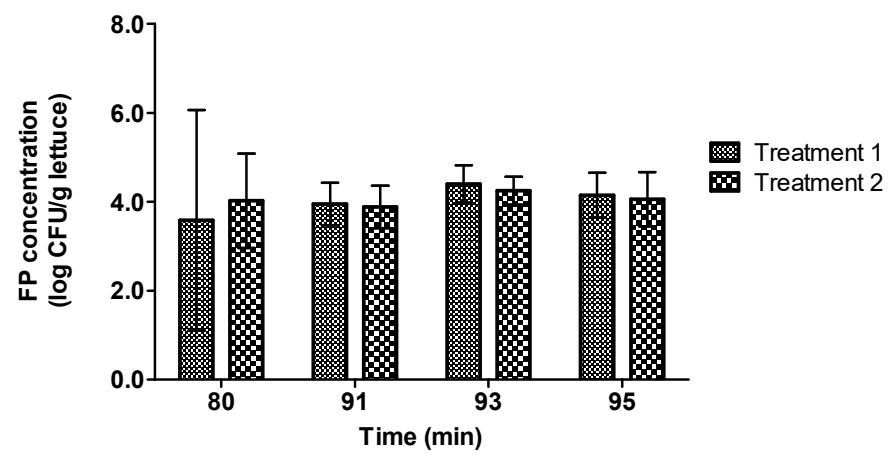

(C)

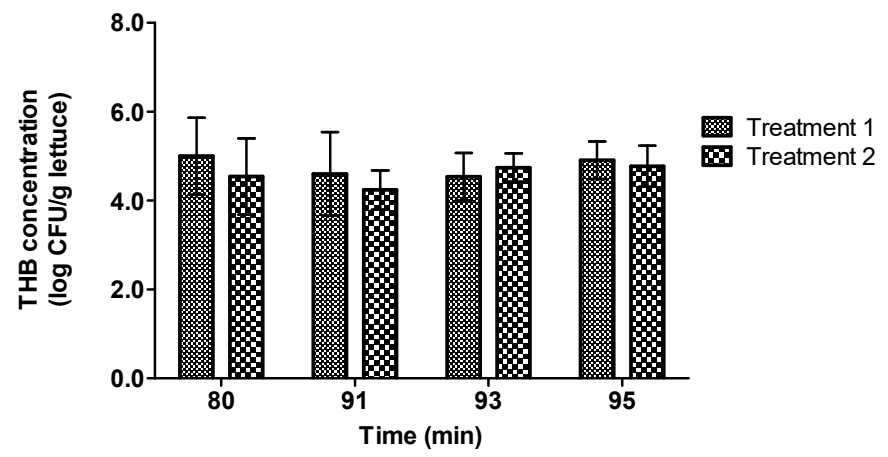

Figure 5.3. Recovery of (A) E. coli, (B) fluorescent pseudomonads (FP), and (C) total heterotrophic bacteria (THB) from lettuce during industrial-scale washing in water treated with a peracetic acid solution. Treatment 1 excluded and Treatment 2 included $E$. coli addition to the water in the wash tank at 90 min. Lettuce samples were collected during processing at the first, second, third, and fourth sampling points of 80,91, 93, and 95 min $(\mathrm{n}=4)$. Error bars represent standard deviation. Significant differences $(p<0.05)$ are denoted by asterisks $(*)$. Values at zero are below the limit of detection (LOD) of c.a. 1 log CFU/g. 

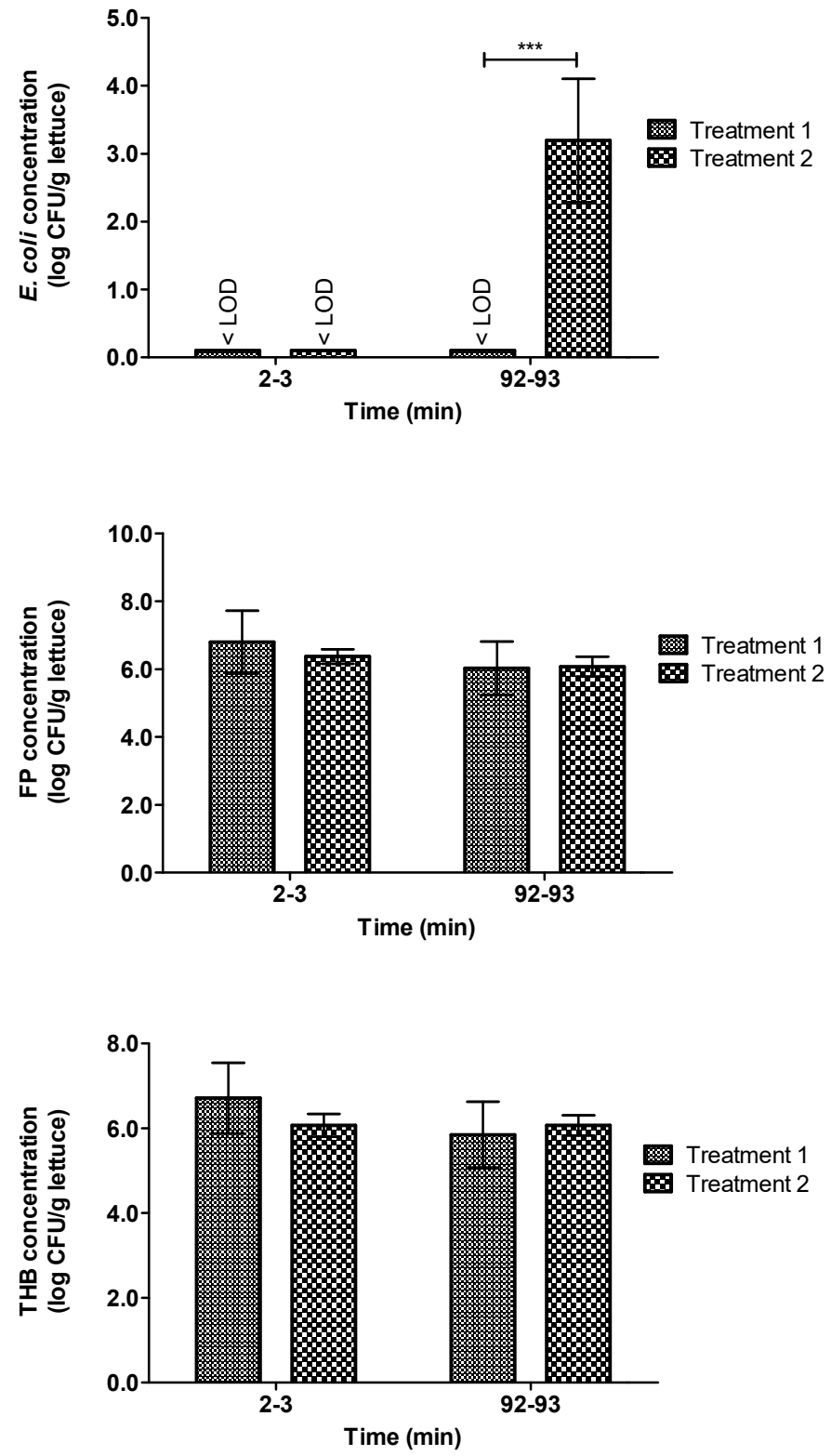

Figure 5.4. Recovery of (A) E. coli, (B) fluorescent pseudomonads (FP), and (C) total heterotrophic bacteria (THB) from industrial-scale processed lettuce after storage for $5 \mathrm{~d}$ at $4{ }^{\circ} \mathrm{C}$. Treatment 1 excluded and Treatment 2 included $E$. coli addition to the water in the wash tank at $90 \mathrm{~min}$. Lettuce samples were collected before and after washing with a peracetic acid solution, respectively, from the conveyor belt at 2-3 min ( $\mathrm{n}=$ $4)$ and the product chute at $92-93 \mathrm{~min}(\mathrm{n}=12)$. Error bars represent standard deviation. Significant differences $(p<0.001)$ are denoted by asterisks $\left({ }^{* * *}\right)$. Values at zero are below the limit of detection (LOD) of c.a. $1 \log \mathrm{CFU} / \mathrm{g}$. 


\subsection{Discussion}

Our study examines the possibility of using a PAA $(\sim 75 \mathrm{mg} / \mathrm{L})$ solution to disinfectant the water to prevent potential microbial cross-contamination during industrial-scale fresh-cut lettuce processing. An important implication of these findings is that PAA is shown to be an effective wash water disinfectant to aid in preventing crosscontamination. Other research has suggested only slight differences in the prevention of cross-contamination between the use of tap water and PAA solutions. For instance, a pilot-scale study observed minimal differences between that of tap water and water containing PAA (30 ppm) for E. coli 0157:H7 in the PWW of (iceberg) lettuce. Results reflected a "best case" scenario during the early stages of processing in which the organic load was extremely low $(0.0006 \%$ blended iceberg lettuce (wt/vol)) and where the incoming water temperature was $12-15^{\circ} \mathrm{C}$ (Davidson, Buchholz and Ryser, 2013). In our study, we opted for a "worst-case" scenario where the organic load of the wash water was built up over time, and contamination occurred near the end of processing. The higher concentration and continuous dose of PAA, albeit at lower water temperatures, most likely attributed to the higher log reductions of $E$. coli observed. Nevertheless, the differences between the studies concerning the lettuce type, $E$. coli analyzed, the composition of the PAA solution (e.g., Tsunami 100 with $11.2 \% \mathrm{H}_{2} \mathrm{O}_{2}$ and 15.2\% PAA (Ecolab, Inc., St Paul, MN) or 17.1\% $\mathrm{H}_{2} \mathrm{O}_{2}$ and 15.2\% PAA (Ecolab B.V., Nieuwegein, the Netherlands), as well as the organic load of the water, should not be disregarded.

The survival of pathogenic bacteria during process wash water disinfection has been shown to be dependent on variables like the organic load of the water, water temperature, and attachment and release to the produce (Banach et al., 2015; Banach et al., 2017). The E. coli strain used in our study is a model for pathogenic E. coli, as the use of a pathogenic strain inside an operating facility is a sanitary and safety concern. Our strain used may attach differently to the lettuce or have different resistance to chemicals than pathogenic strains. Challenge studies to validate this $E$. coli as a surrogate warrant further attention. Despite this limitation, previous research has motivated the use of environmental isolates as surrogates for foodborne pathogens (Cook, Givan, Mayton, Parekh, Taylor and Walker, 2017). Our strain is an environmental isolate coming from surface water and could provide insight considering contamination routes via water. Another study also found that the conditions in which bacterial strains were grown before challenge studies with peracetic acid had a larger effect on bacterial reduction than strain diversity (Harrand, Kovac, Carroll, Guariglia-Oropeza, Kent and Wiedmann, 2019). Therefore, the factors that affect the strain, like the growth conditions, may even be more relevant than the strain itself.

Our results demonstrated that the tested PAA solutions were not adversely affected by the organic load of the water, as supported by the microbial reductions observed. Zhang, Ma, Phelan and Doyle (2009) reported that during laboratory experiments, PAA (30 ppm; Tsunami 100, Ecolab, Inc., St Paul, MN) more effectively reduced E. coli 0157:H7 cells in lettuce washing water versus that of tap or sanitizer-free sterile deionized water. This effect was also observed in our study, given the tested PAA concentrations for laboratory and industrial-scale experiments. However, Zhang et al. 
(2009) observed that PAA at 10 and 20 ppm in organically loaded water negatively affected the effectiveness of PAA on E. coli cells in the water and on the lettuce (Zhang et al., 2009). This result was not observed in our study. The difference is most likely due to a combination of higher concentrations of PAA and different organic loads of the wash water. Also, for industrial-scale experiments, the continuous dose of PAA could have contributed to this difference. Furthermore, a preliminary study evaluating 79 mg/L PAA (Tsunami 100) with tap water and Lolla Rossa PWW (TOC = $50 \mathrm{mg} / \mathrm{L}$ ) from the industrial-scale line that was tested in our study demonstrated $>5$ log reduction of the same strain of E. coli when analyzed on BECSA (data not shown). This additional information shows that the effectivity of tested PAA solutions was not adversely affected by the organic load of the wash water. At the industrial-scale, our results concur with previous research, which found that the organic load rarely affected the efficacy of PAA (50 ppm; Tsunami 100, Ecolab, St. Paul, MN), with reductions up to 5$\log \mathrm{CFU} / \mathrm{mL}$ in the wash water observed on a small-scale production of lettuce (Davidson, Kaminski-Davidson and Ryser, 2017). Overall, the efficacy of the tested PAA solution was shown to be less affected by the organic load in the PWW. Factors like the concentration and dose, nonetheless, may influence its stability in organically loaded waters.

The dose of the PAA solution showed to be a relevant factor for the microbial reduction in the water during our experiments. When testing higher concentrations of PAA and COD of the wash water, López-Gálvez, Allende, Selma and Gil (2009) reported in their laboratory study a $4 \log$ reduction of $E$. coli in the water with PAA use $(500 \mathrm{mg} / \mathrm{L}$; Tsunami 100 containing PAA at $15 \%$ as the active compound, Ecolab, Barcelona, Spain) in processing waters with CODs of 700-1000 mg/L. This observation concurs with our results, albeit we tested lower concentrations of PAA and organic loads (in terms of COD and/or TOC) of the wash water. The results from our study showed a stable COD of between 444-538 mg/L during the processing of fresh (-cut) lettuce with PAA ( $~ 75$ $\mathrm{mg} / \mathrm{L}$ ) at the industrial scale. When considering the same industrial-scale line and processing of the same type of lettuce, the COD of the wash water ranged from 350-800 $\mathrm{mg} / \mathrm{L}$ when no disinfectant was used and between $250-280 \mathrm{mg} / \mathrm{L}$ when $3 \mathrm{mg} / \mathrm{L} \mathrm{ClO}_{2}$ was applied (Banach et al., 2018). The COD concentrations measured during PAA experiments at the industrial scale were higher than the lowest concentrations measurement when no disinfectant was used $(350 \mathrm{mg} / \mathrm{L})$ or when, e.g., $\mathrm{ClO}_{2}$ was tested in our previous research (250 mg/L) (Banach et al., 2018).

Compared to experiments testing $3 \mathrm{mg} / \mathrm{L}$ of $\mathrm{ClO}_{2}$ (Banach et al., 2018), a higher COD concentration with the use of PAA was observed in our study. An increase in the organic load of the processing water with the use of PAA and no effect with $\mathrm{ClO}_{2}$ was also observed (Petri, Rodriguez and Garcia, 2015). Moreover, López-Gálvez et al. (2009) observed an increase in the organic load of PAA-treated wash water. This increase has been explained by the presence of acetic acid, which is present in both PAA and its decomposition product (Kitis, 2004), yet also a result of the peracid itself (Beber de Souza, Queiroz Valdez, Jeranoski, Vidal and Cavallini, 2015; Luukkonen and Pehkonen, 2017). According to Luukkonen and Pehkonen (2017), an increase in TOC and COD is because of PAA dosing. Reported increases of COD are between 1.9 and $4.0 \mathrm{mg} / \mathrm{L}$ per 1 $\mathrm{mg} / \mathrm{L}$ of PAA dosed; however, authors also noted that decreased COD could occur due 
to the oxidation of organic matter (Luukkonen and Pehkonen, 2017). Consequently, monitoring the physicochemical properties of the wash water is crucial to consider along with the dose of the PAA to be used. The use of PAA as a wash water disinfectant should not adversely affect its ability to prevent cross-contamination during processing. Hence, the PAA dose should also be monitored and kept stable for both microbiological reasons and to avoid unnecessary overdosing, which can contribute to higher operational costs.

Our study showed the effectiveness of a PAA solution in reducing cross-contamination during industrial-scale fresh-cut lettuce processing. Fewer E. coli were observed to attach to the lettuce during processing. This phenomenon is important to realize as an estimated $90 \%$ of $E$. coli 0157:H7 have been reported to transfer via wash water during fresh-cut leafy green processing (Buchholz, Davidson, Marks, Todd and Ryser, 2012). In our study, we illustrated the recovery of $E$. coli lettuce after storage for $5 \mathrm{~d}$ at $4{ }^{\circ} \mathrm{C}$. On average, the recovery of $E$. coli after washing $(\mathrm{n}=12)$ was $3.2 \log$ CFU/g. Given a similar experimental design, the control treatments $(n=2)$ without disinfectant, yet with the addition of $E$. coli, resulted in an average $4.5 \log$ CFU of $E$. coli/g lettuce after storage for $5 \mathrm{~d}$ at $4{ }^{\circ} \mathrm{C}$ (Banach et al., 2018). The use of a PAA solution during washing resulted in $>$ $1 \log \mathrm{CFU} / \mathrm{g}$ fewer $E$. coli observed on stored lettuce. The data shows that washing with a PAA solution resulted in fewer E. coli recovered versus that of washing with no disinfection. This result supports PAA disinfection of the water during fresh-cut lettuce washing. Although the molecular mechanisms of PAA use during washing were not the focus of our study, and a restriction of our experimental design, other research has motivated PAA treatment during (fresh-cut) lettuce washing, showing the inactivation on lettuce of oxidative stress-related genes and proteins at early stages of storage (Daddiego, Bianco, Capodicasa, Carbone, Dalmastri, Daroda, Del Fiore, De Rossi, Di Carli, Donini, Lopez, Mengoni, Paganin, Perrotta and Bevivino, 2018). Similar to our study, the ability for $E$. coli to persist on the lettuce after PAA use has been reported (Al-Nabulsi, Osaili, Obaidat, Shaker, Awaisheh and Holley, 2014; Davidson et al., 2013; Davidson et al., 2017; López-Gálvez et al., 2009; Rodgers, Cash, Siddiq and Ryser, 2004; Vandekinderen, Devlieghere, De Meulenaer, Ragaert and Van Camp, 2009; Zhang et al., 2009). The microbial load can be reduced about 1-2 logs with washing and disinfection (Doona, Feeherry, Feng, Grove, Krishnamurthy, Lee, Kustin, Pillai and Shayanfar, 2015; Fatica and Schneider, 2009); however, the notion that disinfectants such as PAA can be used to decontaminate lettuce to ensure end-product safety is misleading. Instead, the need to disinfect the wash water with, e.g., a PAA solution, is to prevent potential crosscontamination during washing.

Previous research has indicated that phyllosphere bacterial communities of plants such as lettuce can be affected by season, irrigation, and other biological factors like the presence of E. coli 0157:H7 (Williams, Moyne, Harris and Marco, 2013). In our study, the effect that PAA (and E. coli) may have on the presence of the microbial communities in the lettuce was investigated. In our study, no difference was observed for culturable microbial communities on the lettuce directly measured before and after PAA washing, even when E. coli was added. Our result differs from Allende et al. (2008), which found a significant difference $(p \leq 0.001)$ in the mesophilic reduction in Tsunami 100 at 80 $\mu \mathrm{L} / \mathrm{L}$ (Ecolab, Barcelona, Spain) applied in a submersion washing system versus that of 


\section{Chapter 5}

the "water" wash. This difference between our studies can be attributed to, among other factors, the concentration of PAA used or the application system. Moreover, in our study, FP and THB were shown to be able to survive and grow during storage $(5 \mathrm{~d}, 4$ $\left.{ }^{\circ} \mathrm{C}\right)$. This result concurs with the work of Allende et al. (2008), who reported no significant differences after eight days of storage $\left(3 \mathrm{~d}\right.$ at $5^{\circ} \mathrm{C}$ and $5 \mathrm{~d}$ at $\left.8{ }^{\circ} \mathrm{C}\right)$ given a dose of 40 and $80 \mu \mathrm{L} / \mathrm{L}$ in a submersion washing system.

Overall, our results showed that during the processing of fresh-cut lettuce, where the accumulation of soil, debris, and other plant exudates can negatively affect the washing system, the use of a PAA ( $75 \mathrm{mg} / \mathrm{L})$ solution was observed to be an effective wash water disinfectant. Moreover, the quality of the water used during washing (fresh-cut) produce is a crucial aspect that should be monitored. Similarly, the dose of the wash water disinfectants, such as PAA, to be used during fresh (-cut) lettuce processing needs to be well-controlled.

\section{Acknowledgments}

This project is financially supported by the Dutch Topsector Horticulture \& Starting Materials (TU) and the Ministry of Economic Affairs (EZ) under the project "Microbiology in Horticulture" (PPS 296, B0-33.05-001-001). We acknowledge C. van Kekem, L.B.J.M. Berendsen, C.H. Lombaers-van der Plas, C. van Tongeren, M.T.J. Helmond (Wageningen University \& Research), and R. Dolmans, G. van Wezel, M. Scheffer, A. van Empel (Ecolab B.V.) for their technical assistance. H.M. Vollebregt (Wageningen University \& Research) is kindly thanked for her contribution to this project, including helping to set up the industrial-scale experiments. The authors acknowledge the contributions from the Dutch fruit and vegetable industry, the Fresh Produce Centre (GFH), and, in particular, Hessing B.V. for the industrial facilities. 


\section{References}

Al-Nabulsi, A.A., Osaili, T.M., Obaidat, H.M., Shaker, R.R., Awaisheh, S.S., Holley, R.A., 2014. Inactivation of stressed Escherichia coli 0157:H7 cells on the surfaces of rocket salad leaves by chlorine and peroxyacetic acid. J. Food Prot. 77, 32-39. doi: 10.4315/0362-028X.JFP-13-019.

Allende, A., Selma, M.V., López-Gálvez, F., Villaescusa, R., Gil, M.I., 2008. Role of commercial sanitizers and washing systems on epiphytic microorganisms and sensory quality of fresh-cut escarole and lettuce. Postharvest Biol. Technol. 49, 155-163. doi: 10.1016/j.postharvbio.2007.12.010.

Baert, L., Vandekinderen, I., Devlieghere, F., Van Coillie, E., Debevere, J., Uyttendaele, M., 2009. Efficacy of sodium hypochlorite and peroxyacetic acid to reduce murine norovirus 1, B40-8, Listeria monocytogenes, and Escherichia coli 0157:H7 on shredded iceberg lettuce and in residual wash water. J. Food Prot. 72, 1047-1054. doi: 10.4315/0362-028x-72.5.1047.

Banach, J.L., Sampers, I., Van Haute, S., van der Fels-Klerx, H.J., 2015. Effect of disinfectants on preventing the cross-contamination of pathogens in fresh produce washing water. Int. J. Environ. Res. Public Health 12, 8658-8677. doi: 10.3390/ijerph120808658.

Banach, J.L., van Bokhorst-van de Veen, H., van Overbeek, L.S., van der Zouwen, P.S., van der Fels-Klerx, H.J., Nierop Groot, M.N., 2017. The efficacy of chemical sanitizers on the reduction of Salmonella Typhimurium and Escherichia coli affected by bacterial cell history and water quality. Food Control 81, 137-146. doi: 10.1016/j.foodcont.2017.05.044.

Banach, J.L., van Overbeek, L.S., Nierop Groot, M.N., van der Zouwen, P.S., van der Fels-Klerx, H.J., 2018. Efficacy of chlorine dioxide on Escherichia coli inactivation during pilot-scale fresh-cut lettuce processing. Int. J. Food Microbiol. 269, 128-136. doi: 10.1016/j.ijfoodmicro.2018.01.013.

Beber de Souza, J., Queiroz Valdez, F., Jeranoski, R.F., Vidal, C.M.d.S., Cavallini, G.S., 2015. Water and wastewater disinfection with peracetic acid and UV radiation and using advanced oxidative process PAA/UV. Int. J. Photoenergy 2015, 7. doi: 10.1155/2015/860845.

Bonetta, S., Pignata, C., Lorenzi, E., De Ceglia, M., Meucci, L., Bonetta, S., Gilli, G., Carraro, E., 2017. Peracetic acid (PAA) disinfection: inactivation of microbial indicators and pathogenic bacteria in a municipal wastewater plant. Water 9. doi: 10.3390/W9060427.

Buchholz, A.L., Davidson, G.R., Marks, B.P., Todd, E.C., Ryser, E.T., 2012. Quantitative transfer of Escherichia coli 0157:H7 to equipment during small-scale production of fresh-cut leafy greens. J. Food Prot. 75, 1184-1197. doi: 10.4315/0362-028X.JFP-11-489.

Centers for Disease Control and Prevention (CDC), 2018a. Multistate outbreak of E. coli 0157:H7 infections linked to romaine lettuce (final update).

Centers for Disease Control and Prevention (CDC), 2018b. Multistate outbreak of Shiga toxin-producing Escherichia coli 0157:H7 infections linked to leafy greens (final update).

Centers for Disease Control and Prevention (CDC), 2018c. Outbreak of E. coli infections linked to romaine lettuce.

Cook, K.L., Givan, E.C., Mayton, H.M., Parekh, R.R., Taylor, R., Walker, S.L., 2017. Using the agricultural environment to select better surrogates for foodborne pathogens associated with fresh produce. Int. J. Food Microbiol. 262, 80-88. doi: 10.1016/j.ijfoodmicro.2017.09.017.

Daddiego, L., Bianco, L., Capodicasa, C., Carbone, F., Dalmastri, C., Daroda, L., Del Fiore, A., De Rossi, P., Di Carli, M., Donini, M., Lopez, L., Mengoni, A., Paganin, P., Perrotta, G., Bevivino, A., 2018. Omics approaches on fresh-cut lettuce reveal global molecular responses to sodium hypochlorite and peracetic acid treatment. J. Sci. Food Agric. 98, 737-750. doi: 10.1002/jsfa.8521.

Davidson, G.R., Buchholz, A.L., Ryser, E.T., 2013. Efficacy of commercial produce sanitizers against nontoxigenic Escherichia coli 0157:H7 during processing of iceberg lettuce in a pilot-scale leafy green processing line. J. Food Prot. 76, 1838-1845. doi: 10.4315/0362-028X.JFP-13-111.

Davidson, G.R., Kaminski-Davidson, C.N., Ryser, E.T., 2017. Persistence of Escherichia coli 0157:H7 during pilot-scale processing of iceberg lettuce using flume water containing peroxyacetic acid-based sanitizers and various organic loads. Int. J. Food Microbiol. 248, 22-31. doi: 10.1016/j.ijfoodmicro.2017.02.006.

Dominguez Henao, L., Turolla, A., Antonelli, M., 2018. Disinfection by-products formation and ecotoxicological effects of effluents treated with peracetic acid: a review. Chemosphere 213, 25-40. doi: 10.1016/j.chemosphere.2018.09.005. 


\section{Chapter 5}

Doona, C.J., Feeherry, F.E., Feng, H., Grove, S., Krishnamurthy, K., Lee, A., Kustin, K., Pillai, S.D., Shayanfar, S., 2015. Combining sanitizers and nonthermal processing technologies to improve fresh-cut produce safety, in: Pillai, S.D., Shayanfar, S. (Eds.), Electron beam pasteurization and complementary food processing technologies. Woodhead Publishing, pp. 95-125.

Fatica, M.K., Schneider, K.R., 2009. The use of chlorination and alternative sanitizers in the produce industry. CAB Rev. Perspect. Agric. Vet. Sci. Nutr. Nat. Resour. 4, 1-10. doi: 10.1079/PAVSNNR20094052.

Greenspan, F.P., MacKellar, D.G., 1948. Analysis of aliphatic per acids. Anal. Chem. 20, 1061-1063. doi: 10.1021/ac60023a020.

Harrand, A.S., Kovac, J., Carroll, L.M., Guariglia-Oropeza, V., Kent, D.J., Wiedmann, M., 2019. Assembly and characterization of a pathogen strain collection for produce safety applications: pre-growth conditions have a larger effect on peroxyacetic acid tolerance than strain diversity. Front. Microbiol. 10, 1223-1223. doi: 10.3389/fmicb.2019.01223.

Kitis, M., 2004. Disinfection of wastewater with peracetic acid: a review. Environ. Int. 30, 47-55. doi: 10.1016/S0160-4120(03)00147-8.

López-Gálvez, F., Allende, A., Selma, M.V., Gil, M.I., 2009. Prevention of Escherichia coli cross-contamination by different commercial sanitizers during washing of fresh-cut lettuce. Int. J. Food Microbiol. 133, 167171. doi: 10.1016/j.ijfoodmicro.2009.05.017.

Luukkonen, T., Pehkonen, S.O., 2017. Peracids in water treatment: a critical review. Crit. Rev. Env. Sci. Tec. 47, 1-39. doi: 10.1080/10643389.2016.1272343.

McDonnell, G., Russell, A.D., 1999. Antiseptics and disinfectants: activity, action, and resistance. Clin. Microbiol. Rev. 12, 147-179. doi: 10.1128/CMR.12.1.147.

Meireles, A., Giaouris, E., Simoes, M., 2016. Alternative disinfection methods to chlorine for use in the freshcut industry. Food Res. Int. 82, 71-85. doi: 10.1016/j.foodres.2016.01.021.

Muñío, M.M., Poyatos, J.M., 2011. Water disinfection using peracetic acid, in: Buchanan, K.M. (Ed.), Water disinfection. Nova Science Publishers, Inc., pp. 229-252.

Ölmez, H., Kretzschmar, U., 2009. Potential alternative disinfection methods for organic fresh-cut industry for minimizing water consumption and environmental impact. LWT Food Sci. Technol. 42, 686-693. doi: 10.1016/j.lwt.2008.08.001.

Petri, E., Rodriguez, M., Garcia, S., 2015. Evaluation of combined disinfection methods for reducing Escherichia coli 0157:H7 population on fresh-cut vegetables. Int. J. Environ. Res. Public Health 12, 8678-8690. doi: 10.3390/ijerph120808678.

Rodgers, S.L., Cash, J.N., Siddiq, M., Ryser, E.T., 2004. A comparison of different chemical sanitizers for inactivating Escherichia coli 0157:H7 and Listeria monocytogenes in solution and on apples, lettuce, strawberries, and cantaloupe. J. Food Prot. 67, 721-731. doi: 10.4315/0362-028X-67.4.721.

Sully, B.D., Williams, P.L., 1962. The analysis of solutions of per-acids and hydrogen peroxide. Analyst 87, 653657. doi: 10.1039/an9628700653.

Van Haute, S., Sampers, I., Jacxsens, L., Uyttendaele, M., 2015. Selection criteria for water disinfection techniques in agricultural practices. Crit. Rev. Food Sci. Nutr. 55, 1529-1551. doi: 10.1080/10408398.2012.705360.

Vandekinderen, I., Devlieghere, F., De Meulenaer, B., Ragaert, P., Van Camp, J., 2009. Optimization and evaluation of a decontamination step with peroxyacetic acid for fresh-cut produce. Food Microbiol. 26, 882-888. doi: 10.1016/j.fm.2009.06.004.

Williams, T.R., Moyne, A.L., Harris, L.J., Marco, M.L., 2013. Season, irrigation, leaf age, and Escherichia coli inoculation influence the bacterial diversity in the lettuce phyllosphere. PLoS One 8, e68642. doi: 10.1371/journal.pone.0068642.

Zhang, G., Ma, L., Phelan, V.H., Doyle, M.P., 2009. Efficacy of antimicrobial agents in lettuce leaf processing water for control of Escherichia coli 0157:H7. J. Food Prot. 72, 1392-1397. doi: 10.4315/0362028X-72.7.1392. 


\section{Supplementary materials}

Table S5.1. Calculated hydrogen peroxide $\left(\mathrm{H}_{2} \mathrm{O}_{2}\right)$ and peracetic acid (PAA) after laboratory experiments with lettuce leaf punches washed with Tsunami 100 (Ecolab B.V., Nieuwegein, the Netherlands) in varying water types based on total organic carbon (TOC).

\begin{tabular}{|c|c|c|c|c|}
\hline E. coli & Tsunami-100 (mg/L) & TOC (mg/L) & $\mathrm{H}_{2} \mathrm{O}_{2}(\mathrm{mg} / \mathrm{L})$ & PAA (mg/L) \\
\hline \multirow[t]{3}{*}{ No } & 0 & $\begin{array}{l}0 \\
500 \\
750\end{array}$ & $\begin{array}{l}0.3 \\
34.1 \\
\text { n.d. }\end{array}$ & $\begin{array}{l}1.0 \\
2.8 \\
\text { n.d. }\end{array}$ \\
\hline & 60 & $\begin{array}{l}0 \\
500 \\
500 \\
750\end{array}$ & $\begin{array}{l}28.9 \\
31.8 \\
31.6 \\
36.6\end{array}$ & $\begin{array}{l}29.2 \\
29.5 \\
24.0 \\
24.2\end{array}$ \\
\hline & 80 & $\begin{array}{l}0 \\
500 \\
500 \\
750\end{array}$ & $\begin{array}{l}41.7 \\
40.5 \\
49.7 \\
42.5\end{array}$ & $\begin{array}{l}42.3 \\
38.9 \\
33.4 \\
29.9\end{array}$ \\
\hline \multirow[t]{3}{*}{ Yes } & 0 & $\begin{array}{l}0 \\
500 \\
750 \\
750\end{array}$ & $\begin{array}{l}0.3 \\
14.7 \\
32.6 \\
28.1\end{array}$ & $\begin{array}{l}1.8 \\
3.7 \\
3.4 \\
6.5\end{array}$ \\
\hline & 60 & $\begin{array}{l}0 \\
0 \\
500 \\
500 \\
750 \\
750\end{array}$ & $\begin{array}{l}33.2 \\
33.1 \\
35.8 \\
29.6 \\
34.0 \\
36.6\end{array}$ & $\begin{array}{l}31.1 \\
32.8 \\
33.0 \\
23.7 \\
10.6 \\
32.4\end{array}$ \\
\hline & 80 & $\begin{array}{l}0 \\
0 \\
500 \\
500 \\
750 \\
750 \\
\end{array}$ & $\begin{array}{l}44.2 \\
41.6 \\
51.1 \\
39.1 \\
48.2 \\
41.9 \\
\end{array}$ & $\begin{array}{l}43.8 \\
41.6 \\
45.3 \\
35.8 \\
35.3 \\
30.1 \\
\end{array}$ \\
\hline
\end{tabular}

n.d. = not determined . 

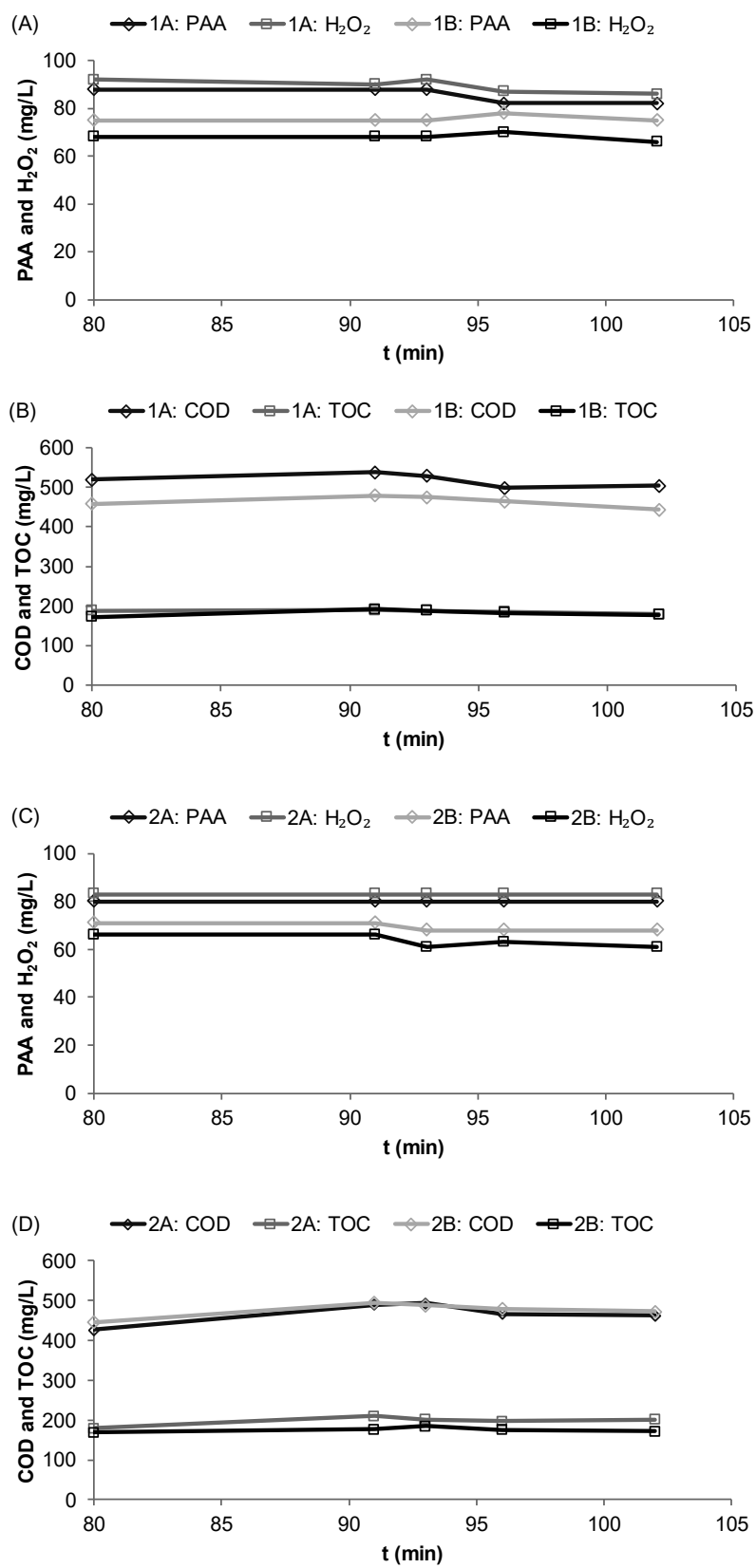

Figure S5.1. Peracetic acid (PAA), hydrogen peroxide $\left(\mathrm{H}_{2} \mathrm{O}_{2}\right)$, chemical oxygen demand (COD), and total organic carbon (TOC) concentrations in the process wash water (PWW) during industrial-scale experiments. Treatment 1 excluded (A, B) and Treatment 2 included (C, D) E. coli addition to the water in the wash tank at 90 min. Each treatment was performed twice. (A, C) show the concentration of PAA and $\mathrm{H}_{2} \mathrm{O}_{2}$ in the PWW; data represent single measurements. (B, D) show the COD and TOC of the PWW; COD data represent duplicate measurements, and TOC data represent single measurements. 

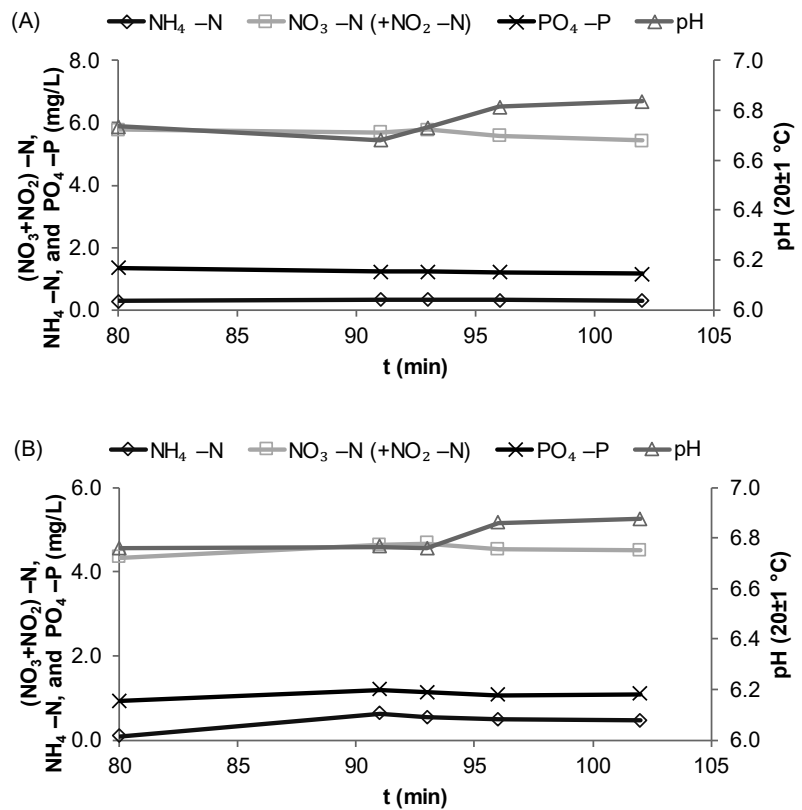

Figure S5.2. Averaged ammonium- $\mathrm{N}\left(\mathrm{NH}_{4}-\mathrm{N}\right)$, nitrate- $\mathrm{N}\left(\left(\mathrm{NO}_{3}+\mathrm{NO}_{2}\right)-\mathrm{N}\right)$, phosphate- $\mathrm{P}\left(\mathrm{PO}_{4}-\mathrm{P}\right)$, and $\mathrm{pH}$ in the process wash water (PWW) during industrial-scale experiments. Treatment 1 excluded $(\mathrm{A})$ and Treatment 2 included (B) E. coli addition to the water in the wash tank at $90 \mathrm{~min}$. Each treatment was performed twice. 



\section{Chapter 6}

\section{Multi-criteria decision analysis to evaluate control strategies for preventing cross- contamination during fresh-cut lettuce washing}

J.L. Banach

M.H. Zwietering

H.J. van der Fels-Klerx

Revised version submitted to: Food Control 


\begin{abstract}
Several chemical disinfection strategies may be used to control cross-contamination of pathogens during fresh-cut produce washing. Deciding which strategy to select not only requires the use of technical information on the relevant criteria but can also make use of stakeholder perception. This study aimed to describe the application of a MultiCriteria Decision Analysis (MCDA) to support decision-makers when determining a control strategy that best meets the views of various stakeholders and their possible conflicting interests. In this case study, five control strategies that can be used to treat the wash water, which comes in direct contact with the produce in the wash tank during processing, were examined. These strategies aimed to control pathogenic crosscontamination during fresh-cut lettuce washing at processors. These strategies were the use of free chlorine, chlorine dioxide, ozone, peracetic acid, or no wash water disinfectant. The performance analysis was based on five main criteria: effectivity, technology, consumer acceptance, economics, and health. Scores for these criteria were evaluated using scientific literature, while the weights of the criteria were assessed using stakeholders. Results for the five control strategies were determined per stakeholder group, which included fresh-cut processors, producers and suppliers of disinfectants and equipment, scientists, and government representatives, as well as per individual. Stakeholders were shown to have different views on the relative importance of the criteria; however, the criterion "health" was consistently considered most important. The ranking of the control strategies was similar for each stakeholder group and over stakeholders. Overall, the results showed that peracetic acid is the preferred control strategy. Based on the results of these analyses, the MCDA approach showed to assist in the complex decision to select a control strategy to control potential crosscontamination directly in the wash tank during fresh-cut lettuce washing, considering the different nature of the criteria and the perceptions of various stakeholder groups.
\end{abstract}

\title{
Keywords
}

Food safety; Water; Disinfection; Processing; Stakeholders; Policy 


\subsection{Introduction}

The European Food Safety Authority (EFSA) has ranked the risk of foodborne disease resulting from pathogens in foods of non-animal origin (FoNAO), and that report provides insight into likely pathogen-food combinations of concern to human health (EFSA Panel on Biological Hazards (BIOHAZ), 2013). For FoNAO where the edible portion is intended to be eaten uncooked, like that of fresh-cut lettuce, both contamination and cross-contamination should be controlled. This control is essential as, throughout the different stages of the food chain, there is no pathogenic reduction, except a minimal effect during washing. An effective way to prevent (cross-) contamination is to disinfect the water used during washing. In order to clean the lettuce, washing with water helps get rid of dirt, soil, sand, and any contamination that may occur. However, if the water used to wash the lettuce gets contaminated, it can also become a source of contamination for uncontaminated parts (Allende, Selma, LopezGalvez, Villaescusa and Gil, 2008; Banach, van Bokhorst-van de Veen, van Overbeek, van der Zouwen, van der Fels-Klerx and Groot, 2017; Holvoet, Jacxsens, Sampers and Uyttendaele, 2012). Therefore, disinfecting the water used during washing can be considered necessary. Using chemical disinfectants, like free chlorine or peracetic acid, directly in the washing tank has been shown to be effective. However, doing so can cause the formation of disinfection by-products (DBPs) in the washing water (Banach, Sampers, Van Haute and van der Fels-Klerx, 2015; Van Haute, Sampers, Holvoet and Uyttendaele, 2013). Control measures should aim to prevent (cross-) contamination of pathogens without jeopardizing chemical safety. Hence, both microbiological and chemical food safety needs to be ensured.

The type of disinfectant products that can be used during fresh-cut produce washing can vary in the European Union (EU) between member states. Ultimately, it is the member states who are responsible for the final evaluation and authorization of the use of disinfectant products (or biocidal products) before they are placed on the market. While controlling the water used during fresh-cut lettuce processing, several complex or conflicting criteria may need to be considered before deciding how to mitigate food safety risks that affect human health. The ability for stakeholders, including policymakers, to make an informed decision and set future policies to implement, or corrective actions to take, becomes multifaceted and, therefore, complicated. However, there are tools available to help facilitate the decision-making process. Van der FelsKlerx, Van Asselt, Raley, Poulsen, Korsgaard, Bredsdorff, Nauta, D'Agostino, Coles, Marvin and Frewer (2018) reviewed methods to rank the risk to human health of foodrelated hazards; among these is a decision-making tool known as a multi-criteria decision analysis (MCDA).

Stakeholders are parties with interest in the decision to be made, and involving them in the decision-making process on the selection of control strategies may increase the uptake and the optimal allocation of resources towards the strategy. Moreover, their involvement can increase the balance in the decision, i.e., so that the decision is not optimal for one stakeholder but is a solution that includes the interest of different stakeholders, as well as create support for the decision selected. By using an MCDA, 
stakeholders can rank the relative importance of multiple diverse, complex, or even conflicting criteria associated with a case. An MCDA aims to help decision-makers select the best scenario(s) based on several criteria, including criteria that have qualitative or (semi-) quantitative data and may be conflicting between the stakeholders. It can be used to combine different types of knowledge or non-comparable outcomes, such as economic impact and health impact (Van der Fels-Klerx et al., 2018). Often, an MCDA can be useful if there is no clear "optimal" solution, yet where the various criteria need to be prioritized among one another to try to find the best compromise (Duret, Hoang, Derens-Bertheau, Delahaye, Laguerre and Guillier, 2019). Overall, an MCDA is a tool that facilitates policy and decision-makers in selecting alternatives and making decisions by providing a comparison of the potential choices and brings structure to the decision-making process.

In the field of food safety, the MCDA approach has been used in the scientific community and by international organizations like the World Health Organization (WHO). For instance, in recent years, the WHO used an MCDA to globally rank foodborne parasites using qualitatively assessed criteria (Food and Agriculture Organization of the United Nations (FAO) and WHO, 2014). Also, Ruzante, Grieger, Woodward, Lambertini and Kowalcyk (2017) outlined an MCDA approach to conduct a food safety risk-benefit assessment to select interventions (i.e., control strategies) for controlling pathogens in foodstuffs. In another study, Duret et al. (2019) further evaluated the MCDA approach while focusing on the cold chain of cooked ham to predict the risk for human health associated with Listeria monocytogenes. In general, the MCDA approach regularly focuses on ranking possible food safety hazards and risks and less frequently has evaluated potential control strategies (Dunn, 2015).

When selecting a control strategy to prevent cross-contamination during fresh-cut produce washing, several criteria such as effectivity, the technology, consumer acceptance, economics, and public health may be considered. The objective of this study was to explore the use of an MCDA to select the best control strategy to treat the wash water used directly in the wash tank during fresh-cut lettuce washing to control crosscontamination with pathogens.

\subsection{Materials and methods}

\subsubsection{Decision problem}

Several chemical-based technologies are available to disinfect the water used during fresh-cut lettuce processing. Among others, the review of Banach et al. (2015) reported that free chlorine, chlorine dioxide, ozone, and peracetic acid could be effective process wash water disinfectants to reduce cross-contamination of pathogens during produce washing. In some European countries, like in the Netherlands, the use of chemicalbased wash water disinfectants is currently not applied during fresh-cut processing. Therefore, the use of these four technologies against the current alternative option - no wash water disinfectant - is of interest to assess. Several peer-reviewed scientific literature sources were used to determine the performance scores of the strategies.

Four groups of stakeholders were considered relevant for our case study, including (i) 
fresh-cut processors, (ii) producers and suppliers of disinfectants and equipment, (iii) scientists, and (iv) government representatives. The views of these four stakeholder groups were elicited using an online survey with a select set of questions to determine the preference weights of the criteria considered to evaluate the control strategies.

\subsubsection{Case study and criteria}

The following case study with assumptions was defined at the start of the study to ensure that survey respondents had the same conditions in mind when filling in the survey: "A fresh-cut lettuce processor treats the wash water directly, i.e., in the wash tank, using one of the five strategies: (i) free chlorine, (ii), chlorine dioxide, (iii) ozone, (iv) peracetic acid, or (v) no disinfectant. The strategy is applied directly to a single commercial wash tank $\left(3.5 \mathrm{~m}^{3}\right)$, which processes $800 \mathrm{~kg}$ of freshly cut lettuce in $90 \mathrm{~min}$ (which equates to one run). Processing is performed six days a week, with four runs per day, over five years. The processing equipment, including the wash tank, is cleaned in between each run. Furthermore, the technology is automated, i.e., an automated dosing system is used to treat the wash water. The consumer price of the (packed) lettuce is not supposed to be affected by the application of chemical disinfection."

Five main criteria were identified to be relevant to evaluate the control strategies: (i) effectivity, (ii) the technology, (iii) consumer acceptance, (iv) economics, and (v) health. Similar criteria have been used in other food safety MCDAs like effectiveness, practicality associated with the intervention (e.g., technology), and costs (e.g., economics) (Fazil, Rajic, Sanchez and McEwen, 2008). The effectiveness of the control strategy is an important health aspect and is based on the potential microbial reduction in the water (i.e., $\log _{10}$ reduction in the water). In this case study, (i) effectivity was considered a pre-requisite for the control strategy. The preference weight was predetermined at $20 \%$ for all stakeholder groups. All five control strategies, except "no use of a water disinfectant," were considered sufficiently effective. In total, nine sub-criteria were aggregated over the remaining four main criteria. For the main criterion (ii) technology, the three sub-criteria were how the technology could be applied in terms of its ease of use, its robustness, e.g., in terms of proper functionality over time, and the scale of the technology, e.g., how much water can be treated with the technology. For the main criterion (iii) consumer acceptance, the two sub-criteria were the consumer perception and organoleptic effects. For the main criterion (iv) economics, the two subcriteria were the direct and indirect costs (for the producer), which assumed a 5-year time for the technology, and reduction in water use. Finally, for the main criterion (v) health, the two sub-criteria were the additional unknown or adverse human health effects from the production of DBPs from the use of the technology, i.e., possible sideeffects, and the adverse effects on workers' safety. The main criteria and sub-criteria were grouped based on a previous list of impacts developed to address the specific nature of food safety policies and assessments of societal concern (Mazzocchi, Ragona and Zanoli, 2013). Definitions of the sub-criteria (Appendix A) were based on expert input from scientists in the field of food safety and chemical engineering. 


\subsubsection{Performance scores of the control strategies}

For the case study, qualitative scores were used to assess the performance of the five control strategies for each of the nine sub-criteria. These performance scores were based on the results from several peer-reviewed, comprehensive scientific literature reviews (Banach et al., 2015; Gil, Selma, Lopez-Galvez and Allende, 2009; Gil, Selma, Suslow, Jacxsens, Uyttendaele and Allende, 2015; Meireles, Giaouris and Simões, 2016; Van Haute, Sampers, Jacxsens and Uyttendaele, 2015). The scientific literature consulted on the use of control strategies is shown in Table 6.1.

The scores were standardized to a value between 0 and 1, reflecting the worst to the best possible option, by dividing the score by the maximum obtained score per criterion. For the criteria where the highest point value was considered the worst possible option (e.g., possible side-effects), one was subtracted from the score. Then, the performance scores of the sub-criteria were averaged per main criterion. Since the sub-criteria are averaged, these, in turn, become weighted.

\subsubsection{Stakeholder survey}

The online survey was developed to collect the stakeholders' views on the importance of the sub-criteria to consider before deciding which one of the five control strategies to apply. Respondents were asked to divide 100 points over the nine sub-criteria (see section 6.2.2 and Appendix A) and were asked to not use the same points for two or more of the criteria. The survey was sent by e-mail to a total of 36 stakeholders belonging to the four stakeholder groups. Respondents were guaranteed anonymity and were informed that the data were intended for scientific publication.

\subsubsection{Calculate overall value}

The performance scores, which were based on scientific literature, and the preference weights, which were based on stakeholder input from the survey, were aggregated using a Weight Sum Model (WSM). A WSM is a transparent and straightforward model that is commonly used to rank alternatives based on the sum of the utility per indicator (Bartolini and Viaggi, 2010). According to Dunn (2015), in a WSM, a global performance score $(G P)$ is determined based on the sum of the criterion performance scores $(p)$ multiplied by the respective weights $(w)$ :

$$
G P_{i}=\sum_{j=1}^{n} p_{i j} w_{j}
$$

In the equation above, $G P_{i}$ represents the global performance score associated with alternative $i$ (i.e., one of the five control strategies in this case). The value $p_{i j}$ represents the performance score of alternative $i$ for criterion $j$ (i.e., one of the five main criteria in this case), and $w_{j}$ represents the weight allocated to criterion $j$. For each of the stakeholder groups, the global performance scores $(G P)$ of the five control strategies were determined, given the performance scores $(p)$ and the averaged weights of the respondents $(w)$. 


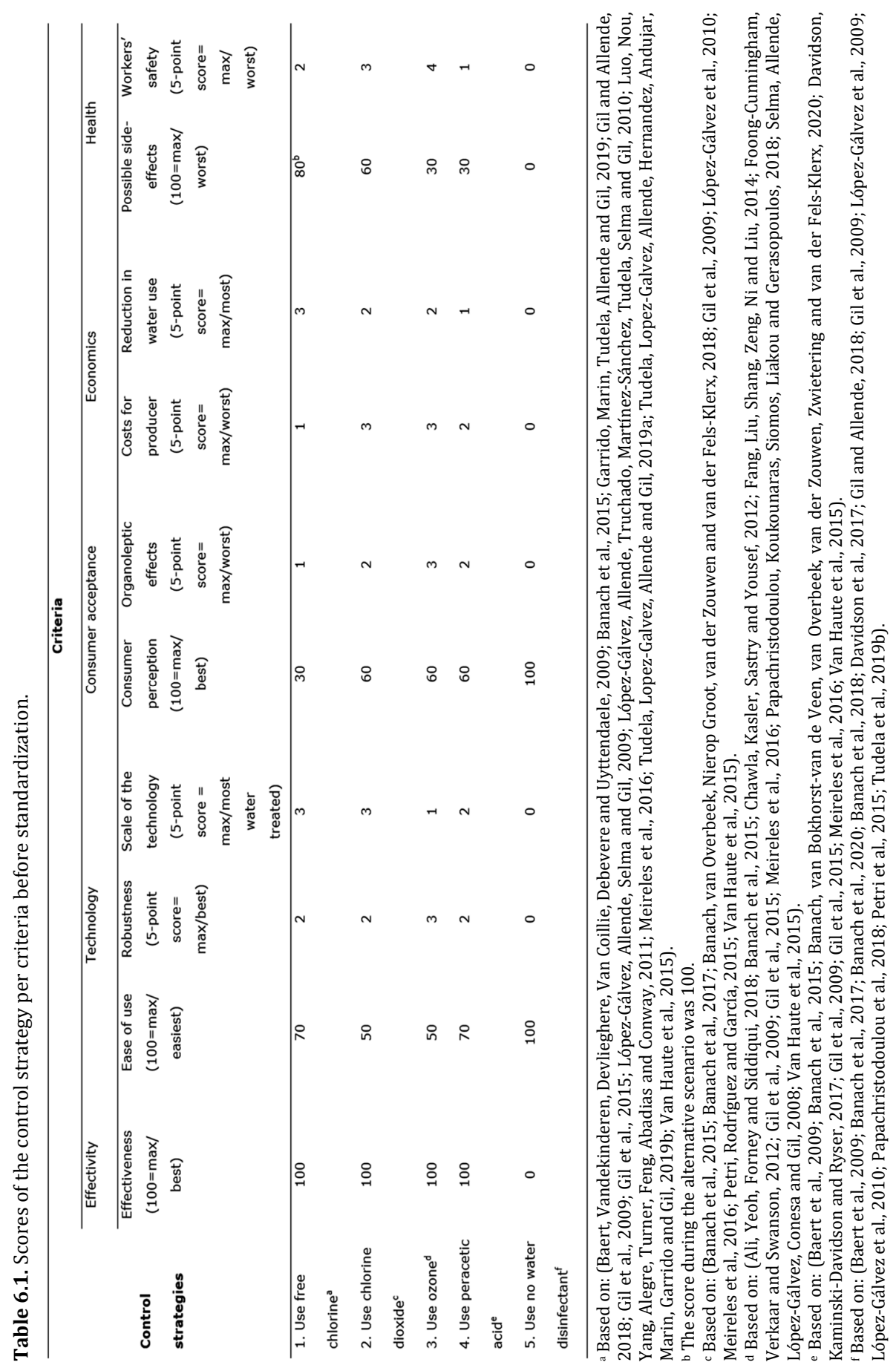




\subsubsection{Scenario analyses}

Since any of the five main criteria could affect the final ranking of the strategies, an alternative scenario was also examined. The scenario analysis was performed following the steps as earlier described, with one exception. The possible side-effects for free chlorine were scored at 100 instead of 80 , where 100 was the worst possible score. This change affected the averaged calculated standardized scores for chlorine dioxide, ozone, and peracetic acid; however, the same weights per stakeholder were applied.

\subsection{Results and discussion}

\subsubsection{Performance scores of the control strategies}

The performance scores of the original scenario before standardization (Table 6.1) and after standardization (Table 6.2) are shown. When determining the original performance scores for the control strategy (Table 6.1), the input depended on the literature. Consequently, this interpretation and standardization are based on the assumptions made given the current literature and data available. The standardized performance scores of the sub-criteria (Table 6.2) were averaged per main criteria and are shown per control strategy (Table 6.3). The criterion "effectivity" was pre-set at either 1 or 0 for each strategy. The criterion "technology" ranged from 0.33 for the use of no water disinfectant to 0.79 for the use of free chlorine. The criterion "consumer acceptance" ranged from 0.30 for the use of ozone to 1.00 for the use of no water disinfectant. The criterion "economics" ranged from 0.33 for chlorine dioxide, ozone, and peracetic acid to 0.83 for free chlorine. The criterion "health" had the broadest range of values, with scores from 0.25 for the use of free chlorine to 1.00 for the use of no water disinfectant (Table 6.3).

In food safety decision-making, the level of consumer protection should be maximized, while the costs and other adverse effects associated with a proposed control strategy should be minimized (Dunn, 2015). The scores in an MCDA provide the foundation for the analysis. Therefore, in our case study, the scores for the control strategies were based on peer-reviewed scientific research. For example, with the use of free chlorine, the costs are generally seen as less expensive than alternative water disinfection technologies (Banach et al., 2015; Garrido et al., 2019; Luo et al., 2011; Meireles et al., 2016). However, the potential health and environmental concerns from DBP formation, e.g., from trihalomethanes (THMs), makes it more controversial in terms of publichealth compared to other water disinfection technologies (Banach et al., 2015; Garrido et al., 2019; Meireles et al., 2016; Tudela et al., 2019a; Tudela et al., 2019b); these aspects were considered for the sub-criterion possible side-effects. Also, free chlorine is reactive with organic matter (Garrido et al., 2019; Luo et al., 2011), more so than chlorine dioxide or peracetic acid (Banach et al., 2015), is sensitive to $\mathrm{pH}$ (Banach et al., 2015; Gil and Allende, 2018) and can be corrosive (Meireles et al., 2016); these aspects were considered when considering the sub-criterion robustness. 
By basing the scores on multiple factors, and in this case study, pre-setting the effectivity values, we aimed to control some bias coming from the stakeholder perspective. Moreover, we enhanced the experimental design of the MCDA by bringing varying degrees of complexity to the identified problem, such as including a time dimension (Mazzocchi et al., 2013). In our study, time (e.g., costs over five years) was included, which further allows the advantages and disadvantages of the technology to be assessed.

\subsubsection{Response rate survey}

The response rate of the 36 stakeholders surveyed was 50\% (i.e., 18 replied). For each stakeholder group, the response rate was as follows: $n=2$ (of 5) for fresh-cut processors, $n=3$ (of 10) for producers and suppliers of disinfectants and equipment, $n$ $=10$ (of 12) for scientists, and $n=3$ (of 9) for government representatives. All surveys were fully completed, although all three government representatives used the same points for more than two of the criteria. By doing so, this disproportionately influences the results coming from this stakeholder group. The effect of this response can be seen in the broader range of preferences for the government representatives and the very high values for the criterion "health" (Table 6.4).

A limitation of this MCDA is the percentage of stakeholder respondents from producers and suppliers of disinfectants and equipment (30\%) and government representatives (33\%). Nonetheless, an advantage to this MCDA is the generally high response rate (50\%) for an online survey, also considering that additional incentives, such as monetary response incentives, were not provided. In a study on survey response rates, Pedersen and Nielsen (2016) showed that surveys that appealed to an individual's egotistical need for approval resulted in an increased survey response rate. In this study, the survey e-mail used an altruistic text appeal (the results would be used in a scientific publication). Also, a somewhat egotistic text appeal was used - where the survey was personally addressed directly to each recipient, meaning they had been specially selected to participate. Another advantage of this MCDA is the high response rate $(83 \%)$ for the stakeholder group scientists. Food safety requires that various technical information be considered from a multitude of scientific disciplines (Bartolini and Viaggi, 2010). Given the inclusive nature of the stakeholder group "scientists" in this study, several types of scientists could fit this profile and complement the needs for multiple scientific perspectives. Moreover, one could consider this stakeholder group to have the least amount of bias since there could be no economic or specific regulatory drive to come to a particular control strategy.

Results of the averaged preference weights for each criterion per stakeholder group are presented in Table 6.4. For the technology and consumer acceptance criteria, the stakeholder group producers and suppliers of disinfectants and equipment rated it higher than the other groups. The weights for economics were, in general, lower for all the other criteria, ranging from $8.8-14.2 \%$. Given the low preference weight for economics, further research to discern these values (e.g., quantitatively) is of lesser value than trying to estimate the determinants of health. This criterion scored highest for all four stakeholder groups, with weights ranging from 25.3 - 46.1\% (Table 6.4). The preference weights per stakeholder are shown in Appendix B, Table SB6.1. 


\section{Chapter 6}

Using stakeholder weights in the analysis can increase uncertainty due to the subjectivity of the stakeholders and their own choices (Dunn, 2015). On the other hand, the preference weights can help to account for uncertainty in the case study and the case-specific nature of the risk (Van der Fels-Klerx et al., 2018). Therefore, the use of weighted preferences is two-sided, contributing subjectively to the MCDA as well as specifically to the case study. Ultimately, having the stakeholder input may increase the acceptance of the control strategy chosen.

This case study explored the use of an MCDA and was situated in the EU, with most respondents coming from the Netherlands. Herein, how culture impacts the criteria and "best" control strategies may be a relevant factor. Future case studies, following a similar approach, may consider comparing results per EU country or even more globally to elucidate the possible differences in the selected control strategy. 
Multi-criteria decision analysis

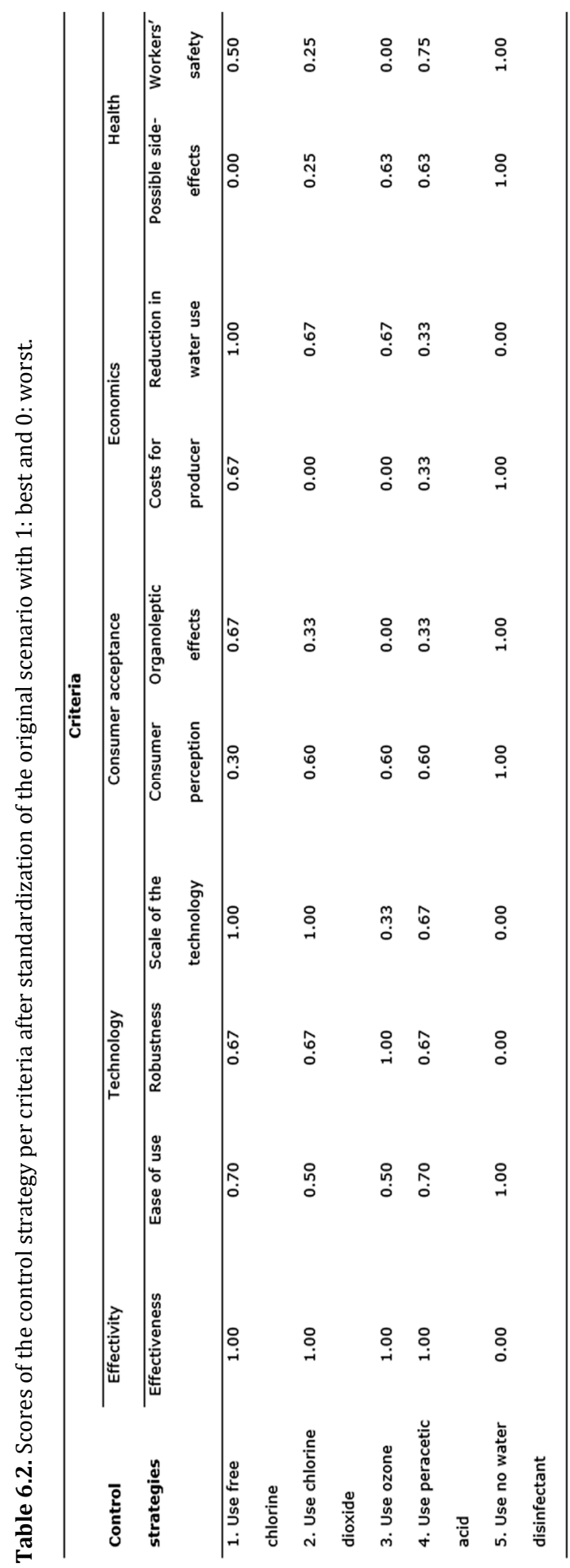




\section{Chapter 6}

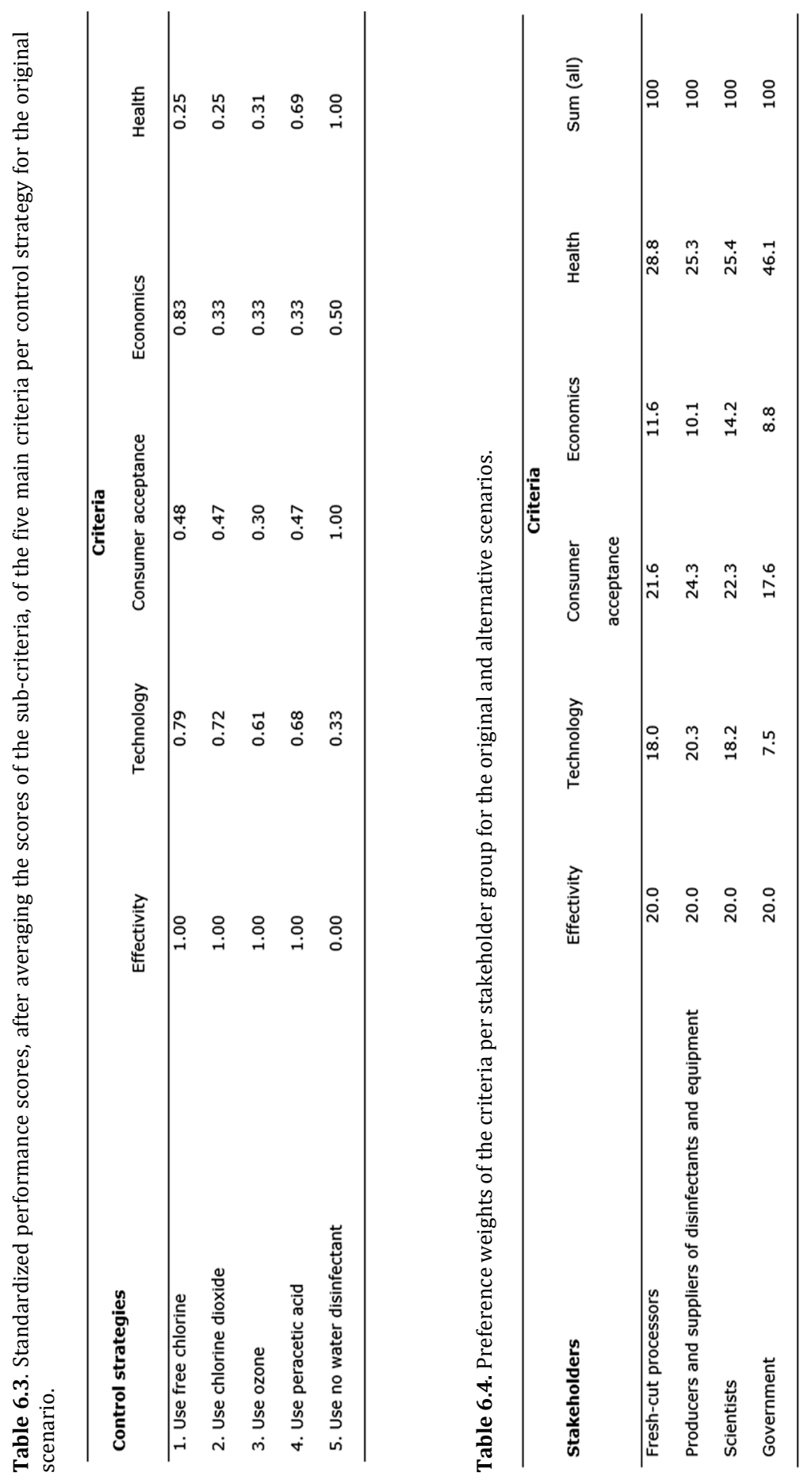




\subsubsection{Ranking of control strategies}

The global performance scores for each control strategy by criteria are reported per stakeholder group in Tables 6.5 to 6.8. Results for fresh-cut processors are shown in Table 6.5. The highest-ranked control strategy was peracetic acid, followed by using no water disinfectant and then free chlorine. Results for producers and suppliers of disinfectants and equipment, as well as scientists, are shown, respectively, in Table 6.6 and Table 6.7. Similar to the fresh-cut processors, these two stakeholder groups had peracetic acid as the highest-ranked control strategy. However, the next best option differed; it was the use of free chlorine, followed by no water disinfectant. All three of these stakeholder groups had ranked ozone as the lowest control strategy. The results for government representatives are presented in Table 6.8. This stakeholder group ranked the use of no water disinfectant as the best control strategy, which differs from all other stakeholder groups. Also, the summed scores for each control strategy were the most varied in this group (range: 47.2 - 70.6, difference: 23.4) compared to all the other groups, where the difference in final scores for the control strategies ranged from 14.5 - 15.6. Also, the lowest control strategy for this stakeholder group was ozone (Table 6.8).

Each stakeholder respondent's global performance scores per control strategy were determined (Appendix C, Tables SC6.1 - SC6.18). Results showed that for fresh-cut processors $(n=2)$, the best control strategy was peracetic acid, and the worst was ozone $(n=2)$ (Tables SC6.1 - SC6.2). This can be explained by the low scores for economics. For producers and suppliers of disinfectants and equipment $(n=3)$, the best control strategy was either no water disinfectant $(n=2)$ or free chlorine $(n=1)$. At the same time, the worst was either ozone $(n=2)$ or the use of no water disinfectant $(n=1)$ (Tables SC6.3 - SC6.5). This can be explained by the high scores for health and low scores for economics, and in the case of free chlorine, the high scores for technology and low scores for health. Results for scientists showed that the best control strategy was either peracetic acid $(n=6)$, free chlorine $(n=4)$, or no water disinfectant $(n=1)$. In contrast, the worst control strategy was either ozone $(n=10)$ or no water disinfectant ( $\mathrm{n}=1$ ) (Tables SC6.6 - SC6.15). This can be explained by the high scores for health and/or technology. For government representatives $(n=3)$, the best control strategy was either peracetic acid $(n=2)$ or the use of no water disinfectant $(n=1)$, while the worst was either ozone $(n=2)$ or chlorine dioxide $(n=1)$ (Table SC6.16 - SC6.18). This can be explained by the high scores for health.

In this study, four stakeholder groups were chosen to participate in the analyses, and their input affects the outcome of the MCDA. The stakeholder group "fresh-cut processors" is financially and legally responsible for ensuring the quality and safety of their product. Ultimately, they need to choose the control strategy to apply during freshcut lettuce washing. Hence, it is most important that this group was considered in the analysis. The other three stakeholder groups' views are valuable since they provide insight into different judgments of value and help facilitate further discussion on the best control strategy. Other stakeholder groups, like non-governmental organizations (NGOs), retailers, or consumers, are interesting to consider in future case studies. These groups can represent the effects on the societal impact of the control strategy. The 


\section{Chapter 6}

robustness of an MCDA is linked to the quality of the implemented scores and participation by stakeholder groups, including expert involvement in the exercise (Bartolini and Viaggi, 2010). Incorporating additional stakeholder groups into the analyses can affect the outcome and robustness of an MCDA. Stakeholder representation in an MCDA is important towards building a consensus in the ultimate decision, and its application in the food safety domain to assist in the decision-making process has been advocated (Fazil et al., 2008). Given the complexity in making food safety-related decisions, an MCDA approach has shown to be a suitable method that can be used to combine various outcomes with different scales (e.g., of quantitative, qualitative, and semi-quantitative data) during the decision-making process and can be used in future case studies.

A limitation to this MCDA is the input provided by the governmental representatives, which influenced the MCDA since participants provided the same points for two or more criteria despite the instructions presented, e.g., multiple zeros or low scores were used for some criteria. By providing scores in this way, this, in turn, inflated some (sub-) criteria, like those related to health. On the other hand, since all participants from this group filled these criteria similarly, these results may accurately reflect the view of this stakeholder group. However, additional participation would help to affirm this result and decrease sample bias. 
Multi-criteria decision analysis
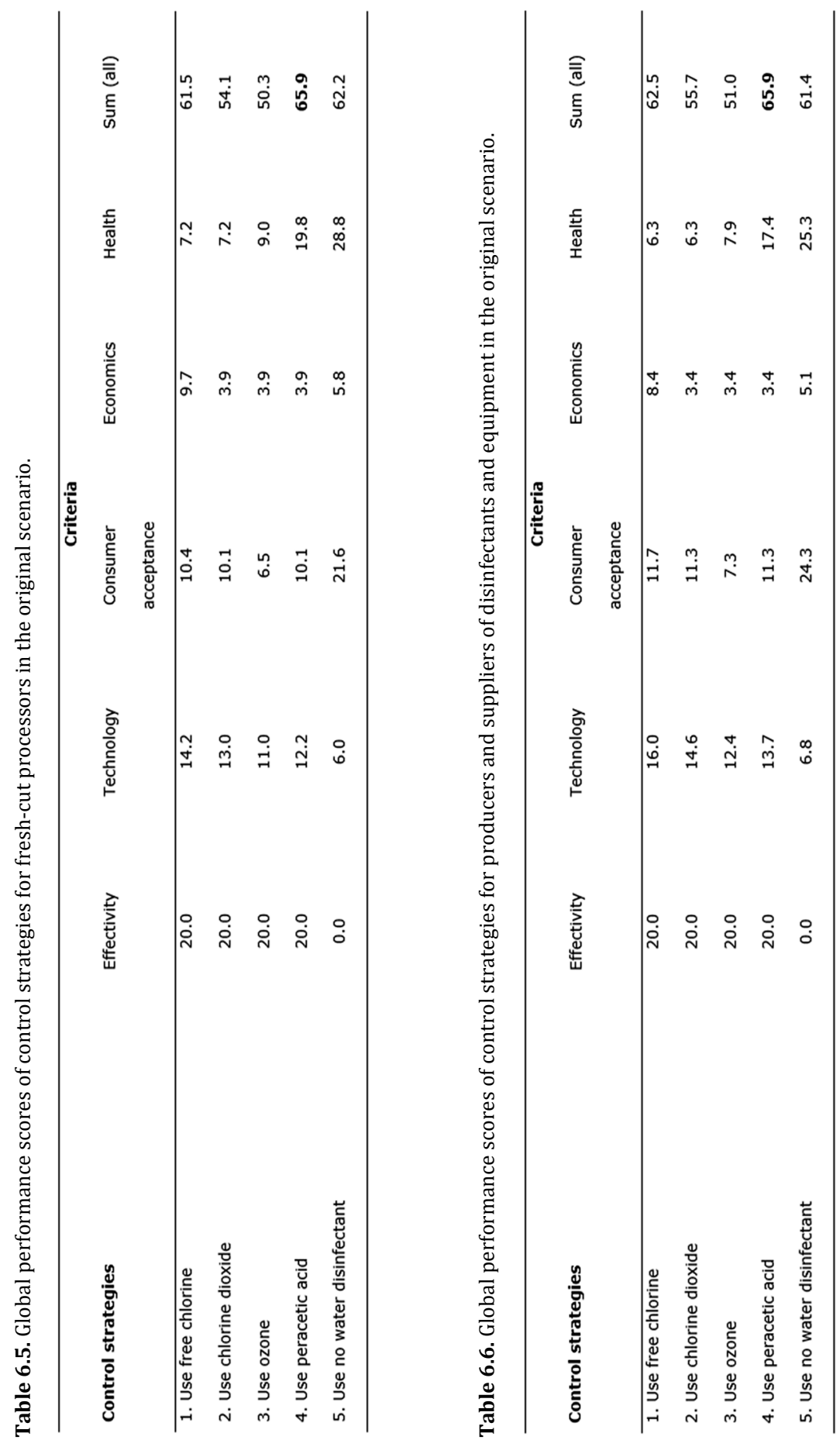


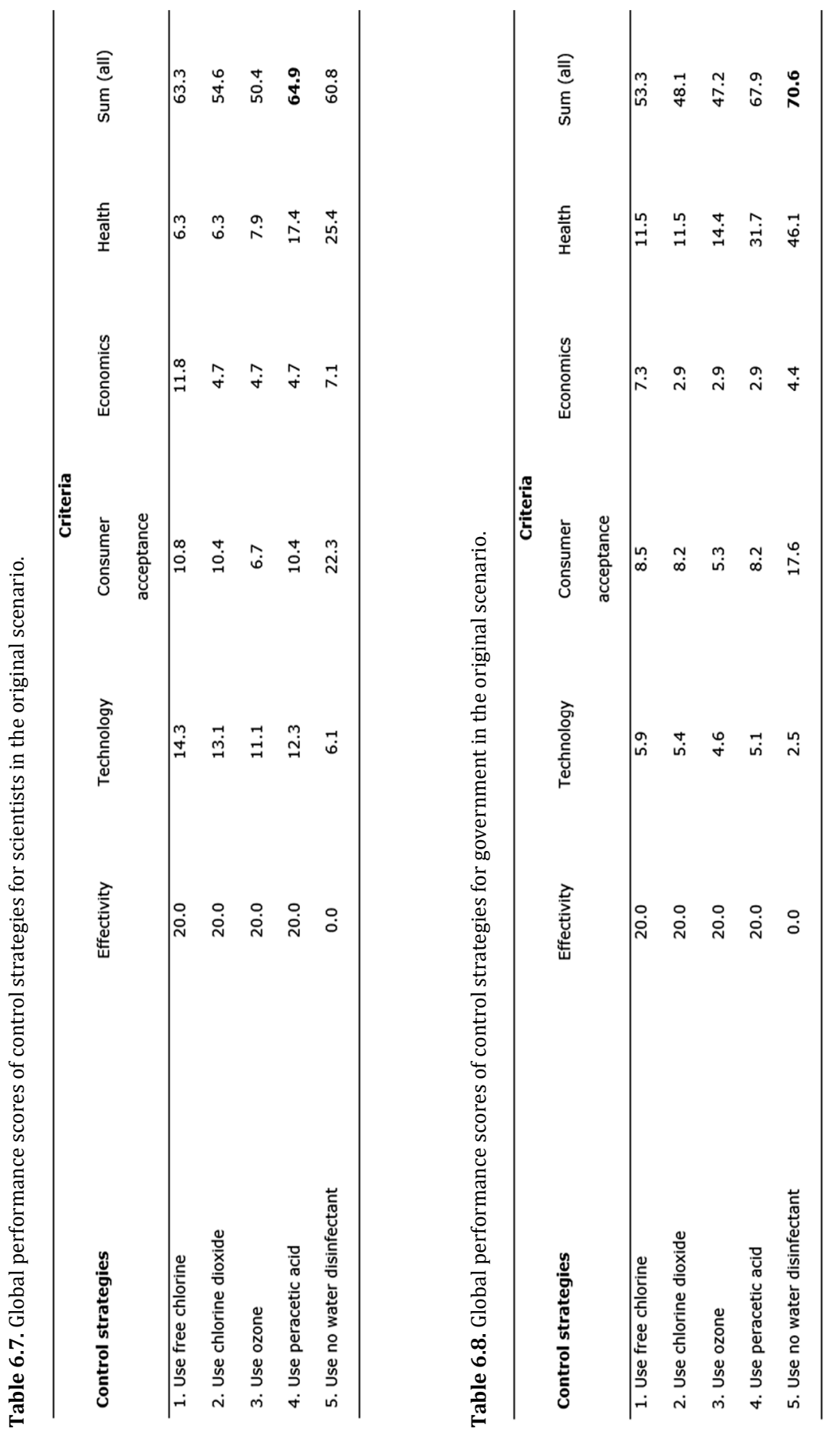




\subsubsection{Final analysis and an alternative scenario}

The effect of the weight of the criterion "health" was of interest to evaluate given the results of the original scenario. In the alternative scenario, the effect that the weight of the criterion "health," including the sub-criteria "possible side-effects," was tested. The scores after the standardization of the alternative scenario are shown in Table 6.9. The results of our case study were compared to an alternative scenario (Table 6.10). The ratio of a score to the maximum score for the stakeholder group was aggregated across each stakeholder group to determine the "relative sum (all)" of a control strategy. These scores were then ranked amongst one another to come with the best overall control strategy. In both the original and alternative scenarios, overall, the best control strategy was the use of peracetic acid. This result has the same outcome for each stakeholder group, except for government representatives (Table 6.8, Table 6.10). Given the averaged results of the government representatives, the best option was the use of no water disinfectant, followed by peracetic acid. However, of the three-government representatives, two had found peracetic acid as the best control strategy (Table SC6.16, Table SC6.18), meaning the scores of the third government representative (Table SC6.17) shifted this overall best-choice for this stakeholder group. Furthermore, the next best control strategy overall was the use of no water disinfectant. This result is the same across all stakeholder groups except for producers and suppliers of disinfectants and equipment and scientists, whose next best control strategy was the use of free chlorine. Overall, the least likely control strategy for the case study was the use of ozone.

Using high concentrations of chlorine is linked to the increased presence of DBPs in the water and on the produce. One main concern with the use of free chlorine is the presence of THMs in the water; however, some research has shown that it does not correlate with higher DBPs on the produce (Tudela et al., 2019b). That study also showed, though, that different types of produce were shown to affect the characteristics of the wash water and that the use of a final rinse with tap water also reduced the concentration of DBPs on the produce (Tudela et al., 2019b). Another concern is the formation of other DBPs like 3-chlorotyrosine, which forms when hypochlorous acid reacts with tyrosine residues in proteins (Bao Loan, Jacxsens, Kurshed and De Meulenaer, 2016.) Research suggests that depending on the exposure from consuming foods like fresh-cut lettuce or spinach, 3-chlorotyrosine could be a health concern, and additional toxicological data is required to assess this risk (Bao Loan et al., 2016; Komaki, Simpson, Choe, Plewa and Mitch, 2018).

As outlined earlier, the score for the possible side-effects of free chlorine was changed from 80 to 100 and analyzed in an alternative scenario. Given conflicting perspectives in the EU on the best disinfectant practices and effects of DBPs, comparing the change in this score provides an alternative take on the ultimate choice for control measures considering the worst-case or safest option (Table 6.10). Consequently, this change increased the standardized scores to be used for the criterion "health" (Table 6.3) for the control strategies chlorine dioxide ( 0.25 to 0.33 ), ozone ( 0.31 to 0.35 ), and peracetic acid (0.69 to 0.73 ). Despite this change, the overall best control strategy remains 


\section{Chapter 6}

peracetic acid, while the second-best option is the use of no water disinfectant (Table 6.10).

Any MCDA model has its limitations. The WSM chosen in this case study is a relatively simple model, and other MCDA models may also be applied to compare the final rankings. Recent research by Garre, Boué, Fernández, Membré and Egea (2020) concluded that during an MCDA, the differences between models have a relevant impact on the outcome rankings. Uncertainty is a factor that highly influences the results, even more than the preference weights (Garre et al., 2020). In our case study, this could mean an alternative ranking to the best control strategy, peracetic acid. Within this WSM, there were no differences in the best final control strategy when the score changed from 80 to 100 for possible side-effects of free chlorine. However, other changes to the original scores, due to uncertainty in the comparison of the control strategies, may lead to changes in the final outcome or ranking.

Although uncertainty is a factor that can limit an MCDA, the possibility of using several types of input on the scores in this study motivates the strength of this MCDA approach. The ease of use of a WSM makes it advantageous. Also, the outcome for the various stakeholders is understandable, and the differences in changing the scores or weights are transparent (Dunn, 2015). This advantage is evident in our case study, given the comparison of the final outcomes for two scenarios (Table 6.10), where the best-choice is peracetic acid for all stakeholder groups except government representatives. 


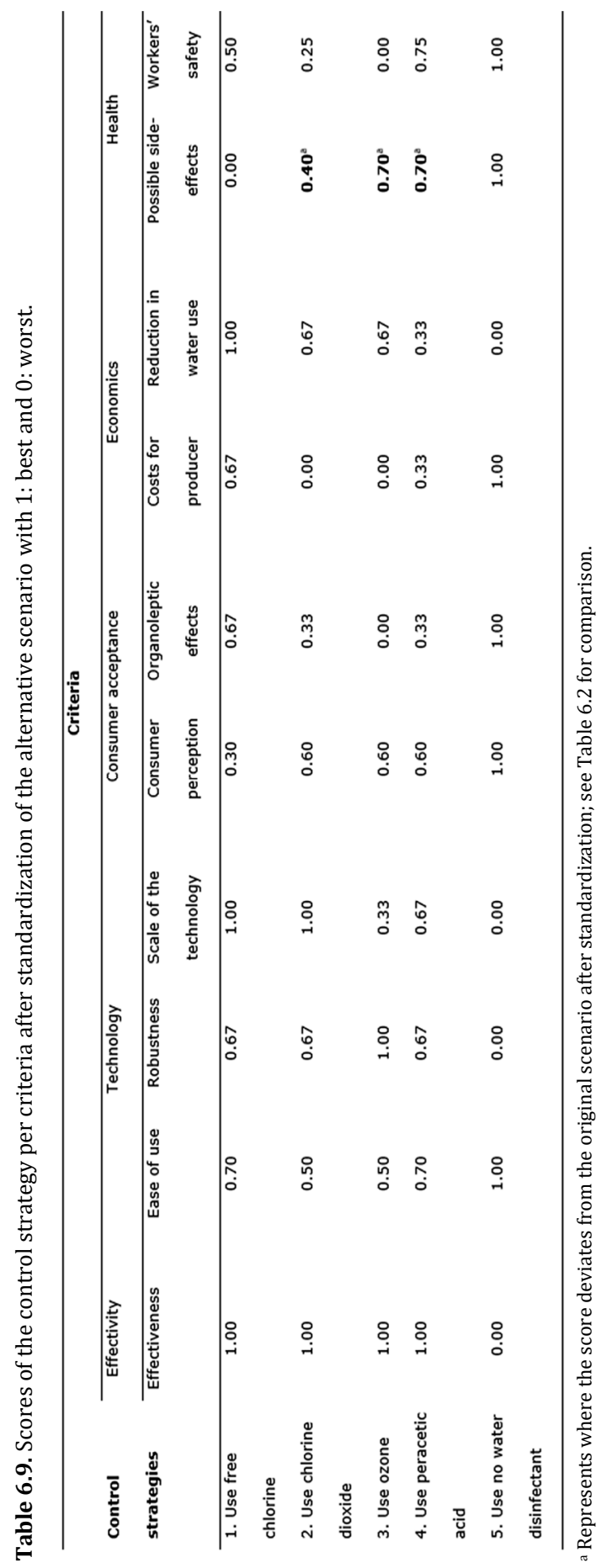




\section{Chapter 6}

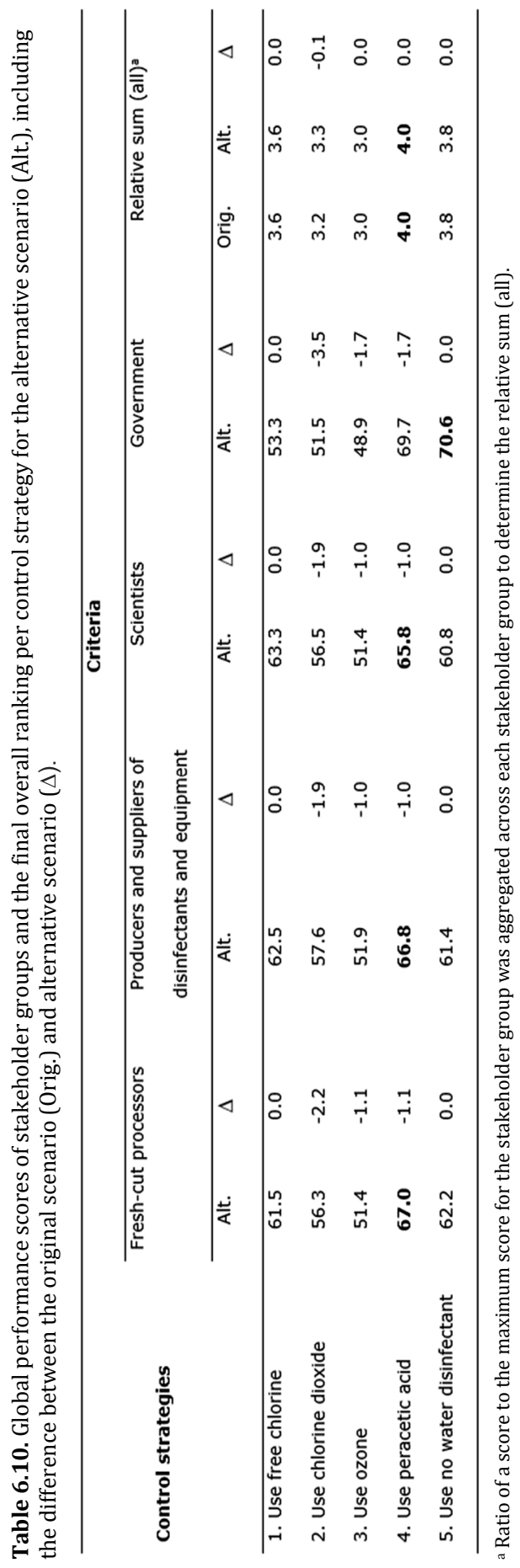




\subsection{Conclusion}

Our study demonstrated the use of an MCDA method as a decision-making tool for a case study on choosing between alternative (mainly chemical) control strategies to treat the wash water that comes in direct contact with the produce in the wash tank during fresh-cut lettuce processing. The case study results showed that from the five control strategies, peracetic acid was found to be the overall best strategy to control pathogenic cross-contamination. Using an MCDA brought structure to the analysis while assisting in the decision-making process. The MCDA approach used in this case study can be used as a first step while evaluating control strategies on food safety themes like the cross-contamination of pathogens during food processing. We expect that using an MCDA approach will help increase the optimal allocation of resources towards the control strategy, as well as create balance and support for the decision to be selected.

\section{Acknowledgments}

This research is financially supported by the Ministry of Agriculture, Nature and Food Quality (LNV) under Knowledge base research (KB)-37-002-023. We also gratefully acknowledge Esther van Asselt, Marcel Klüche, and Yvette Hoffmans (Wageningen Food Safety Research) and Wilfred Appelman and Hermien van Bokhorst-van de Veen (Wageningen Food \& Biobased Research) for providing the criteria and definitions used in this study. Esther van Asselt is also kindly thanked for her suggestions on an earlier version of the paper. Also, the survey participants are kindly acknowledged for their contribution to this research. 


\section{References}

Ali, A., Yeoh, W.K., Forney, C., Siddiqui, M.W., 2018. Advances in postharvest technologies to extend the storage life of minimally processed fruits and vegetables. Crit. Rev. Food Sci. Nutr. 58, 2632-2649. doi: 10.1080/10408398.2017.1339180.

Allende, A., Selma, M.V., Lopez-Galvez, F., Villaescusa, R., Gil, M.I., 2008. Impact of wash water quality on sensory and microbial quality, including Escherichia coli cross-contamination, of fresh-cut escarole. J. Food Prot. 71, 2514-2518. doi: 10.4315/0362-028x-71.12.2514.

Baert, L., Vandekinderen, I., Devlieghere, F., Van Coillie, E., Debevere, J., Uyttendaele, M., 2009. Efficacy of sodium hypochlorite and peroxyacetic acid to reduce murine norovirus 1, B40-8, Listeria monocytogenes, and Escherichia coli 0157:H7 on shredded iceberg lettuce and in residual wash water. J. Food Prot. 72, 1047-1054. doi: 10.4315/0362-028x-72.5.1047.

Banach, J.L., Sampers, I., Van Haute, S., van der Fels-Klerx, H.J., 2015. Effect of disinfectants on preventing the cross-contamination of pathogens in fresh produce washing water. Int. J. Environ. Res. Public Health 12, 8658-8677. doi: 10.3390/ijerph120808658.

Banach, J.L., van Bokhorst-van de Veen, H., van Overbeek, L.S., van der Zouwen, P.S., van der Fels-Klerx, H.J., Groot, M.N.N., 2017. The efficacy of chemical sanitizers on the reduction of Salmonella Typhimurium and Escherichia coli affected by bacterial cell history and water quality. Food Control 81, 137-146. doi: 10.1016/j.foodcont.2017.05.044.

Banach, J.L., van Bokhorst-van de Veen, H., van Overbeek, L.S., van der Zouwen, P.S., Zwietering, M.H., van der Fels-Klerx, H.J., 2020. Effectiveness of a peracetic acid solution on Escherichia coli reduction during fresh-cut lettuce processing at the laboratory and industrial scales. Int. J. Food Microbiol. 321, 108537. doi: 10.1016/j.ijfoodmicro.2020.108537.

Banach, J.L., van Overbeek, L.S., Nierop Groot, M.N., van der Zouwen, P.S., van der Fels-Klerx, H.J., 2018. Efficacy of chlorine dioxide on Escherichia coli inactivation during pilot-scale fresh-cut lettuce processing. Int. J. Food Microbiol. 269, 128-136. doi: 10.1016/j.ijfoodmicro.2018.01.013.

Bao Loan, H.N., Jacxsens, L., Kurshed, A.A.M., De Meulenaer, B., 2016. 3-Chlorotyrosine formation in ready-toeat vegetables due to hypochlorite treatment and its dietary exposure and risk assessment. Food Res. Int. 90, 186-193. doi: 10.1016/j.foodres.2016.10.048.

Bartolini, F., Viaggi, D., 2010. Recent developments in multi-criteria evaluation of regulations. Qual. Assur. Saf. Crop. Foods 2, 182-196. doi: 10.1111/j.1757-837X.2010.00076.x.

Chawla, A.S., Kasler, D.R., Sastry, S.K., Yousef, A.E., 2012. Microbial decontamination of food using ozone, in: Demirci, A., Ngadi, M.O. (Eds.), Microbial Decontamination in the Food Industry. Woodhead Publishing, pp. 495-532.

Davidson, G.R., Kaminski-Davidson, C.N., Ryser, E.T., 2017. Persistence of Escherichia coli 0157:H7 during pilot-scale processing of iceberg lettuce using flume water containing peroxyacetic acid-based sanitizers and various organic loads. Int. J. Food Microbiol. 248, 22-31. doi: 10.1016/j.ijfoodmicro.2017.02.006.

Dunn, A.H., 2015. A multi-criteria approach to the evaluation of food safety interventions, Department of Management, Marketing and Entrepreneurship. University of Canterbury, Christchurch, NZ.

Duret, S., Hoang, H.-M., Derens-Bertheau, E., Delahaye, A., Laguerre, O., Guillier, L., 2019. Combining quantitative risk assessment of human health, food waste, and energy consumption: the next step in the development of the food cold chain? Risk Anal. 39, 906-925. doi: 10.1111/risa.13199.

EFSA Panel on Biological Hazards (BIOHAZ), 2013. Scientific opinion on the risk posed by pathogens in food of non-animal origin. Part 1 (outbreak data analysis and risk ranking of food/pathogen combinations). EFSA J. 11, 138. doi: 10.2903/j.efsa.2013.3025.

Fang, J., Liu, H., Shang, C., Zeng, M., Ni, M., Liu, W., 2014. E. coli and bacteriophage MS2 disinfection by UV, ozone and the combined UV and ozone processes. Front. Env. Sci. Eng. 8, 547-552. doi: 10.1007/s11783-013-0620-2.

Fazil, A., Rajic, A., Sanchez, J., McEwen, S., 2008. Choices, choices: the application of multi-criteria decision analysis to a food safety decision-making problem. J. Food Prot. 71, 2323-2333. doi: 10.4315/0362-028x-71.11.2323.

Food and Agriculture Organization of the United Nations (FAO), World Health Organization (WHO), 2014. Multicriteria-based ranking for risk management of food-borne parasites. FAO/WHO, Rome, IT.

Foong-Cunningham, S., Verkaar, E.L.C., Swanson, K., 2012. Microbial decontamination of fresh produce, in: Demirci, A., Ngadi, M.O. (Eds.), Microbial Decontamination in the Food Industry. Woodhead Publishing, pp. 3-29. 
Garre, A., Boué, G., Fernández, P.S., Membré, J.-M., Egea, J.A., 2020. Evaluation of multicriteria decision analysis algorithms in food safety: a case study on emerging zoonoses prioritization. Risk Anal. 40, 336-351. doi: 10.1111/risa.13391.

Garrido, Y., Marin, A., Tudela, J.A., Allende, A., Gil, M.I., 2019. Chlorate uptake during washing is influenced by product type and cut piece size, as well as washing time and wash water content. Postharvest Biol. Technol. 151, 45-52. doi: 10.1016/j.postharvbio.2019.01.014.

Gil, M.I., Allende, A., 2018. Water and wastewater use in the fresh produce industry: food safety and environmental implications, in: Pérez-Rodríguez, F., Skandamis, P., Valdramidis, V. (Eds.), Quantitative Methods for Food Safety and Quality in the Vegetable Industry. Springer International Publishing, Cham, CH, pp. 59-76.

Gil, M.I., Selma, M.V., Lopez-Galvez, F., Allende, A., 2009. Fresh-cut product sanitation and wash water disinfection: problems and solutions. Int. J. Food Microbiol. 134, 37-45. doi: 10.1016/j.ijfoodmicro.2009.05.021.

Gil, M.I., Selma, M.V., Suslow, T., Jacxsens, L., Uyttendaele, M., Allende, A., 2015. Pre- and postharvest preventive measures and intervention strategies to control microbial food safety hazards of fresh leafy vegetables. Crit. Rev. Food Sci. Nutr. 55, 453-468. doi: 10.1080/10408398.2012.657808.

Holvoet, K., Jacxsens, L., Sampers, I., Uyttendaele, M., 2012. Insight into the prevalence and distribution of microbial contamination to evaluate water management in the fresh produce processing industry. J. Food Prot. 75, 671-681. doi: 10.4315/0362-028x.Jfp-11-175.

Komaki, Y., Simpson, A.M.A., Choe, J.K., Plewa, M.J., Mitch, W.A., 2018. Chlorotyrosines versus volatile byproducts from chlorine disinfection during washing of spinach and lettuce. Environ. Sci. Technol. 52, 9361-9369. doi: 10.1021/acs.est.8b03005.

López-Gálvez, F., Allende, A., Selma, M.V., Gil, M.I., 2009. Prevention of Escherichia coli cross-contamination by different commercial sanitizers during washing of fresh-cut lettuce. Int. J. Food Microbiol.133, 167171. doi: 10.1016/j.ijfoodmicro.2009.05.017.

López-Gálvez, F., Allende, A., Truchado, P., Martínez-Sánchez, A., Tudela, J.A., Selma, M.V., Gil, M.I., 2010. Suitability of aqueous chlorine dioxide versus sodium hypochlorite as an effective sanitizer for preserving quality of fresh-cut lettuce while avoiding by-product formation. Postharvest Biol. Technol. 55, 53-60. doi: 10.1016/j.postharvbio.2009.08.001.

Luo, Y.G., Nou, X.W., Yang, Y., Alegre, I., Turner, E., Feng, H., Abadias, M., Conway, W., 2011. Determination of free chlorine concentrations needed to prevent Escherichia coli 0157:H7 cross-contamination during fresh-cut produce wash. J. Food Prot. 74, 352-358. doi: 10.4315/0362-028x.Jfp-10-429.

Mazzocchi, M., Ragona, M., Zanoli, A., 2013. A fuzzy multi-criteria approach for the ex-ante impact assessment of food safety policies. Food Policy 38, 177-189. doi: 10.1016/j.foodpol.2012.11.011.

Meireles, A., Giaouris, E., Simões, M., 2016. Alternative disinfection methods to chlorine for use in the freshcut industry. Food Res. Int. 82, 71-85. doi: 10.1016/j.foodres.2016.01.021.

Papachristodoulou, M., Koukounaras, A., Siomos, A.S., Liakou, A., Gerasopoulos, D., 2018. The effects of ozonated water on the microbial counts and the shelf life attributes of fresh-cut spinach. J. Food Process. Pres. 42, e13404. doi: 10.1111/jfpp.13404.

Pedersen, M.J., Nielsen, C.V., 2016. Improving survey response rates in online panels: effects of low-cost incentives and cost-free text appeal interventions. Soc. Sci. Comput. Rev. 34, 229-243. doi: $10.1177 / 0894439314563916$.

Petri, E., Rodríguez, M., García, S., 2015. Evaluation of combined disinfection methods for reducing Escherichia coli 0157: H7 population on fresh-cut vegetables. Int. J. Environ. Res. Public Health 12, 8678-8690. doi: 10.3390/ijerph120808678.

Ruzante, J.M., Grieger, K., Woodward, K., Lambertini, E., Kowalcyk, B., 2017. The use of multi-criteria decision analysis in food safety risk-benefit assessment. Food Prot. Trends 37, 132-139.

Selma, M.V., Allende, A., López-Gálvez, F., Conesa, M.A., Gil, M.I., 2008. Disinfection potential of ozone, ultraviolet-C and their combination in wash water for the fresh-cut vegetable industry. Food Microbiol. 25, 809-814. doi: 10.1016/j.fm.2008.04.005.

Tudela, J.A., Lopez-Galvez, F., Allende, A., Gil, M.I., 2019a. Chlorination management in commercial fresh produce processing lines. Food Control 106. doi: 10.1016/j.foodcont.2019.106760.

Tudela, J.A., Lopez-Galvez, F., Allende, A., Hernandez, N., Andujar, S., Marin, A., Garrido, Y., Gil, M.I., $2019 b$. Operational limits of sodium hypochlorite for different fresh produce wash water based on microbial inactivation and disinfection by-products (DBPs). Food Control 104, 300-307. doi: /j.foodcont.2019.05.005. 


\section{Chapter 6}

Van der Fels-Klerx, H.J., Van Asselt, E.D., Raley, M., Poulsen, M., Korsgaard, H., Bredsdorff, L., Nauta, M., D'Agostino, M., Coles, D., Marvin, H.J.P., Frewer, L.J., 2018. Critical review of methods for risk ranking of food-related hazards, based on risks for human health. Crit. Rev. Food Sci. Nutr. 58, 178193. doi: 10.1080/10408398.2016.1141165.

Van Haute, S., Sampers, I., Holvoet, K., Uyttendaele, M., 2013. Physicochemical quality and chemical safety of chlorine as a reconditioning agent and wash water disinfectant for fresh-cut lettuce washing. Appl. Environ. Microbiol. 79, 2850-2861. doi: 10.1128/aem.03283-12.

Van Haute, S., Sampers, I., Jacxsens, L., Uyttendaele, M., 2015. Selection criteria for water disinfection techniques in agricultural practices. Crit. Rev. Food Sci. Nutr. 55, 1529-1551. doi: 10.1080/10408398.2012.705360. 


\section{Supplementary materials}

\section{Appendix A. Definitions of the sub-criteria}

\section{Criterion 2: Technology}

- Ease of use: this sub-criterion refers to the easiness for employees to apply the technology. For instance, is a special course or training needed to apply the technology, or can it be demonstrated and applied easily?

- Robustness: this sub-criterion refers to the ability of the technology to obtain the same effect over time regardless of the water quality, seasonal or geographic differences, and/or technical failures.

- Scale of the technology: this sub-criterion refers to the amount of water that can be treated with the technology.

\section{Criterion 3: Consumer acceptance}

- Consumer perception: this sub-criterion reflects the consumer perception towards the use of this technology.

- Organoleptic effects: this sub-criterion refers to the possible adverse or undesired effect on the lettuce in terms of sensory quality.

\section{Criterion 4: Economics}

- Costs (for the producer): this sub-criterion assumes a 5-year time for the technology, considering direct costs (e.g., purchase of the chemicals, equipment) and indirect costs (e.g., quality control, depreciation, energy use) required.

- Reduction in water use: this sub-criterion refers to the amount of water that can be saved during processing by applying the technology.

\section{Criterion 5: Public health}

- Possible side-effects: this sub-criterion refers to the possible production of byproducts with unknown or adverse human health effects.

- Workers' safety: this sub-criterion refers to the effect of the technology on the workers' safety (e.g., irritation). 


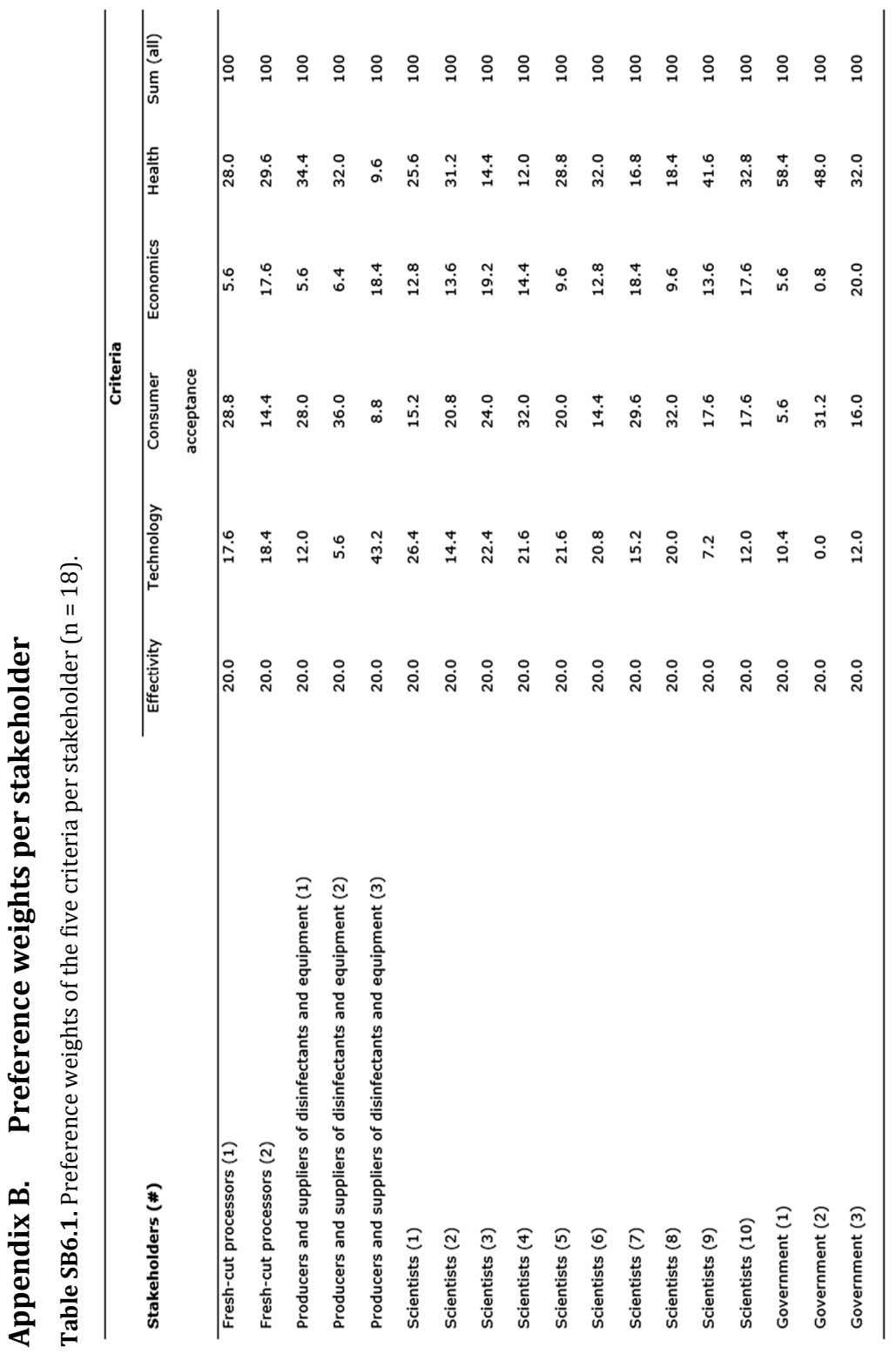


Multi-criteria decision analysis

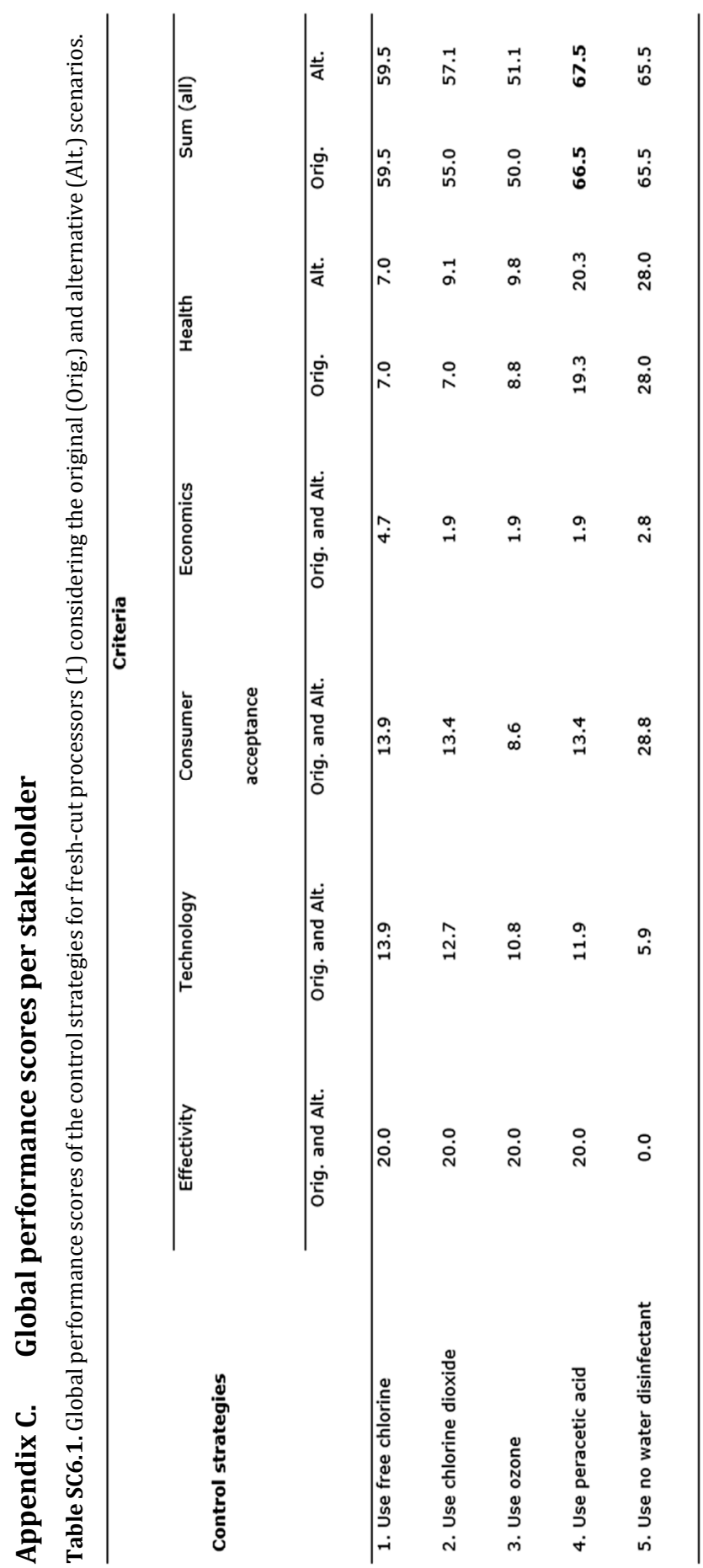




\section{Chapter 6}

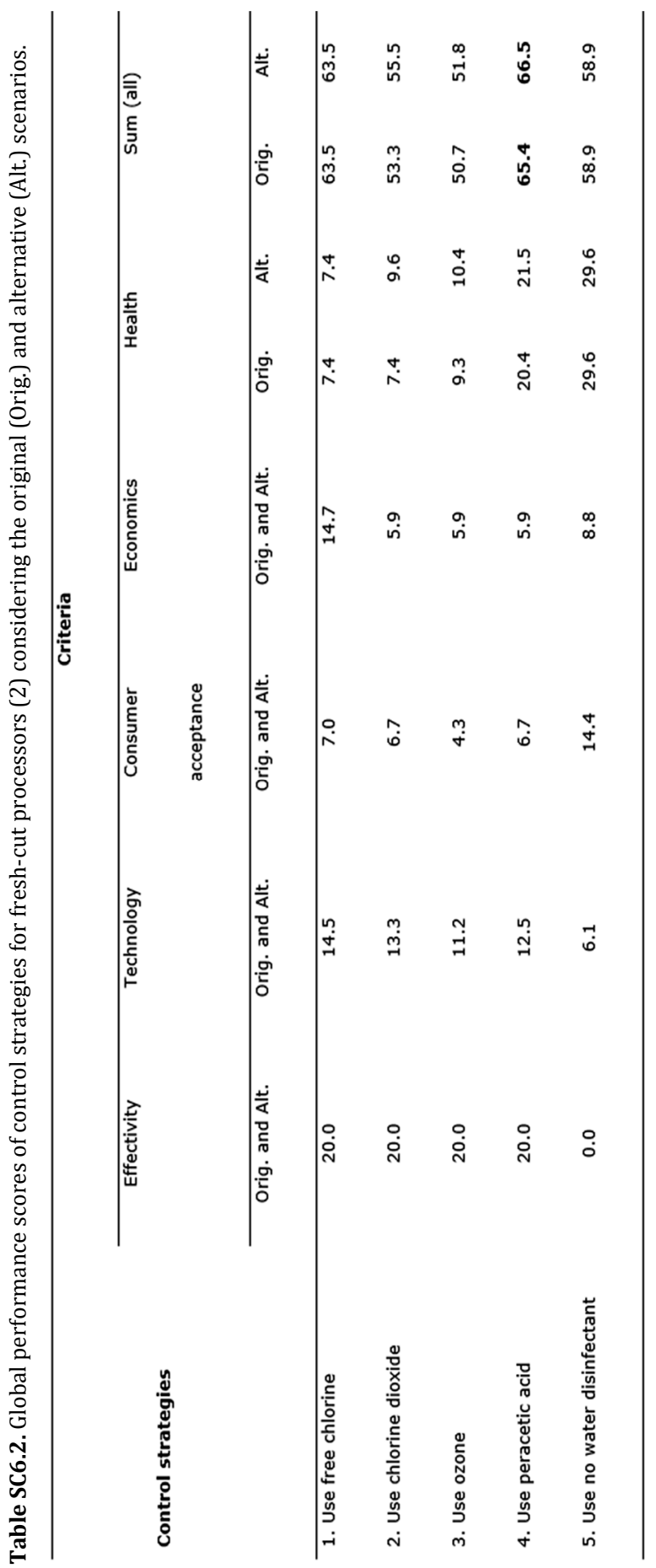


Multi-criteria decision analysis

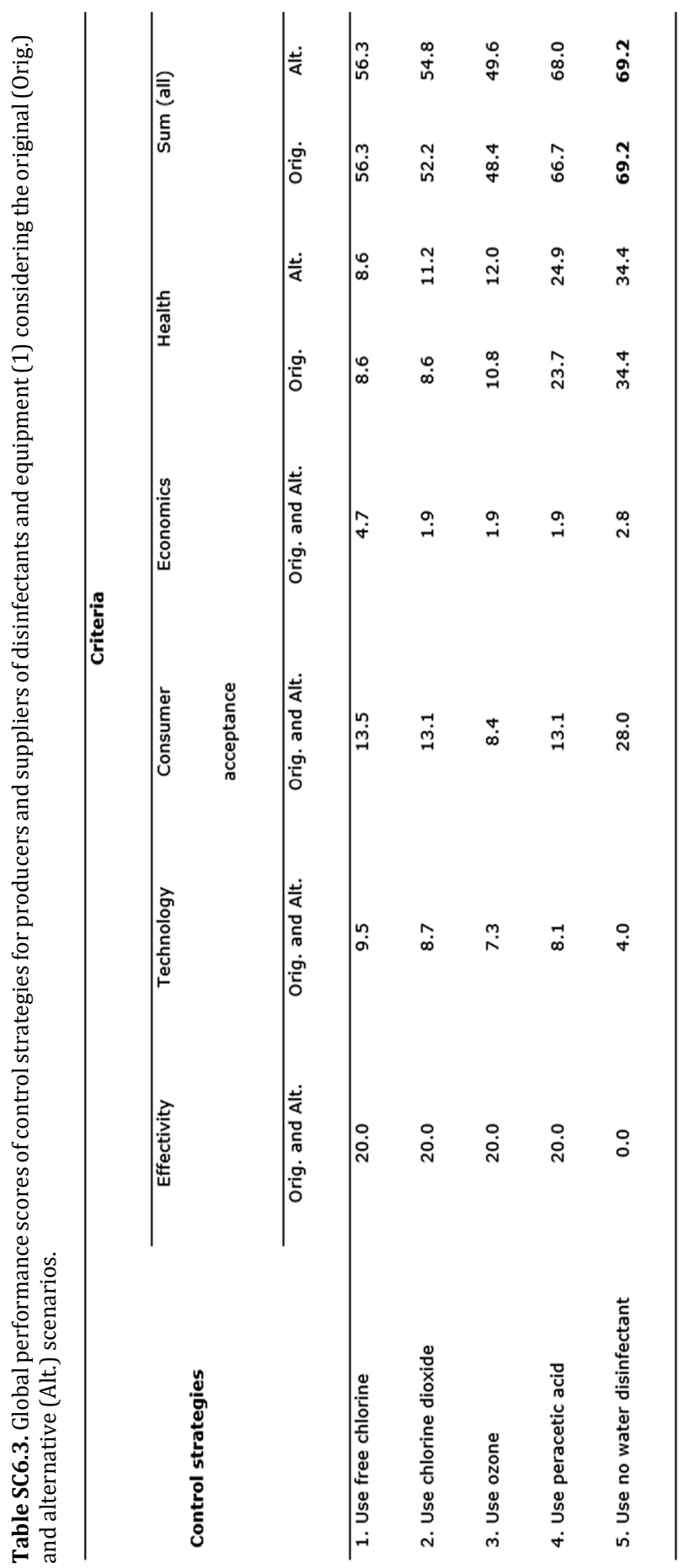




\section{Chapter 6}

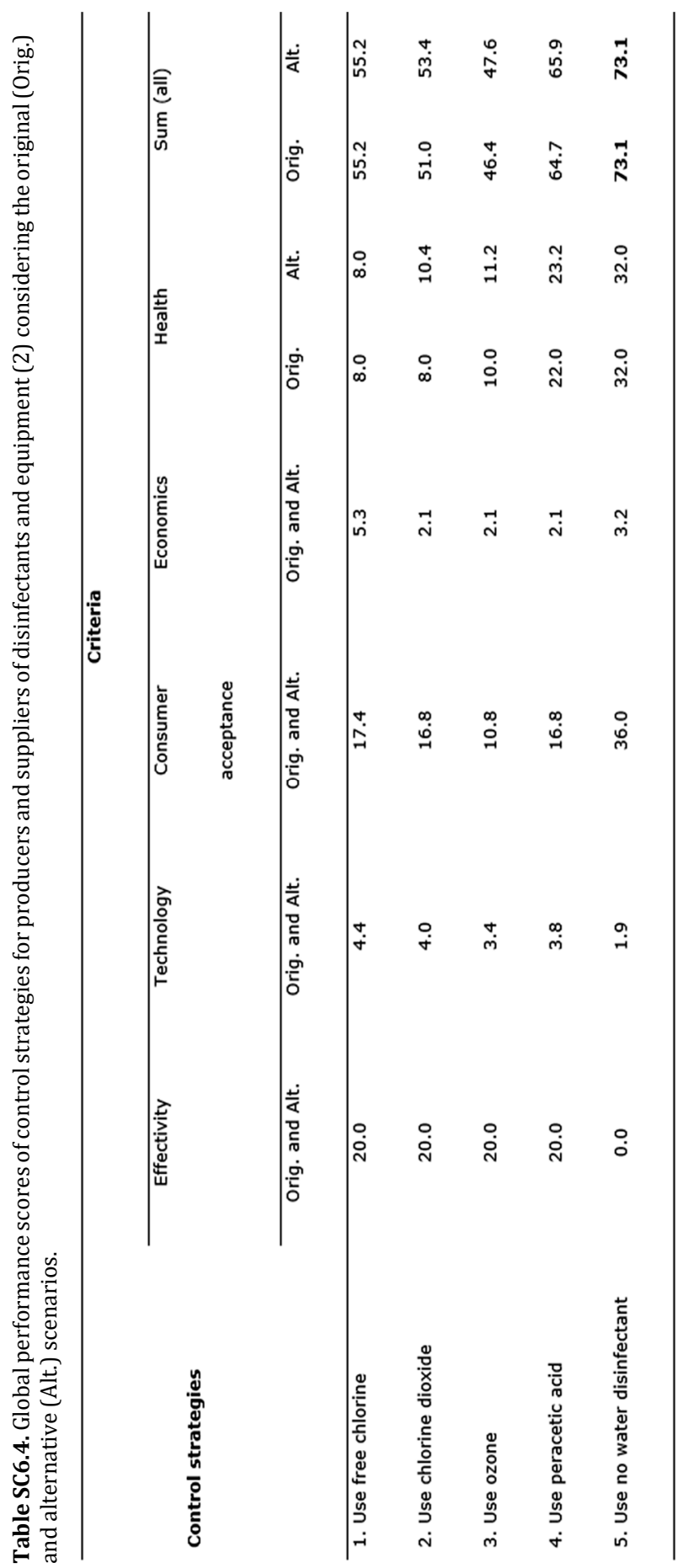




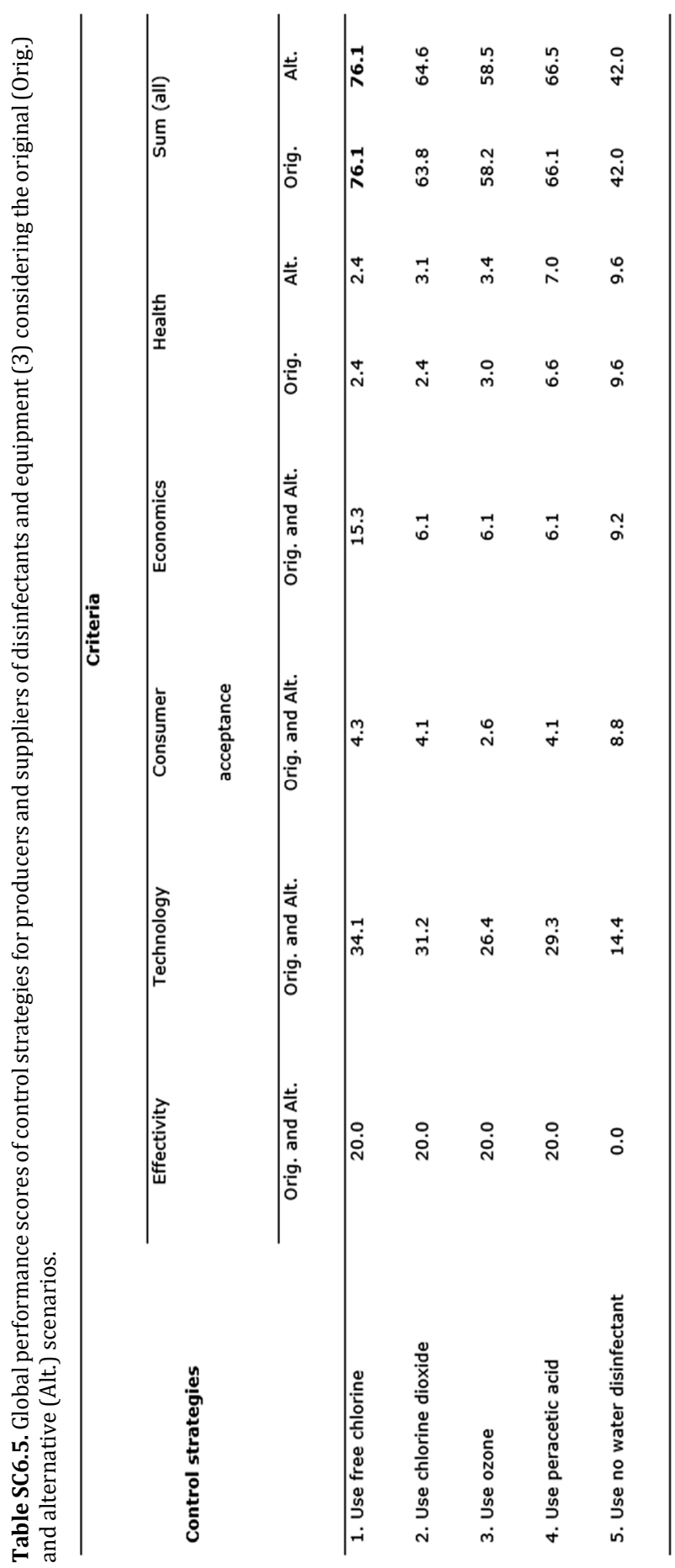




\section{Chapter 6}

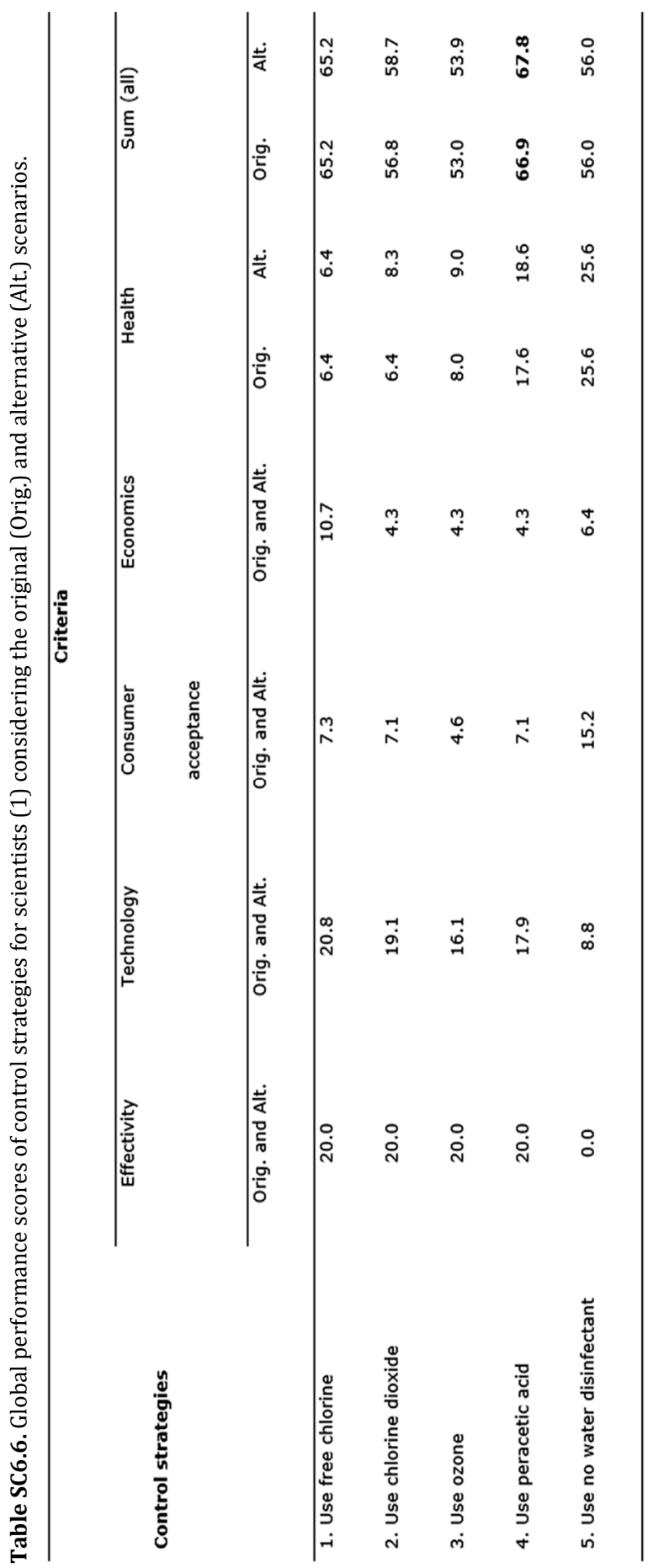


Multi-criteria decision analysis

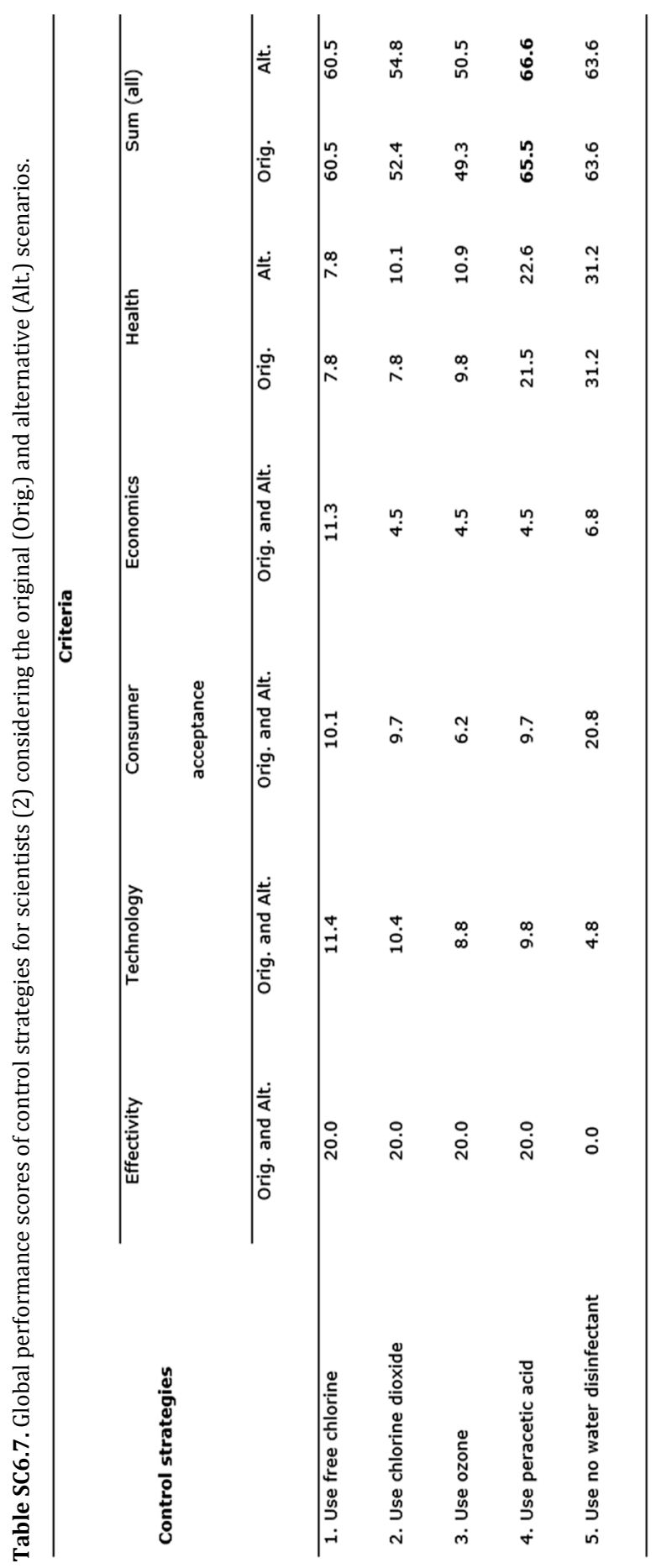




\section{Chapter 6}

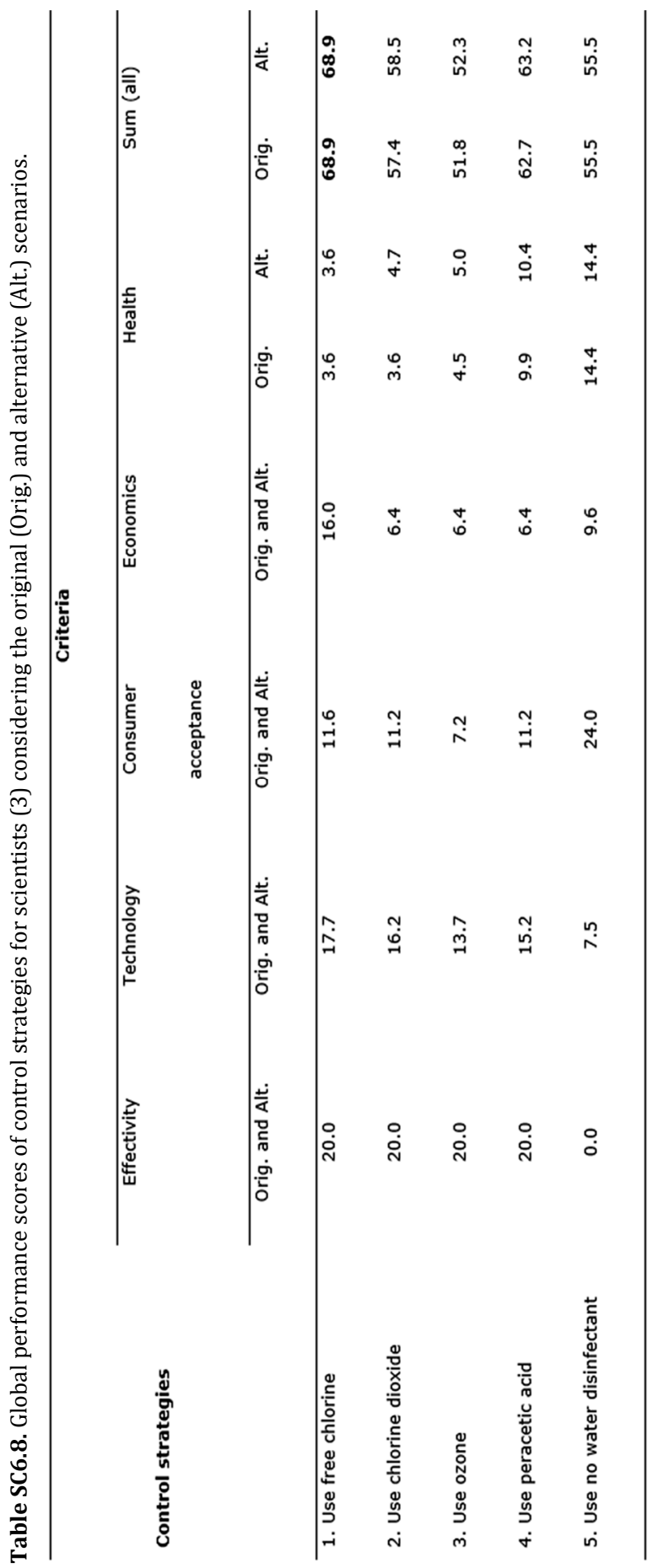




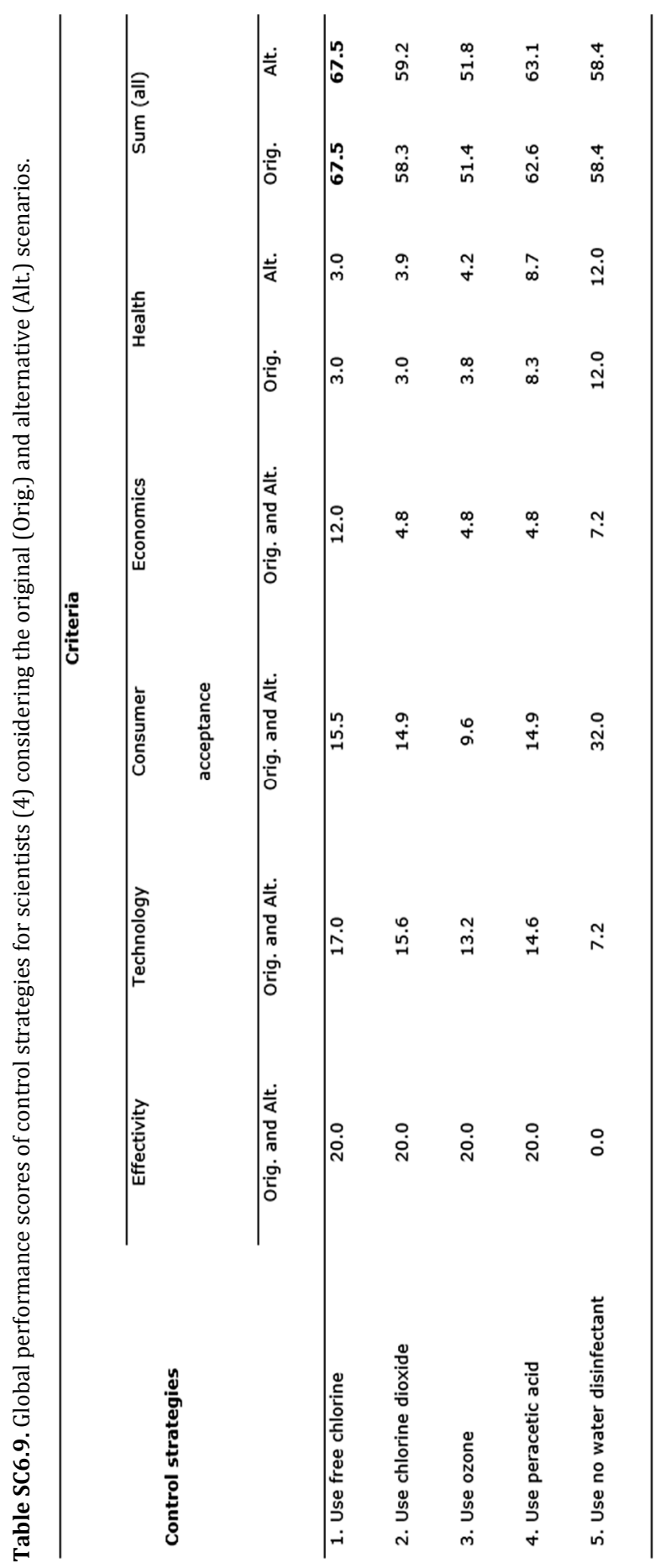




\section{Chapter 6}

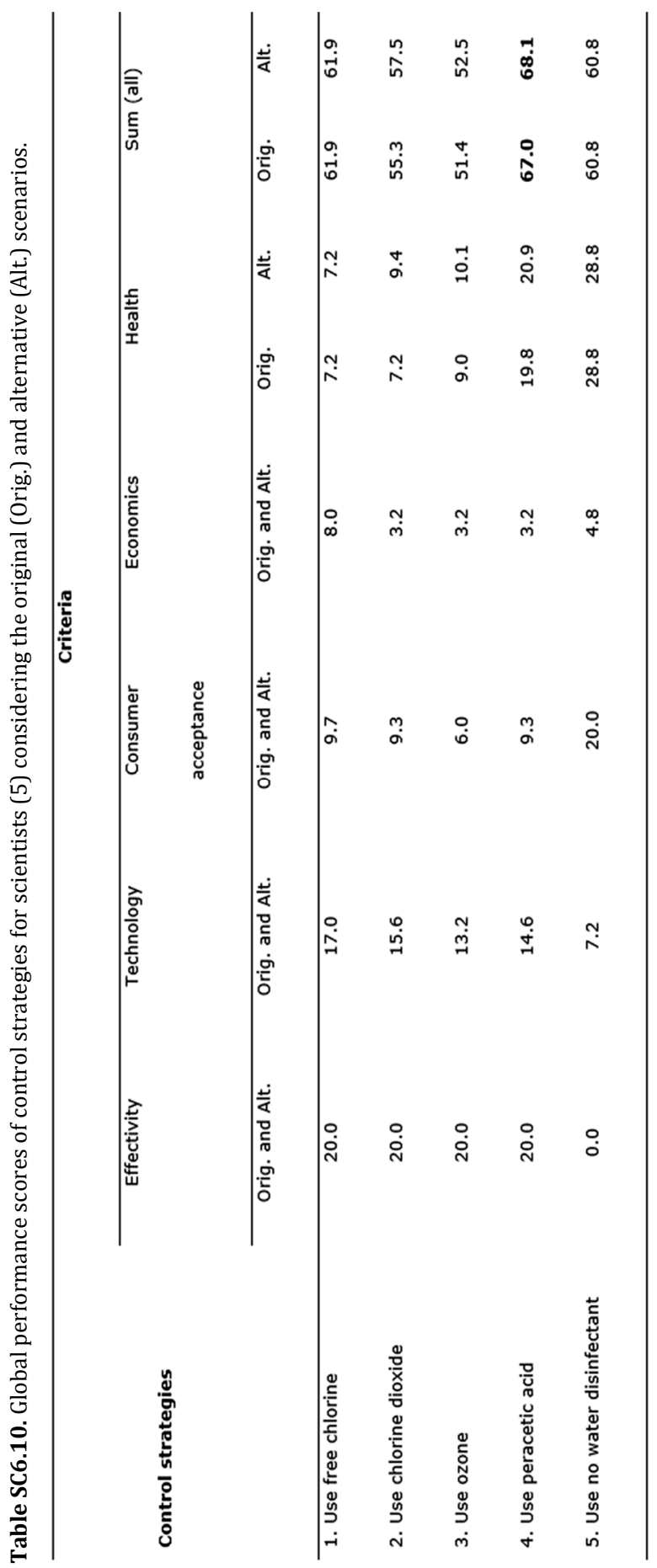


Multi-criteria decision analysis

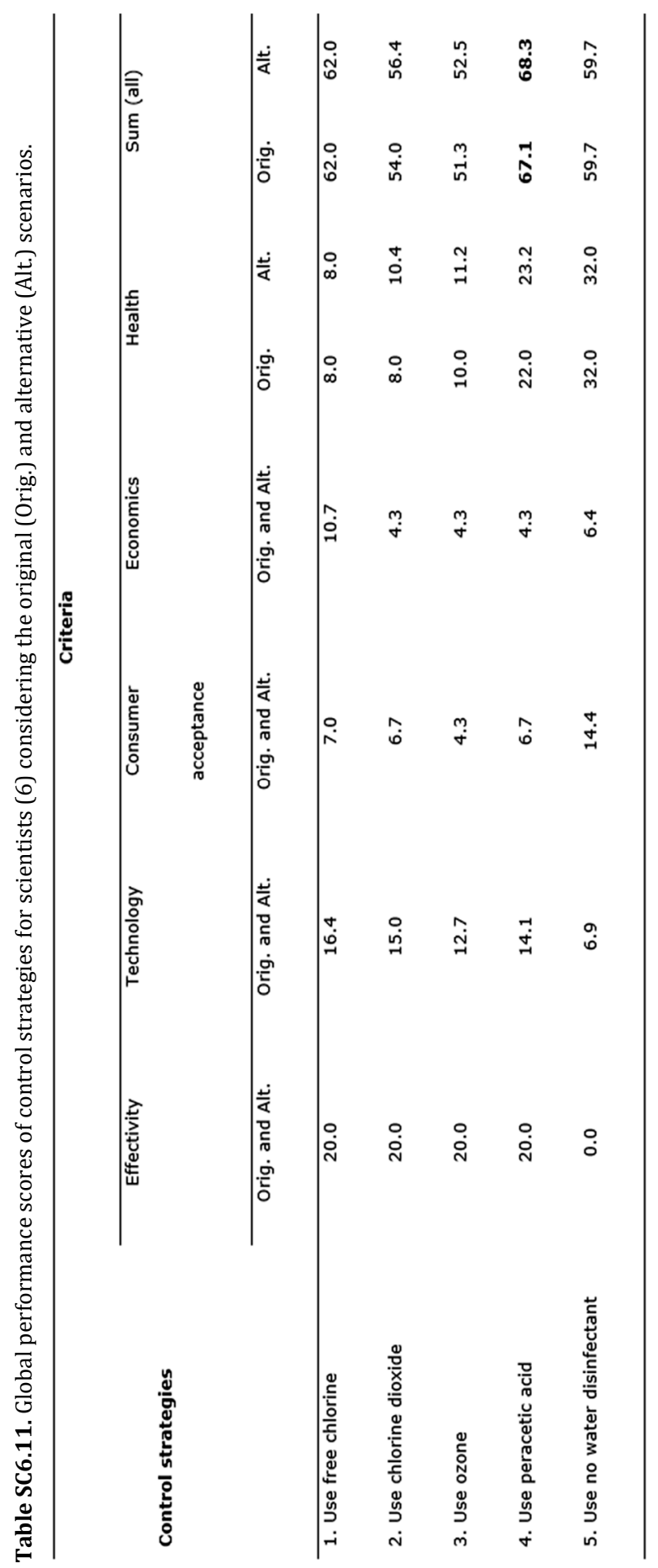




\section{Chapter 6}

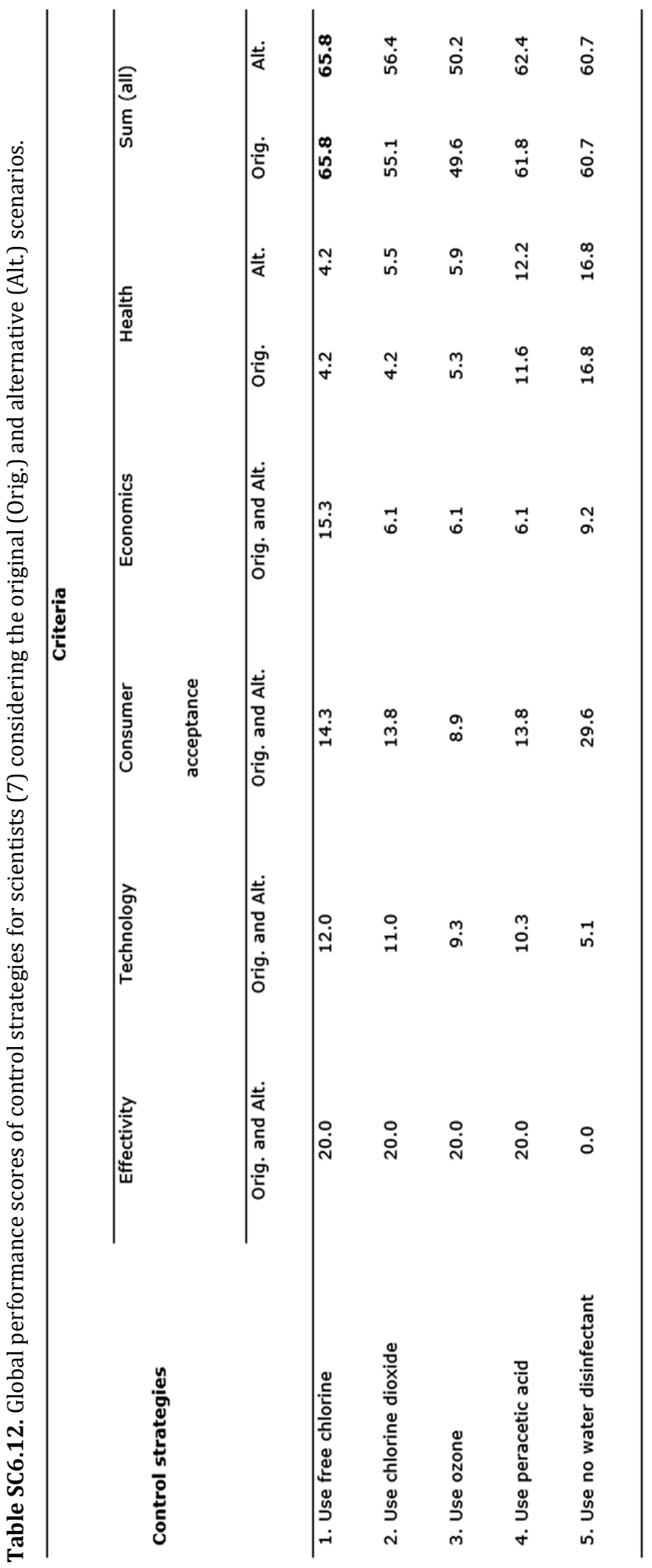


Multi-criteria decision analysis

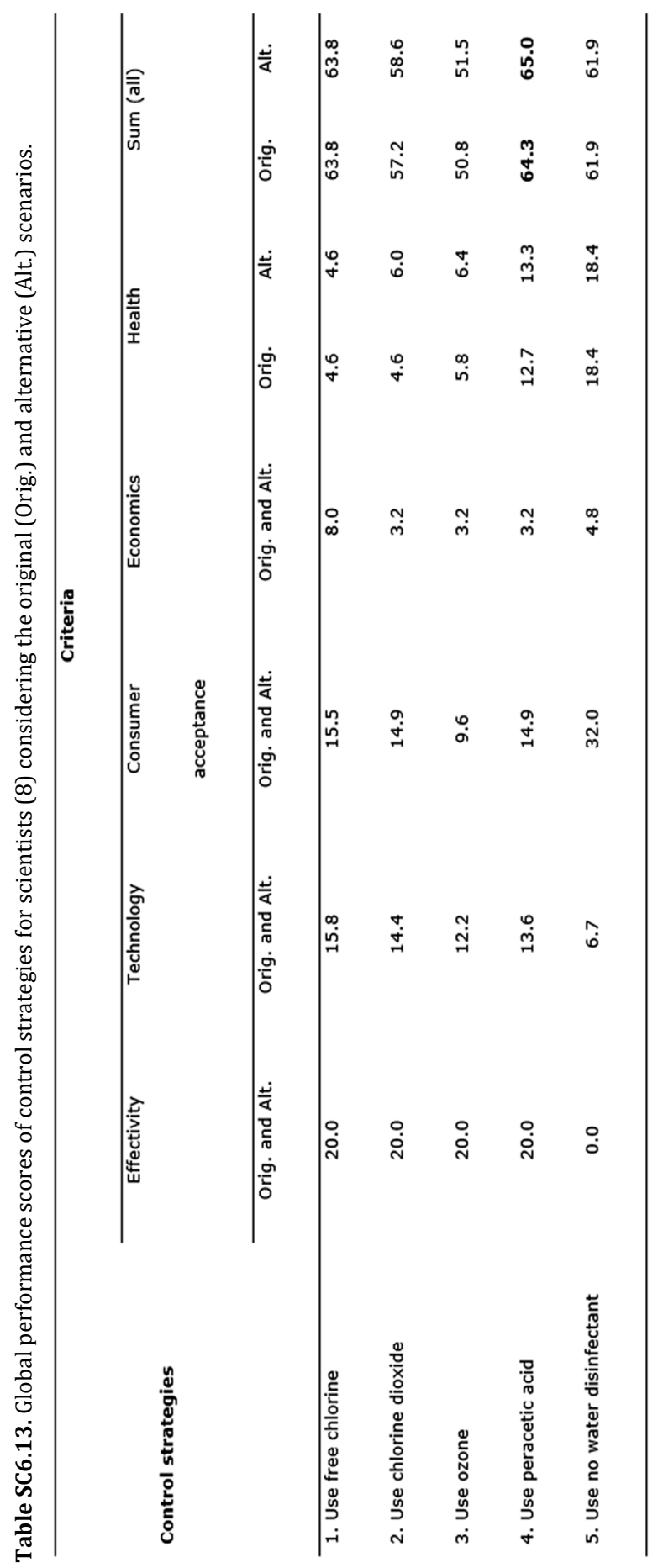




\section{Chapter 6}

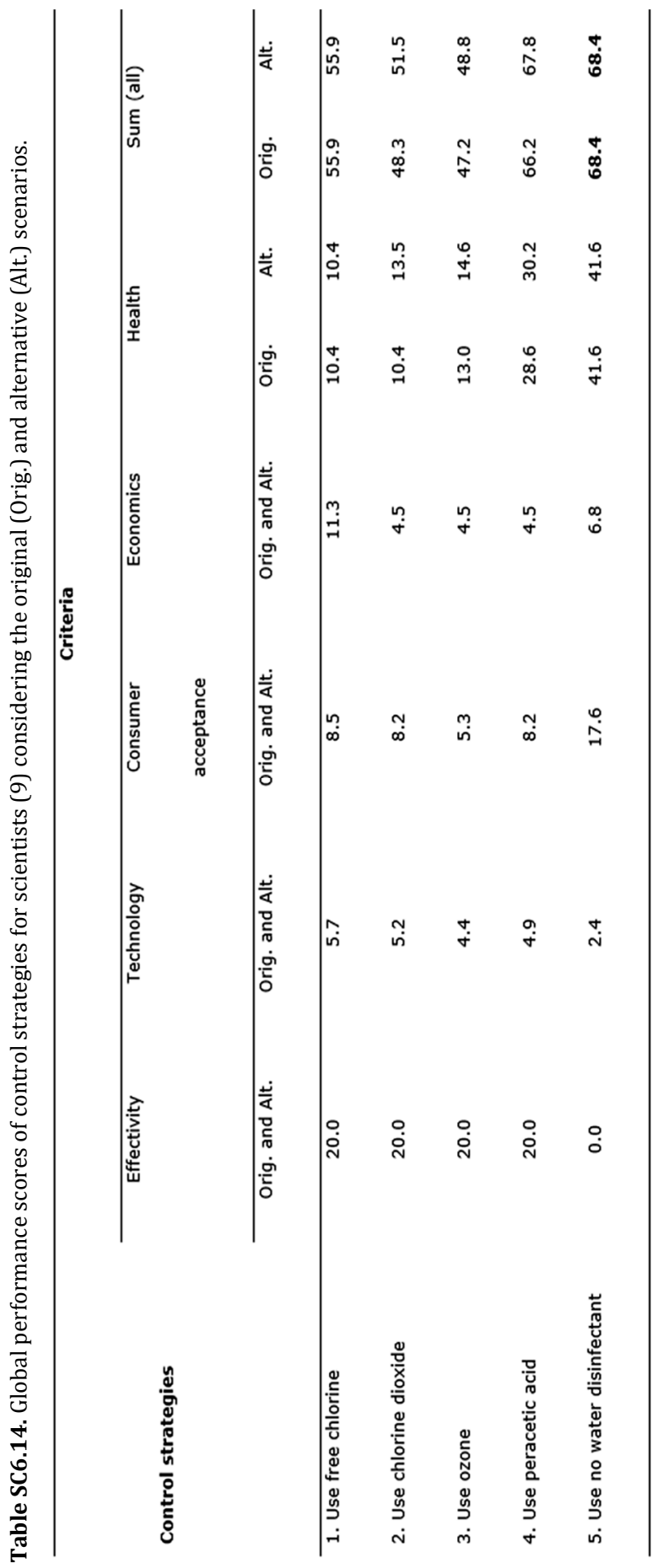


Multi-criteria decision analysis

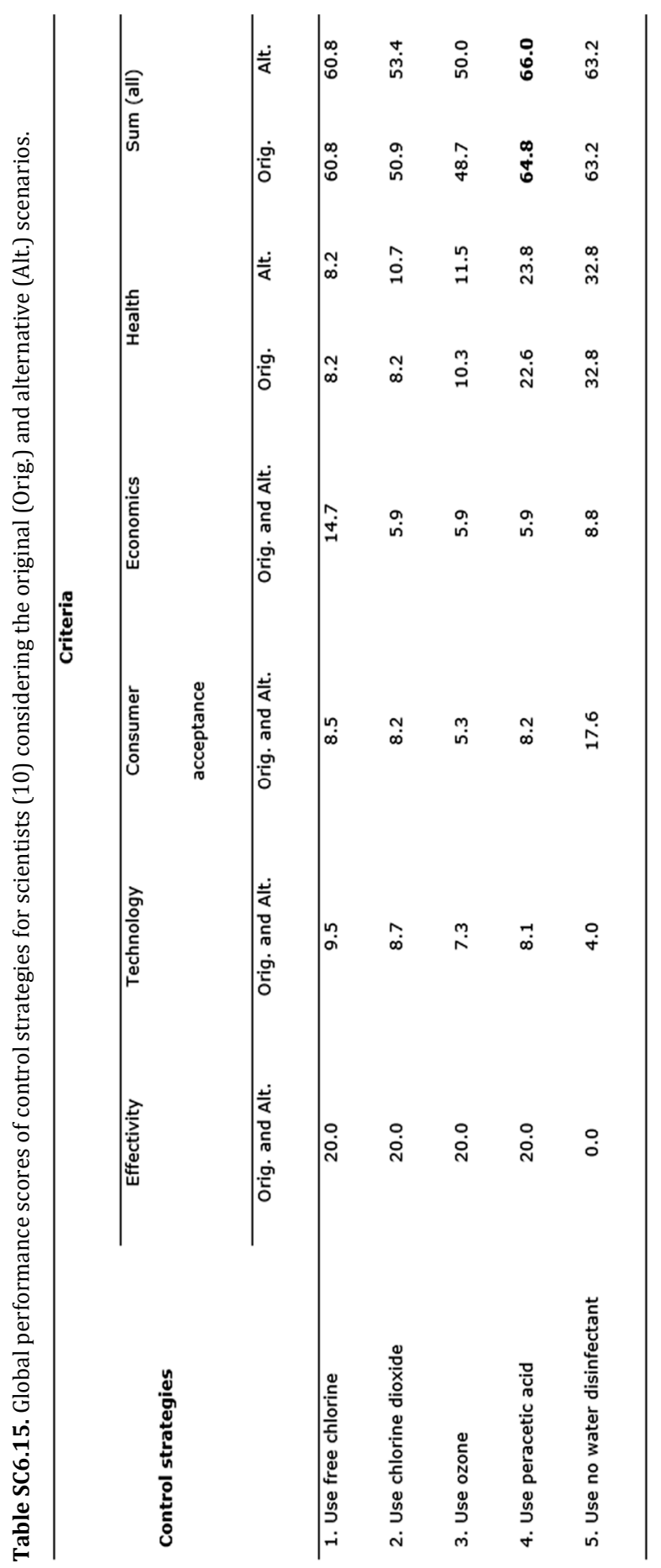




\section{Chapter 6}

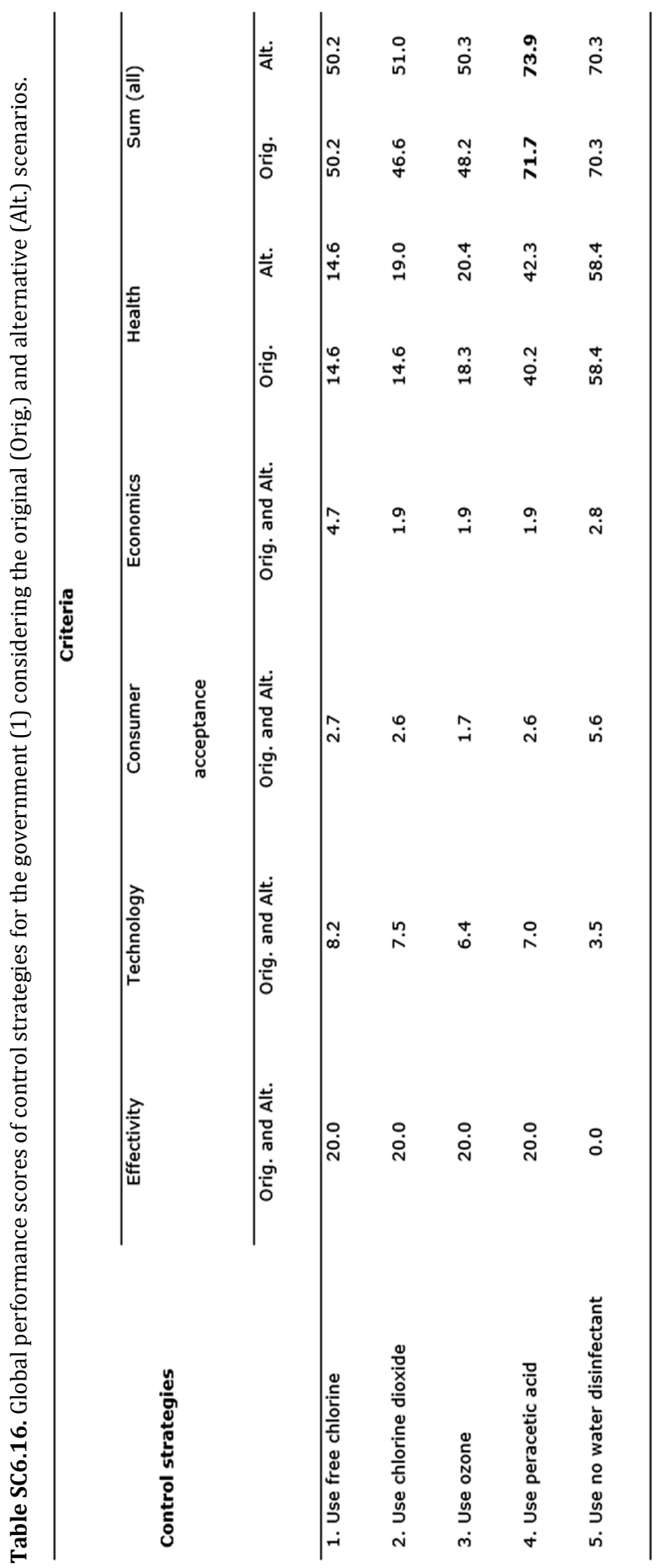


Multi-criteria decision analysis

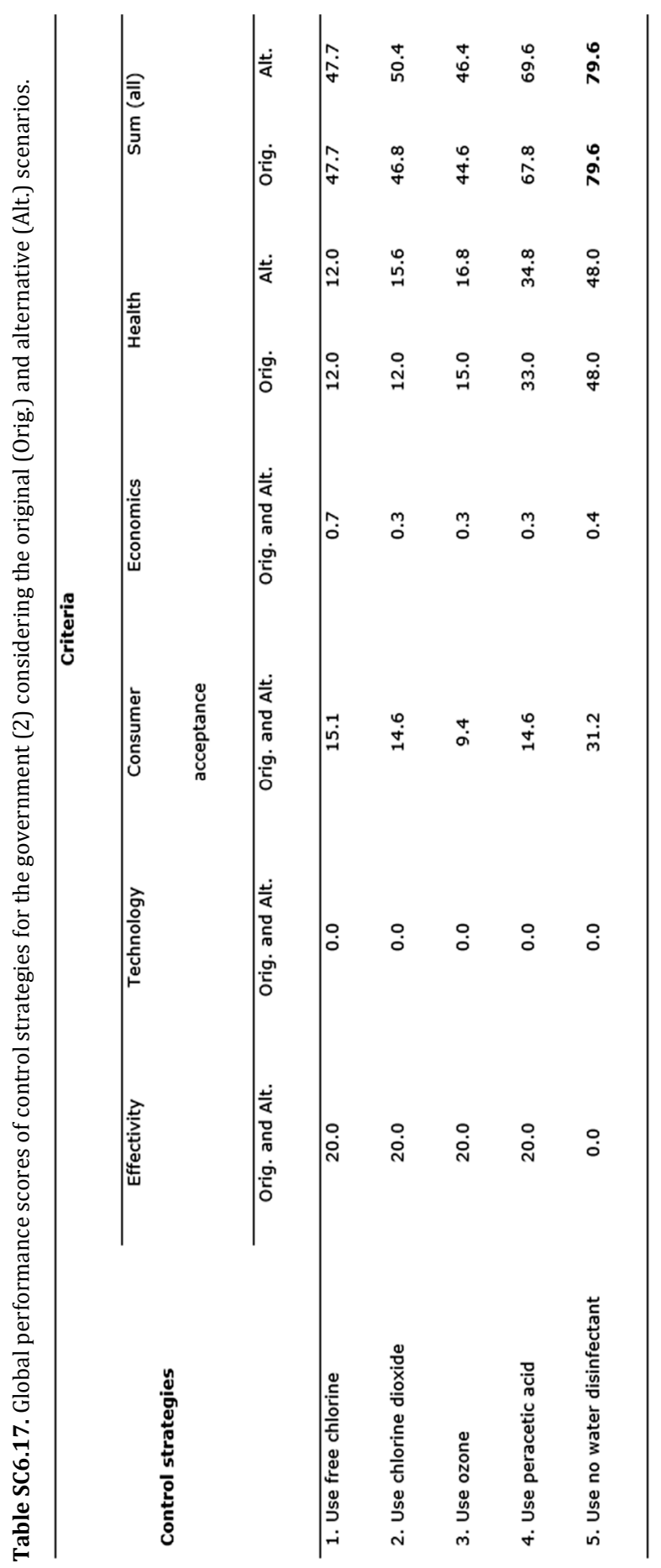




\section{Chapter 6}

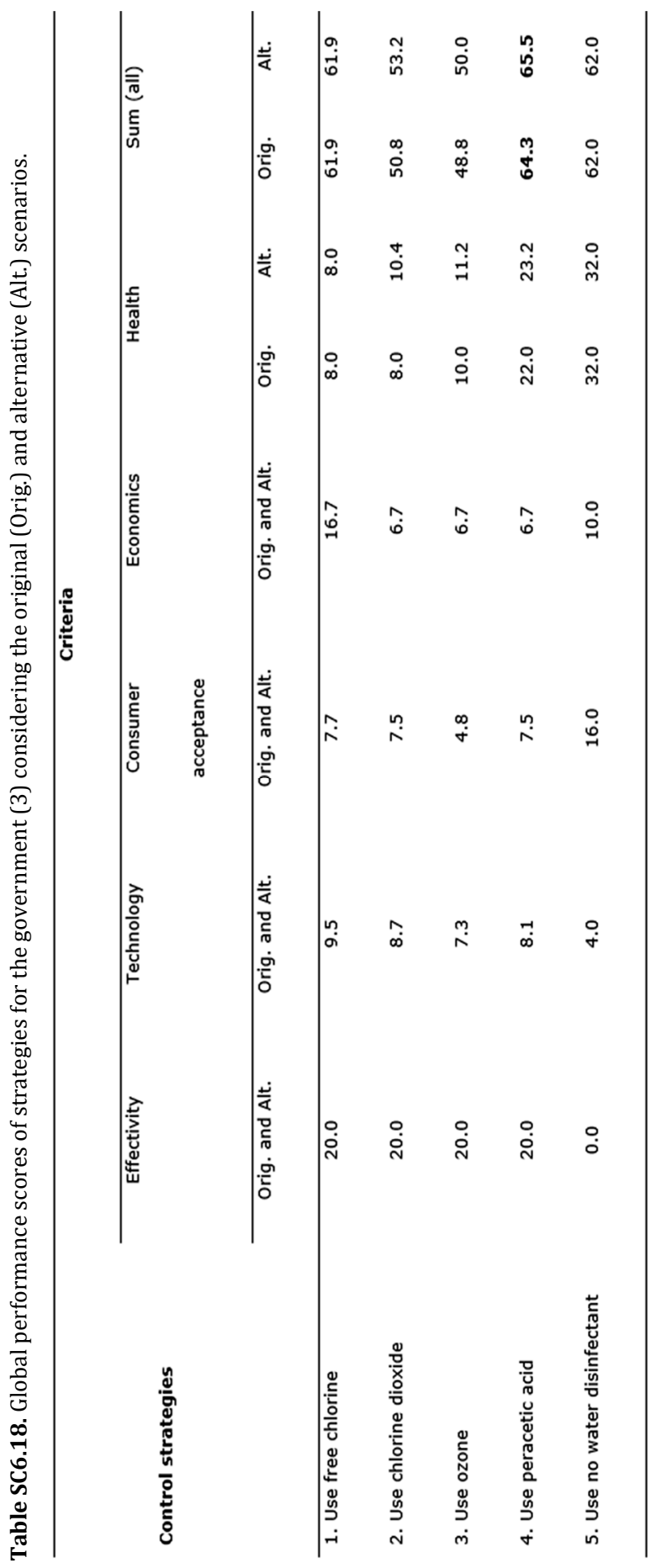




Chapter 7

General discussion 


\subsection{Introduction}

Foodborne disease outbreaks linked to fresh-cut produce continually occur and contribute negatively to public health. Apart from outbreaks, individual cases can also contribute to the burden of foodborne diseases. European Union (EU) data shows that foodborne disease outbreaks and cases related to vegetables repeatedly occur in the EU (European Food Safety Authority (EFSA) and European Centre for Disease Prevention and Control (ECDC), 2019).

Washing incoming fresh(-cut) produce like lettuce before packaging is one way to reduce potential pathogenic contamination. The washing process aims to improve food safety and is a pivotal action in the supply chain from farm to fork. This is because if a product or batch of produce, for example, lettuce, is contaminated with pathogens, subsequent contamination of other products via, for instance, the water used during processing can occur. If the fresh-cut lettuce is then exposed to pathogens, there is the possibility that the pathogens can attach to the surface or even internalize in the lettuce. When contaminated lettuce is then consumed, this can result in foodborne diseases. Although the washing step is intended to be a risk lowering control measure, it can be a risk factor for food safety and public health when not done correctly. Namely, this occurs if the water used to wash the lettuce is not treated or incorrectly treated. Therefore, in addition to washing the produce, disinfecting the water used to wash produce is needed to control pathogenic cross-contamination, and prevent foodborne disease.

Currently, disinfecting the process wash water (PWW) in the wash tank (i.e., in-line) where the produce is washed is commonly performed during processing. This requires that pathogens are quickly inactivated to prevent cross-contamination via the water. This washing and disinfection step is pivotal in the supply chain since effective microbial inactivation later in the fresh produce chain is lacking. Hence, washing and disinfecting water during produce processing help prevent pathogenic crosscontamination during lettuce washing.

Chemical disinfectants, especially chlorine-based disinfectants, are often used to treat the water during fresh-cut produce washing. In the EU, using chemical disinfectants to treat the water used during processing is not common in all member states. For instance, in the Netherlands, chemically based water disinfection technologies are not currently applied during fresh-cut lettuce processing. In addition to the limited use of chemical disinfectants to treat water during processing, water scarcity and access to potable freshwater is another growing global concern, which may be curbed by disinfecting water, so it is safe to reuse. Consequently, adjusting processing practices to incorporate water disinfection technologies that ensure safety and simultaneously sustain freshwater sources are sought in the long-term.

Even though chemical disinfectants like chlorine are often used to treat the water during fresh-cut washing, there are public health concerns against using chlorine and initiatives to look for alternative chemical disinfectants. Most information on using chemical disinfectants during fresh-cut produce washing is based on research examining how disinfectants can be used to enhance the product quality or shelf-life, 
i.e., to decontaminate the produce (Van Haute, Sampers, Holvoet and Uyttendaele, 2013; World Health Organization (WHO) and Food Safety Team \& Food and Agriculture Organization of the United Nations, 1998). Other research has reasoned that the main focus of using chemical disinfectants is to prevent cross-contamination in the washwater during produce washing (Davidson, Buchholz and Ryser, 2013; Gil, Selma, LópezGálvez and Allende, 2009; López-Gálvez, Allende, Selma and Gil, 2009). Current knowledge on the effectiveness of alternative (non-chlorine based) chemical disinfectants to be used as PWW disinfectants (in-line) to prevent cross-contamination via the wash water is scattered. Research in the laboratory and industrial settings that demonstrates the effectiveness of alternative chemical disinfection technologies is limited. Also, assessing different chemical disinfection technologies used as control measures to treat the PWW during washing fresh-cut lettuce from a broader perspective is required. This assessment should include stakeholder input and evaluating criteria beyond the technology's effectiveness. These identified needs served as the basis for the research in this thesis.

The main aim of this thesis was to evaluate the effectiveness of chemical disinfection of the water during fresh-cut lettuce washing to reduce pathogenic cross-contamination. The thesis encompassed a multi-perspective approach in food safety as it considers microbiological and chemical safety of using non-chlorine-based chemicals. The research focused on water used directly in the wash tank during commercial processing, i.e., cutting and washing, of lettuce. The potential for chemical wash water disinfection, as measured by the effect on generic E. coli during industrial-scale experiments, was taken as a proxy for microbial safety. The thesis examined the effectiveness at the laboratory and industrial settings. A case study evaluating several chemical wash water disinfectants, alongside no disinfectant use, was explored using a multi-criteria decision analysis (MCDA) to determine the best control strategy for stakeholders.

In order to answer the main aim of the thesis, five sub-objectives (SOs) were formulated to guide the analysis. The aims of these SOs are:

1) To obtain state-of-the-art knowledge on the effectiveness of chemical disinfectants suitable for PWW disinfection and their use to prevent pathogenic cross-contamination (Chapter 2).

2) To evaluate the effectiveness of chemicals used during PWW disinfection on reducing pathogenic bacteria at the laboratory-scale (Chapter 3).

3) To evaluate the effectiveness of chlorine dioxide $\left(\mathrm{ClO}_{2}\right)$ during industrial-scale processing of fresh-cut lettuce on the reduction of E. coli in the PWW and on the processed fresh-cut lettuce itself, and to evaluate the possible formation of disinfection by-products (DBPs) (Chapter 4).

4) To evaluate the effectiveness of peracetic acid (PAA), in solution with hydrogen peroxide $\left(\mathrm{H}_{2} \mathrm{O}_{2}\right)$, during laboratory and industrial-scale processing on the reduction of E. coli in the PWW and on processed fresh-cut lettuce (Chapter 5). 
5) To determine the best control strategy for stakeholders by evaluating strategies to treat the PWW used during washing fresh-cut lettuce, considering effectiveness, easiness of use/robustness of the technology, consumer acceptance, costs, and side effects on human health (Chapter 6).

This chapter synthesizes the results of the main aim and five sub-objectives of the thesis (sections 7.2-7.5), reflects on the applied research approach (section 7.6), discusses the implications of the research for decision-makers (section 7.7), elaborates on future research opportunities (section 7.8), and ends with the main conclusions of the thesis (section 7.9).

\subsection{Effectiveness according to the scientific literature}

The scientific literature on the effectiveness of chemical disinfectants fit for PWW disinfection and their ability to prevent pathogenic cross-contamination was reviewed in Chapter 2 (SO1) of the thesis. Many biological, physical, or chemical technologies can be selected to disinfect the water used during fresh-cut produce processing (Gil et al., 2009; Meireles, Giaouris and Simoes, 2016). When deciding on a technology to select, one must evaluate the processing set-up, including where the treatment will be applied. In this thesis, the focus was on disinfection in the wash tank. Given this prerequisite, the disinfectant's effect, including the effects of the dose and exposure on reducing cross-contamination, was a prominent factor.

In Chapter 2, four disinfectants were evaluated based on legislation, production of DBPs, and effectiveness in reducing cross-contamination in the PWW. These disinfectants were free chlorine, $\mathrm{ClO}_{2}, \mathrm{O}_{3}$, and PAA. Current and local legislation is relevant to consider during the application of technologies as this can vary between, for instance, the USA and EU, but also between member states within the EU. Also, optimizing the disinfectant dose is essential to ensure that food safety is not negatively affected. For example, DBPs can form when using these disinfectants. One should consider DBP toxicity, the likelihood for toxic DBPs to form, and human exposure to these DBPs as these affect public health. These four disinfectants have been reported to effectively treat the PWW, although various parameters affect their effectiveness. Overall, the organic matter and the remaining residual concentration of the disinfectant are two critical parameters to control during PWW disinfection to prevent pathogenic cross-contamination via the water.

In Chapter 2, we found that the disinfectants' stability can be evaluated in terms of their reactivity with organic matter. With a lower reactivity, less chemical needs to be dosed in the water to maintain a residual concentration to disinfect the water. Overall, the decreasing reactivity of PWW disinfectants is as follows: $\mathrm{O}_{3}>$ hypochlorous acid $\approx \mathrm{ClO}_{2}$ $>$ PAA. This knowledge serves as a basis for the subsequent research in the laboratory and industrial experiments (Chapter 3-5) and a basis for defining effectiveness in the case study (Chapter 6).

During industrial processing, the amount of organic material in the wash tank increases with time. Figure 7.1 shows the concentration of total organic carbon (TOC) in the PWW in relation to the $\mathrm{pH}$ for several types of fresh(-cut) leafy vegetables during washing at 
an industrial scale (Microbiology in Horticulture project (PPS 296), unpublished data). By the end of washing, a batch of lettuce can be exposed to very high organic loads (from sand, soil, exudates, etc.). A relationship between TOC and chemical oxygen demand (COD), the latter of which has been often reported in other fresh-cut processing studies, depends on the water composition (The Dow Chemical Company, 2015). This implies that it is crucial to monitor the organic load of the water during processing and continuously optimize the disinfectant dose, given the water quality, to obtain an effective residual concentration. Parameters like the residual concentration available for disinfection, contact time, temperature, $\mathrm{pH}$, among others, are important to monitor when aiming to apply chemicals during fresh-cut processing (Davidson et al., 2013; Gil et al., 2009; Van Haute, López-Gálvez, Gómez-López, Eriksson, Devlieghere, Allende and Sampers, 2015a). Overall, the wash water quality is important to monitor, as physiological parameters of the water influence the efficacy of the disinfectant (GómezLópez, Gil, Allende, Vanhee and Selma, 2015; López-Gálvez et al., 2009; Van Haute, Sampers, Jacxsens and Uyttendaele, 2015b; Van Haute, Tryland, Veys and Sampers, 2015c). Based on this finding, four chemical disinfectants were suitable for PWW disinfection in-line: free chlorine, $\mathrm{ClO}_{2}, \mathrm{O}_{3}$, and PAA (in solution with $\mathrm{H}_{2} \mathrm{O}_{2}$ ).

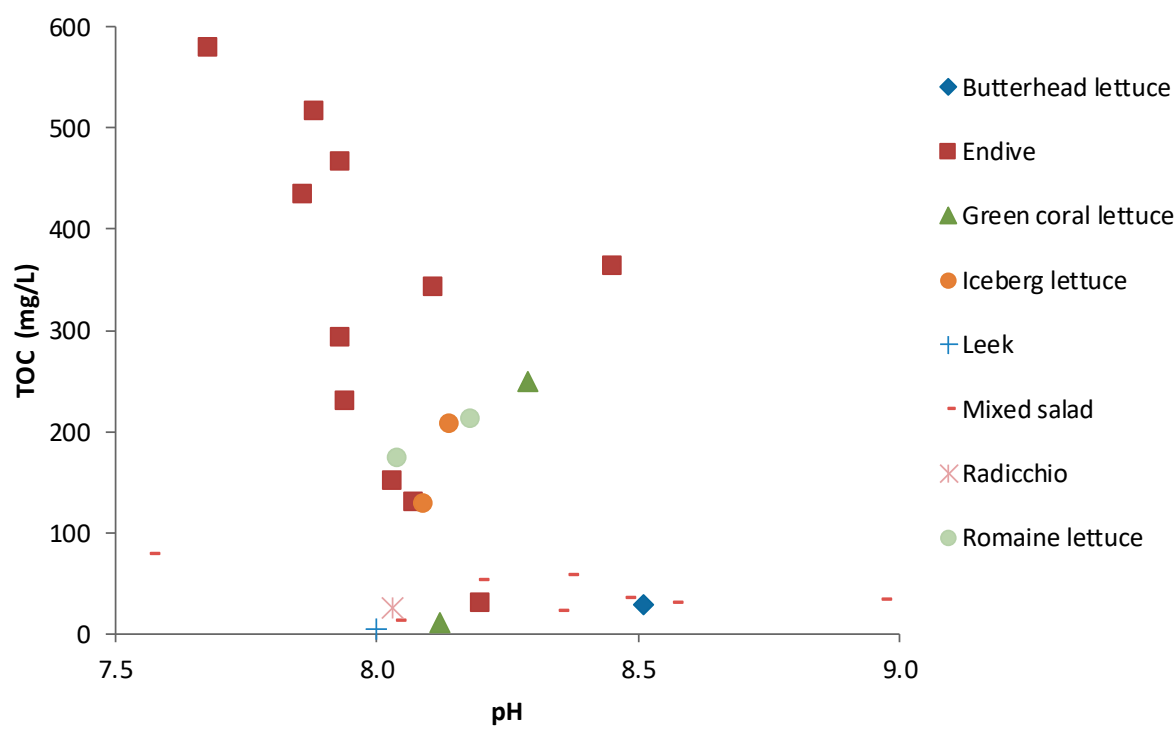

Figure 7.1 The concentration of total organic carbon (TOC) in the process wash water to the $\mathrm{pH}$ during fresh(-cut) leafy vegetable washing at an industrial scale.

In conclusion, the results from Chapter 2 of this thesis provided a basis to further focus research on alternatives to chlorine. Given the feasibility of testing some technologies at the laboratory and industrial scales, the thesis focused on the application of $\mathrm{ClO}_{2}$ (Chapters $3 \& 4$ ) and PAA (Chapter 5). 


\subsection{Effectiveness at the laboratory-scale}

The effectiveness of chemical water disinfection at the laboratory-scale was described in Chapter 3 (SO2) and Chapter 5 (SO4) of the thesis. In Chapter 3, the effectiveness of sodium hypochlorite (which served as a proxy for free-chlorine and the positive control for the experiments), $\mathrm{ClO}_{2}$, and a silver-copper solution to reduce Salmonella Typhimurium and extended-spectrum beta-lactamase (ESBL) E. coli were evaluated. $\mathrm{ClO}_{2}(5 \mathrm{mg} / \mathrm{L})$ showed a similar effectiveness to sodium hypochlorite $(10 \mathrm{mg} / \mathrm{L})$ in reducing $S$. Typhimurium and ESBL E. coli in potable water, lettuce wash water, and on the lettuce. The organic load of the water and pathogen type affected the effectiveness of the disinfectant in the water. In Chapter 5, the effectiveness of PAA in solution with $\mathrm{H}_{2} \mathrm{O}_{2}$ on the reduction of $E$. coli in water and on the fresh-cut lettuce was evaluated. With 60 and $80 \mathrm{mg} / \mathrm{L}$ of PAA, E. coli cells were not recovered in each of the water types tested, indicating that at least a 6-log reduction occurred. There was a significant difference between using no water disinfectant and PAA for each of the concentrations tested.

The organic load of the water and pathogen type affected the effectiveness of the disinfectant in the water. First, the effectiveness of $\mathrm{NaClO}$ and $\mathrm{ClO}_{2}$ showed to be affected by the water quality, particularly the organic load, as observed by testing varying TOC concentrations in the water. This observation concurs with other research that found that with higher organic loads, chorine-based disinfectants were quickly inactivated (Davidson et al., 2013; Van Haute et al., 2013). On the other hand, this thesis showed that PAA was not adversely affected by the water's organic load. The organic load of the wash water treated with PAA increased, which is attributed to the PAA dose (Luukkonen and Pehkonen, 2017). Secondly, this thesis showed inactivation differences between non-starved cells of $S$. Typhimurium and E. coli. This result suggests that the disinfectant effectiveness can be pathogen dependent, which concurs with research by López-Velasco, Tomás-Callejas, Sbodio, Artés-Hernández and Suslow (2012), who observed $S$. enterica serovar variability to $\mathrm{ClO}_{2}$ dose and tolerance thereof in water. The organic load and water temperature can be adjusted during processing, unlike the pathogen attachment and release from the produce.

\subsection{Effectiveness at the industrial scale}

The effectiveness of chemical water disinfection at the industrial scale was described in Chapter 4 (SO3) and Chapter 5 (SO4) of this thesis. In Chapter 4, the industrial-scale effectiveness of $\mathrm{ClO}_{2}$ (at $5 \mathrm{mg} / \mathrm{L}$ and $3 \mathrm{mg} / \mathrm{L}$ ) during the processing of fresh-cut lettuce to reduce E. coli was evaluated. E. coli was not detected in the PWW when analyzed after $E$. coli had been supplemented to the wash tank, and thus, at least a 5-log reduction occurred. On the processed, fresh-cut lettuce, a 2.0-2.3 log reduction of E. coli was observed. Although chlorate and chlorite values in the PWW exceeded WHO guidelines in drinking water of $0.7 \mathrm{mg} / \mathrm{L}$ (WHO, 2005) when $\mathrm{ClO}_{2}$ was used, these values were not exceeded on the lettuce. $\mathrm{ClO}_{2}$ application in the $\mathrm{PWW}$ is favorable when combined with a final rinse step with potable water. This study contributes data to minimize data gaps in chlorate and chlorite residues in lettuce during food processing. In Chapter 5, the industrial-scale efficacy of PAA $(75 \mathrm{mg} / \mathrm{L}$ of PAA) during the processing of fresh-cut lettuce to reduce $E$. coli was evaluated. $E$. coli was not detected in the water when 
analyzed after it had been supplemented to the wash tank; thus, at least a 5-log reduction occurred. Disinfecting the water with PAA did not result in the complete elimination of $E$. coli from the washed produce. Microbial communities on the lettuce were detected before and after lettuce had been washed with PAA disinfected water. No significant differences were observed between the treatments, implying that disinfecting the water did not decontaminate microbial communities on the lettuce. Overall, the results found in Chapter 4 showed that $\mathrm{ClO}_{2}$ decreased the probability for cross-contamination via the water between the lettuce for point contaminations ( $6 \mathrm{log}$ $\mathrm{CFU} / \mathrm{mL}$ ) compared to when no water disinfectant had been used. Despite $\mathrm{ClO}_{2}$ treatments, E. coli attached to the lettuce. These results were also found for PAA in Chapter 5 . These results reaffirm the importance of preventing pathogenic crosscontamination during fresh-cut produce washing.

This thesis validated results from lab experiments during industrial-scale processing. $\mathrm{ClO}_{2}$ lab results showed that E. coli cells were inactivated in the water (Chapter 3 ), and during industrial-scale processing, a 5-log reduction of $E$. coli was validated (Chapter 4). Results for $\mathrm{ClO}_{2}(5 \mathrm{mg} / \mathrm{L})$ also concur with other research investing the efficiency of $\mathrm{ClO}_{2}$ (Van Haute, Tryland, Escudero, Vanneste and Sampers, 2017). Similarly, in this thesis, the PAA lab results showed at least a 6-log reduction of $E$. coli. This was validated during industrial-scale processing, where around a 5-log reduction of E. coli was observed (Chapter 5). This result concurs with other experiments evaluating the small, industrial-scale application of PAA, where reductions up to 5-log CFU/mL in the wash water were found (Davidson, Kaminski-Davidson and Ryser, 2017). Overall, the results of this thesis validate the industrial-scale application of $\mathrm{ClO}_{2}$ and PAA.

In this thesis, the $E$. coli strain used was a model for pathogenic $E$. coli. The use of a pathogenic strain inside an operating facility is a sanitary and safety concern (Chapters 4 \& 5). The survival of pathogenic bacteria during PWW disinfection is dependent on variables like the organic load of the water, water temperature, and attachment and release to the produce (Chapters $2 \& 3$ ). Consequently, the strain used in this study may attach differently to the lettuce or have different resistance to chemicals than pathogenic strains. However, previous research motivated the use of environmental isolates as surrogates for foodborne pathogens (Cook, Givan, Mayton, Parekh, Taylor and Walker, 2017) and has found that the way bacterial strains were grown before challenge studies with PAA had larger effects on bacterial reduction than strain diversity (Harrand, Kovac, Carroll, Guariglia-Oropeza, Kent and Wiedmann, 2019). In short, our model strain was a practical option for industrial-scale experiments.

This thesis's findings suggest that other managerial measures are then required before and after processing to control pathogens. Since there are several routes of pathogenic cross-contamination for fresh vegetables (see Figure 1.4), it would help to evaluate if the produce has been susceptible to these routes at different points along the supply chain. For instance, using clean freshwater during cultivation and post-harvest washing helps to minimize pathogenic cross-contamination. Good Agricultural Practices (GAP) and Good Handling Practices (GHP) should be mandatory, especially for susceptible chains like that of fresh(-cut) produce intended to be consumed uncooked. Testing and controlling the soil and irrigation water quality more frequently at critical points during cultivation and (post-) harvest are relevant for primary producers to obtain a safe food 
product. In order to optimize these processes, practices should be well-specified and achievable to implement and evaluate. Governments should support measures to implement these practices, based on scientific knowledge from research alongside application and monitoring feasibility during primary production. Similarly, later in the chain, retailers and consumers should continue to ensure food safety by, e.g., keeping lettuce stored cooled with controlled humidity during transport, at stores, and in households. Such "good retailer practices" and "good consumer practices" can be more clearly drawn-up in this latter part of the chain. Here, the expression "a chain is only as strong as its weakest link" is only too fitting; food safety practices for stakeholders span the entire chain from farm to fork. Overall, it is paramount that all stakeholders implement such "good" practices in this delicate chain so that the final product is safe.

In Chapters 4 and 5, the microbial communities on the lettuce were not affected by the respective technologies and remained on the lettuce after treatments. This implies that there were no effects attributed to the use of disinfectants to decontaminate the lettuce. During experiments, the minimal concentrations of, respectively, $\mathrm{ClO}_{2}$ and PAA used probably have affected this outcome, although this observation may also be attributed to the type of washing system. In conclusion, the thesis results suggest that the main focus of using chemical disinfectants is to prevent pathogenic cross-contamination in the PWW during fresh-cut lettuce processing rather than to decontaminate the final product.

\subsection{Looking beyond the microbial effectiveness}

In Chapter 6, several criteria were evaluated to determine the best control strategy for stakeholders during fresh-cut lettuce washing (SO5). In addition to microbial effectiveness, criteria like the easiness of use/robustness of the technology, consumer acceptance, costs, and side effects on health can support decision-makers when determining a control strategy. An MCDA method was used to evaluate the case study.

The case study evaluated five control strategies - the use of free chlorine, $\mathrm{ClO}_{2}, \mathrm{O}_{3}, \mathrm{PAA}$, or no wash water disinfectant - to control pathogenic cross-contamination during fresh-cut lettuce washing at processors. The performance scores of the assessed criteria were based on the results from several peer-reviewed, comprehensive scientific literature reviews (Gil et al., 2009; Gil, Selma, Suslow, Jacxsens, Uyttendaele and Allende, 2015; Meireles et al., 2016; Van Haute et al., 2015b). Other scientific literature was also consulted on using control strategies, including the results from Chapters 2-5 of this thesis.

In Chapter 6, results showed that stakeholders had different views on the relative importance of the criteria. The criterion considering the side effects on health was consistently considered the most important. The control strategies ranked similarly for each stakeholder group and over stakeholders. The results showed that - considering the different criteria and stakeholders' views - PAA was a preferred control strategy to disinfect PWW during fresh-cut lettuce processing. Other research has found PAA to be a preferred control strategy, among others, to treat water, based on the technologies ease of maintenance, limited disadvantages related to worker safety and DBP 
formation, and the lessened negative impact from organic matter (Van Haute et al., $2015 \mathrm{~b}$ ). Also, while evaluating wash water disinfection strategies, PAA, among others, was suggested as an alternative to chlorine during produce washing (Meireles et al., 2016). Unlike these other studies, Chapter 6 includes stakeholder input in the evaluation and provides the results and options in a structured approach. Stakeholder representation in an MCDA is important for building a consensus in the ultimate decision. Its application in the food safety domain to assist in the decision-making process has been advocated (Fazil, Rajic, Sanchez and McEwen, 2008).

The MCDA case study evaluated was situated in the EU. Herein, how culture impacts the criteria and "best" control strategies is a factor to consider along with the results of this study. From this point, other case studies can consider comparing results per EU country or even more globally to elucidate if there are differences in the selected control strategy. Furthermore, the MCDA analyses and the model type (Weight Sum Model) selected are one of many possibilities to consider when trying to determine control strategies. Case studies looking to evaluate control measures may benefit from an MCDA analysis or a similar approach.

\subsection{Reflection of the methods}

\section{Strain selection}

In this thesis, the industrial-scale studies used a non-pathogenic E. coli strain (Chapters $4 \& 5$ ). The choice to use a non-pathogenic strain was thoroughly evaluated. For instance, a Salmonella strain was too pathogenic for these types of experiments (see the results of Chapter 3). Using an ESBL strain could create undesired media attention (e.g., negative public perception towards an antibiotic-resistant strain). Also, there can be issues with culturing media choices (e.g., selective media showing overestimated results) and a need for additional special waste treatment. There were no indications that an ESBL strain would behave significantly differently in terms of resistance and adhesion compared to a non-ESBL strain (data not shown). The E. coli strain selected for the commercial experiments was serotyped as 0-:H56 and was isolated from surface water. This environmental isolate could provide insight into the contamination routes via water. Although this strain may attach differently or have different resistance, it serves its purpose as a model organism since introducing a pathogenic strain in an operating facility is a sanitary and safety concern. Altogether, research that validates this $E$. coli as a surrogate or cocktails thereof on the efficacy of the disinfection technologies warrants further attention. Similarly, research on the effects of pathogens (e.g., at the laboratory scale) may be of interest to examine, model, and compare to the pilots performed.

\section{Detection methods}

Culture-based methods have a high sensitivity to detect living, culturable microorganisms, even pathogenic strains, given the appropriate media type. Previous research has reported that using total psychrotrophic aerobic count (TPAC) is a poor indicator of microbial quality, and the effects on TPAC during washing are negligible 
(Holvoet, 2014). In this thesis, the laboratory experiments (Chapter 3) evaluated the microbial reduction on two media types: a non-selective media - Luria Broth agar (LB) and a selective media - Brilliance $E$. coli/coliform selective agar (BECSA). The results showed no differences between CFUs quantified on LB and BECSA, and thus, during industrial processing, the PWW was analyzed on BECSA. When using selective media, there is the possibility that damaged cells may not grow out due to the selective components in the media. Thus, levels may be underestimated, and the inactivation effect overestimated.

This thesis used plating techniques to determine colony forming units (CFUs) following water disinfection. The CFUs of live cells were enumerated, yet it may be possible that damaged cells could not grow and were not detected. The PWW is a complex matrix to analyze, and following the disinfection of the water, pathogenic cells may retain their virulence. Research shows that techniques like flow cytometry have been recommended to quantify viable but non-culturable (VBNC) cells of E. coli when water was treated with sodium hypochlorite and PAA (Teixeira, Fernandes, Silva, Dias and Azeredo, 2020); however, other research has shown that flow cytometry can lead to an overestimation of dead cells (Truchado, Gil, Larrosa and Allende, 2020). Instead, a viability quantitative polymerase chain reaction ( $\mathrm{v}$-qPCR) with ethidium monoazide and propidium monoazide dyes as DNA amplificatory inhibitors were promising when trying to distinguish VBNC cells in chlorine-treated PWW (Truchado et al., 2020). If the same technique holds for other (chemical) wash water disinfectants, and other pathogens (besides that researched of Listeria monocytogenes) has yet to be validated in practice and remains a data gap. Overall, understanding how much VBNC cells contribute to cross-contamination during fresh(-cut) lettuce washing, and eventually, the impact on public health is warranted (Truchado et al., 2020).

Also, the non-use of neutralizers during analyses may have influenced the results observed during industrial processing as using neutralizers can stop the chemical reaction from continuing. However, before plating the PWW, serial dilutions in a peptone physiological salt solution were made, and before plating the lettuce homogenates, the lettuce was washed with water. The decision to analyze these samples given these methods - without neutralizers yet with a simple rinse - reflects industrial conditions, where following post-harvest washing with disinfectants, often a rinse with tap water is performed.

\section{Statistical analyses}

In this thesis, statistical analyses with either an analysis of variance (ANOVA) (Chapters $3 \& 5$ ) or Student's $t$-test (Chapter 4) were performed to discern the significance of the microbial reductions following treatments. These are parametric tests that assume, among other points, that the data follow a continuous or ordinal scale, are normally distributed, and that the distributions have the same variance, i.e., equal standard deviation. One way to increase the power of these tests is to increase the sample size, as additional samples provide more information about the population. When examining microbial reductions, data were log-transformed to conform to normality, giving a nearnormal distribution. Adhering to the normality assumption is required, and with an increased sample size, it can become easier to deduce the normality. Otherwise, if 
normality cannot be assumed, then a nonparametric test would be more suited, although the latter is often less sensitive.

\section{From laboratory to industrial scales}

The disinfectant concentrations examined in this thesis were in part chosen based on the lab experiments performed, where the lowest concentration at which the effectiveness was still observed was selected. The laboratory studies were performed under static conditions (Chapters 3 \& 5). During processing, the wash tank has dynamic conditions, e.g., turbulent water and changing water quality conditions. The technologies need to quickly adapt to the new environment so that the water is continuously treated. This need is also essential when scaling-up the technology and treatment size. The thesis showed the influence that water type and quality had on the technologies' effectiveness and provided a valuable comparison between disinfectant effectiveness in potable water, water "made" in the laboratory from washing the produce, and water from produce washed at industrial scale processing lines. Evaluating the disinfectant's effectiveness in water used to wash the produce gave insight into its functioning at a larger scale. Overall, trying to optimize the disinfectant dose based on water type and quality is critical to avoid unnecessary DBP formulation and to optimize costs, as overdosing is economically undesirable. However, underestimating the minimal effective dose is detrimental to the effectiveness. In short, the residual concentration of the effective dose must be stable, although this is challenging given potential fluctuations during processing.

Altogether several design choices were made to be able to set up an industrial scale experiment. Besides those already mentioned, others include the health effects of using chemicals in practice (e.g., on worker's safety), waste disposal, and cleaning and disinfection of the line before and after experiments. Here, the complexity and time investment for industrial-scale experiments becomes evident.

\section{Design of the industrial processing line}

The studies in this thesis examined in-line disinfection during fresh-cut lettuce washing within a single wash tank. In the past years, a washing line with two tanks has become more common in the industry, where the first tank is to remove sand, soil, and other debris, and the second is where the disinfection technology is then applied. When comparing the lettuce results in Figure 7.1 to the results from Chapter 4 of the controlled experiments without disinfection, the TOCs are similar. With a single wash tank, one can assume a worst-case scenario, where the organic load has had time to increase throughout processing, and it is at the highest concentration at the point where E. coli contamination then occurs. The set-up allows one to examine the effect of the residual concentration of the PWW disinfectant towards the end of processing. Hence, the robustness of the technology, in terms of maximal performance, is tested. This implies that if processing, including washing, is set-up in a more favorable design, other technologies could reduce pathogenic cross-contamination in the water. Therefore, the design of these experiments is important to realize when comparing results. 


\section{Other technologies on the market}

There are more water disinfection technologies available today besides those studied in this thesis. At the time, however, these technologies were feasible to implement at the laboratory and industrial scales. Since then, other technologies like electrolyzed water and cold plasma may be interesting for future research. Their future use could depend on factors like effectiveness, costs (e.g., of the equipment), and the (dosing) capacity to scale-up the technologies. In short, we should continue trying to improve the technologies and promising research solutions.

\section{Multi-criteria decision analysis}

In the MCDA study (Chapter 6), the effectivity was standardized across the stakeholder groups as a main criterion. Four stakeholder groups and five main criteria were investigated, yet it is possible to include other stakeholder groups and/ or criteria. This is both an advantage (flexibility) and disadvantage (subjectivity) to using an MCDA. For example, stakeholder groups like consumers, non-governmental organizations (NGOs), or retailers may be of interest to consider in future case studies. These groups can represent the effects on the societal impact of the control strategy. However, in this study, the stakeholder group "fresh-cut processors" were financially and legally responsible for ensuring food safety. Thus, this group was needed to be considered in the analysis. The other three stakeholder groups (producers and suppliers of disinfectants and equipment, scientists, and government representatives) were the ones dealing most closely with the case study, and they had technical and/or legal knowledge on the subject. Particularly, the scientific stakeholder group could provide a non-biased and collective perspective on the case study. Hence, these four stakeholder groups appeared most fitting to be included in the case study investigated.

Moreover, the use of the five main criteria was a choice when analyzing the study. We aimed to standardize one aspect directly influencing health, which was the microbiological effectiveness of the disinfectant in terms of microbial log reductions. This choice was in part due to the preliminary need to have an effective disinfectant. Given the term "effectiveness," some stakeholders may not have questioned the healthrelated aspects of this criterion. Alongside that, the criterion relating to the side effects on health (by-product formation and workers' safety) may have further complicated the need to rank criteria for some of the stakeholder groups, this finding which can be inferred from the results from the government stakeholder group.

The advantage of an MCDA method is that different types of data (qualitative, semiquantitative, and quantitative) can be translated and compared to one another on one scale. This helps decision-makers to standardized subjective data in a fair, communicative way. A limitation of the study was the limited data accessible (e.g., quantitative data on the costs) and estimations used to evaluate some criteria in the MCDA. With this method, stakeholder involvement can increase the balance in the decision, i.e., so that the decision is not optimal for only one stakeholder. Using an MCDA approach in food safety brings about questions regarding the separation of risk assessment (scientist-based processes) and risk management (policy-based processes). The overlap of these risk analysis steps and communication surrounding 
these steps should be considered when using an MCDA. The output of an MCDA can be further evaluated by risk managers since the ultimate decision depends on many aspects. Clear communication on the risk managerial aspects may be required or even considered in the risk assessment stages. For policy-based decisions, a risk manager can decide how much weight to give to each stakeholder and which stakeholder group to include when deducing the effects on the outcome; this is then communicated back to the risk-assessors to refine the scientific analysis.

\subsection{Implications for decision-makers}

Several factors influence the decision to select a control measure to be eventually implemented in practice. This thesis showed that the disinfectants like $\mathrm{ClO}_{2}$ and PAA effectively treated the water used during fresh-cut lettuce processing, and consequently, help prevent pathogenic cross-contamination via the water. The use of a PAA solution to treat the PWW is a control measure that fresh-cut processors could use to treat their water (in-line) during processing. The choice to use 'no disinfectants' during processing has repercussions on food safety, public health, as well as other disciplines like economics, legislation, and media/communication. These repercussions should all be addressed and discussed proactively and compared to other possible choices to improve food safety.

In earlier research, the public health relevance of pathogenic $E$. coli was estimated via direct and indirect routes during fresh-cut processing, and the authors indicated that wash water disinfection is a suitable risk management option (Chardon, Swart, Evers and Franz, 2016). However, when washing one does not know if contamination has already occurred, or the extent of the contamination, and similarly, the type of pathogenic contamination is unknown. Consequently, wash water disinfection is a precautionary risk management option that should always be consulted to protect public health proactively.

For the scientific community, the thesis provides insight into the effect that chemical technologies have on the inactivation of microbial (food) pathogens at the laboratory and industrial scales. These results showed that the laboratory results were confirmed in the industrial setting, and upscaling the technologies was possible. Industrial-scale experiments of this nature are seldom performed, and the results from this thesis should be used for future modeling purposes to determine pathogen inactivation during washing. Food technologists, processing technologists, and engineers can also use the results when developing designs for the processing equipment. Overall, the scientific insight is important to those directly and indirectly associated with food safety.

For society, these technologies may provide an opportunity to increase food production sustainably, thereby releasing a burden on food security and excess freshwater use and providing an economic advantage to the technologies to be invested. These developments also inform processors and other actors along the supply chain about realistic expectations for treating water in the fresh(-cut) lettuce chain for the processing sector. They can support future water and food quality policies for 
governments, given the growing society and food safety and security demands. Consequently, the thesis results can be valuable beyond the scientific realm to tackle global issues like water scarcity and food security.

\subsection{Further research}

\section{Alternative detection techniques}

Besides plating techniques, other methods are available to enumerate cells, especially when looking to distinguish between live and dead cells. Research has investigated flow cytometry and v-qPCR with DNA amplificatory inhibitor dyes to enumerate VBNC cells in the PWW during fresh-cut produce processing. Results on the most suitable techniques are mixed since factors like the type of PWW disinfectant, target pathogen, and the complex matrix of the PWW influence the technique's robustness. It would be interesting to compare the different techniques to elucidate cross-contamination effects during produce washing better. For instance, one could explore the effects of VBNC cells during fresh(-cut) lettuce washing (Truchado et al., 2020). Such research would ultimately improve our understanding of the role that cross-contamination has during this process. From there, the results could serve as a stepping stone to future research focusing on industrial validation of rapid and sensitive (on-site) techniques to differentiate live and dead cells.

\section{Compiling data unknowns}

Within the last decade, the use of blockchain technologies for food safety in the agrifood sector, especially for cold chains, has increased (Tian, 2018). Blockchain technologies can provide an information platform for stakeholders to exchange relevant information (e.g., on processing and storage conditions) regarding a product's safety. The platform aims to promote transparency, reliability, and security in the sector. Given stringent food safety requirements, especially for cold chain products, a common information platform may improve traceability between the different actors. Research on applying food safety systems that use blockchain with practical case studies can help better understand the platform's value in terms of food safety and public health. In this thesis, an MCDA case study was examined, and the information available was qualitative. It may be possible that through information-sharing platforms like blockchain, additional (quantitative) data can be accessed and incorporated into future MCDAs or other decision-making tools for stakeholders. For instance, in an MCDA, one could use blockchain information to re-assess the technical inputs for the scientific analyses and improve the estimated effect. From there, risk management options can be fine-tuned.

\section{Multiple water disinfection technologies}

Besides chemical-based disinfection strategies, physical and microbial strategies are available (Meireles et al., 2016). Combining chemical, physical, and/or microbial strategies warrants further attention to optimizing the (microbial) effectivity and technological application. If one uses multiple technologies on-site, the costs for the 
application and maintenance may increase. However, it may be possible to optimize energy use and food safety. Even more, since water is a valuable resource that needs to be used optimally, it would be interesting to investigate technologies that can treat water used only once during fresh(-cut) processing to be reused elsewhere, or that can minimize the amount of water that would need to be used during processing. Overall, further research on other, especially combined, water disinfection technologies that can be applied to optimize water use and research that evaluates a set-up more closely resembling current industrial practices is warranted.

\section{Alternative processing designs}

In this thesis, the effectiveness of several chemical-based wash water disinfection technologies was evaluated considering an in-line set-up with a single wash tank. Other technologies and set-ups are available to treat the water used during processing. Given recent European initiatives to transition to a circular economy (European Commission (EC), 2019), one could infer that when it comes to fresh(-cut) produce washing, alternative strategies in the sector are required to optimize water use. Recycling and treating the PWW via a by-pass system, i.e., not directly in the wash tank itself, can provide an alternative strategy for water disinfection, allowing for longer contact, i.e., treatment times. However, with longer contact times and closed recirculation loops, chemical by-products may accumulate, meaning it would be important to monitor these.

With these alternative processing designs, research on how water disinfection affects different pathogens is interesting to examine, model, and compare to this thesis's laboratory and industrial-scale experiments.

\section{Looking beyond fresh-cut washing}

Alongside water disinfection during processing, the application of water disinfection treatments in other parts of the fresh produce supply chain, such as disinfecting irrigation water and other post-harvest water uses like that at retail (spraying produce), warrants attention. This need to disinfect water becomes even more crucial to research given aims to transition to a (bio-)circular economy and reuse water in closed manufacturing loops for food purposes.

Overall, initiatives that target a circular economy and include food safety should focus on a chain-wide approach to ensure optimal implementation. For fresh(-cut) produce, the processing stage is an important point for microbial and chemical safety, and likewise, safety preceding and following this stage is just as critical. 


\subsection{Main conclusions}

The objective of this thesis was to evaluate the effectiveness of chemical disinfection of the water during fresh-cut lettuce washing to prevent pathogenic cross-contamination. The microbial effectiveness of the laboratory and industrial-scale experiments of chemical disinfection was assessed. The main conclusions of the thesis are:

- Industrial processing with $\mathrm{ClO}_{2}$ or PAA disinfection technologies reduced E. coli in the PWW around $5 \log \mathrm{CFU} / \mathrm{mL}$, thereby reducing potential crosscontamination during fresh-cut lettuce processing (Chapters $4 \& 5$ ).

- The results of laboratory experiments disinfecting water with $\mathrm{ClO}_{2}$ (Chapter 3) and a PAA solution (Chapter 5) had similar findings. The laboratory tests confirmed the industrial results, and up-scaling of the disinfection technologies was feasible (Chapters $4 \& 5$ ). The thesis demonstrated that it is possible to execute industrial-scale $\mathrm{ClO}_{2}$ and PAA disinfection of the water to prevent pathogenic cross-contamination.

- The organic load and water temperature influenced the effectiveness of chemical disinfectants. These parameters can be adjusted during processing, unlike pathogen attachment and release from the lettuce in the wash water, which also influenced a disinfectant's effectiveness (Chapter 3 ).

- During industrial processing, E. coli cells attached to the lettuce during washing regardless of the water quality or disinfectant concentration (Chapters 4 \& 5).

- After washing with disinfected water and storage for 5 days at $4{ }^{\circ} \mathrm{C}$, microbial communities survived and grew on lettuce (Chapters $4 \& 5$ ).

- In addition to microbial safety, a disinfectant's chemical safety, considering its effect on public health, is imperative to consider when selecting disinfectants and technologies for application during fresh-cut produce washing (Chapters $2 \& 6)$.

- Stakeholders differed on the relative importance of criteria when determining a control strategy to prevent cross-contamination during fresh-cut lettuce processing. However, the criterion concerning side effects on human health was consistently considered more critical than effectiveness, easiness of use/robustness of the technology, consumer acceptance, and costs (Chapter 6).

- Through using an MCDA approach and including stakeholders' perspectives, we observed that PAA was the overall best strategy to control pathogenic cross-contamination during fresh-cut lettuce washing (Chapter 6). This proposed disinfection strategy appears to be the right balance between safety and effective water disinfection during fresh-cut produce processing. 


\section{References}

Chardon, J., Swart, A., Evers, E., Franz, E., 2016. Public health relevance of cross-contamination in the freshcut vegetable industry. J. Food Prot. 79, 30-36. doi: 10.4315/0362-028x.Jfp-15-272.

Cook, K.L., Givan, E.C., Mayton, H.M., Parekh, R.R., Taylor, R., Walker, S.L., 2017. Using the agricultural environment to select better surrogates for foodborne pathogens associated with fresh produce. Int. J. Food Microbiol. 262, 80-88. doi: 10.1016/j.ijfoodmicro.2017.09.017.

Davidson, G.R., Buchholz, A.L., Ryser, E.T., 2013. Efficacy of commercial produce sanitizers against nontoxigenic Escherichia coli 0157:H7 during processing of iceberg lettuce in a pilot-scale leafy green processing line. J. Food Prot. 76, 1838-1845. doi: 10.4315/0362-028x.Jfp-13-111.

Davidson, G.R., Kaminski-Davidson, C.N., Ryser, E.T., 2017. Persistence of Escherichia coli 0157:H7 during pilot-scale processing of iceberg lettuce using flume water containing peroxyacetic acid-based sanitizers and various organic loads. Int. J. Food Microbiol. 248, 22-31. doi: 10.1016/j.ijfoodmicro.2017.02.006.

European Commission (EC), 2019. Circular economy.

European Food Safety Authority (EFSA), European Centre for Disease Prevention and Control (ECDC), 2019. The European Union one health 2018 zoonoses report. EFSA J. 17, e05926. doi: 10.2903/j.efsa.2019.5926.

Fazil, A., Rajic, A., Sanchez, J., McEwen, S., 2008. Choices, choices: The application of multi-criteria decision analysis to a food safety decision-making problem. J. Food Prot. 71, 2323-2333. doi: 10.4315/0362028x-71.11.2323.

Gil, M.I., Selma, M.V., López-Gálvez, F., Allende, A., 2009. Fresh-cut product sanitation and wash water disinfection: problems and solutions. Int. J. Food Microbiol. 134, 37-45. doi: 10.1016/j.ijfoodmicro.2009.05.021.

Gil, M.I., Selma, M.V., Suslow, T., Jacxsens, L., Uyttendaele, M., Allende, A., 2015. Pre- and postharvest preventive measures and intervention strategies to control microbial food safety hazards of fresh leafy vegetables. Crit. Rev. Food Sci. Nutr. 55, 453-468. doi: 10.1080/10408398.2012.657808.

Gómez-López, V.M., Gil, M.I., Allende, A., Vanhee, B., Selma, M.V., 2015. Water reconditioning by high power ultrasound combined with residual chemical sanitizers to inactivate foodborne pathogens associated with fresh-cut products. Food Control 53, 29-34. doi: 10.1016/j.foodcont.2014.12.032.

Harrand, A.S., Kovac, J., Carroll, L.M., Guariglia-Oropeza, V., Kent, D.J., Wiedmann, M., 2019. Assembly and characterization of a pathogen strain collection for produce safety applications: pre-growth conditions have a larger effect on peroxyacetic acid tolerance than strain diversity. Front. Microbiol. 10, 1223. doi: 10.3389/fmicb.2019.01223.

Holvoet, K., 2014. Bacterial safety of lettuce in primary production and fresh-cut processing industry, Faculty of Bioscience Engineering. Ghent University, Ghent, BE.

López-Gálvez, F., Allende, A., Selma, M.V., Gil, M.I., 2009. Prevention of Escherichia coli cross-contamination by different commercial sanitizers during washing of fresh-cut lettuce. Int. J. Food Microbiol.133, 167171. doi: 10.1016/j.ijfoodmicro.2009.05.017.

López-Velasco, G., Tomás-Callejas, A., Sbodio, A., Artés-Hernández, F., Suslow, T.V., 2012. Chlorine dioxide dose, water quality and temperature affect the oxidative status of tomato processing water and its ability to inactivate Salmonella. Food Control 26, 28-35. doi: 10.1016/j.foodcont.2011.12.016.

Luukkonen, T., Pehkonen, S.O., 2017. Peracids in water treatment: a critical review. Crit. Rev. Environ. Sci. Technol. 47, 1-39. doi: 10.1080/10643389.2016.1272343.

Meireles, A., Giaouris, E., Simoes, M., 2016. Alternative disinfection methods to chlorine for use in the freshcut industry. Food Res. Int. 82, 71-85. doi: 10.1016/j.foodres.2016.01.021.

Microbiology in Horticulture project (PPS 296), unpublished data. Results of process wash water analyses.

Teixeira, P., Fernandes, B., Silva, A.M., Dias, N., Azeredo, J., 2020. Evaluation by flow cytometry of Escherichia coli viability in lettuce after disinfection. Antibiotics 9. doi: 10.3390/antibiotics9010014.

The Dow Chemical Company, 2015. Dow water and process solutions - correlation between KMnO4, COD, BOD, DOC and TOC.

Tian, F., 2018. An information system for food safety monitoring in supply chains based on HACCP, blockchain and Internet of Things, Institute for Production Management. Vienna University of Economics and Business, Vienna, AT.

Truchado, P., Gil, M.I., Larrosa, M., Allende, A., 2020. Detection and quantification methods for viable but nonculturable (VBNC) cells in process wash water of fresh-cut produce: industrial validation. Front. Microbiol. 11. doi: 10.3389/fmicb.2020.00673. 


\section{Chapter 7}

Van Haute, S., López-Gálvez, F., Gómez-López, V.M., Eriksson, M., Devlieghere, F., Allende, A., Sampers, I., 2015a. Methodology for modeling the disinfection efficiency of fresh-cut leafy vegetables wash water applied on peracetic acid combined with lactic acid. Int. J. Food Microbiol. 208, 102-113. doi: 10.1016/j.ijfoodmicro.2015.05.020.

Van Haute, S., Sampers, I., Holvoet, K., Uyttendaele, M., 2013. Physicochemical quality and chemical safety of chlorine as a reconditioning agent and wash water disinfectant for fresh-cut lettuce washing. Appl. Environ. Microbiol. 79, 2850-2861. doi: 10.1128/AEM.03283-12.

Van Haute, S., Sampers, I., Jacxsens, L., Uyttendaele, M., 2015b. Selection criteria for water disinfection techniques in agricultural practices. Crit. Rev. Food Sci. Nutr. 55, 1529-1551. doi: 10.1080/10408398.2012.705360.

Van Haute, S., Tryland, I., Escudero, C., Vanneste, M., Sampers, I., 2017. Chlorine dioxide as water disinfectant during fresh-cut iceberg lettuce washing: disinfectant demand, disinfection efficiency, and chlorite formation. LWT Food Sci. Technol. 75, 301-304. doi: 10.1016/j.lwt.2016.09.002.

Van Haute, S., Tryland, I., Veys, A., Sampers, I., 2015c. Wash water disinfection of a full-scale leafy vegetables washing process with hydrogen peroxide and the use of a commercial metal ion mixture to improve disinfection efficiency. Food Control 50, 173-183. doi: 10.1016/j.foodcont.2014.08.028.

World Health Organization (WHO), 2005. Chlorite and chlorate in drinking-water. World Health Organization (WHO/SDE/WSH/05.08/86), Geneva, CH.

World Health Organization (WHO), Food Safety Team \& Food and Agriculture Organization of the United Nations, 1998. Surface decontamination of fruits and vegetables eaten raw: a review / prepared by Larry R. Beuchat. World Health Organization (WHO), Geneva, CH. 


Summary 
Fresh leafy greens like lettuce are often consumed raw and can be contaminated by foodborne pathogens. Pathogenic foodborne outbreaks related to leafy greens continue to occur, meaning the need to alleviate the human health burden associated with these outbreaks is evident. During fresh-cut lettuce processing, washing with potable water removes microorganisms, providing about a 1- to 2-log reduction, but this process also poses an opportunity for pathogenic cross-contamination in the washing tank. This is because the potential for cross-contamination not only depends on the produce quality but also is highly dependent on the quality of the water used during processing. Thus, washing fresh-cut lettuce is a step in the supply chain that needs to be well controlled to avoid cross-contamination.

Several water disinfection strategies can be used to control pathogenic crosscontamination during fresh-cut lettuce washing. Globally, current measures to control the quality of lettuce during washing include using chemicals like chlorine. However, questions regarding the safety of chlorine and consumer perception on its use have prompted research into alternative process wash water (PWW) disinfectants. Deciding which disinfection control strategy to use during fresh-cut lettuce washing requires technical information, yet insight into its eventual application can be further elucidated using stakeholder input. The main aim of this thesis was to evaluate the effectiveness of chemical disinfection of the water during fresh-cut lettuce washing to reduce pathogenic cross-contamination.

Chapter 1 addresses current vegetable production and consumption alongside foodborne diseases associated with fresh produce. The problems with washing and disinfection of fresh-cut produce, like lettuce, are explained. Finally, the objectives and outline of the thesis are presented.

In Chapter 2, the literature on the effectiveness of chlorine, chlorine dioxide $\left(\mathrm{ClO}_{2}\right)$, ozone, and peracetic acid (PAA) during produce processing when aiming to reduce potential cross-contamination of pathogens on fresh produce was studied. These chemicals were assessed for their use as PWW disinfectants. Results showed that PWW disinfection requires short contact times, so pathogens need to be quickly inactivated during processing. The literature review highlighted the effectiveness of microbial reductions and assessed legislation and disinfection by-product (DBP) production.

In Chapter 3, the effectiveness of sodium hypochlorite $(\mathrm{NaClO}), \mathrm{ClO}_{2}$, and a silvercopper solution to reduce Salmonella Typhimurium and extended-spectrum betalactamase (ESBL) Escherichia coli was studied on the laboratory-scale, alongside the impact of the bacterial cell history and water quality. In this chapter, three scenarios evaluated the effect of strain history on effectivity and water quality. We observed that $\mathrm{NaClO}$ and $\mathrm{ClO}_{2}$ were more effective in preventing cross-contamination in the potable water than the silver-copper solution. There were minor differences between the effectiveness of starved and non-starved bacterial cells in potable water and lettuce wash water. Overall, the water's organic load, wash water temperature, and pathogen attachment and release from the produce affected the effectiveness during washing. These results support the aim to focus on wash water disinfection during processing. 
In Chapter 4, the effectiveness of using $\mathrm{ClO}_{2}(5 \mathrm{mg} / \mathrm{L}$ and $3 \mathrm{mg} / \mathrm{L})$ to disinfect the water used during fresh-cut lettuce washing at the industrial scale was studied. In this chapter, the disinfection effectiveness of a fixed residual concentration of $\mathrm{ClO}_{2}$ on reducing supplemented nonpathogenic E. coli to the PWW was assessed. The microbial and chemical safety of the water was evaluated and compared to control experiments without water disinfection. Results showed that $\mathrm{ClO}_{2}$ use reduced the E. coli contamination in the PWW. The study also assessed the microbial quality of the lettuce. We observed that after storage $\left(5\right.$ days, $\left.4{ }^{\circ} \mathrm{C}\right), \mathrm{ClO}_{2}$ did not have an apparent effect on the levels of fluorescent pseudomonads and total heterotrophic bacteria in lettuce. Overall, $\mathrm{ClO}_{2}$ decreased the potential for cross-contamination in the water between the lettuce compared to when no PWW disinfection was used.

In Chapter 5, the effectiveness of using a PAA solution $(75 \mathrm{mg} / \mathrm{L})$ to disinfect the water used during fresh-cut lettuce washing at the laboratory and industrial scales was studied. In this chapter, the effect of a PAA solution on reducing supplemented nonpathogenic $E$. coli in the water at these two scales was compared. The physicochemical and microbial quality of the water and the microbial quality of the fresh-cut lettuce were evaluated. We observed that the use of PAA was not adversely affected by the organic load in the water. The contact time and dose were relevant factors, as observed by the approximately 5-log reduction of $E$. coli in the water. We observed that after storage $\left(5\right.$ days, $4{ }^{\circ} \mathrm{C}$ ), PAA did not have an apparent effect on the levels of fluorescent pseudomonads and total heterotrophic bacteria in lettuce. Results also showed that once introduced during washing, E. coli remained attached to the lettuce, supporting the need to control pathogenic bacteria earlier in the supply chain and during post-harvest washing. A PAA solution appears to be an effective and safe PWW disinfectant that can potentially be used at the industrial scale.

In Chapter 6, a multi-criteria decision analysis (MCDA) was applied to a case study determining which control strategy to use during fresh-cut lettuce processing when applied directly in the wash tank. The control strategies evaluated were free chlorine, $\mathrm{ClO}_{2}$, ozone, PAA, or no wash water disinfectant. The five main criteria used to assess the control strategies' performance were effectiveness, easiness of use/robustness of the technology, consumer acceptance, costs, and possible side effects on human health. Scores for these criteria were evaluated using scientific literature. The weights of the criteria were assessed using input from four stakeholder groups (fresh-cut processors, producers/suppliers of disinfectants and equipment, scientists, and government representatives). Stakeholders had different views on the relative importance of the criteria; however, the criterion concerning the side effects on human health was consistently considered most important. The ranking of the control strategies was similar for each stakeholder group and over stakeholders. Overall, considering all criteria and stakeholder groups, we observed that PAA was the preferred control strategy. 
Finally, Chapter 7 discusses this thesis's main findings, reflects on the applied research approach, discusses the implications of the research for decision-makers, elaborates on future research opportunities, and ends with the main conclusions. The main conclusions of the thesis are:

- Industrial processing with $\mathrm{ClO}_{2}$ or PAA disinfection technologies reduced E. coli in the PWW around $5 \log \mathrm{CFU} / \mathrm{mL}$, thereby reducing potential crosscontamination during fresh-cut lettuce processing (Chapters $4 \& 5$ ).

- $\quad$ The results of laboratory experiments disinfecting water with $\mathrm{ClO}_{2}$ (Chapter 3) and a PAA solution (Chapter 5) had similar findings. The laboratory tests confirmed the industrial results, and up-scaling of the disinfection technologies was feasible (Chapters $4 \& 5$ ). The thesis demonstrated that it is possible to execute industrial-scale $\mathrm{ClO}_{2}$ and PAA disinfection of the water to prevent pathogenic cross-contamination.

- The organic load and water temperature influenced the effectiveness of chemical disinfectants. These parameters can be adjusted during processing, unlike pathogen attachment and release from the lettuce in the wash water, which also influenced a disinfectant's effectiveness (Chapter 3).

- During industrial processing, E. coli cells attached to the lettuce during washing regardless of the water quality or disinfectant concentration (Chapters 4 \& 5).

- After washing with disinfected water and storage for 5 days at $4{ }^{\circ} \mathrm{C}$, microbial communities survived and grew on lettuce (Chapters $4 \& 5$ ).

- In addition to microbial safety, a disinfectant's chemical safety, considering its effect on public health, is imperative to consider when selecting disinfectants and technologies for application during fresh-cut produce washing (Chapters 2 \& 6).

- Stakeholders differed on the relative importance of criteria when determining a control strategy to prevent cross-contamination during fresh-cut lettuce processing. However, the criterion concerning side effects on human health was consistently considered more critical than effectiveness, easiness of use/robustness of the technology, consumer acceptance, and costs (Chapter 6).

- Through using an MCDA approach and including stakeholders' perspectives, we observed that PAA was the overall best strategy to control pathogenic cross-contamination during fresh-cut lettuce washing (Chapter 6). This proposed disinfection strategy appears to be the right balance between safety and effective water disinfection during fresh-cut produce processing. 




\section{Annexes}

Acknowledgments

About the author

List of publications

Overview of completed training activities 



\section{Acknowledgments}

"Life is a journey, not a destination."

\section{— Ralph Waldo Emerson}

My journey started many years ago, and along the way, I have come to know countless names and faces. Although some of those have faded with time, I try to remember our interactions and realize you have shaped me. In this section, I attempt to highlight those who contributed directly and indirectly to this chapter of my life by name. For those that I may have overlooked, please know you are still wholeheartedly acknowledged.

First, I would like to thank Marcel Zwietering and Ine van der Fels-Klerx for providing me the opportunity to pursue my Ph.D. alongside my work. Your support along the way was essential. I enjoyed our discussions and continue to appreciate your constructive feedback. Without your confidence in me, I would not have gotten this far, and for that, I am genuinely thankful for your time and efforts.

Next, I express my sincere gratitude to the PPS 296 project members. In my early years as a researcher, your knowledge was passed onto me through our discussions and collaboration. I must extend my further appreciation to my co-authors: Hermien, Leo, Patricia, Masja, and Ine. Your patience and support during my journey are remembered.

To several of my colleagues at RIKILT and WFSR with whom I have worked with over the years - both in the Argochain group and throughout the institute - I am thankful for our coffee breaks, lunch walks, outings, discussions, and your support during my years working and pursuing my Ph.D. Thank you, Amelia, Anand, Andries, Anna, Ans, Antoine, Arjen, Bram, Carl, Cheng, Elise G., Elise H., Els, Erika, Erwin, Esmée, Esmer, Esther v. A., Esther K., Fieroza, Gijs, Ha, Hannie, Hans, Hurria, Ilona M., Ilona S., Ine, Irene, Isabelle, Jacob, Jeannette, Joop, Jordan, Lennert, Leonieke, Lonneke, Louise, Lucie, Lukas, Marcel, Marcia, Marko, Marloes, Marlou, Marlous, Martijn Sl., Martijn St., Maryvon, Meike S., Meike v.d. Z., Miranda, Mirjam, Monique N., Monique d. N., Nathan, Nicole, Ningjing, Paulien, Piet, Robert, Roel, Ron, Rosan, Saskia, Sergio, Siebren, Stefan, Suzanne, Theo, Valentina, Viola, Wenjuan, Yamine, Yannick, and Yvette!

Also, I want to extend my gratitude to the staff and students at the Laboratory of Food Microbiology, with whom I traveled to Italy on our Ph.D. Trip: Anneloes, Bernard, Evelien, Irma, James Noah, Jeroen, Judith, Marcel T., Marcel Z., Martine, Natalia, Oscar, and Yue. This experience was very memorable, and I appreciate our time together. Also, I want to thank Ioanna for working with me on the EU SPICED project and Gerda for helping arrange my travels, subscriptions, and other Ph.D. courses for me.

To Esmée and Yvette, thank you for being my paranymphs. Esmée, the steps, travels, and in-depth discussions have shaped me during this leg of my journey. I am thrilled to know you will be with me in the next chapter as well. Yvette, the past years have been outstanding, and I look forward to our future research projects together!

A special thank you to my opponents for their time and willingness to read and evaluate this thesis. 


\section{Acknowledgments}

Along my journey, I have made a few lifelong friends. Esmée, Ilona, and Rachel, thank you for your help both directly and indirectly with making this thesis come alive. I enjoy our travels together (or to you) and look forward to picking these up again once the world is ready for us.

I must also acknowledge - who I still refer to today as the Bruna boys - Jos, Martijn, Peter, Robin, and Thijs. Thank you for taking care of the American girl in the Netherlands and helping Pascal when I could not. The list would be incomplete if I did not recognize Rianne, Astrid, Sharone, Evelien, and Ilona for your care here. Since moving to the Netherlands, I gained a lovely support group.

I want to thank my (extended) family for your love and understanding over these past years. My family has grown immensely - aunts, uncles, cousins, a niece, nephews, grandparents, siblings, parents-in-law, and along with it, the support to pursue my passions. With large hubs in Chicago and the Netherlands, I know I always have a home on both sides of the ocean.

Pascal, we have been together for over a decade, seeing the highs and lows with love and loss coming in that mix. I cannot imagine a life without you, and I am proud to be your wife. Thank you for letting me go first with my dreams.

Finally, I want to dedicate this Ph.D. thesis to my Mom and Dad. Without their love and support, I would not have made it this far. Thank you for taking care of me. I love you forever. 


\section{About the author}

\section{Curriculum Vitae}

Jennifer L. Banach (Jen) was born on April 9th, 1989, in New Lenox, IL, USA. After high school, she obtained a Bachelor of Arts with majors in Biology and Pre-Medicine in 2011 from Augustana College in Rock Island, IL, USA. During her undergrad, she gained travel experience with a study term abroad in Vienna (2009) and a medical service trip in Nicaragua (2010). In August 2011, Jen moved to the Netherlands to pursue her master's degree. During that time, she conducted her thesis research at the Department of Toxicology (Wageningen University) and her internship at the 57 Centre Heinz Innovation Center in Nijmegen, the Netherlands. In 2013, she obtained a Master of Science in Food Safety from Wageningen University. During this study, her research concerned the effect of metabolic changes from green tea consumption in humans, microbial spoilage of emulsified acidified sauces, and challenge tests on self-formulated and commercial ketchup recipes. In 2014, Jen started working as a Food Safety Researcher at RIKILT (currently Wageningen Food Safety Research, WFSR) at the Department of Toxicology, Bioassays \& Novel Foods. In 2016, she started her Ph.D. journey in cooperation with the Laboratory of Food Microbiology (Wageningen University). During this time, she restarted the YoungWUR organization and joined the YoungWUR board (2016-2017). Jen's current research focuses on risk-based monitoring of microorganisms and chemicals in food and feed production chains, focusing on chains like fresh-cut produce, spices and herbs, and seaweed. She has worked on several national and international multi-disciplinary research projects. Jen is passionate about learning, personal growth, and helping people understand food safety. She finds it pivotal to provide high-quality research and communicate her scientific findings to the world. Jen continues her career and research endeavors working as a Food Safety Researcher in the Argochain team at WFSR. 


\section{List of publications}

\section{Publications in this thesis}

Banach, J.L., Sampers, I., Van Haute, S., van der Fels-Klerx, H.J., 2015. Effect of disinfectants on preventing the cross-contamination of pathogens in fresh produce washing water. Int. J. Environ. Res. Public Health 12, 8658-8677. doi: 10.3390/ijerph120808658.

Banach, J.L., van Bokhorst-van de Veen, H., van Overbeek, L.S., van der Zouwen, P.S., van der Fels-Klerx, H.J., Nierop Groot, M.N., 2017. The efficacy of chemical sanitizers on the reduction of Salmonella Typhimurium and Escherichia coli affected by bacterial cell history and water quality. Food Control 81, 137-146. doi: 10.1016/j.foodcont.2017.05.044.

Banach, J.L., van Bokhorst-van de Veen, H., van Overbeek, L.S., van der Zouwen, P.S., Zwietering, M.H., van der Fels-Klerx, H.J., 2020. Effectiveness of a peracetic acid solution on Escherichia coli reduction during fresh-cut lettuce processing at the laboratory and industrial scales. Int. J. Food Microbiol. 321, 108537. doi: 10.1016/j.ijfoodmicro.2020.108537.

Banach, J.L., van Overbeek, L.S., Nierop Groot, M.N., van der Zouwen, P.S., van der Fels-Klerx, H.J., 2018. Efficacy of chlorine dioxide on Escherichia coli inactivation during pilot-scale fresh-cut lettuce processing. Int. J. Food Microbiol. 269, 128-136. doi: 10.1016/j.ijfoodmicro.2018.01.013.

\section{Other scientific peer-reviewed publications}

Banach, J.L., Hoek-van den Hil, E.F., van der Fels-Klerx, H.J., 2020. Food safety hazards in the European seaweed chain. Compr. Rev. Food Sci. Food Saf. 19, 332-364. doi: 10.1111/1541-4337.12523.

Banach, J.L., Hoffmans, Y., Appelman, W.A.J., van Bokhorst-van de Veen, H., van Asselt, E.D., 2021. Application of water disinfection technologies for agricultural waters. Agric. Water Manag. 244. doi: 10.1016/j.agwat.2020.106527.

Banach, J.L., Stratakou, I., van der Fels-Klerx, H.J., Besten, H.M.W.d., Zwietering, M.H., 2016. European alerting and monitoring data as inputs for the risk assessment of microbiological and chemical hazards in spices and herbs. Food Control 69, 237-249. doi: 10.1016/j.foodcont.2016.04.010.

Banach, J.L., van den Burg, S.W.K., van der Fels-Klerx, H.J., 2020. Food safety during seaweed cultivation at offshore wind farms: an exploratory study in the North Sea. Marine Policy 120. doi: 10.1016/j.marpol.2020.104082.

Banach, J.L., van der Fels-Klerx, H.J., 2020. Microbiological reduction strategies of irrigation water for fresh produce. J. Food Prot. doi: 10.4315/JFP-19-466.

Schaarschmidt, S., Spradau, F., Mank, H., Banach, J.L., van der Fels-Klerx, H.J., Hiller, P., Appel, B., Bräunig, J., Wichmann-Schauer, H., Mader, A., 2016. Public and private standards for dried culinary herbs and spices - part II: production and product standards for ensuring microbiological safety. Food Control 70, 360-370. doi: 10.1016/j.foodcont.2016.06.003.

van Asselt, E.D., Banach, J.L., Klüche, M., Appelman, W.A.J., 2021. Prioritising water disinfection technologies to improve food safety of leafy vegetables. British Food Journal. doi: 10.1108/BFJ-03-2020-0197.

van Asselt, E.D., Banach, J.L., van der Fels-Klerx, H.J., 2018. Prioritization of chemical hazards in spices and herbs for European monitoring programs. Food Control 83, 7-17. doi: 10.1016/j.foodcont.2016.12.023.

van den Burg, S.W.K., Röckmann, C., Banach, J.L., van Hoof, L., 2020. Governing risks of multi-use: seaweed aquaculture at offshore wind farms. Front. Mar. Sci. 7, 60. doi: 10.3389/fmars.2020.00060.

van Hoof, L., van den Burg, S.W.K., Banach, J.L., Röckmann, C., Goossen, M., 2020. Can multi-use of the sea be safe? A framework for risk assessment of multi-use at sea. Ocean Coast. Manag. 184, 105030. doi: 10.1016/j.ocecoaman.2019.105030. 


\section{Overview of completed training activities}

\section{Discipline specific activities}

Veg-i-trade Mini-Symposium "Impact of Water Quality and Water Treatment (pre- and postharvest) on the Safety of Fresh Produce"

IAFP 2014 European Symposium on Food Safety

Veg-i-Trade Closing Event "Taking safety of fresh produce to the next level" Day 2

SUSCLEAN Symposium "Less water and less/no chlorine in fresh-cut food industries: a dream?" Open symposium and round table discussion

SPICED 2nd Work Package Meeting and Workshop Quantitative Microbiology

IAFP 2015 European Symposium on Food Safety

SPICED 2nd Annual Meeting and Spice, herbs, and authenticity/fraud workshop

EFSA's 2nd Scientific Conference - Shaping the Future of Food Safety, Together

FiMM Symposium 'MICRO-ORGANISMEN, ZO HOU JE ZE IN DE HAND'

3rd Wageningen PhD Symposium "Diversity in Science"

IAFP 2016 European Workshop "In vitro, In vivo \& In silico in Predictive Microbiology"

IAFP 2016 European Symposium on Food Safety

Global Burden of Disease: Foodborne Pathogens, The FERG Approach

SPICED 3rd Annual Meeting

SPICED Symposium

Decontamination of Fresh Produce

Symposium Publish for Impact

Stichting FoodMicro Event Omgevingshygiëne, Technologie en Microbiologie

Network Event TKI Horticulture \& Propagation Materials

Microbials "Keep it Clean" Workshop
EU Project Veg-i-trade

IAFP

EU Project Veg-i-trade

EU Project SUSCLEAN

EU Project SPICED

IAFP

EU Project SPICED

EFSA

FiMM

Wageningen PhD Council

IAFP

IAFP

KNVM

EU Project SPICED

EU Project SPICED

Campden BRI

WGS

Stichting FoodMicro

Topsector TU

AHDB
Brussels, BE

Budapest, HU

Brussels, BE

2014

Wageningen, NL

2014

Berlin, DE

2015

Cardiff, UK

Wageningen, NL

2015

2015

Milan, IT

Wageningen, NL

2016

Wageningen, NL

2016

Athens, GR

2016

Athens, GR

2016

2016

Berlin, DE

2016

Berlin, DE

2016

2016

2017

2018

2018

Nieuwegein, NL

2020

\section{General courses}

Communication and Feedback Course

Applied Statistics

Workshop on Gender and Diversity Awareness

Personal Efficiency Program PEP® Training Workshop

Writing Grant Proposals Course

The Essentials of Scientific Writing and Presenting

Essential Courses Project Management

Reviewing a Scientific Paper (RSP)

Introduction to $\mathrm{R}$ course
RIKILT HR

Wageningen Academy

WUR Corporate HR

RIKILT HR with IBT

EUROPE BV

WGS

WGS

WUR, KSG Incompany

Trainers \& Consultants,

Bereschot

WGS

VLAG
Wageningen, NL

Wageningen, NL

Wageningen, $\mathrm{NL}$

Wageningen, NL

Wageningen, NL

Wageningen, NL

Wageningen, NL

Wageningen, NL

Wageningen, NL
2014

2014

2015

2015

2015-2016

2016

2017

2017

2018

\section{Optionals}

Preparation of research proposal

Food Microbiology Ph.D. Week

Scientific discussions at RIKILT \& WFSR
RIKILT \& FM

FM

RIKILT/WFSR
Wageningen, NL

Bologna, Parma, Milan, 2017

\& Turin, IT

Wageningen, NL 
The research described in this thesis was financially supported by the Ministry of Economic Affairs (EZ) via the Dutch Topsector Horticulture \& Starting Materials (TU) under the project "Microbiology in Horticulture" (PPS-296, B0-33.05-001-001), by the Ministry of Agriculture, Nature and Food Quality (LNV) under the Knowledge base research project KB-37-002-023, by Wageningen Food Safety Research (Wageningen Research), and by the Laboratory of Food Microbiology (Wageningen University).

Cover design by Rachel Ayoung Chee and Jennifer L. Banach Printed by ProefschriftMaken || www.proefschriftmaken.nl 



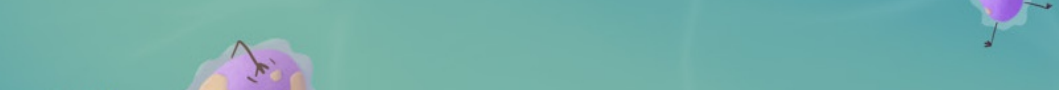

$\left.e^{2}=\right\}^{2}$
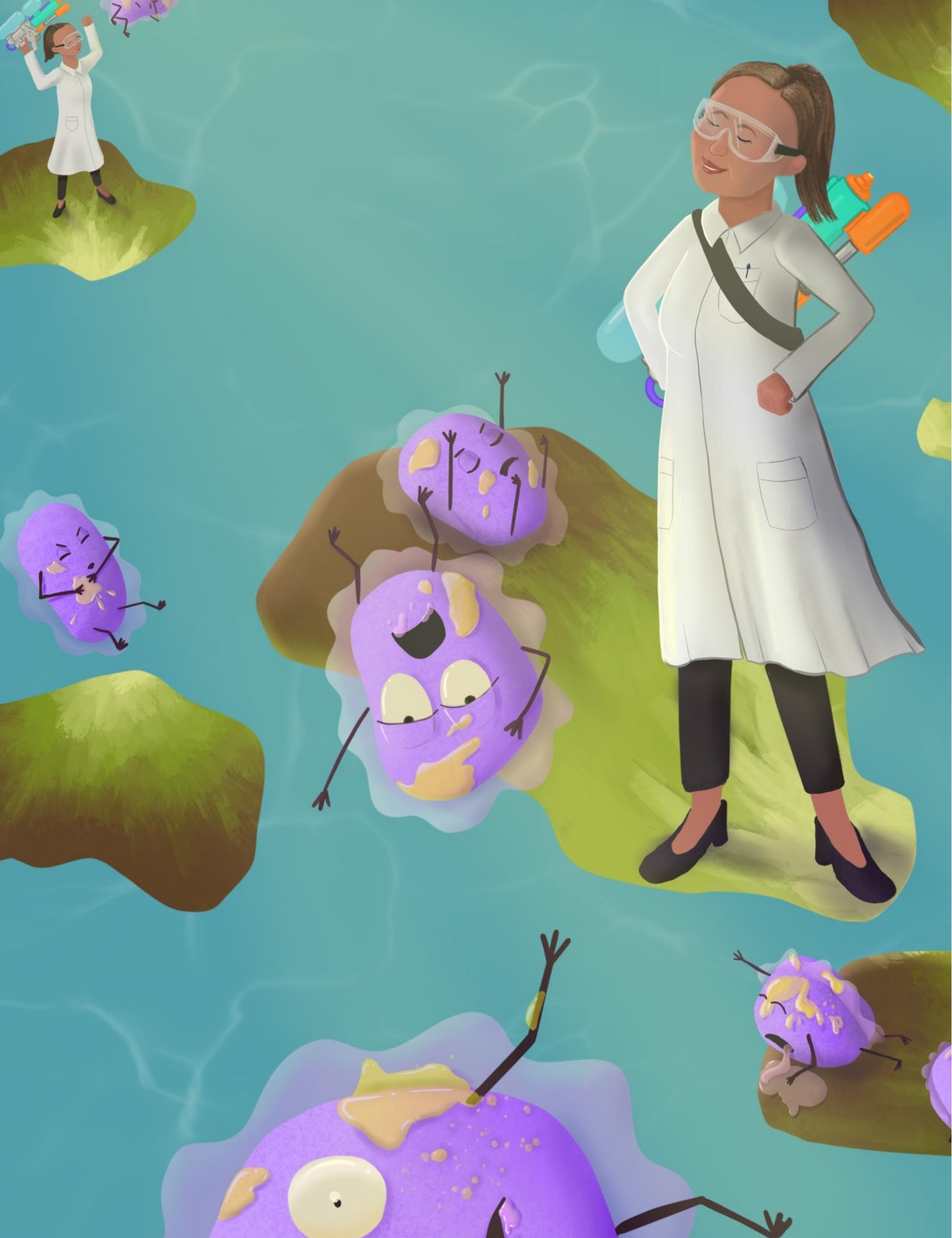